
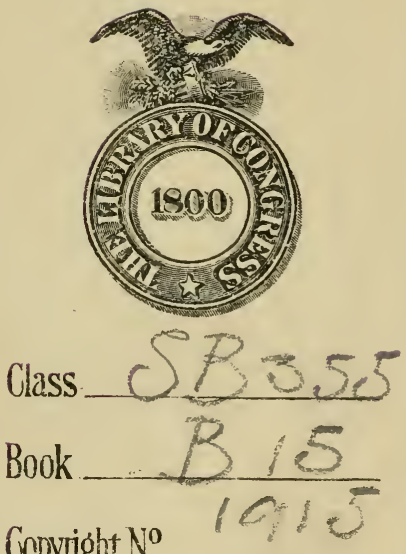

Copyright No.

COPYRIGHT DEPOSTY. 


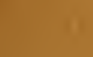

$+$

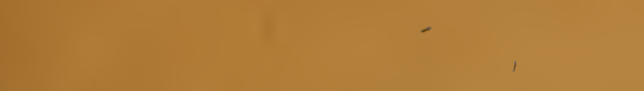

I
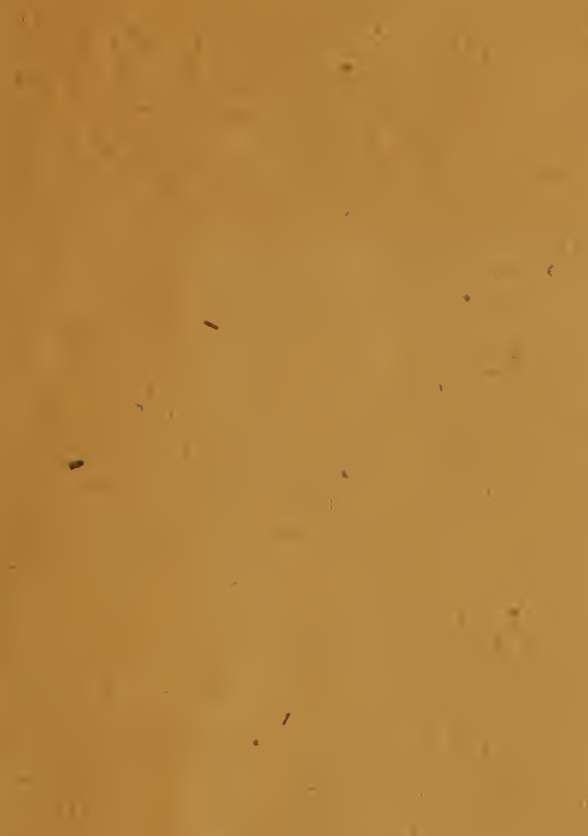

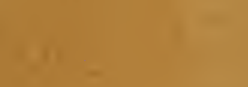

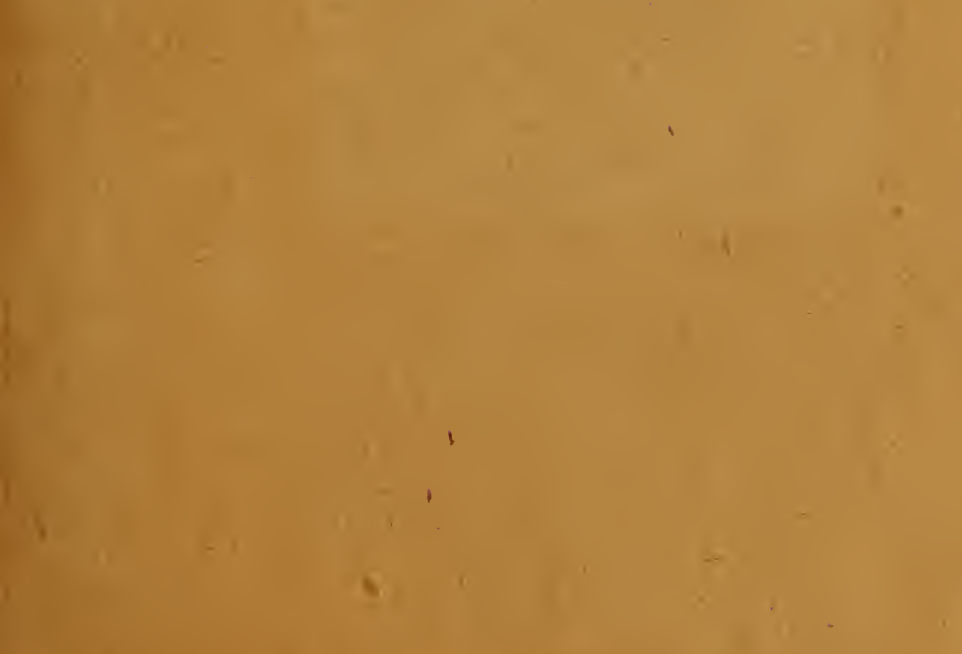






\section{The hural Grience Geries}

Edited by L. H. Bailey

\section{THE PRINCIPLES OF FRUIT- GROWING}




\title{
The Ihural Science Series
}

\author{
Edited By L. H. BaILey
}

The Sorl. King.

The Spraying of Plants. Lodeman.

Milk and Its Products. Wing. Enlarged and revised.

The Fertility of the Land. Roberts.

The Principles of Froit-Growing. Bailey. 20th edition, revised.

Bush-Fruits. Card.

Fertilizers. Voorhees.

The Principles of Agriculture. Bailey. 15th edition, revised.

Irrigation and Drainage. King.

The Farmstead. Roberts.

Rural Wealth and Welfare. Fairchild.

The Principles of Vegetable-Gardening. Bailey.

Farm Poultry. Watson. Enlarged and revised.

The Feeding of Animals. Jordan.

The Farmer's Business Handbook. Roberts.

The Diseases of Animals. Mayo.

The Horse. Roberts.

How to Choose a Farm. Hunt.

Forage Crops. Voorhees.

Bacteria in Relation to Country Life. Lipman.

The Nursery-Book. Bailey.

Plant-Brending. Bailey and Gilbert. Revised.

The Forcing-Book. Bailey.

The Pruning-Book. Bailey.

Fruit-Growing in Arid Regions. Paddock and Whipple.

Rural Hygiene. Ogden.

Dry-Farming. Widtsoe.

LAW FOR THE American Farmer. Green.

Farm Boys and Girls. McKeever.

The Training and Breaking of Horses. Harper.

Sheep-Farming in North America. Craig.

Coöperation in Agriculture. Powell.

The Farm Woodlot. Cheney and Wentling.

Household Insects. Herrick. 



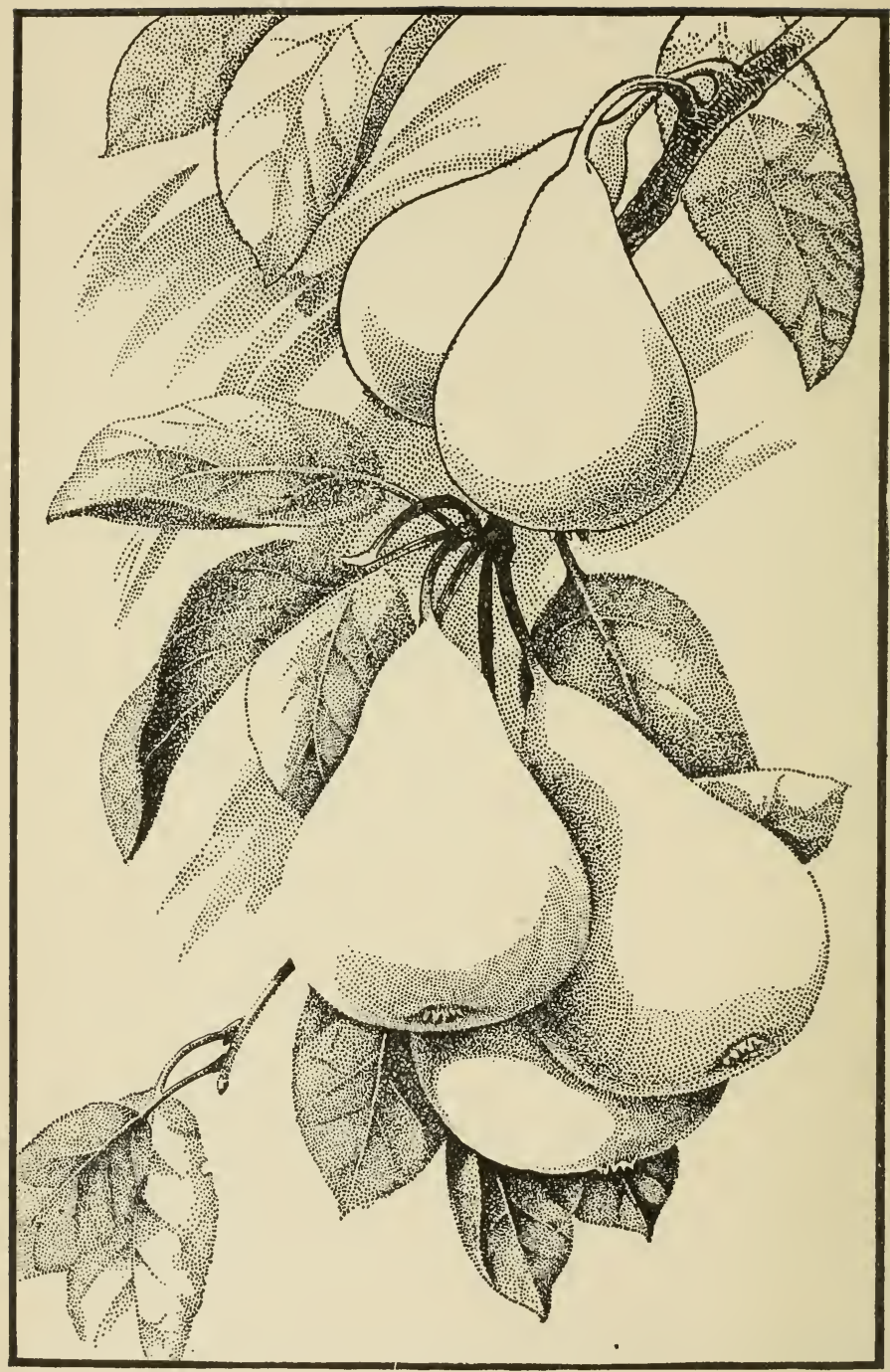

The fruit of the tree. 


\title{
THE PRINCIPLES \\ OF FRUIT - GROWING
}

\section{WITH APPLICATIONS \\ TO PRACTICE}

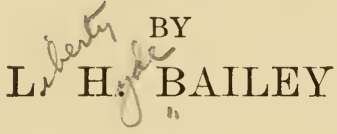

TWENTIETH EDITION, COMPLETELY REVISED

理ew 具ork

THE MACMILLAN COMPANY

LONDON: MACMILLAN \& CO., LTd.

1915

All rights reserved 


\section{SB 355 \\ .815 \\ 1915}

Copyright, 1897, 1915

By L. H. BAILEY

Set up and electrotyped June, 1897

Reprinted July, 1898; July, 1900; July, 1901; June, 1902;

February, 1904; January, 1905; January, November, 1906;

October, 1907; June, 1908; January, July, 1909; January, 1910;

January, November, 1911; April, 1912; March, 1913;

February, 1914

Completely revised edition. Published February, 1915

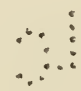

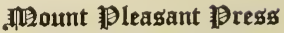

FEB 251915

J. Horace McFarland Co.

Harrisburg, $\mathrm{Pa}$. 


\section{PREFACE}

This book was first published in 1897, seventeen years ago. The second edition was called for in 1898, and the preface for it was written in the Tyrol, where I was then looking into the interesting fruit-growing of certain regions. Aside from minor changes in the text, this edition included an addition to the appendix of "remarks on classifying and describing fruits." The third edition appeared in 1900, with no change except in details; and the fourth in 1901. The present issue of the book, which is the twentieth, is a new work, it having been rearranged and reset, and largely rewritten.

In the years since the book first appeared, much new knowledge has come to the aid of the fruit-grower. The advanced opinions of that day on the merits of tillage over hay and sod have now been affirmed by experience and experiments, although the sod-mulch method has proved itself under certain circumstances. The many investigations of insects and fungi, and the means of attacking them, have resulted in a new literature and more certain means of control. We are beginning a new line of approach to the difficult problem of protection from frost. We have more rational recommendations to make on the fertilizing of fruit-lands. We are beginning in many ways to adapt practices of caring for the 
plants to the better understood physiology of the plants themselves. The older and traditional opinions and notions are gradually giving way to the results of careful investigation.

In this edition I have had the great advantage of the advice of many persons. I have freely incorporated the work of others, as appears in the text. Particularly am I indebted to Prof. C. S. Wilson and Prof. W. H. Chandler, of the Department of Pomology in the New York State College of Agriculture at Cornell University. The one has read all the proof in galleys and the other has read it all in pages. They have helped me over many doubtful places, and have thereby made the book more worth the while.

L. H. BAILEY.

IthaCA, N. Y., December 25, 1914. 


\section{CONTENTS}

\section{CHAPTER I}

Pages

The Field of Inquiry . . . . . . . . . . . 1-37

Inventory of Fruits . . . . . . . . . . . . . . . . . . 2 2 2- 8

The Course of Development of a Fruit Region . $8-10$

The Determinants in Fruit-growing. . . . . . $10-20$

The temperature determinant . . . . . . . . . 11- 12

The moisture determinant . . . . . . . . . . . . 12- 13

The soil determinant . . . . . . . . . . . . 13- 15

The subsoil . . . . . . . . . . . . . . . 15- 16

The parasite determinant . . . . . . . . . . 16- 20

The Outlook for Fruit-growing . . . . . . . . . 20- 24

The Organizing of the Business ....... . . 24- 31

Cost-accounting . . . . . . . . . . . . . 27-31

The Two Kinds of Commercial Fruit-growing . . $31-34$

Garden and Amateur Fruit-growing . . . . . . . 34- 36

The General Practice and the Special Practice . . 36- 37

\section{CHAPTER II}

The Location and Its Climate . . . . . . . 38-63

The Place ............. . . . 39- 51

Location with reference to market . . . . . . . . 40

Location with reference to weather . . . . . . 41- 51

Rain at blossoming time . . . . . . . . . 41- 42

Wind ............ . . 42-44

Low temperature . . . . . . . . . . 44- 48

Atmospheric drainage . . . . . . . . . . . 49- 51

The Site for the Fruit-plantation ....... . 52- 55

The aspect . . . . . . . . . . . . . 53- 55 
The Location and Its Climate, Continued Pages

Windbreaks for Fruit-plantations. . . . . . 55-63

Benefits . . . . . . . . . . . 56

Injuries . . . . . . . . . . . . . 56

Forests and fruit-growing . . . . . . 57- 58

General statement . . . . . . . . 58- 60

How to make the windbreak. . . . . . . 60-63

\section{CHAPTER III}

The Tillage of Fruit-Lands . . . . . . . 64-108

The case of the early apple plantings . . . . . 67-69

Sod orchards . . . . . . . . . . . . . . . 69- 72

Allowable use of sod . . . . . . . . . . . . 72- 75

The Philosophy of Tillage . . . . . . . . 75- 84

The structure of the soil . . . . . . . . . 77-81

The moisture of the soil . . . . . . . . . . . 81- 84

Use of the Variods Tools in Relation to MoistureSAVING . . . . . . . . . . . 84- 91

Plowing to save moisture . . . . . . . . . . 84- 85

Harrowing to save moisture . . . . . . . . . . 85- 88

Cultivators and moisture-saving . . . . . . . . . 88-89

The roller, in its relation to soil-moisture . . . . . 89- 91

Suggestions for the Tilling of Fruit-lands . . . . 91-102

Preparation of the land . . . . . . . . . . . . . 91-94

Subsequent tillage . . . . . . . . . . . . 94- 97

Specific advice on tillage . . . . . . . . . 97-102

Cropping the Plantation .......... . . 102-106

Orchard crops . . . . . . . . . . . 104-106

IRRIGATION OF FrUIt-LANDS . . . . . . . . . 106-108

Irrigation in the East . . . . . . . . . 106-108

\section{CHAPTER IV}

The Enriching of Fruit-Lands . . . . . . . 109-152

The land is to be kept at work . . . . . . . . 109-112

The lesson of nursery lands . . . . . . . . . . 112-113

Cover-Crops . . . . . . . . . . . . . . . . . 113-126

The kinds of cover-crops . . . . . . . . . . . . 116-123

List and rates of seeding of cover-crop plants . . . . 123

Average quantity of seed to the acre . . . . . 124-125

Weights of the seeds of cover-plants . . . . . 125-126 
The Enriching of Fruit-Lands, Continued Pages

Rotation of Plantations . . . . . . . . . . . . 126-129

Stable Manures ............... . . 129-131

Chemical Fertilizers . . . . . . . . . . . . 131-152

Apple-orchard experiments . . . . . . . . . . . 134-140

What to do . . . . . . . . . . . . 140-151

Individual plants . . . . . . . . . . . . . . . 142-143

Recommendations for apples. . . . . . . . . . 143-144

Other suggestions for apples and pears . . . . . 144-145

A test plat for apples . . . . . . . . . . . . 145-146

Peaches . . . . . . . . . . . . . . . 146-147

Plums, apricots, cherries . . . . . . . . 147

Quinces . . . . . . . . . . . . 147

Grapes . . . . . . . . . . . . . . . 147-149

Berry bushes . . . . . . . . . . . . . . . 149-150

The cranberry . . . . . . . . . . 150

Strawberries . . . . . . . . . . . 150-151

How to apply . . . . . . . . . . . . . . 152

\section{CHAPTER V}

The Plants and the Planting . . . . . . . . . . 153-190

The Choice of Varieties . . . . . . . . . . . 153-164

Self-sterile varieties . . . . . . . . . . . . . 156-160

Pears . . . . . . . . . . . . . . . . 157-158

Apples . . . . . . . . . . . . . . . . 158

Plums . . . . . . . . . . . . . . . 158

Grapes . . . . . . . . . . . . . . 158

Scoring the varieties . . . . . . . . . . . . . 161-162

How did the varieties of fruits originate . . . . . 162-164

The Securing of the Plants. . . . . . . . . . 164-173

Dwarfs vs. standards . . . . . . . . . . . . . . 167-168

Pedigree plants . . . . . . . . . . . . . . . . . . . . 168-169

Stocks . . . . . . . . . . . . . . . . . . . 169-171

Stock for top-working. . . . . . . . . . . . . . . 171-172

Buying the trees . . . . . . . . . . . . . . . . 172-173

The Setting of the Plants' . . . . . . . . . 174-190

When to plant. . . . . . . . . . . . . 174-176

Distance apart . . . . . . . . . . . . . . . . 176-178

Double-planting; fillers . . . . . . . . . . . . 178-181

How to plant . . . . . . . . . . . . . . . . 181-184

Trimming the trees . . . . . . . . . . . 184-190 


\section{CHAPTER VI}

The Laying Out of the Plantation . . . . . 191-226

Contour Planting . . . . . . . . . . . . . . . . 192

ORCHARD SYSTEMS . . . . . . . . . . . . 192-194

Making the Rows Straight . . . . . . . 194-206

'To lay out with a plow . . . . . . . . . . 198-201

Laying out with a line . . . . . . . . . . . . 201

Another line method . . . . . . . . . . . 201-202

Staking methods . . . . . . . . . . . . . 202-206

Details of Orchard Lay-outs . . . . . . . . . 206-217

Lining-in method. . . . . . . . . . . . . . 212-213

Wire-compass method . . . . . . . . . . . . 213-214

The Family Fruit-plantation . . . . . . . . 217-221

MAPS AND RECORDS. . . . . . . . . . . 221-226

Labels . . . . . . . . . . . . . 222-226

\section{CHAPTER VII}

Subsequent Care of the Fruit-Plantation . . . . 227-287

Pruning . . . . . . . . . . . . . . . . . 230-241

The bearing wood . . . . . . . . . . . 232-234

The kind of top . . . . . . . . . . . . . 234-236

What to remove . . . . . . . . . 236

Renewing old trees by pruning; "dehorning" . . . . 236-237

Heading-in . . . . . . . . . . . . . . 238-241

The Thinning of the Frutt . . . . . . . . 241-250

Thinning the apple... . . . . . . . . . . 243-248

Thinning other fruits . . . . . . . . . . . . 248-249

How to thin . . . . . . . . . . . . . 249-250

Protecting Plantations from Frost .... . . 251-273

How to predict frost . . . . . . . . . . 252-255

Mulching to enable plants to escape frost . . . . 255-257

Covering the plants to protect from frost . . . . . 257-259

Whitewashing as a protection .. . . . . . 259

Making currents of air . . . . . . . . . . 260

Adding vapor of water to the air; flooding . . . 260-261

Explosives for frost and hail . . . . . . . 261-263

The making of smudges . . . . . . . 263-265

Heating the plantation . . . . . . . . 265-273 
Subsequent Care of the Fruit-Plantation, Continued Pages Spectal Care of the Plants . . . . . . . . . 273-283

Staking young trees . . . . . . . . . 273-274

Watering .......... . . . . 274

Bark-bound trees. . . . . . . . . . 274-276

Scraping trees . . . . . . . . . . . 276-277

Whitewashing trees . . . . . . . . 277

Ringing . . . . . . . . . . . . . 277-279

Top-grafting bearing trees . . . . . . . 279-281

Grafting-wax . . . . . . . . . . 281-282

Bagging fruits . . . . . . . . . . . 282

Winter preparations . . . . . . . . . 282-283

Renovating Old Orchards . . . . . . . . . . 283-287

Why are orchards barren? . . . . . . 286-287

\section{CHAPTER VIII}

ACCIDENTS AND InJURIES . . . . . . . . 288-318

Miscellaneous InJURIEs. . . . . . . . . . . . . . 289-299

Depredations of live-stock . . . . . . . . . . . 289

Birds . . . . . . . . . . . . . . . . 289-290

Rodents. . . . . . . . . . . . . 290

Girdled trees . . . . . . . . . . . 290-292

Hail injuries . . . . . . . . . . . . . . 292

Sun-scald . . . . . . . . . . . . . . . . . . 292-294

Borers . . . . . . . . . . . . . . . 294-296

Cankers and bad spots; wounds . . . . . . . . 296-298

Root-galls . . . . . . . . . . . . 298-299

WiNTER-KILLING . . . . . . . . . . . 299-307

Winter-killing of the wood. . . . . . . . 299-304

Frost cankers . . . . . . . . . . . . . . 304-305

Winter-killing of the fruit-buds . . . . . . 306-307

Injury by Frosts in the Growing Season . . . . 307-317

What is an injurious degree of cold? . . . . . . . . 313-317

The Effect of Rain on the Setting of Fruit . . .317-318 


\section{CHAPTER IX}

The Spraying of Fruit-Plantations . . . . . . 319-363

The Kinds of Difficdlties . . . . . . . . . 322-324

Specific Remarks on SPRAYing . . . . . . . 324-333

Lists and Formdlas . . . . . . . . . . . . 333-336

Synopsis of the principal considerations in the choice of

a power sprayer and nozzles . . . . . . . 334-336

InseCticides AND Fungicides . . . . . . . . . . . 336-343

Leading Froit Insects and Diseases That Are Con-

TROLLEd by SPRAYING. . . . . . . . . . 343-361

Arsenical Poisoning of Frdit Trees . . . . . 361-363

\section{CHAPTER X}

Harvesting and Marketing the Fruit . . . . . .364-422

Picking Fruits . . . . . . . . . . . . . . . . . 365-380

When to pick . . . . . . . . . . . . . 365-369

Apples . . . . . . . . . . . . . . . 366-367

Pears . . . . . . . . . . . . . 367-368

Stone-fruits . . . . . . . . . . . 368-369

How to pick . . . . . . . . . . . 370-374

Ladders for picking . . . . . . . . . . 374-377

Fruit-pickers and harvesters . . . . . . . . . 377-380

Necessity of hand-picking . . . . . . . . . . . 380

Caring for the Froit After Picking. . . . . . . 380-383

Keeping records with the pickers . . . . . . . 380-383

The Grading and Packing of Fruit. . . . . . . .383-407

What is first-class fruit? . . . . . . . . . . . 383-384

The grading . . . . . . . . . . . . . . . . . 384-385

The packages ... . . . . . . . . . 386-392

How to pack . . . . . . . . . . . 392-400

Box-packing of fruits . . . . . . . . . . 400-407

Farm Packing-hodses and Appliances . . . . . 407-413

Storing Fruits at the Farm . . . . . . . . . . .413-422

Requisites for domestic storage without ice . . . . 415-418

Farm storage buildings . . . . . . . . . . 418-422 


\section{THE PRINCIPLES OF FRUIT- GROWING}

\section{CHAPTER I}

\section{THE FIELD OF INQUIRY}

IT Is natural for a fruit-plant to bear. There are certain hindrances, however, that must be overcome; and the better the conditions under which the plant is placed, the better will be the results in the production of acceptable fruit.

The whole subject of producing fruit is known as fruit-growing or pomology. This subject comprises the art of raising and handling fruits and fruit-plants, and the applications of the various sciences thereto. It is impossible exactly to define what a fruit is, in the sense in which the term is understood in pomological writings. It is best delimited by giving a list of the products that are commonly known as fruits. If a definition were attempted of the pomological use of the word, it would be approximately correct to say that a fruit is the edible product mostly of a woody or a tree-like plant-as of a tree, bush, or vine-that is intimately associated in its development with the flower. This conception of a fruit is unlike the botanical idea, for the botanist defines the fruit to be the ripened pericarp and attachments. It should be said, however, that this confusion in terminology 
is not the fault of the horticulturist, for the botanists have given a special or technical meaning to a commonlanguage word. The word belongs primarily to general literature and horticulture, and if the botanist desires to impress it into other service, he must be prepared to accept the confusion that arises.

The "fruit" of the pomologist is not defined in terms of botanical structure. It may be a ripened pericarp (or ovary), as in the currant, gooseberry, cranberry, grape, plum, peach, orange, olive; an ovary or pericarp immersed in a receptacle, as the pomes, comprising apples, pears, quinces; a greatly enlarged fleshy receptacle bearing achenes, as the strawberry; an aggregation of pericarps, as in the raspberry, or combined with the receptacle, as in the blackberry; an aggregation of thickened flowers and flower-parts, as in the mulberry and pineapple; a nut inclosed in a husk, as in hazel and chestnut.

Among fruit-growers, several large classes of fruits are recognized, as stone-fruits, pome-fruits, citrous fruits, berries, grapes, and nuts; or the division may be orchard- or tree-fruits, grapes, small-fruits or berries. None of these classifications is inclusive or exact; and it would not be profitable to enlarge on the discussion here.

\section{INVENTORY OF FRUITS}

Pomological fruits may be roughly classified under four heads from the cultural point of view,-tree-fruits, vine-fruits, small-fruits, and herb-like fruits. The following is an inventory of the staple fruits of the United States and Canada, and of many of those lesser known species which, having been tried in this territory, either give 
promise of successful cultivation here or have been more or less prominent subjects of discussion or sale:

\section{Class I. Orchard* Culture, or Tree-Fruit Culture.}

SUbClass 1. Pomaceous fruits.

Apple, Pyrus Malus.

Crab-apple, Pyrus baccata and P. prunifolia.

Prairie crab, Pyrus ioensis.

Atlantic crab, Pyrus coronaria.

Pear, Pyrus communis.

Sand pear, Pyrus serotina.

Quince, Cydonia oblonga.

Chinese quince, Chænomeles sinensis.

Japan quince, Chænomeles japonica.

Maule's quince, Chænomeles Maulei.

Medlar, Mespilus germanica.

Loquat, Eriobotrya japonica.

Subclass 2. Drupaceous or stone-fruits.

Common plum, Prunus domestica.

Bullace, mirabelle and damson plum, Prunus insititia.

Cherry and myrobalan plum, Prunus cerasifera.

Japan plum, Prunus triflora.

American plum, Prunus americana.

Canada plum, Prunus nigra.

Hortulana plum, Prunus hortulana.

Chickasaw plum, Prunus angustifolia and P. Munsoniana

Sand plum, Prunus Watsoni.

Beach plum, Prunus maritima.

Pacific plum, Prunus subcordata.

Apricot plum, Prunus Simonii.

Sweet cherry, Prunus Avium.

Sour cherry, Prunus Cerasus.

Sand cherry, Prunus Besseyi.

Peach and nectarine, Prunus Persica.

Apricot, Prunus armeniaca.

Japan apricot, Prunus Mume.

Purple apricot, Prunus dasycarpa.

* Orchard, an inclosure, assemblage or plantation of fruit trees. Oranges are commonly said to be grown in "groves." The word orchard is not used in this country for the shrub fruits. 
Subclass 3. Citrous fruits.

Common or sweet orange, Citrus sinensis.

Sour or Seville orange, Citrus Aurantium.

King orange, mandarin, tangerine, and satsuma orange, Citrus nobilis.

Calamondin orange, Citrus mitis.

Citron, Citrus Medica.

Lemon, Citrus Limonia.

Lime, Citrus aurantifolia.

Grapefruit, Shaddock or Pomelo, Citrus grandis.

Kumquat, Citrus japonica.

Trifoliate orange, Poncirus trifoliata.

Glycosmis, Glycosmis aurantiaca.

Lime berry, Triphasia trifoliata.

White sapote, Casimiroa edulis.

Subclass 4. Moraceous fruits.

Fig, Ficus Carica, F. Sycomorus.

White (and Russian) mulberry, Morus alba.

Black mulberry, Morus nigra.

Red mulberry, Morus rubra.

Downing mulberry, Morus multicaulis.

Japan mulberry, Morus japonica.

Bread-fruit, Artocarpus incisa.

Jack-fruit, Artocarpus integrifolia.

Subclass 5. Annonaceous fruits.

Sour-sop, Annona muricata.

Sweet-sop, sugar-apple, Annona squamosa.

Cherimoya, Annona Cherimola.

Custard-apple, Annona reticulata.

Pond-apple, Annona glabra.

And other annonas.

Northern papaw, Asimina triloba.

Subclass 6. Myrtaceous fruits.

Guava, Psidium Guajava, and others.

Feijoa, pineapple guava, Feijoa Sellowiana.

Rose-apple, jamrosade, Eugenia Jambos.

Surinam cherry, Eugenia uniflora.

Jambolan, Eugenia jambolana.

And other eugenias. 
SUbCLASS 7. Sapotaceous fruits.

Sapodilla, Achras Sapota.

Marmalade tree, Lucuma mammosa.

Star-apple, Chrysophyllum Cainito.

And others.

Sobclass 8. Anacardiaceous fruits.

Mango, Mangifera indica.

Jew plum, Spondias dulcis.

Cashew, Anacardium occidentale.

SUbchass 9. Ebenaceous fruits.

Kaki (Japan persimmon), Diospyros Kaki.

Persimmon, Diospyros virginiana.

SUbCLAss 10. Leguminous fruits.

Tamarind, Tamarindus indica.

St. John's Bread, or Carob, Ceratonia Siliqua.

SubClass 11. Nut-fruits (Nuciculture).

Walnut, Juglans regia.

Japan walnut, Juglans Sieboldiana.

Black walnut, Juglans nigra.

Butternut, Juglans cinerea.

And other species of Juglans.

Pecan, Carya Pecan.

Shellbark hickory, Carya ovata and C. laciniosa.

And other species of Carya.

Beechnut, Fagus grandifo'ia.

European chestnut, Castanea sativa.

American chestnut, Castanea dentata.

Japan chestnut, Castanea crenata.

Chinese chestnut, Castanea mollissima.

Chinquapin, Castanea pumila.

Filbert, cobnut, Corylus Avellana, C. Colurna, C. pontica, C. maxima.

Hazelnut, Corylus americana, C. rostrata, and others.

Japan hazelnut, Corylus Sieboldiana.

Litchi, Litchi chinensis.

Longyen, Euphoria Longana.

Ginkgo, Ginkgo biloba.

Almond, Prunus Amygdalus.

Russian almond, Prunus nana. 
Tropical almond, Terminalia Catappa.

Pistacio, Pistacio vera.

Pili nut, Canarium ovatum.

Brazil-nut, Bertholletia excelsa.

Chile-hazel, Gevuina Avellana.

Strclass 12. Palmaceous fruits.

Coconut, Cocos nucifera.

Date, Phœnix dactylifera.

Peach palm, Bactris Gasipaes.

And other palms.

Subclass 13. Miscellaneous tree-fruits.

Olive, Olea europea.

Pomegranate, Punica Granatum.

Papaw, Carica Papaya.

Hovenia, Hovenia dulcis.

Jujube, Zizyphus. Jujuba, and others.

Myrica, Myrica Nagi (M. rubra).

Sea-grape, Coccoloba uvifera.

Otaheite gooseberry, Phyllanthus disticha.

Spanish lime, Melicocca bijuga.

Avocado, Persea gratissima.

Strawberry tree, Arbutus Unedo.

Mammee apple, Mammea americana.

And many others.

\section{Class II. Vine-Fruit Culture.}

Subclass 1. Viticulture; comprising

Wine grape, Vitis vinifera.

Fox grape, Vitis Labrusca.

Summer grape, Vitis æstivalis.

Post-oak grape, turkey grape, Vitis æstivalis var. Lincecumii.

Herbemont grape, Vitis æstivalis, var. Bourquiniana.

Muscadine and scuppernong grapes, Vitis rotundifolia.

Sand grape, Vitis rupestris.

River-bank grape, frost grape, Vitis vulpina.

And other native species of Vitis.

Stbclass 2. Passifloraceous fruits.

Granadilla, Passiflora edulis.

And others. 


\section{Class III. Small-Fruit* Culture (The Berries).}

\section{Subclass 1. Bush-fruits. $\dagger$}

Group $a$. Rubaceous fruits, or (bramble-fruits).

Raspberry, Rubus idous.

Blackcap raspberry, Rubus occidentalis.

Red raspberry, Rubus strigosus.

Wineberry, Rubus phænicolasius.

Blackberry, Rubus nigrobaccus and other species.

Thornless blackberry, Rubus canadensis.

Evergreen blackberry, Himalaya berry, Rubus laciniatus.

Northern dewberry, Rubus villosus, $R$. invisus.

Southern dewberry, Rubus trivialis.

Pacific dewberry, Rubus vitifolius.

Group $b$. Ribaceous fruits.

Currant; Ribes vulgare.

Black currant, Ribes nigrum.

Buffalo currant, Ribes aureum.

Gooseberry, Ribes Grossularia.

American gooseberry, Ribes oxycanthoides (or R. hirtellum).

Group $c$. Blueberries.

Swamp or High-bush blueberry, Vaccinium corymbosum.

Canada blueberry, Vaccinium canadense.

Low-bush blueberry, Vaccinium pennsylvanicum.

Group $d$. Miscellaneous bush-fruits.

Juneberry, Amelanchier oblongifolia, A. alnifolia and others.

Buffalo berry, Shepherdia argentea.

Goumi, Elocagnus multiflora.

Caraunda, Carissa Carandas.

Natal plum, Carissa grandiflora.

Amatungulu, Carissa bispinosa.

*Small-fruits. A term applied io all small and berry-like fruits produced on bushes or perennial herbaceous plants; as currant, blackberry raspberry, strawberry. In Europe the strawberry is classed with garden vegetables, and melons are often treated with the fruits. Small-fruits is an American term.

$\dagger B$ ush-fruits. Fruits borne on bushes, or small woody plants destitute of a central stem or axis. It is an English term, and is equivalent to small-fruits, except that it does not include the strawberry. 
SubClass 2. Strawberry-fruits.

Garden strawberry, Fragaria chiloensis.

Hautbois strawberry, Fragaria moschata.

Alpine strawberry, Fragaria vesca.

Virginian strawberry, Fragaria virginiana.

Everbearing strawberry, Fragaria mexicana.

Subclass 3. Cranberry-fruits.

Common cranberry, Vaccinium macrocarpon.

Cowberry, Vaccinium Vitis-Idæa.

Class IV. Miscellaneous Non-woody or Herb-like Fruits.

Subclass 1. Musaceous fruits.

Banana, Musa Sapientum.

Plantain, Musa paradisiaca.

Subclass 2. Pineapple.

Common pineapple, Ananas sativus.

Subclass 3. Cactaceous fruits.

Prickly pear, Opuntia Tuna, and others.

Indian fig, Opuntia Ficus-indica.

Barbadoes gooseberry, Pereskia aculeata.

Subclass 4. Other herb-like fruits.

Cyphomandra, Cyphomandra betacea.

Cerinam, Monstera deliciosa.

\section{THE COURSE OF DEVELOPMENT OF A FRUIT REGION}

Fruit-growing has usually been a comparatively late development in any region. The epochs that precede the agricultural occupation of a country are commonly about as follows: Discovery, exploration, hunting, speculation, lumbering, or mining. The real and permanent prosperity of a country begins when the agriculture has evolved so far as to be self-sustaining and to leave the soil in constantly better condition for the growing of plants. 
Lumbering as now practised, and mining, are simply means of utilizing a reserve that nature has laid by, and these industries, therefore, are self-limited, and are constantly moving on into unrobbed territory. Agriculture, when at its best, remains forever in the same place, and gains in riches with the years; but in this country it has so far been mostly a species of mining for plant-food, and then a rushing on for virgin lands.

The first effort in an agricultural region is usually the growing of the staple crops, as the grains or breadstuffs. This is both because the capabilities of the country are all unknown, and because such regions are far removed from the markets, and must, therefore, grow such commodities as can be stored or shipped long distances; and it may be said, also, that the growing of these crops in a new country demands comparatively little special skill. Moreover, the new lands are cheap, and the supply of labor is small; and grain-raising and cattle-ranging are economically possible. The second development is very often a wellregulated stock-raising or grazing industry.

If the country possesses special adaptabilities for fruits, a man here and there will be found enlarging his orchards or small-fruit plantations, and in time there is a widespread change from general farm practices to fruit-growing. The growing of specialties, or perishable products, or those that are essentially luxuries, demands the finer skill, the more developed ideals, and the less fluctuating employments of an old or at least of a well-settled country; and it is in such areas, also, that the best special markets are to be found. It has been a frequent experience that when any area has fully committed itself to the raising of any particular fruit, the business is devoted too exclusively to one product and the individual farms may not be 
good economic units. The lesson is that mixed industries are best for any community, even though the region make a specialty of one or of a few commodities, and that it is practically impossible to reduce the agriculture of any large region to a dead level of uniformity. The diversity of industries also brings a diversity of population.

In the present development of the newer parts of North America, however, these stages in the evolution of fruitgrowing may not be marked. Fruit has now come to be such a standard commodity that virgin areas in newly opened regions may be developed at once as fruit lands; but there is a large element of risk in such undertakings in virgin regions.

\section{THE DETERMINANTS IN FRUIT-GROWING}

Fruit-growing, in common with all agricultural pursuits, thrives best in certain geographical areas. That is, the business is not capable of equal development in all parts of the country.

Four of the most apparent determinants of the distribution of fruit-growing may be mentioned briefly. The distribution of fruits may also be studied in their relations to life-zones, and particularly as determining the adaptabilities of varieties (see for example, Bull. No. 10, Div. of Biol. Surv., U. S. Dept. Agric., 1898, by C. Hart Merriam, on "Life Zones and Crop Zones," as one of the early contributions to the subject). The leading determinative factor in the distribution of fruit-culture is climate. The particular factor of climate that determines the fruitzones differs with each type group of fruits; but in general it may be said that the relative annual temperature is the most influential factor. 
The temperature determinant.

It is customary to recognize three general climatal fruit-zones, - the temperate (typified by the apple and the peach), the semi-tropical (citrous tribes, fig, olive, pomegranate), and the tropical (coconut, banana, annona, mango). There are no positive limits of temperature to mark off or separate these zones; but it is sufficient for our purpose to say that the temperate zone is marked by a long winter of freezing and by the deciduous types of fruits; in the semi-tropical zone the winter is a short season of light frosts or only occasional freezes, and the fruit trees are evergreen or very nearly so; and the tropical zone is frostless, and is marked by evergreen and largely ever-growing fruit-plants.

The limits of these climatal zones are exceedingly devious. In eastern North America, the northern limit of profitable fruit-growing is not far from the 45th parallel, and the limit sinks considerably lower than this in the Middle West, and rises much above it on the Pacific slope. The northern limit of the subtropical zone in the East is northern Florida and a narrow area skirting the Gulf of Mexico, and on the western side of the continent it extends in the valley climates as high as the 40 th parallel. The only part of the tropical fruit-zone in the United States is in extreme southern Florida, comprising about 2 degrees of latitude (reaching northward to about $27^{\circ}$ ). Beyond all these bounds are special localities in which fruits of the adjacent zone may thrive for a series of years, and the fruits of contiguous zones overpass. The strawberry is probably the most tractable of all our fruits as respects climate, because its stature and habit allow it to be protected from extreme cold, and its short period of growth allows it to thrive in the cool season of the subtropical regions. 
The annual temperature of a region is chiefly determined by four factors, - the latitude, the altitude, the physical configuration, and the proximity or remoteness of large bodies of water.

\section{The moisture determinant.}

The second chief factor of climate in determining the fruit-zones is relative humidity. Whilst the isothermsor lines of equal temperatures - run easterly and westerly, the isohyetals-or lines of equal rainfall-have no intrinsic direction. They are determined by physiographical features. In the United States, we might recognize very roughly six general fruit-zones marked by peculiarities of rainfall. These are the Atlantic zone, a moist area bounded westward approximately by the Mississippi River; the Plains zone, extending westward to the Rocky Mountains, mostly of low rainfall and in some parts semiarid; the inter-mountain region, being mostly arid and requiring irrigation; the Sonoran zone of New Mexico and Arizona and southward; the California region, mostly arid and semi-arid; the upper Pacific region, comprising the humid belt of Oregon, Washington, and British Columbia. Within all these regions are geographical areas of special precipitation conditions. The interior or plains region is particularly trying to fruits because of the strong and dry winter winds, which evaporate the moisture from the trees while the ground is often so deeply frozen that the roots cannot supply moisture. There is probably always evaporation from tree tops in the winter when the air is drier than the wood. The fact that moisture may be lost from winter twigs is a most important consideration in the study of the winter injury of trees, and it throws light upon the severe damage that often follows the "dry 
freezing" of nursery trees in transit and of fall-planted trees.

\section{The soil determinant.}

There are special adaptations of fruits to soils. Pomologists have been well aware of this fact as a general truth, but only recently has close attention been given, in this country, to the minor and detailed applications of it. It is well understood that pears flourish best in clay soils and peaches best in sandy or at least in open soils, but no doubt there are distinct preferences in the varieties of pears and peaches themselves. It is possible, in fact, that each distinct family or type of varieties of any species has preferences of land and location, and it will be the business of coming generations to determine what these peculiarities are. With the increasing refinements and competitions of the future, the special and local problems must receive more and more attention. If these positions are well taken, it must follow that the promiscuous and wholesale dissemination of a few varieties over the country must eventually cease, and that local and special sorts must constantly tend to drive out the cosmopolitan and general varieties.

These questions of soil adaptations for fruits have been made the subject of study over a wide range by Wilder of the national Department of Agriculture, and he is able to discuss the soil requirements of the Baldwin apple, the Wagener, Spy, Hubbardston, Gravenstein, and others, with considerable definiteness. He points out that the common advice as to "any deep, well-drained soil, on hill or slope," being adapted to apple-growing is not sufficiently exact and discriminating. "The loss from choosing a soil for orchard planting that is not adapted 
to the purpose is so much more serious than a similar mistake with an annual crop that too much care can scarcely be taken in selecting the most suitable soils located on sites otherwise favorable." (Tribune Farmer, April 3, 1913.)

Many fruits are very cosmopolitan as to soils, although probably none of them is indifferent to even comparatively minor variations in land. Of the temperate tree-fruits, the apple undoubtedly has the most generalized adaptabilities to soils, and this is closely followed by the domestica plum. Among semi-tropical fruits, the orange thrives in a wide range of soils. The peach and grape are more exacting, and the same may be said of the pineapple.

Now and then fruits are made to grow in uncongenial soils by working them on adaptive stocks. Thus the plum is said to thrive best in sandy regions when it is budded on the peach, the pear is recorded as sometimes grown on very light lands by working it on the mountain-ash, and the mahaleb cherry is thought by most persons to be a better stock for strong soils than for light soils. We may look for the time when certain varieties of the same species may be selected as stocks for given soils. But all this forced adaption to soils is a very special matter, and it only illustrates the more strongly the great importance of giving particular attention to the general subject of the adaptabilities of species, varieties, and even of strains, to variations in soils.

The grower should give particular attention to the character of the land. An experienced fruit-grower commonly determines whether the land is adaptable by its "looks;" and this suggests that the novice secure the advice of an experienced person if he would choose a farm for fruit. The success or failure of existing trees or orchards 
in the neighborhood may give some indication of soil conditions. If the region is soil-surveyed, the intending grower should attempt to recognize the successful orchards on the soil-map. In a few cases, special studies by an expert have been made of the soil types in relation to fruits, and advantage should always be taken of such work.

The subsoil.-In making soil-determinations, the planter should not be guided by the character of the surface-soil alone. With modern methods of soil-examination, the subsoil is always taken into account. Booth goes so far (Okla. Exp. Sta.) as to say that "The character of the surface-soil appears to have little or nothing to do with making good tree land. Good orchards will be found on all kinds of soils, from dense clays to light sands. It is certainly not due to the richness of the soil, for many of the best orchard sections of the United States have thin soils which require constant feeding. In fact, there is only one thing which is found constantly associated with good orchard land, and that is an open porous subsoil. The adaptability of land for tree-growth is shown by the character of the soil from 1 to 6 feet below the surface. If the land is satisfactory for 4 feet down, usually this is deep enough for satisfactory tree-growth, although 6 feet is better. The average farmer knows but little about his land below the bottom of the furrow made by the plow, so that he is frequently but little better fitted to say where his trees should be planted than someone who has never seen the land.

"There are many ways of becoming acquainted with the subsoil. One of the best is by the use of a spade. The digging of a few holes 5 or 6 feet deep in different parts of the farm will reveal an astonishing amount of information as to the character of the subsoil. The number of 
holes necessary to give satisfactory information as to the character of the underlying strata will vary. If it be found that half a dozen holes dug in a certain 5- or 10-acre tract give practically the same result in each case, it may usually be assumed that these indicate the general character of the subsoil. If, on the other hand, the verdict is variable, more holes will have to be dug until the limits of the different formations are shown. Where neither rocks nor stones are present, this work may be done more quickly and quite as satisfactorily with a ground-auger as with a spade. A home-made auger is usually quite as satisfactory for this purpose as the more expensive article purchased on the market. Take an old $11 / 2$ - or 2 -inch wood-auger and have the local blacksmith weld it to the end of a 6 -foot length of $3 / 4$-inch pipe or $1 / 2$-inch wrought iron rod. The welding of a short cross-piece at the top completes the device.

"An open porous subsoil insures drainage and thus promotes the establishment of deep feeding roots. Trees with such root-systems are not subject to the vicissitudes of varying seasons to the same extent as those of a shallower rootsystem. . . . The capacity to penetrate impervious subsoils does not depend on the boring power of the roottip. All roots have a boring power which is quite sufficient to force their way down in any ordinary subsoil. The reason for the absence of roots is that they are unable to live in the denser soil, owing to the lack of the necessary air. Thus it will be found that a soft mucky subsoil is quite as efficient a barrier to root-growth as solid rock."

The parasite determinant.

Inasmuch as many of the organisms that seriously interfere with fruit-growing are more or less restricted in their range, it would seem to follow that the zones of profit- 
able fruit-culture may be determined more or less by the parasite factor. A moment's reflection will show, however, that the geographical distribution of the parasite is determined primarily by climate and by the distribution of its host-plants; so that, on the one hand, the climatal limit of the cultivation of the fruit may be approximately the climatal distribution of the pest, and, on the other hand, the parasite may be local or cosmopolitan according as the fruit is either local or widely grown.

Many of the common pests are restricted in range because they have not yet reached the full limit of their distribution. An excellent illustration of this fact is the codlin-moth. Once Michigan was represented to be the Eutopia of the apple-grower because of the absence of this pest, and in our own day similar recommendations have been made of far western states. To the naturalist, however, it was evident from the first that the insect was following closely behind the apple frontier, as a storm follows an area of high pressure.

In practice, the energetic and intelligent fruit-grower will think last of the parasite factor when locating his plantation, for this factor is variable and migratory, and, moreover, there are means of keeping most fruit pests under control. Insects and fungi are of course to be reckoned with, and for this reason they are the direct and perhaps the most effective means of keeping the farmer in a state of mental alertness. There are a few cases, of course, to which these remarks will not well apply, but they are clearly exceptions. One of these is the dreaded nematode root-knot of the southern states, and one might hesitate in planting peaches on certain land where it does not freeze deep enough to destroy the pest. The professional experimenters can determine the course of the 
life-histories of the various pests, and can point out their most vulnerable points, and may even devise general means for their eradication; but the final application of this knowledge is a local problem, which each man must work out for himself. Laws are only secondary means of keeping insects and diseases in check on a man's own farm; they are chiefly useful in providing a way of controlling the man who is neglectful, ignorant, or devoid of public responsibility. They are most applicable in those cases in which disease is more or less permanent or perennial, and in which there is no practicable recourse but to destroy the plant or the part affected. Such troubles are peach yellows and black-knot of the plum and cherry. A law cannot be enforced unless public sentiment is behind it, and when public sentiment is completely aroused the law may not be needed. Yet a good law is one of the best educators, and if properly enforced may save an industry, but it must be remembered that the final recourse is always greater knowledge and enlightenment on the part of the individual growers.

That the grower may not expect so much of the operation of laws as to lessen his own activity, let him consider the practical difficulties in the enforcement of them. It is practically impossible to detect the eggs of insects or spores of fungi on large numbers of plants, and there are many natural and uncontrollable ways in which the parasites may spread. A law may very properly require that "whenever any trees, plants, or vines, are shipped into this state from another state, every package thereof shall be plainly labeled on the outside with the name of the consignor, and a certificate showing that the contents had been inspected by a State or Government officer, and that the trees, plants, or vines therein contained are free from all San José 
scale, yellows, rosette, and other injurious insect or disease;" yet it would be impossible for any botanist to certify that a dormant tree were certainly free of all disease; and even in the matter of some insects, an entomologist could not give a clean bill of health without giving more time to the examination of the tree than it is worth. These difficulties are not justification for opposition to statutes or for indifference to them, but they are reasons why the grower should be careful to avoid a false security. The grower must add his personal endeavor, and watch his plantation minutely with his own eyes even if it has passed the scrutiny of the inspector.

A knowledge of the natural history of the pests provides the only final security. Most insects and diseases are beyond the reach of legislative fiats. Some of the demands for functionary proceedings against the bugs recall the laborious efforts of the Middle Ages. "At one time," writes Fernald, "a thoroughgoing procedure, according to all the rules of jurisprudence, occurred before the spiritual judge. The accused insects were summoned, and in case of non-appearance, which always occurred, unless the insects were moving to new feeding-grounds and the courthouse happened to be in their way, a proxy was appointed to represent the accused insects, who debated the whole subject with the accuser, after which judgment was rendered, invariably against the accused insect in the form of an excommunication, which was carried into effect only when the insects disappeared at the time of pupation."

The most effective legal means are those that endeavor to regulate the commerce in diseased and affected plants, - to prevent the spread of the difficulty rather than to solve the difficulty on a given plantation. In recent years, 
a useful body of inspection and quarantine laws has arisen that puts the power of the people behind the effort to stop invasion. It is to be expected that these laws will tend toward greater uniformity and therefore toward greater effectiveness, between the different political units of the country. It is particularly important that ports of entry and points of distribution be watched. The grower also must recognize that he has no right carelessly or wantonly to harbor an insect or a disease that may inflict great damage on his neighbors, and that if he violates this principle he is morally liable (as he ought to be legally liable) to correction.

\section{THE OUTLOOK FOR FRUIT-GROWING}

Two sets of factors chiefly control or determine the outlook of the fruit-grower: the ability of the grower, and the prospective conditions of the market. Few persons appreciate how personal a thing success is: yet everyone knows that any two persons placed in the same physical and environmental conditions, and given an equal chance, will arrive at very different results in business. The real directive forces are matters of character and personality, of which the most important requisites seem to be love of the occupation, indomitable energy, cool judgment, honesty, and ability to handle the details of the business.

It is not probable that agricultural products are to be raised in too large quantities. Both population and rate of consumption are increasing. It is a common practice to estimate the amount of fruit which will be produced at any given time in the future by multiplying the number of acres of plantation by the yield of a normal acre of that kind of fruit. The fallacy in these calculations 
lies in the fact that very many of the orchards that are planted in hope and expectation yield only indifferent results.

Not often is there a sufficiency of the best in any commodity. It is in the production and careful marketing of the best that the greatest hope lies with any individual; and this raises at once the personal qualifications. A man cannot make the best unless he has ability for it. It is more important, therefore, that the first tillage and fertilizing and pruning and spraying be applied to the man rather than to the land or the crop; and while the man is acquiring discipline for the direct prosecution of his business, he is at the same time opening his mind to all the satisfactions of living. On the other hand, there is commonly a surplus of the ordinary. In fact, it is the ordinariness that often makes it a surplus. Now, inasmuch as most men are ordinary, it follows that most things which they make will be ordinary; and it does not matter if we raise the standard of all men, the greater part will still be ordinary, for we have only raised the ordinariness of the mass. This is equivalent to saying that the effort at excellence must be continuous and must not be satisfied with any achievement.

One cannot expect to escape competition in the fruit business. As a rule, the best results are to be anticipated when one grows his fruit in a fruit-growing region in company and in competition with other fruit-growers. If every occupation is already full, then it follows that the choice of an occupation resolves itself into what one cares for and what he has capital for, provided always that he can secure the proper land and location for the prosecution of the business. He need have no fear of his success if he grows what people want, or puts it up so as to make 
them think that they want it. In its common levels, fruitgrowing, like every other business, is undoubtedly overdone, and there is only a precarious living in it. This is specially illustrated in apple-growing,- - to which the least skillful attention has been given,- - for the years of crop are years of low prices. This means that apple-growers allow the seasons and other circumstances to dictate the bearing time of the orchard, and when one man has a crop other men may have a crop. Yet there is no fruit that comes so near to being a staple commodity as does the apple, and none that has a longer market season, or is capable of manufacture into a greater number of secondary products. The demand for first-class apples, delivered in prime condition at the proper moment, is seldom fully satisfied.

The most profitable stock-in-trade of the fruit-grower, therefore, is training for his work; and if a good part of his training is in business methods, very much will be gained, for there are probably ten men who can grow a given quality of fruit where there is one who can sell it to advantage. All this is proved by the fact that many successful farmers were not brought up on the farm, or they soon left it for other business. Good business men are likely to make a success of farming, if they are not too old and if they have learned the occupation. They come into the business with trained minds, skilled judgment, and especially without too much prejudice. They are willing to learn, and they quickly assimilate new ideas.

There are most important non-commercial rewards in fruit-growing. A fruit-grower need not set before himself the single standard of money-getting. The end of life is satisfaction, and it may often be secured just as well on a moderate income as on a large one. It is one of the blessings that agriculture bestows on both the individual and 
the nation that it may make its workers happy and comfortable without making them wealthy. Of all the leading occupations, perhaps there is less scramble for big money in agriculture than elsewhere; and for this reason the farmer should remain a stalwart and conservative element in the national structure. Farming on a modest scale is capable of yielding a competent income; but the larger part of the wealth of the small farmer is of a different kind from that of the tradesman or manufacturer.

All these remarks raise the old inquiry as to whether there is an over-production of fruit. The probability is that there is not over-production except in special years; that is, that there is not more fruit grown than can be consumed in one way or another. It is very likely, however, that there is frequently a relative over-production,- - that there is more fruit grown than can be consumed in the markets that are ordinarily at the reach of the grower. The difficulty is probably rather more of unequal or imperfect distribution than of over-production of the commodity. The tendency of the time is to remedy this defect by more perfect means of dissemination, but it is too much to hope for a perfectly equal distribution of fruits, since the fruit areas are more or less limited in their geographical position, whereas the fruit-consuming population is distributed far and wide; and most fruits are very perishable under shipment. When there are heavy gluts in some markets and fruit does not pay for the freight, there are often other places, a few hundred miles away, in which the commodity is insufficient or even scarce. The introduction of special fruit and refrigerator cars and the better grading and the practice of pre-cooling have lessened the difficulties of distribution. But these appliances are of use mostly to organizations, or to those growers who have a 
large quantity of product; or, to those localities in which so much fruit is grown that the community of interests amounts to an organization.

Of course, one cannot succeed commercially in the growing of fruit if his land, location, and climate are not proper, even though he may have all the personal qualifications for the business; but if he has these personal qualifications, he will probably not choose unfavorable or impossible conditions. Many orchards reared with the greatest care and looking well in photographs are on lands unsuited to the production of profitable yields; or they may be in frosty localities, or too far from market or shipping stations, or be otherwise seriously handicapped. These disabilities must all be eliminated in any effective discussion of the general outlook for the fruit business; and this outlook seems to the writer to be good.

\section{THE ORGANIZING OF THE BUSINESS}

Perhaps the last thing the farmer learns, in respect to his own business, is thoroughly to master his local problem. He must feel that his problems of soil and exposure, his limitations of capital, and his own tastes, are all special and possibly unique, and he must then begin to work out his results for his particular conditions. From books and teachers he can learn principles and truths, he can pick up suggestions, and he can, above all, acquire an ability to grasp his particular situation; but he must solve his problems for himself. This is the secret of that close and single-minded attention to business that makes for the greatest success.

A knowledge of the details and the local special requirements should enable the grower to organize all the units 
and items into a consistent business procedure, or to subdivide it into its parts. Merely to raise fruit is not the end and consummation of fruit-growing. The raising of the fruit is a part in an enterprise, and this enterprise should make the best use of capital and of labor and equipment, and it should secure the greatest results with the least expenditure of effort. In other words, the enterprise should be economically efficient.

Fruit-growing is preferably one part-perhaps the leading part-of a farm scheme; but usually it should not comprise the entire farm scheme. Farm-management studies have shown that the most profitable fruit-growing is often that which is combined with general farming.

The general farm, with liberal parts of it devoted to crops other than fruit, provides economical use of men, teams, and equipment for the larger part of the year, as also a stimulating variety in work. It also enables the fruit-grower to produce much or all of the feed and bedding for his work animals, as well as many supplies for his family; it insures him against years of failure in the fruit crop.

On the other hand, too much general farming directly detracts from the fruit-growing part of the business. Oats and potatoes must be planted at a certain time, but the orchards may wait. What one gains in the raising of feed and other supplies, may be more than lost in the neglect of the fruit-plantations. Years may be required to repair the damage accruing from one or two seasons of neglect to the orchard, with the stunted growth, lack of pruning, neglect of spraying, injuries from borers, and other disabilities, although this damage may not be immediately expressed in dollars and cents. Where the happy mean shall be drawn between a business devoted too 
narrowly and exclusively to fruit-growing and one demanding too much diversion and dividing of one's energies, only the grower himself can determine.

It is certain that if one is to make a good business of fruit-growing, he must devote his best energies to it. Other things may wait, but not the fruit-plantations. He must have a "feeling" for fruit more than for anything else, and the fruit must have first call on men, teams, time, and painstaking oversight. If he does not have this feeling, he does not possess the essentials of a fruit-grower. The pride of a fruit-farm is in the fruit.

By this it is not meant that the fruit-farm must be a "show place." Nothing is more attractive in a picture than a fruit-farm with rows all regular and uniform and the trees or bushes all complete and perfect, and with tillage faultless; and yet some of the most profitable fruit-plantations exhibit little of this beauty of regularity. Perhaps it would be better if the plantation were more comely and attractive, but this condition is not necessary to success. In fact, heavy bearing often makes the orchard irregular; and if there are many varieties, it is impossible to secure stereotyped uniformity. The good fruit-farm is told by its performance and not by its looks.

Caution should be strongly expressed to those who would undertake fruit-farming by proxy. Delegated and absentee farming is ineffective enough at the best, but there are special difficulties in fruit-farming by that method or lack of method. One year's neglect to fight borers and other pests may be disastrous. Every tree or bush is liable to special injury, from winter-killing or otherwise, and much skill may be required to repair or overcome the damage. It is alluring to anticipate an orchard waiting for one on retirement from active busi- 
ness and which has been grown and cared for by others; but if the plantation has good care, in most cases it will be because the owner maintains a complete establishment of work animals, tools and men and does not depend on the hiring of the work from neighboring farmers. This means a general farming business. The costs accumulate rapidly, and the risks are heavy. The contingencies and difficulties are more than anyone can foresee. It is a common opinion that the tilled crops from the orchard land will pay for the care of the orchard until it comes into bearing, but this is seldom true (if the orchard receives good care) and then only when this cropping is part of a good farm scheme and does not depend on fugitive hired labor. Purchasers should be careful of orchard land-schemes in which the work and oversight are all provided for in advance. Orcharding by others is rarely profitable.

The annual cost of the care of an orchard for the first five years, including first cost of trees, pruning, fertilizing, tilling, cover-cropping, interest on moderate-priced land, may be expected to run from $\$ 25$ to $\$ 30$ an acre if one has his own equipment and does the work well.

Cost-accounting.

A well-organized business plan calls for a system of keeping account of costs, founded on an annual inventory and an analysis of the labor of men and teams and machinery on each crop or for each part of the plantation, the general outlays, and the receipts. A daily workreport is necessary. The elaborate bookkeeping forms often devised for farmers' use should be avoided. It is more important to analyze the business than to keep a perfect set of books. Most of the bookkeeping blanks do not bring out the facts that the farmer needs. Warren 
gives the following example (Standard Cyclopedia of Horticulture) of a useful accounting with a 3-acre apple orchard:

Work-Report for Apple Orchard.-Three Acres

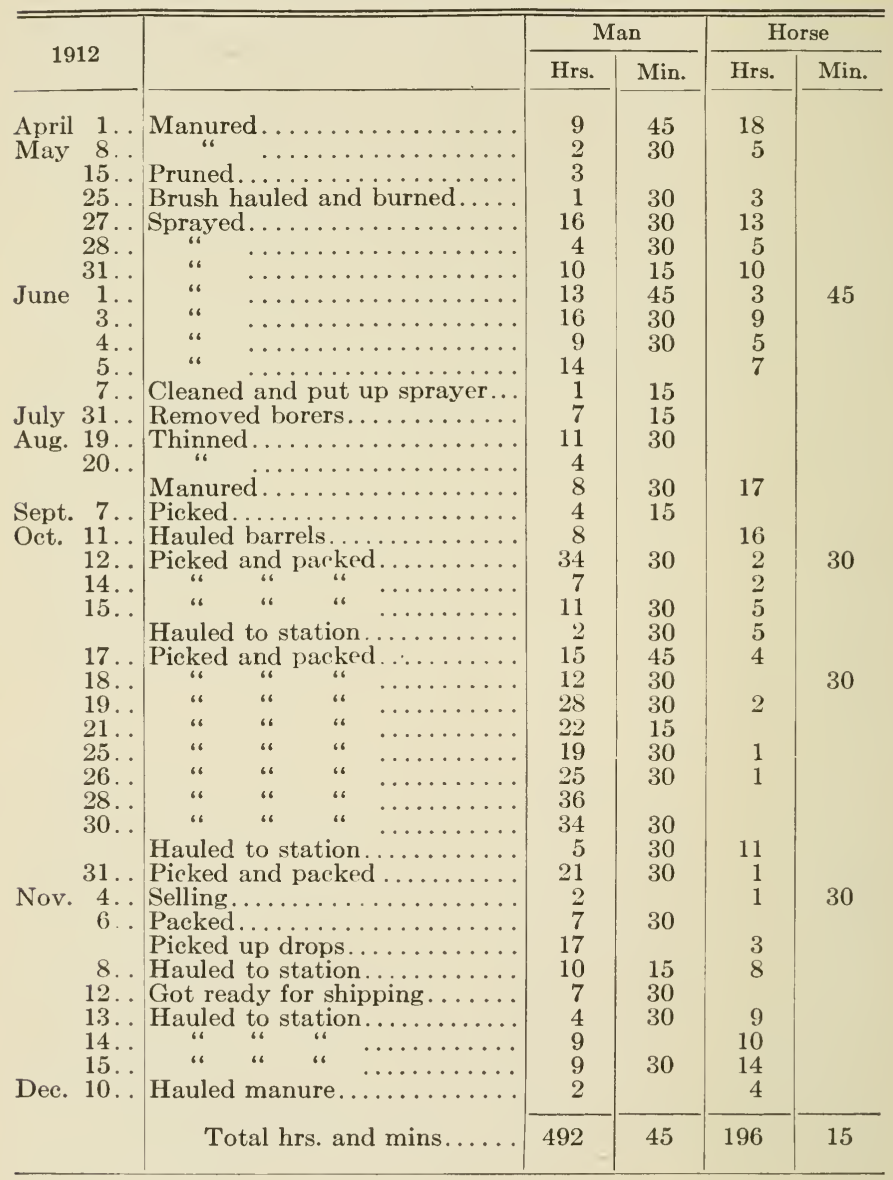




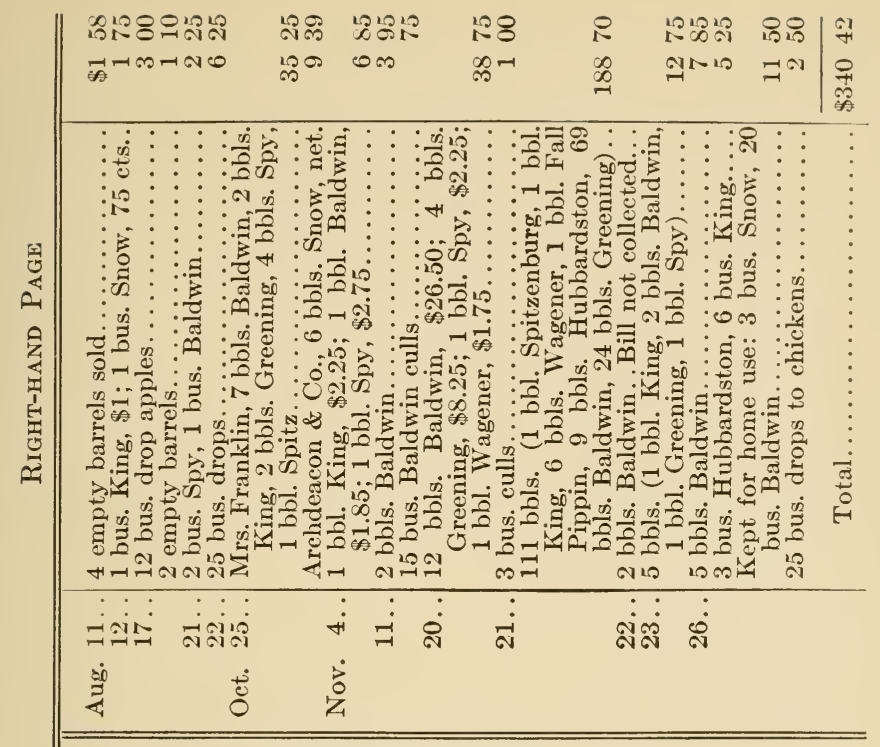

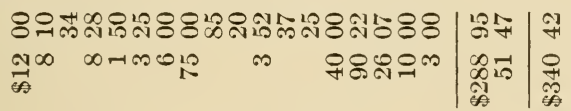

国

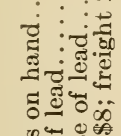

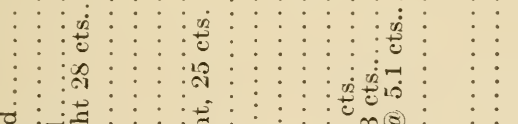

क०

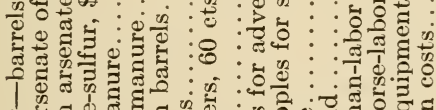

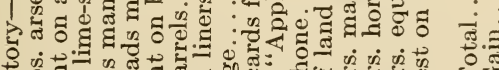

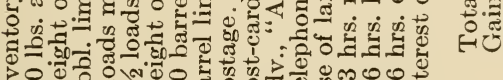

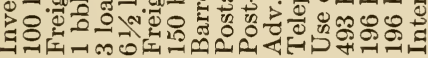

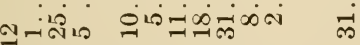

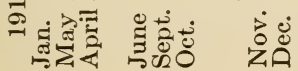


Much may be learned from such simple records, for the mere keeping of cost-accounts is not the end. The following are a few of the facts that the farmer used in the preceding records and the suggestions derived from them:

Total crop:

Bus.

Baldwin.............421

Greening............. 93

Hubbardston ........... 30

Spy ................ 23

King. ............... 22

Snow .............. 22

Carried forward....... $\overline{611}$

Total crop: Bus.

Brought forward ......611

Wagener..............21

Spitzenburg........... 6

Fall Pippin........... 3

641

Drops and culls.........105

He was able to determine the yields to the tree of different varieties;

Yields to the acre good apples, 214 bushels;

Yields to the acre culls and drops, 33 bushels;

Percentage of culls and drops, 14;

Total receipts, good apples, less cost of barrels, $\$ 233.07$; Average price a bushel, good apples, without barrels, 36 cents;

Hours of man-labor, to the acre, 164;

Hours of horse-labor, to the acre, 65;

Profit, to the acre, $\$ 17$;

Profit, by hour of man-labor, 10 cents;

Cost, by bushel, good apples, without barrels, 28 cents; Profit, by bushel, 8 cents.

It will be seen that the cost of barrels was very high owing to buying late in the season. Ten cents a barrel extra cost is more than equal to the profit on a bushel of apples, or one-third of the entire profit. Usually the profit on an enterprise can be greatly changed by small changes in cost.

The profit to the acre is in addition to pay for use of land. 
If all the profit is expressed in terms of land, the orchard paid $\$ 27$ an acre rent, or gave a profit of $\$ 14$ an acre.

If the profit is all expressed in terms of labor, the orchard paid 28 cents an hour for time spent on it, or gave a profit of 10 cents an hour.

\section{THE TWO KINDS OF COMMERCIAL FRUIT-GROWING}

With the foregoing points of view in mind, we may make a further contrast of the two aims in fruit-raising for market. We may classify the business, in respect to the objects in view, into the fruit-growing that desires the product primarily for home use, and into that which desires it primarily for market.

Of market or commercial fruit-growing there are again two types - that which aims at a special or personal market, and that which aims at the general or open market. The ideals in these two types of fruit-growing are very unlike, and the methods and the varieties that succeed for the one may not succeed for the other. The man who grows fruits for the special market has a definite problem. The product is desired for its intrinsic qualities; and special products demand special prices. The man who grows fruit for the world's market has no personal customer. The product is desired for its extrinsic or market qualities; and the world's products bring the world's prices. The special-market fruit-grower usually works on a small base. The world's market fruit-grower works on a large base; or he sells to another who, by combining similar products of many persons, is able to command the attention of the market.

It is the large base on which American fruit-growing is established that enables it to enter European markets. 
In America are thousands of acres of one variety, and the conditions under which the fruits are grown are so similar as to produce uniformity in the product. We speak one language, and, although we are two nations, we live in practically the same political environment. We go to Europe, and to our own great markets, with wholesale quantities.

In Europe, on the contrary, nearly every fruit-growing center is special; it may be unique. The industry is the outcome of years, maybe of centuries, of local effort and tradition. There is no general uniformity of methods and varieties. Community of interests on a continental base is impossible. There are insurmountable difficulties of physiography, of races, languages and political systems. In the staple products, the European grower may not be able to compete with Americans in his own markets, so long as those markets remain naturally open.

The American fruit-grower quickly assimilates new methods. He is unfettered by tradition; and how much this means only those can understand who know the European customs and ideals. He is bold and confident. He easily buys and sells land. He controls his own efforts and destinies. He has much help from teachers and experiment stations.

In many parts of Europe, the farmer is a tenant, and he therefore has little interest in planting trees. But even if he owns land, the area is usually small, notwithstanding the fact that there are many very large individual plantations. The environments of the Old World farmer are relatively inflexible. The result is that his methods tend to become stereotyped and rigid. He lacks the inspiration that comes of conditions which are easily recast and modified. His small areas must be so crowded with many 
kinds of plants that machine-work is often impossible. There are few orchards in most parts of Europe, as orchards are understood in America, meaning an area devoted exclusively to tree-fruits set at regular distances and cultivated systematically with labor-saving machinery.

For these and other reasons, as well as for the fact that our fruits and their manufactured products are attractive and of good quality, the American fruit-grower should find an increasing market in Europe. But the greater the quantity sent abroad, the more discriminating will that market become; and it must be true that the brands and the varieties of inferior quality tend to supply the inferior markets.

But if American fruit-growing is in advance of the European in its general commercial aspects, it is equally true that the European is in advance in growing for special and personal uses. The narrowness of the enterprises, the competition in restricted areas, the respect for traditional methods and varieties, conserve the very elements that appeal to the discriminating consumer, while, at the same time, they develop great skill in the fruit-grower. The eare bestowed on individual plants, the niceties of exposure and of training, the patient handwork, may almost be said to develop special traits in the fruits themselves. Such fruits may not find a place in the open market, but for that very reason they may have a higher commercial value.

At the head of a little valley, closely shut in by the Alps, is a famous apple plantation. The trees are trained upright on the opposite sides of a double espalier or trellis, the sides of which are less than 2 feet apart. In each of these rows, the trees are 2 to 4 feet asunder. These trellises are perhaps 10 feet the one from the other, and between 
each two is a row of apples on cordons or single horizontal wires; and in the intervals potatoes or other annual crops are often planted. Even the wires that brace the end posts of the trellises have apple trees trained on them like strands of vines. Each tree is trained to a definite number of branches or arms, and even the fruit-spurs are carefully determined. This plantation is the property of a company whose business it is to care for the land and the trees, and to find a market for the fruit. It is expensive to grow apples in this way; but the best Calvilles often bring a gulden (about 41 cents) apiece.

Perhaps the most important lesson the American fruit-grower has yet to learn is the fact that there are two types of effort in commercial fruit-growing, and that there may be pecuniary reward in fruits that are unknown in the market. Failure to distinguish these two categories is the result of a confusion of ideas. One grows fruit either for a special and personal market, in which case he looks for his own customer and is independent of general trade; or he grows what the market demands, and allows the machinery of trade to handle the product. In the latter effort, the American fruit-grower is preëminent; but in the former he has made little more than a beginning.

\section{GARDEN AND AMATEUR FRUIT-GROWING}

The point of view of most current American writing on fruits is to give advice for the management of the commercial plantation. There is another large realm of fruit-growing, however, that must not be overlooked, and which is as much worth the while within its sphere or place: this is the growing of fruits for home use and for the personal satisfaction in the effort. Once the amateur 
or connoisseur growing was relatively more important, even in North America; that time preceded the great commercial extension. The prominent American pomological writers made their reputation mostly in the amateur field, as the Downings, Robert Manning, Wilder, Thomas, Kendrick, Cox, and others. At one time, a pleasant collection or museum of growing fruits was considered to be a part of a good private estate; but instead of the fruit-garden for fancy and for keen enjoyment, it is now the custom to grow collections of shrubs, native plants, roses or other plants, and to pay great heed to lawns, ornamental planting, and landscape designs.

It is much to be desired that the fruit-garden shall return to men's minds, with its personal appeal and its collections of many choice varieties, even the names of which are now unknown to the fruit-loving public. The discriminating admiration of fruits for odor, good form and color, and for choice quality is little known amongst us today. Our desire for fruits is mostly uncritical, easily contented, and confined within narrow and uninteresting limits. Such fruits as the Ben Davis apple, Kieffer pear, and Elberta peach have done much to deprave the public taste and to lower the level of appreciation. The commercial market ideals have come to be controlling, and most fruit-eaters have never eaten a first-class apple or pear or peach, and do not know what such fruits are; and the names of the choice varieties have mostly dropped from the lists of nurserymen. All this is as much to be deplored as a loss of standards of excellence in literature and music, for it is an expression of a lack of resources and a failure of sensitiveness.

In practically any part of the country, a small collection of fruits can be grown in a well-placed plot. In fact, to 
overcome the difficulties of soil or climate is one of the compensations in the effort. The exchange of cions and specimens of fruit with connoisseurs and collectors is another recompense. A person with a few acres should be able to supply himself with choice fruits of his own raising as well as with choice flowers. It is easily possible from an outdoor plantation to have good fruit every day in the year; in fact, this can be accomplished with apples alone. The raising of grapes, peaches and other fruits under glass may add greatly to the interest, if one is so inclined.

In the home fruit-plantation, very few of the ordinary commercial varieties should be attempted. Collections should be built up by exchange, representing only those kinds that grade not lower than nine and ten in a decimal scale of quality.* A good fruit-cellar should accompany it, and this should be readily provided in an unheated basement or in a simple separate outdoor construction.

\section{THE GENERAL PRACTICE AND THE SPECIAL PRACTICE}

The standard methods, that rest on broad underlying principles, are general practices. They are the essentials. The intending fruit-grower should grasp these practices at the outset.

The methods that meet particular local or personal conditions or modifications are the special practices. They are naturally in endless dispute.

The clean tilling of orchards is a general and fundamental practice; the sod-mulch method is a special practice, and it must be proved in every case. The grow-

*For lists of fruits graded on a decimal scale of quality, see Repts. Amer. Pomol. Soc., 1901 and previous; and Repts. Mich. Hort. Soc., 1890 and previous. For lists of fruits, see Bull. No. 151, Bur. Pl. Ind., U. S. Dept. Agric. (1909). 
ing of standard full-size trees is the general practice; the growing of dwarfs is the special practice and must justify itself. Leaving the roots on trees when they are transplanted is general practice; cutting them off is special practice, and it may work.

The general practice is always the norm. It is not to be discarded except for very good reasons. The burden of proof is on the special practitioner. The grower may save himself much confusion, as also considerable bad and injudicious labor, if he keeps these distinctions in mind. He should read every article and analyze every lecture with this conscious discrimination. Much needless combat is waged over special practices. 


\section{CHAPTER II}

\section{THE LOCATION, AND ITS CLIMATE}

ALL the difference between failure and success may turn on the particular location or site in which the fruitplantation is placed; and yet it is apparent that any advice respecting the proper place for engaging in fruitgrowing must be of the most general nature, since the species of fruits are so numerous, and the elements that enter into a choice of location and soil are so various and indefinable. That is to say, the problem is local.

Yet there are certain considerations of general application and to which the reader may profitably give heed. These may be found to be suggestive in improving one's practice in his established plantation, as well as useful in aiding him in the choice of location and land.

The intending fruit-grower will usually find it to his advantage to locate himself among fruit-growers. In a "fruit-region" he finds conditions adapted to the growing of the product. Such a region attracts buyers, speakers, experimenters; it invites association and discussion. The constant association with fruit-growers quickens inquiry, keeps one informed, and develops the fruit mind.

Regions that carry a reputation for fruits not only attract buyers and sellers, but also encourage many forms of coöperation. Buying and selling exchanges, shipping associations, societies, and other groups are likely to grow out of the situation and to be very useful to all active 
growers. The educational value of such associations is likely to be beyond calculation.

\section{THE PLACE}

The choice of the place in which to grow fruit, leaving aside the element of soil, is determined by the location and the site. The problems comprised in the selection of the proper soil must be determined for each particular fruit. They are, therefore, special questions, and must be treated in books devoted to the different fruits and different regions, and not in a general work on fruitgrowing.

The location is the position of the place as fixed by the map or the surveyor. It is in such and such a township, and lies along such and such a highway. It is a question of local geography; it may lie in any one of a thousand places in the general fruit-zones that were outlined in the preceding chapter.

The site is the particular or actual place, in the location or on the farm, upon which the plantation is set. It comprises the aspect as to whether the exposure is toward the north or the south, and the consideration of the minor elevations and other topographical features of the place.

To proceed, then, from the general to the specific, we may say that a certain fruit-plantation is located at X, in the state $\mathrm{X}$, and that it has a high site, with a sharp eastward exposure.

In the choice of a location with reference to its geographical position, there are two chief elements to be considered, the choice with reference to market and that with reference to weather; and to these we may now proceed. 
Location with reference to market.

Time has overcome distance. Market facilities are, therefore, determined more by transportation facilities than by nearness to the market itself. To have the choice of two or more means of shipping - as by rail or water, or by more than one railroad-is a most desirable feature in the location of any fruit-farm. This is not only because competitive rates may be secured, but also because more and various markets may be reached. The choicer the fruits and the greater the desire to reach personal markets, the more should the grower prize any means that will enable him to reach a number of markets. Such a grower will desire to locate within easy reach of a number of cities or large towns. He will not care, perhaps, to grow what may be called the staple varieties, leaving that effort to those persons who are farther removed from points of consumption. It would seem to be unwise, therefore, for the fruit-grower who has access to several or many unlike markets to attempt to copy the methods of those in the West or South, who must grow largely of one thing and in sufficient quantity to command concessions from transporters and salesmen. Fruit-growing can never be reduced to a dead-level of ideals and practice. In one place great specialization may be most profitable, but in another place generalization-the extensive growing of generalpurpose varieties - may be best.

The cost of haulage to the shipping-point or to the market is a most important item, and one that is often overlooked. It is expensive to haul peaches or berries 5 to 10 miles, particularly if the roads are indifferent. This cost alone may forestall any profit in the enterprise. 
Location with reference to weather.

In the preceding chapter, the general influence of cold and heat in determining the fruit-zones was discussed. At that place, the subject was the average annual temperature. But within these various zones there are endless minor variations in physiographical features that have a direct influence in determining the areas of the incidental frosts of late spring and early fall. Moreover, the exposure to destructive winds is to be considered, and in some regions the liability to rains at blooming time, and to drying winds when the fruit is maturing. While these dangers are beyond the control of man, nevertheless they may be avoided to some extent; and we are beginning to construct charts and tables of average local weather so that the grower may calculate his risks in advance. Herein is one of the greatest services that the science of meteorology can render the farmer.

"The average daily range in temperature," as found by Hedrick, is "an important constituent of blooming-time weather. When the daily range is highest the danger to blossoms is greatest. The most jeopardizing weather to the fruit-crop, from the standpoint of temperature, consists of warm, sunny days followed by still, cloudless, cold nights. The danger is all the greater in such stresses of weather because the heat of the day forces out the blossoms prematurely."

Rain at blooming-time.-In his study of New York conditions for the years 1881 to 1905, Hedrick concludes that "Rain and the cold and wind that usually accompany it at blossoming-time cause the loss of more fruit than any other climatal agencies. The damage is done in several ways. The most obvious injury is the washing of the pollen from the anthers. The secretion on the stigmas also 
is often washed away or becomes so diluted that the pollen does not germinate. It is probable that the chill of rainy weather decreases the vitality of the pollen and an excess of moisture often causes pollen-grains to swell and burst. Rain also prevents bees and insects from carrying pollen.

"A temperature low enough to be harmful to blossoms is usually associated with frost or rain; but a low temperature, even though it does not touch the frost point, nor accompany rain, is often disastrous to the setting of fruit. The injurious effect is probably due to the prevention of the growth of the pollen-tubes."

Wind.-The effects of wind, according to Hedrick, who has studied the question, may be summarized as follows: "Winds whip blossoms from the trees and prevent insects from working. Long continued, warm, dry winds injure blossoms by evaporating the secretion from the stigmas, thereby preventing the retention and germination of pollen. Damp, warm winds, if long continued, are unfavorable to pollination. A cold, dry, north wind in blooming-time chills vegetation and stops the normal functions of flowers and leaves. On cold, clear nights, winds keep off frosts by renewing the heat; or by bringing fogs or clouds from lakes or ocean, frosts are prevented on the leeward side of the water." In compiling the records of weather in relation to the setting of fruit from 1881 to 1905 in New York, Hedrick found that "wind of sufficient strength to damage blossoms" occurred in the years 1881, 1882,1883 , and 1895, thus making an element of risk; and similar risks must be general.

The disasters from wind often occur in winter when trees are laden with ice; and the damage to ripe or maturing fruit is often very great. Protection from high winds, if it can be accomplished without interfering with the 
usual movement of air, is much to be desired. A naturally protected area is to be preferred; but in default of this, windbreaks may be planted, as subsequently advised.

There are the most various and contradictory opinions amongst fruit-growers as to the influence of winds on fruitplantations. It is commonly admitted that high or rolling lands are best suited to most fruits, and many growers suppose that the reason of it is that winds there find free course. The truth is, however, that several features conspire to render these lands congenial to fruits. Some of these characteristics are the following: Good atmospheric drainage; the avoidance of still air in frosty weather; good water-drainage; earliness or lateness, according as they are southward or northward exposures. High or strong winds are always to be avoided, if possible.

As a rule, winds are beneficial to fruit-plantations only when they bring warmer air, or when they keep the air in motion in frosty weather. If, therefore, high lands could be protected from winds without endangering atmospheric drainage or exposing the plantation to frost, much should be gained.

In dry regions there is a special reason for desiring to abate the winds, from the fact that they subtract so much moisture from soil and plants. Even a slight obstruction in the path of the wind may give marked results in the conservation of moisture. On this point, King writes as follows:

"In arid or semi-arid countries, and in districts where the soil is light and leachy, but especially where there are large tracts of land whose incoherent soils suffer from the drifting action of winds, it is important that the velocity of the winds near the ground should be reduced to the minimum. We have in Wisconsin extensive areas 
of light lands which are now being developed for purposes of potato-culture; but while these lands are giving fair yields of potatoes of good quality, they are in many places suffering great injury from the destructive effects of winds. On these lands, wherever broad, open fields lie unprotected by windbreaks of any sort, the clearing west and northwest winds after storms often sweep entirely away crops of grain after they are 4 inches high, uncovering the roots by the removal of from 1 to 3 inches of the surface soil. It has been observed, however, that such slight barriers as fences and even fields of grass afford a marked protection against drifting for several hundred feet to the leeward of them."

Low temperature, however, is the greatest danger in the weather environment. The reader must clearly distinguish between frosts and freezes. Frosts occur on still, clear nights, and are more or less local; freezes are usually accompaniments of storms, often of high winds, and are general or even continental in range, and their courses are not marked by the whiteness of frost. They were freezes, and not frosts, that swept over Florida in the winter of 1894-5, and over the northeastern states in May, 1895, and which have made much havoc in recent years on the Pacific coast and other regions; and most of the serious disasters of untimely cold are of this kind. These freezes are mostly beyond the reach of man. Particular men may protect themselves by means of fires, but in the main the grower can only move beyond their limits. But injurious frosts may not only be avoided, in many cases, by the choice of the location or even of the site, but they may sometimes be prevented on the very night when they are expected. (For ways and means, consult Chap. VII.) Of course, we eliminate from this discussion all consideration of regions 
in which the winter temperature is too low for the growing of fruits.

The chief local determinant of immunity from frost (aside from latitude and altitude) is proximity to bodies of water. These bodies act as equalizers of temperature. The water holds latent heat, and it does not respond quickly to atmospheric fluctuations. Therefore, it is cooler in summer and warmer in winter than the adjacent land. The larger and deeper the body of water, the greater is this equalizing effect on the temperature of the shores, other things being equal. As between the two, great depth is more important than great expanse of surface. Lakes only a mile or two wide may exert a very profound influence over the adjacent land if they are very deep. The distance to which the protecting influence of the water may extend is determined very largely by the conformation of the shore lands. As a rule, there are distinct slopes toward the water, and it is rare that the effect of the water on the temperature extends much beyond the crest of the elevation. When the elevation is 300 feet or more, in the northeastern states, the region of immunity from frost ordinarily does not extend more than twothirds of the distance to the summit. Along the central New York lakes, when the slopes are steep, the area of the tender fruits, as grapes, does not reach more than $1 / 2$ mile or one mile. The famous Chautauqua grape-belt is confined to a strip about 2 to 3 miles wide lying against Lake Erie, and reaching an elevation at its landward margin of less than 200 feet. Along the eastern shore of Lake Michigan, the peach area extends from 1 or 2 miles to 15 or 20 , depending on the conformation of the surface. Along the lower Hudson River the area of the tender fruits does not depart, as a rule, more than a mile or two from the 
stream. In very gradual slopes, the ameliorating influence of the water usually extends farther, but it is likely to be less marked than on the lower parts of abrupt slopes. In all these cases, the limit of the boundary of the area is determined largely by two factors,- - the distance from the water, and the elevation above it.

Tarr, after studying the local geography of the Chautauqua grape country, makes the following observations on the ameliorating influence of Lake Erie, and the remarks will apply to most other bodies of water: "The lake is a great modifier of climate. In the spring, by reason of the low temperature of its waters, it holds back the vegetation, and this tends to keep it behind the ordinary frosts. Its very presence checks frosts by moderating the temperature of the neighboring air. In the summer, the water tends to cool the air of the day and to keep the nocturnal temperature fairly high. During the fall, the water has been warmed by the summer sun, and the influence of this warm body of water lengthens the growing season and tends to keep off the early autumn frosts. There are many other influences, but nothing of importance can be stated, excepting on the basis of a careful study extending over several years. The lake breeze of the day must moderate the daytime temperature; and the land breeze of the night may, in some cases, so keep the air in motion as to prevent frosts. That there is a marked influence upon climate as a result of the peculiar conditions of topography and neighborhood of water, is evident at the very first. Sketch maps show that the mean annual rainfall is greater on the escarpment than on the lake plain, and that the mean annual temperature of the hills is lower than that near the lake."

The particular influence exerted by the water over 
frost-injury in spring is often due more to the retardation of the period of bloom than to the actual prevention of frost, although its influence in the latter direction is important. The lands adjacent to the water ordinarily warm up later in spring, and the trees are not likely, therefore, to swell their buds until danger of serious frosts is past. The extent of this retardation of bloom is often as great as ten to twenty days within a stretch of 10 or 20 miles from a large body of water.

It is well known that the danger from frosts is greatest in mild climates, in which "warm spells" are likely to occur in late winter or early spring. In the central and southern states, this frost injury following a period of warm weather is commoner than true winterkilling, whereas in the northernmost states and Canada serious injury to the trees from late spring frosts is comparatively infrequent. In the northern states, also, the plant usually goes into the winter in a perfectly dormant and ripened condition, and is thereby able to withstand great cold. It has been said that injury from cold is more frequent in the Gulf states than in New York.

The elevation of any place also stands in close relation to frostiness. Perfectly flat lands are nearly always frosty, because there is no atmospheric drainage, a subject to which we shall soon recur. On the other hand, very high lands are also frosty, because the air is drier and rarer and therefore allows of rapid radiation of heat from the land; and they are exposed to cold, unbroken winds. The local altitude to which the fruit-lands may be carried can be determined only by actual experiment; but in the North the best elevations for the tender fruits are usually between 100 and 300 feet above the local rivers or lakes. While it is extremely important that the location for 
the growing of tender or early-blooming fruit should be chosen with reference to its immunity from disastrous winter temperatures and untimely frosts, it should also be said that climate is often held responsible for failures that are chargeable to ignorance or neglect. This is particularly well illustrated in the perishing peach-growing of some parts of the North.

The date of last "killing frost," however, may mean little to the grower of orchard fruits, for fruit-buds or even expanding flowers are not destroyed by frosts that kill tender plants on the ground. In a subsequent discussion (Chap. VIII), the degree of cold that fruit-buds may withstand is given in some detail. Growers attribute to frost injuries that may have been caused by cold rains or to long-continued cold weather at blooming-time. Good phenological studies need to be made, whereby there shall be complete correlation of weather phenomena and vegetation phenomena.

Frost data need to be worked out for every state and province, for the risk is great in every one of them. The imminence of this risk enforces the importance of reinforcing the fruit business with the raising of other crops and products, and also the necessity of choosing one's locality carefully. Frost records must be compiled, to exhibit the average last killing frost, or the last freeze, in spring, the latest date of such freeze, the average first killing depression in autumn, the first killing temperature that has occurred in any year, and the length of the crop season. (See for example, Bull. No. 5 of the U. S. Weather Bureau on "Frost Data of the United States," 1911.) We shall eventually work out such records minutely for small regions, for the farmer will find the information of value in proportion as it applies to his farm. 
Location with reference to weather.-Atmospheric drainage.

The air is rarely, if ever, perfectly still. This is well illustrated in the vagaries of light frosts, which touch here and there where the air is the stillest or the radiation most rapid. This is particularly true in the growing months, when the earth becomes very warm in the day and loses the heat rapidly at nightfall, and when, also, the

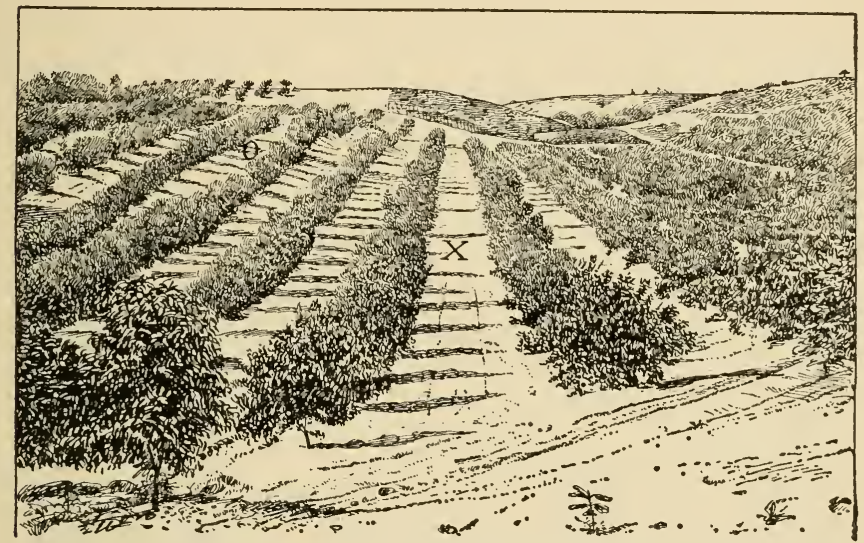

FIG. 1. Atmospheric drainage. Peach buds on the trees in region of $\mathrm{X}$ are frequently destroyed by late frosts, while those on trees in region of $\mathrm{O}$ are not injured.

sky is less overcast by clouds than it is in the winter months.

Much of this unrecognizable movement of the air is due to the draining off or settling away of the cold air, which is densest and therefore heaviest. It pours down the valleys of hilly and mountainous countries, and as its vapor condenses it gives rise to the valley fogs and clouds It lies in the low places, and there may cause frost. A person riding across an undulating country on a still sum- 
mer night can scarcely fail to notice the chillier air of the depressions. This escape of the cold air is the secret of much of the success of fruit-growing on rolling and sloping land; and this fact explains the importance of giving great attention to the selection of the site and aspect when setting a plantation of the tenderer fruits. Barden and Eustace (Mich. Bull. No. 63) give a picture (drawn in Fig. 1), of a peach-orchard containing a pocket in the

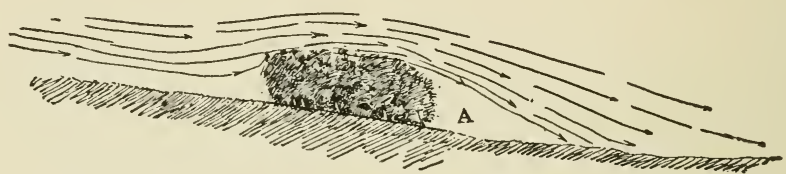

FrG. 2. The frosty belt on a hillside below a wood.

region $\mathrm{X}$ in which buds are frequently destroyed by late frosts, whereas those in the region $\mathrm{O}$ escape uninjured.

Features of such little apparent importance as not to appeal to the fruit-grower often exert great influence on the quiet movements of air. A frequent case is this: A strawberry field is on a gentle slope, and on the upper side is a wood. In time of frost, the only injury occurs in a belt two or three rods wide just against the wood, in the very place where the greatest immunity was expected. This is probably because the slight bodily movement of the air down the hillside and over the forest strikes obliquely downward from the edge of the wood-top, and leaves a narrow belt of dead air against the timber (as at A in Fig. 2).

The atmospheric drainage is marked only in still air. Winds mix up the air, and bring it all to a comparatively uniform condition. The slightest obstacles may sufficiently retard the movement to leave their impress in the distribu- 
tion of a light frost. A rail fence, a stone wall, a row of bushes, a slight elevation of land, the earth thrown out of a ditch,-all of these, when they extend across a slope, are obstacles to drainage of cold air. In some cases, there may be a difference of $10^{\circ}$ in temperature in as many feet of elevation. A dense row of trees standing diagonally across a slope may convey away the cold air that settles down against it, and thereby prevent injury to plants on the lower levels.

The range of elevation through which atmospheric drainage acts beneficially to the fruit-grower is limited. A fall of a few feet in a plantation is often sufficient for the very best protection from light frosts; and a fall of 100 to 200 feet on a farm or large plantation may be regarded as the general maximum throughout which the benefit may be observed, for very high elevations are, as we have seen, bleaker and colder in sum-temperature than comparatively low ones. What may be gained by airdrainage may be lost by coldness of elevation. The temperature decreases by $1^{\circ} \mathrm{F}$. for each 300 feet elevation, and, according to Hann, is independent of latitude.

"It is a common experience," writes W. M. Wilson, "that vegetation at the surface is sometimes killed when the temperature of the air 4 feet above the surface remains above freezing; but rarely is there an absence of frost or of injurious temperature when the air temperature 4 feet above the surface falls to $32^{\circ}$. This is due to the fact that on clear, quiet nights when frost is likely to occur, the air at the surface is nearly always colder than it is a few feet above the surface. This difference may amount to as much as $10^{\circ}$, or even $15^{\circ}$, in as many feet, but usually it is much less. The difference is greater on clear nights than on cloudy nights." 


\section{THE SITE FOR THE FRUIT-PLANTATION}

The grower is confined to his general region, but he may have much choice in the lay of the land, or the particular site of his plantation. The preceding discussions will enable the reader to approach this subject reasonably.

As a rule, especially in northern countries, the ideal site for a fruit-plantation is somewhat elevated above adjoining lands. Such a site presents the two advantages of atmospheric and soil-drainage. Of these advantages, the atmospheric drainage is the greater, inasmuch as soil-drainage can be secured by artificial means. In speaking of elevated lands, it is not necessarily meant that they be rolling. Some entire farms that are almost level may be sufficiently elevated above the local streams or the general contour of a flat country to answer all purposes of an ideal fruit site.

The pronounced minor elevations often present other advantages of temperature than those incident to atmospheric drainage. They offer various exposures, and they may be utilized as windbreaks by placing the plantations on the slopes opposite the severest winds. If they are near large bodies of water, they are usually more profoundly influenced by such bodies than flatter lands, because more open to the movements of air from them.

Despite all these remarks, there are certain cases in which comparatively low lands are preferable for fruitraising, but this is because such lands are moister, richer, leveler, or more sheltered, rather than because they are lower than surrounding areas; for all these advantages may sometimes be secured on comparatively elevated lands, and atmospheric drainage be secured in addition. Strawberries are grown on lower lands largely because 
such lands are moist and level. Quinces and blackberries demand a moister land than is usually found on pronounced slopes. In any event, however, the grower should avoid flat lands that are hemmed in on all sides by elevations, for these "pockets" are nearly always frosty.

\section{The aspect.}

The aspect or exposure of a fruit-plantation is determined by the direction and extent of the slope of the land. The exposure exerts great influence on the temperature of the soil and on the force of winds, and it therefore becomes an emphatic problem in the location of a fruit area, especially when the tender and early-blooming fruits are under consideration. There is the greatest diversity of opinion respecting the proper exposure for fruits, some growers contending that the northward slope is always the best, and others preferring a southward exposure. The truth is that no one exposure is best in all cases. Much depends on the location and the particular environment of the plantation, and on the kind of fruit which it is proposed to grow. The subject may be analyzed by discussing it under five generalizations:

1. In locations adjoining bodies of water, the best slope is toward the water. The very reason for the location of fruit-farms in such places is that the ameliorating effects of the water may be secured, and these effects are most marked when the fruit-land is most exposed to the influence of the river or lake. In all these cases, therefore, the particular direction of the slope in respect to the points of the compass is of a very secondary importance. There is often great choice between the two sides of the river or small lake, particularly when the slopes are sharp and 
high. The side facing away from strong prevailing winds is usually preferable, particularly if the elevation back of it is sufficient to act as a windbreak.

2. In interior or frosty regions, the best slope for the tender and early-blooming fruits, as a rule, is one that retards the blooming period, thereby causing the plant to remain comparatively dormant until the incidental spring frosts are passed. In such places, therefore, the northward and westward slopes are commonly most advisable; although, if these slopes are too pronounced, they may be so very cold and backward that what is gained by the retardation in spring may be lost by the retardation in fall, and the fruits may fail to ripen properly, or be caught by early fall frosts. In wholly interior places, a somewhat pronounced northward exposure is usually preferable for peaches and apricots, since these fruits are likely to swell their buds with the first fitful warmth of spring.

3. In regions in which there is much danger of sunscald on the trunk and larger branches, as in the midcontinental country and in hot arid areas, it is well to avoid pronounced southwestern exposures if possible; or if it is not possible, extra precaution should be exercised to train the heads of the trees in such a way as to provide the requisite shade.

4. If one desires to secure particularly early results and bright colors of fruits, a warm and sunny exposure, to the southward or southeastward, is most advisable. This is a matter of considerable moment with the finer dessert varieties of fruits.

5. It is sometimes necessary, also, to study the exposure with reference to prevailing winds, when these winds are more or less constant and strong. The selection of the 
aspect may, in a large measure, obviate the necessity of establishing elaborate windbreaks. The contour of the land should always be carefully considered when the planting of shelter-belts is under advisement.

\section{WINDBREAKS FOR FRUIT-PLANTATIONS}

We are now able to approach the troubled subject of windbreaks in a rational way. Although the best writers on horticultural topics are nearly unanimous in recommending windbreaks for fruit-plantations, there is, nevertheless, wide difference in opinion and practice among good cultivators. Fruit-growers hold, as a rule, decided opinions concerning windbreaks. In fact, they usually hold extreme opinions, either wholly opposing shelter-belts in all cases, or strongly ad-

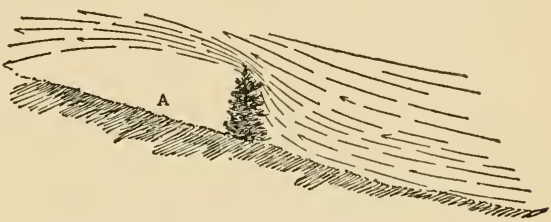

FIG. 3. The protected area, A, behind a row of evergreens.

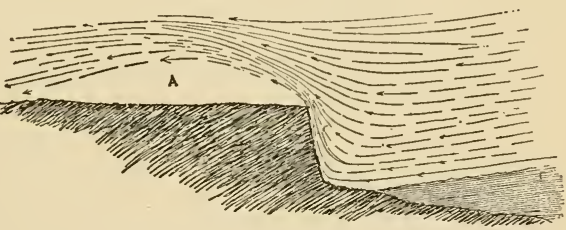

FIG. 4. The upward deflection of winds by a high lake bank. vocating them. All who are engaged in the growing of fruits or who attend fruit-growers' gatherings, have heard the most positive experiences cited in support of both opinions. There must be good reasons for these opposing views. There appear to be no well-grounded maxims or precepts among growers themselves, and statements concerning the merits of shelter-belts are commonly vague.

Of course there is no dispute as to the marked effect 
of breaks in deflecting or checking strong winds. Even a fence may have a marked effect. Persons and animals instinctively seek shelter. Two simple illustrations will suffice. Fig. 3 shows the still area back of the shelterbelt which stands across the prevailing winds. Fig. 4 is a diagram of the effect of a high bank on the Great Lakes. The strong winds strike the bank and are deflected upward and reach the surface at some distance back, leaving a relatively dead area at $\mathrm{A}$.

Benefits.-An epitome of the benefits derived from windbreaks as reported by growers of fruit may be arranged as follows:

1. A windbreak may protect from cold.

2. It reduces evaporation from the surface of the land, tending to mitigate drought in summer and root-injury in winter.

3. Prevents or lessens windfalls.

4. Lessens breaking of trees laden with fruit or ice.

5. Retains snow and leaves, thus tending to prevent deep freezing and excessive evaporation.

6. Facilitates labor in the fruit-plantation.

7. Protects blossoms from severe winds.

8. Enables trees to grow straighter.

9. Reduces injury from the drying of small fruits on the plants.

10. Holds the sand in certain places.

11. Sometimes causes fruits to ripen earlier.

12. Encourages birds.

13. It may be made an ornament to the property.

Injuries reported from windbreaks:

1. A windbreak may render a plantation colder at certain times.

2. Fruit immediately adjoining the windbreak is liable to be much injured by insects and diseases, and to be small and inferior in color.

3. Trees immediately against the windbreak are often less thrifty than others.

4. There may be greater damage from late spring frosts in sheltered plantations. 
Forests and fruit-growing.-One of the reasons why fruit-growing is attended with increasing difficulties is because the forests have been destroyed, thereby opening the country to the winds. There is no evidence that the extremes of temperature or fluctuations in annual means have become larger in recent years from the effects of forest-removal, or that there are more high winds now than formerly, but it is true that winds blow over the farm with greater force. Winds sweep the surface and bear away the moisture of the soil at the same time that they come in contact with the trees and bushes themselves, and take away their moisture. The chief effect of the forest is to check the force of winds in prescribed areas. It has a local influence. Aside from all this, if forests were retained about the sources of creeks and on springy hillsides, a more continuous supply of water might be secured for irrigation, live-stock, spraying and domestic uses. It is worth saying, also, that a country dotted here and there with forest areas is much more attractive to every person who loves variety of landscape and nature.

While there are thus many advantages to fruit-growing of small forest preserves, there are also disadvantages. In certain cases they may become the harbors and breeding-places of insect or fungous invasions. This difficulty may be largely avoided by cutting out those trees and bushes that breed the fruit-grower's enemies. The wild cherries are much loved of the tent-caterpillars, the elm of the canker-worm, and wild roses and their kin of the rosechafer. The cedar-apple fungus thrives on the red cedar, and is thence transported to the quince or apple orchard, and a form of it affects the wild thorn trees. The red-rust flourishes on the wild blackberries, dewberries and black raspberries, and the strawberry diseases breed in the 
patches of wild berries. It is not often, however, that the forest areas become a very serious menace to fruit-growers.

General statement.-The advantages derived from windbreaks are many, positive, and they appear to warrant the strongest recommendations of horticultural writers. Yet the injuries occasionally sustained in consequence of shelter-belts may be serious, for it is well attested that trees sometimes suffer from cold in the immediate vicinity of a dense windbreak when they escape injury in other places. This fact is easily explained, however. The influence of a windbreak on the temperatures of an adjacent plantation is governed by its position with reference to prevailing or severe winds. Of itself, wind probably exerts little or no influence on temperature. It acquires the temperature of surfaces over which it passes. If these surfaces are colder than the given area, cold winds are the result, or if warmer, as a large body of water, the winds are warm. But wind often causes great injury to plants because of its acceleration of evaporation; and winds that are no colder than the given area, if comparatively dry, may consequently do great damage to fruit-plantations. This is particularly true at certain times in the winter season. Land winds, being cold and dry, are at that time likely to be dangerous; whereas winds that traverse large bodies of water, and are therefore comparatively warm and moist, are usually in themselves protectors of tender plants.

The advantage or disadvantage of the windbreak, therefore, depends directly on the configuration or topography of the particular place, and the problem is strictly local. But it may be said that a windbreak is desirable wherever the fruit-plantation is much exposed to strong winds. To prevent possible injury from too little circu- 


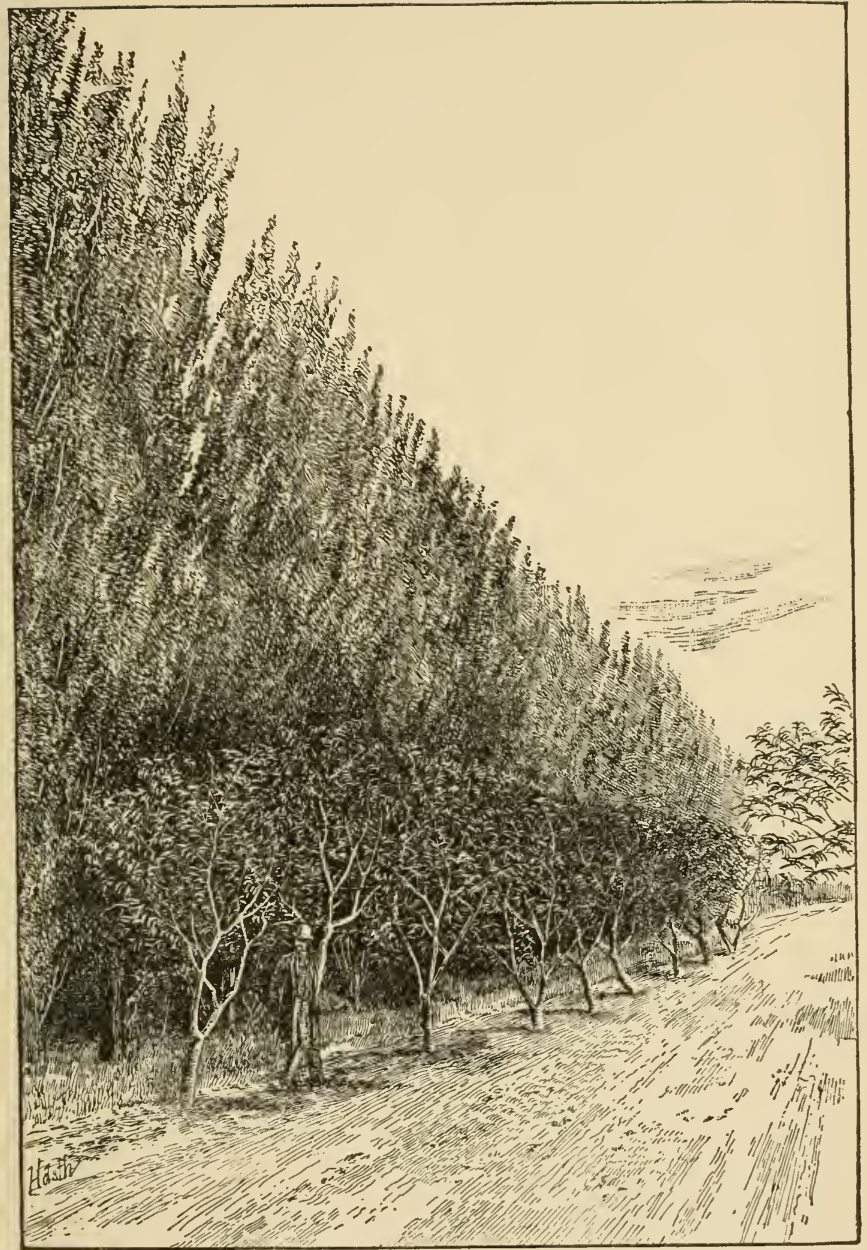

Fig. 5. A Lombardy poplar break protecting a peach orchard from violent winds on the shore of Lake Michigan. The fruit trees are too near the break. 
lation of air in certain localities, particular care should be exercised in the construction of the windbreak. The prevailing winds are the ones chiefly to be avoided. This is particularly important in regions in which these winds are normally strong, as on the ocean shore. In fact, it is usually impossible to grow successful orchards in full exposure to the ocean.

How to make the windbreak.-From a general study of the subject, it appears that in interior localities dense plantings are commonly advisable, tight hedges often being recommended. This is because the winds, coming off the land, are likely to make the plantation colder. In localities influenced by bodies of water, however, it is apparently better practice to plant a belt only for the purpose of breaking or checking the force of the warmer winds, still allowing them to pass in their course. Such a belt gives the desired shelter to trees when laden with fruit and ice, and may hold the snow, while danger from comparatively still air is averted. The damage from still air is usually observed in the lee of natural forests, and it is in such places that injury is reported by correspondents. The writer has found no indisputable evidence to show that such injury ever accompanies artificial windbreaks; places where such injury was reported have been visited, but the loss of trees and fruit was plainly due to age of trees or other obvious reasons. Still, it is probable that a hedgelike windbreak may sometimes be the cause of mischief; and such should never be made in any locality until the problems of local atmospheric drainage have been well considered.

The coarser evergreens, planted close together, are therefore advisable for interior places, while deciduous trees, or evergreens somewhat scattered, are often better 
for the lake regions. In these latter cases, however, the lay of the land is important, for if atmospheric drainage is good there is less danger of injury from tight belts. Lower levels, upon which cold air settles, are more in need of open belts than higher lands. For interior places, a strip of natural forest is the ideal windbreak. A Lombardy poplar windbreak alongside a peach orchard is shown in Fig. 5. In artificial belts, the kind illus-

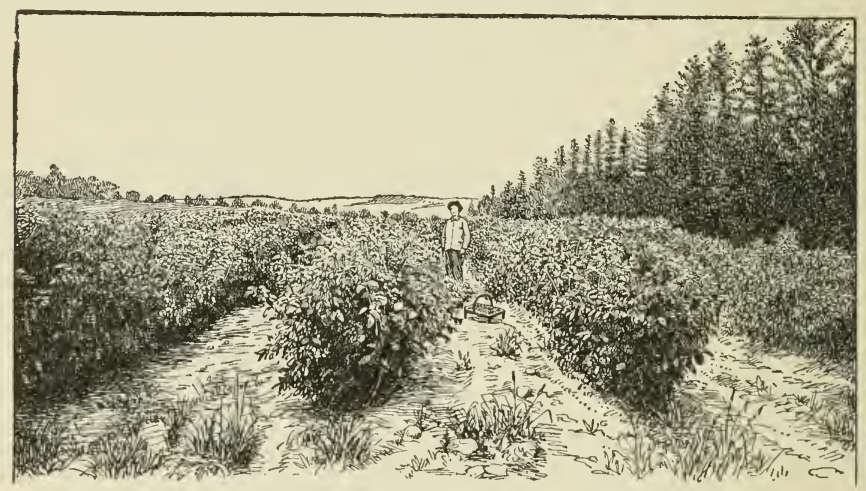

FIG. 7. Raspberry plantation protected by a windbreak.

trated in Fig. 6, is undoubtedly one of the best. The illustration shows two rows of maples backing up a row of Norway spruce. The maples then receive and break the force of the wind, and prevent the spruces from becoming ragged. Fig. 7 presents a good raspberry plantation protected by a windbreak.

The gist of the matter is to choose those kinds of trees that are most thrifty and healthy in the particular locality, and that are least infested by fungi and insects common to fruit-plants, and then to study the local conditions carefully to determine how dense or how open the shelter 
should be. For California, Wickson recommends species of eucalyptus, pepper or schinus, Monterey cypress, Monterey pine, osage orange, locust, and maples. "Quite a number of the larger-growing deciduous fruit trees," he continues, "are used to some extent along the exterior lines of orchards for the protection of the inclosure. The fig, the walnut, the chestnut, seedling almonds, and apricots are especially commended for such use."

In Florida it is a common practice to leave strips of the original forest to serve as shelter-belts. If this forest is hammock land, and therefore well clothed und=rneath, the protection of a belt 2 to 4 rods wide will b most complete. The cabbage palmetto is often allowed to stand promiscuously through the orange plantation, partly to serve as a protection from winds, partly for shade and ornament. In exposed places, orange groves are sometimes protected by very tall open fences.

The break should not be planted so close to the rows of fruit as to deprive them of light, food and moisture. It should never be dense enough to force the buds on fruit trees in those localities subject to late spring frosts, as it may sometimes do when it faces the south and acts like a southern exposure for the plantation. Payne makes the following observation (Colo. Exp. Sta.) on windbreaks in a given dry-land orchard: "Trees used for windbreaks for orchards under dry-farming conditions are expensive unless the trees of the windbreak group are planted far enough from the fruit trees so that the roots of the windbreak group will not compete with the fruit trees for moisture. The root-development of the Russian mulberry and black locust found at the Plains Substation indicate that the windbreak group should be planted 100 feet from the fruit trees." 


\section{CHAPTER III}

\section{THE TILLAGE OF FRUIT-LANDS}

THE study of the development of the ideas associated with the tillage of the land opens one of the most interesting chapters in history. The subject is all the more suggestive because tillage is such a commonplace and almost universal labor that no one thinks of it as having had a history. Yet the practice of the simple stirring of the soil has been slowly evolved, like all other methods and institutions, through a long period and as the result of many forces that were unobserved or even unknown at the time.

We think of tillage as a custom; and if one considers the condition of farming at the present moment, he would seem to be warranted in such an association, for a custom is a habit that is not suggested by reason and inquiry. Perhaps the only reason that most persons could give for the tillage of the land is that they are obliged to practice it. It would seem to be the simplest and dullest thing to till the land. It is merely the driving of the animal and the holding of the plow, or taking care that the harrow scarifies the entire surface; or it may be only the stubborn wielding of the hoe or rake. This view of the matter is wholly correct when one thinks of tillage only as labor. The work must be done because, somehow, plants thrive best when it is done; but the sooner it is done and the less there is of it the easier, and what is the easier is the better.

It was, no doubt, some such mind as this that domi- 
nated the rude farmers in the early history of the race. Throughout all the years until now-and, unfortunately, too often even now-tillage has been a mere necessity forced upon the husbandman by a most ungenerous Nature. The first tillage probably arose from necessity of breaking the earth to get the seed into it; and the second step was the digging out of other plants that interfered with its growth. In many cases, still another hardship was imposed, for the earth must be disturbed to get the crop out of it. These three necessities served to keep the surface of tamed lands in a greater or less state of agitation until it finally came to be seen that there is something in the practice which causes plants to thrive wholly aside from the lessening of the conflict with weeds. But it is only in the last century or two that there appears to have been any serious attempt to discover why this age-long practice of stirring the earth is such a decided benefit to plants.

One reason why the art of tillage has made such slow progress is because it seems to be contrary to the order of nature. In recent years it has been proclaimed that the proper treatment of an orchard is to plant it thick and to allow the leaves and litter to cover the ground, wholly omitting the stirring of the soil, for this is the method of the forest; and forest lands increase in fertility from year to year and the moisture is held in them as in a sponge. The reasoning is plausible but not exact. There are two ways of testing it,-by experience and by reflection. It needs only to be suggested that the experiment has been tried, and is now trying, upon an extended scale, as a large part of the apple orchards of the country testify. The chief beneficiaries of the experiment are the bugs, mice and fungi, all of which would vote the method a success. The reasons why the forest method is successful 
for the forest are because the trees stand so thickly that the earth is protected from the drying effect of sun and winds, the forest cover is so extensive as to produce a climate of its own, all the product is returned to the soil, and there is no haste. In every one of these essentials the orchard is unlike the forest. Those writers who urge that the orchard be planted thick enough to imitate the forest condition should also make it clear how the insects and fungi are to be kept at bay, or how acceptable fruit can be secured on trees that are unpruned, unthinned and untamed. The objects to be attained in the forest and in the orchard are wholly unlike. In one case it is the perpetuation of the species, and there results a severe conflict for existence, in which more plants die than reach maturity; in the other it is the securing of an abnormal product of the plant, - a product that can be held to its abnormal or artificial development only by abnormal conditions,--and the struggle for existence is reduced to its lowest terms, for it is desired that not a single plant be lost. Because it is impossible to imitate the forest conditions, the forest methods cannot be followed in fruit-plantations.

Now that we have come to understand why and how it is that the stirring of the surface earth makes plants thrive, the old-time drudgery of tillage becomes the most important, the most suggestive, and therefore the most difficult properly to understand and perform of all farming operations. If we cannot have the protection of the forest cover and the forest mulch, we must make a mulch for the occasion; and if we wait impatiently for results, we must unlock the granaries of the soil more rapidly than Nature does. We must till for tillage's sake, and not wait to be forced into the operation-as men have generally 
been forced-by the weeds; yet, whilst we have outgrown the need of weeds, we should not despise them, but remember them kindly for the good they have done the race. They have been an inexorable priesthood, holding us to duty whilst we did not know what duty was, and they stand ready still to extend their holy offices.

\section{The case of the early apple plantings.}

Orchard trees are capable of sending their roots so far and deep into the soil in search of food and moisture that they are able to live and grow under the most indifferent treatment of the surface soil. This fact has obscured the importance of tillage and fertilizing, so much so that there is a widespread opinion that orchards thrive and bear quite as well in sod as in tilled land. The greater part of the few apple and pear orchards that are kept in good tilth were put under such treatment only after the trees had attained some age and all the ill effects of early neglect had become established. Even those orchards that have been tilled from the first may have been quite as improperly maraged as those that are left to sod. Therefore, there is no undisputed body of popular experience touching the value of thorough tillage of apple orchard lands; but there are abundant experiences with the tillage of peach and plum orchards, and other fruit-plantations, which show unequivocally that such treatment is essential to the largest results. It is a significant observation that those fruits from which the farmer expects the greatest profits-as the stone-fruits-are the ones that everywhere receive the best care; whereas the apple, from which less is expected, commonly receives no attention until all other crops have been served. The apple-grower has cheapened his efforts by conceiving of a low estimate of value. 
Aside from these related experiences, the theoretical considerations in favor of tillage are so clear and forcible that they amount to a demonstration of the superiority of tillage over sod or grain for apple orchards.

My older readers will recall that until recent years the effort of farmers has been directed to the growing of hay, grain and live-stock. Previous to this generation, the growing of fruit had been a matter of secondary or even incidental importance. A bit of rocky or waste land, or an odd corner about the buildings, was usually given over to the apple orchard, and if the trees received any attention whatever it was after all other demands of the farm had been satisfied. The apple and standard pear orchards of the country still record the old method. It has required at least a generation of men in which completely to establish any new agricultural system, and the time is not yet fully arrived for the passing out of the old orchards and the coming in of the new. In other fruits than apples and standard pears, the generations of trees are comparatively short-lived, and those fruits sooner feel the effect of new agricultural teaching. Vineyards, and orchards of plums, dwarf pears, apricots, cherries, and quinces, have mostly come into existence along with the transition movement from the old to the new farming, and they have been planted seriously, with the expectation of profit, the same as have the grain crops. Peaches had passed out in most parts of the East, and they came in again with the new agriculture. At the present time, men buy farms for the sole purpose of raising fruit, a venture which would have been a novelty fifty years ago; but the habit of imitation is so strong that the apple-planter patterns after the old orchards that were grown under another and now a declining system of agriculture, and many of which are 
still standing on the old farms. The apple orchard, therefore, on the one hand, and the well-tilled vineyard on the other, are the object-lessons illustrating the faults of nontillage and the gains of good tillage. The apple country is no longer coextensive with the sod country, and new methods must prevail.

Sod orchards.

It is not to be inferred from the foregoing remarks that orchards in sod are necessarily failures, or even that they must be unsatisfactory. There are notable examples to the contrary; but they are special cases, and the success is probably in spite of the sod rather than because of it. They are cases in which the land is specially good or retentive of moisture, in which the other care is painstaking, and mostly in which the grass is not mown for hay. In some cases, the grass is cut and spread under the trees; this is the so-called "sod-mulch" method. It probably will be found that most very successful sod orchards are in regions of heavy rainfall or of light evaporation, or that there are local underground supplies of moisture.

Tests on apples by the New York (Geneva) Experiment Station show in favor of tillage over sod in yield, larger fruit, longer-keeping fruit, better quality, uniformity of trees and crops, greater growth of trees, better foliage, less dead wood in the tree-tops, deeper rooting, a better supply in the soil of humus and nitrogen. The fruit in the sod-mulched plat was much more highly colored than in the tilled plat and matured one to three weeks earlier. At the end of a ten-year test, Hedrick concludes as follows:

"Grass militates against apples growing in sod in several ways which act together, as: (1) Lowering the 
water-supply, (2) decreasing some elements in the foodsupply, (3) reducing the amount of humus, (4) lowering the temperature of the soil, (5) diminishing the supply of air, (6) affecting deleteriously the beneficial micro-flora, (7) forming a toxic compound that affects the trees.

"General statements are: Sod is less harmful in deep than in shallow soils; there is nothing in this experiment to show that apples ever become adapted to grass; sod may occasionally be used in making more fruitful an orchard growing too luxuriantly; other fruits than the apple are probably harmed quite as much or more by sod; the effects of grass occur regardless of variety, age of tree, or cultural treatment, and are felt whether the trees are on dwarf or standard stocks; because of their shallow rootsystems, dwarf trees are even more liable to injury from grass than standards; hogs, sheep or cattle pastured on sodded orchards do not overcome the bad effects of the grass; owners of sodded orchards often do not discover the evil effects of the grass because they have no tilled trees with which to make comparisons; it is only under highest tillage that apple trees succeed in nurseries, and all the evidence shows that they do not behave differently when transplanted; grass left as a mulch in an orchard is bad enough; grass without the mulch is all but fatal-it makes the trees sterile and paralyzes their growth, and it is the chief cause of unprofitable orchards in New York."

In New Hampshire, Gourley reports (Bull. No. 168) that "The five-year average shows all methods of treatment to be superior to growing trees in sod as regards yield and size of fruit, and growth of tree. Cultivation annually every two weeks until September 1 has given results on yield and growth superior to cultivation every other year, including a cover-crop the alternate years of 
cultivation. A good system of culture, namely, cultivating the orchard every two weeks until midsummer, then seeding down with crimson clover, has given practically as good results on yield of fruit and growth of tree as that obtained by the addition of a complete fertilizer or when either phosphoric acid, potash, or nitrogen are used in excess in the complete fertilizer."

The experiments of Picket in New Hampshire on the formation of fruit-buds by different methods of soiltreatment (Bull. No. 153) give comparable results as the consequence of three years' test. Some of the deductions are that "thorough cultivation throughout the season from May 15 to September 1, without the addition of cover-crop or fertilizer, resulted in the production of three times as many blossoms (fruit-buds) and somewhat more than three times as much fruit as no cultivation (sod). Clean cultivation throughout the season produced considerably fewer fruit-buds and a noticeably smaller crop of fruit than cultivation till July 10, with a cover-crop of crimson clover sown with the last cultivation and plowed under the following spring. The results indicate that clean cultivation till July 10, followed by a cover-crop of crimson clover, alternating every other year with a stand of mixed clover and grass sown early in the spring, may produce a sufficient number of fruit-buds for a satisfactory crop. This cannot be conclusively shown till the experiments have progressed at least one more season. Cultivation and cover-crop one year in three produced only two-thirds as many fruit-buds and one-half as many apples as cultivation two years in three. Cultivation and cover-crop one year in three doubled the production of fruit-buds and increased the crop of apples three times compared with no cultivation at all. Cultivation and cover-crop two years 
in three gave almost as good results as cultivation and cover-crop yearly."

These results of experiments are confirmed by the extensive apple-orchard surveys made by Warren in New York, in which the actual experiences of growers are tabulated and compared.

\section{Allowable use of sod.}

Notwithstanding these authoritative findings, sod may hold a very important part in the present management of an orchard of apples or pears. In many cases, it is impossible to secure the time and labor to keep all the orchards in a state of good tilth, and it may be better to till one part thoroughly and then seed it down for a short time than to try to till the whole area indifferently. This is particularly true in clay lands, in which the period of useful plowing in the spring is very short. In this way, one may practise a rotation of tillage in different parts of the plantation; but care must be taken that no part remains in sod so long that the trees become weakened or injured. In other cases, it is necessary to hold the orchard in sod to prevent serious washing on steep slopes. In hillside orchards, strips of sod may be left across the slope alternating with tilled areas, and the areas may rotate from year to year. Some orchard areas are so steep or so stony (Fig. 8) that tillage is impossible; in this case, the stones provide the surface mulch.

The results with sod depend largely on the other treatment that the orchard receives. The trees should have at least as good care in pruning, grubbing, spraying, and otherwise as they receive in tilled lands. The grass should not be cut for hay; it may be mown and allowed to lie as a mulch; or the area may be pastured with hogs or sheep. 
If no animals are pastured, the orchard may need liberal fertilizing. The general color, vigor and productiveness of the trees afford a good index of the effect of the sod.

The sod-mulch method, or any acceptable sod treatment, must not be confused with weeds and neglect. If the sod is employed at all, it should be good sod, which means that it must be fertilized or top-dressed, bad weeds kept out, and bare or thin spots re-seeded.

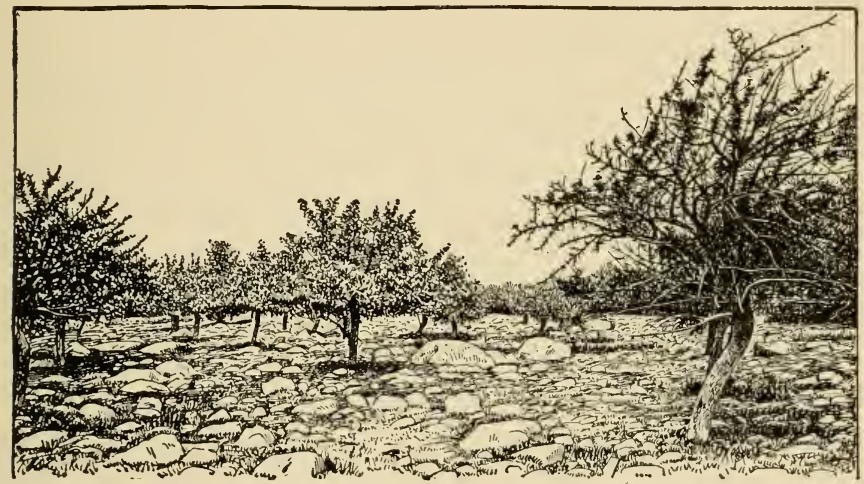

FIG. 8. Where tillage is impossible.-An old orchard that in its day has borne well among the rocks.

Sod lands are not only drier than cultivated ground, but they are favorite breeding-places of insects. Borers are particularly bad in grass land. No stone-fruits should ever be allowed to stand in sod, and the same may be said of dwarf pears. Very thrifty young apple and pear orchards may sometimes be thrown into bearing by seeding them down for a time, but the sod should be broken up before the trees become checked in vigor.

The whole question as to whether sod is hurtful or beneficial to an orchard is a local question. The grower must determine it for himself. If the orchard is in sod and 
is not doing well, the best advice in general is to plow and till it. Certainly it is better to make tillage the rule and sod the exception than to start with the intention of growjng an orchard in grass and cultivating it only when forced

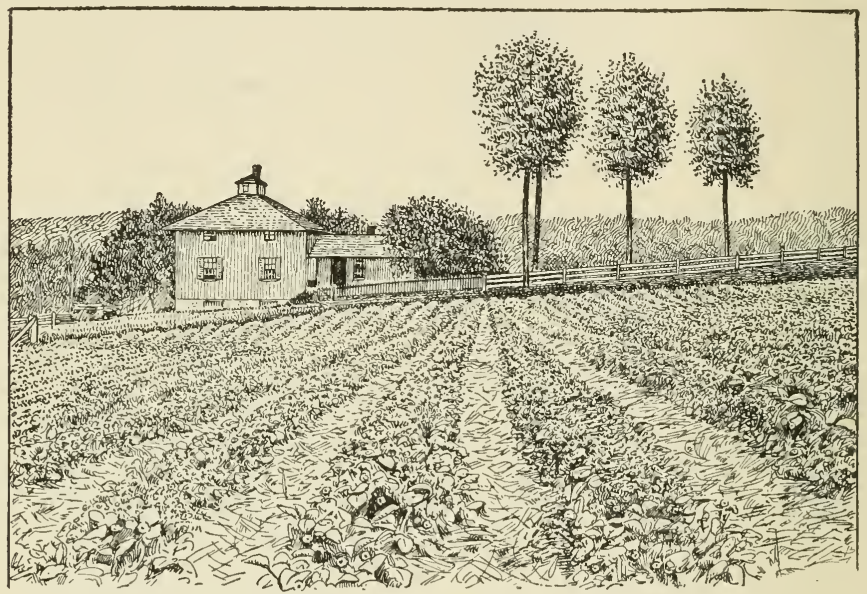

Fig. 9. A well-kept strawberry plantation. Good tillage and mulch.

to do so. It is better to pasture an orchard than to allow the grass to grow at will, but close pasturing can by no means take the place of tillage and fertilizing. If a person wants to raise hay or grain, it is cheapest to grow it where there are no trees to bother. If he wants to grow apples or grapes, he would better choose some other place than a meadow or grainfield. The use of clover and other temporary cover-crops as a means of fertilizing the land is quite another matter, and is discussed in the next chapter.

Growers are always asking whether the apple orchard shall be plowed up. If the grower of apples is satisfied with the crops and growth of the trees, let the orchards alone; but if it is thought that better crops are desirable, 
do not hesitate to make an effort to secure them. If it is a question of varieties, it may be worth while to top-graft the trees. If the roots are too near the surface to allow of plowing, harrow the land thoroughly when the turf is soft in spring, and continue to work it in the growing season. If this is not feasible, then pasture it closely with sheep or hogs, feeding the stock at the same time. If all this cannot be done, and the orchard is unprofitable, cut it down.

\section{THE PHILOSOPHY OF TILLAGE}

Tillage may be defined as the stirring of the soil for the direct purpose of making plants thrive. Its immediate effect is to ameliorate and modify the soil itself, but its secondary effects are those desired and which are also intimately concerned in the welfare of the plant. For example, tillage is capable of lessening the capillarity of the surface soil, and from this there may result a saving of moisture from evaporation, and it is the moisture that is sought. For practical purposes, however, it is unnecessary

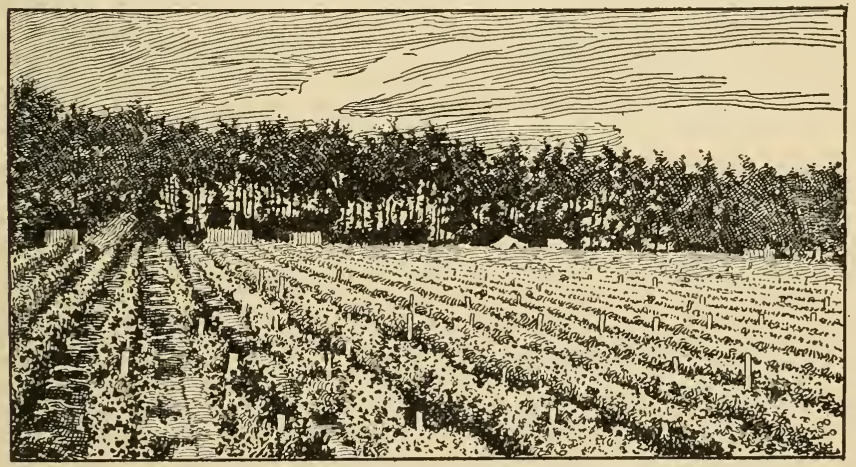

FIG. 10. Good tillage and good care--Loganberries in Oregon. 
to keep this distinction in mind, and we may classify the benefits of tillage under four general heads, arranging them approximately in their order of importance to the fruit-grower:

1. Tillage improves the physical condition or structure of the land,

(a) By fining or comminuting the soil, and thereby presenting greater feeding-surface to the roots;

(b) By increasing the depth of the soil, and thereby giving a greater foraging and root-hold area to the plant;

(c) By warming and drying the soil in spring;

(d) By reducing extremes of temperature and moisture;

(e) By supplying air to the roots.

2. Tillage may save moisture,

(f) By increasing the water-holding capacity of the soil;

(g) By checking evaporation.

3. Tillage may augment chemical activities,

(h) By aiding in setting free plant-food;

(i) By promoting nitrification;

(j) By hastening the decomposition of organic matter;

(k) By extending these agencies $(h, i, j$,$) to greater depths$ of the soil.

4. Tillage indirectly protects the fruit-plantation,

(l) By destroying weeds;

$(m)$ By destroying insects ard breaking up their breeding-places;

(n) By tending to reduce plant diseases, in the removal of host-plants, burying of affected leaves and fruits, and the like;

(o) By aiding in the keeping down of mice, rabbits and other pests.

The simple statements of these offices of tillage is sufficient for the present occasion, except, perhaps, in respect to the improving of the structure of the soil and the conservation of the moisture, for if the cultivator is skilled in these latter matters, all the other benefits will follow. 
The methods of tillage are of course endlessly variable. The novice should inspect the methods of good growers. The pictures accompanying this Chapter (Figs. 9-15) show what results have been secured by successful men.

The structure of the soil.

The structure or physical state of the soil is commonly more important than its mere richness in plant-

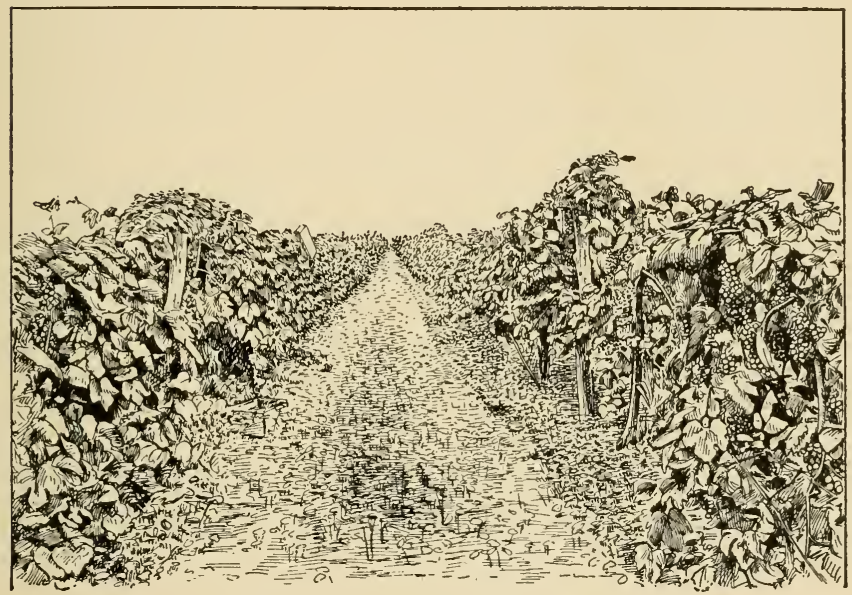

FIG. 11. The tillage strip in a vineyard.

food. That is, the productivity of the land is not determined wholly, and perhaps not even chiefly, by the amount of fertilizing elements it contains. This is particularly true of all lands-like the clays - that tend to become and to remain hard and unpleasant if left to themselves. Plantfood is of no consequence unless the plant can use it. The hardest rocks may contain various plant-foods in abundance, and yet plants cannot grow on them. A stick of wood con- 
tains potassium and phosphorus and nitrogen, and yet nothing grows upon it until it begins to decay. A hundred pounds of potash in a stone-hard lump is worth less to a given plant than an ounce in a state of fine division. Soils that the chemists may pronounce rich in plant-foods may grow poor crops. In other words, a chemist cannot tell what a soil will produce; he can tell only what it contains.

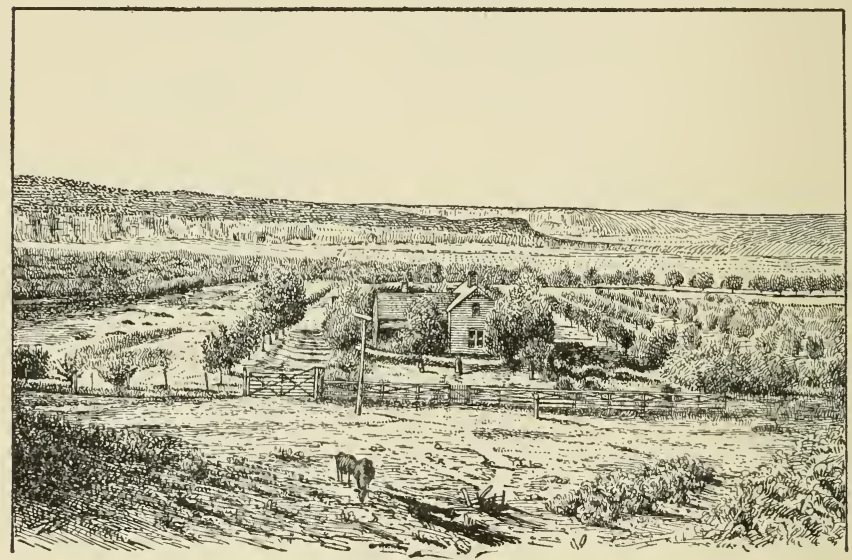

Frg. 12. A fruit-plantation in New Mexico, under tillage.

Every good farmer knows that a hard and lumpy soil will not grow good crops, no matter how much plant-food it may contain. A clay soil that has been producing good crops for any number of years may be so seriously injured by one injudicious plowing in a wet time as to ruin it for the growing of heavy crops for two or three years. The injury lies in the modification of its physical structure, not in the lessening of its natural fertility. A sandy soil may also be seriously impaired for the growing of any crop 
if the humus, or decaying organic matter, is allowed to wear out of it. It then becomes leachy, it quickly loses its moisture, and is excessively hot in bright, sunny weather. Similar remarks may be appled to all soils, although they are not equally true of all.

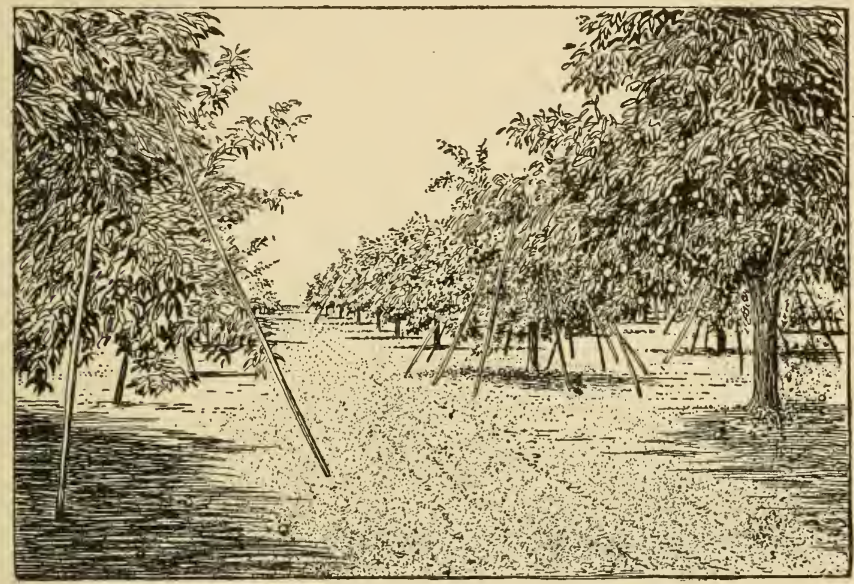

FIG. 13. A well-tilled orchard in New York.

If these remarks are true, then it follows that it is useless to apply commercial fertilizers to lands not in proper physicial condition for the best growth of crops. If potash, for example, were applied to hard lumps of clay, it could not be expected to aid much in the growth of plants, because plants cannot grow on such a place. If the same quantity were applied to mellow soil, however, the greater part of it would be presented to the roots of plants at once, and its effects would no doubt be apparent in the season's crop. The improvement of the structure of the soil is not only a means of presenting the plant-foods to the roots and of uniformly distributing what fertilizer may 
be applied, but it is also a direct means of conserving moisture and of hastening chemical activities.

The soil is a vast storehouse of plant-food, and the first effort of the husbandman should be to make this store available to plants. In "An Essay for Advancement of Husbandry-Learning," published in 1651 in London, Samuel Hartlib wrote: "Men take him for a foole or a mad

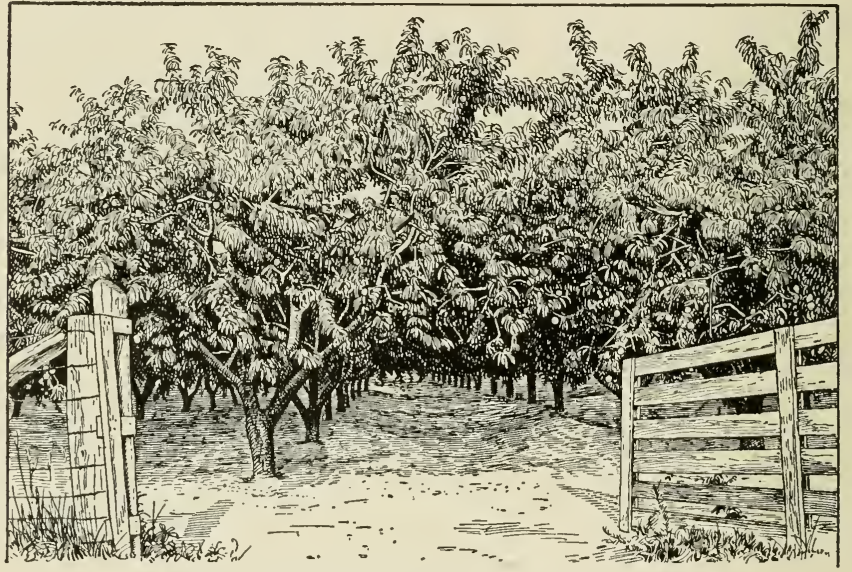

FIG. 14. Clean tillage in a Michigan peach orchard.

man that, having store of wealth in his trunck, doth yet complain of want. What though the key be rusty for want of use? 'tis easier to get that scoured, then to obtaine such another treasure. And surely I may upon most sure grounds say, that our Native Countrey, hath in its bowels an (even almost) infinite, and inexhaustible treasure; much of which hath long laine hid, and is but new begun to be discovered. It may seem a large boast or meer Hyperbole to say, we enjoy not, know not, use not, the one-tenth part of that plenty or wealth \& happinesse, that our 
Earth can, and (Ingenuity and Industry well encouraged) will (by Gods blessing) yield."

The moisture of the soil.

Lands oftener need moisture in the growing season than they need fertilizers. They usually need both, if the largest and best crops are to be secured. Drought seems to most persons to be one of those calamities in which

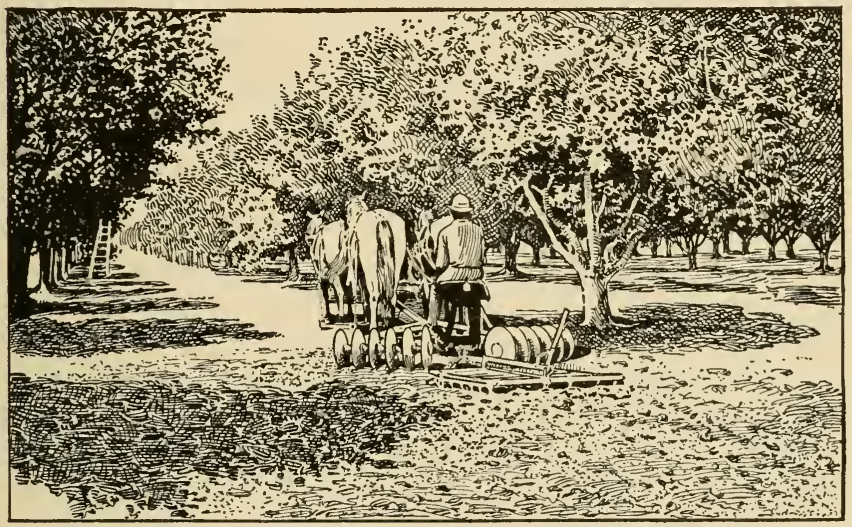

FIG. 15. The use of the disc-harrow with a spike-tooth follower.

there are no secondary or incidental blessings, and it must be confessed that the lesson of the recurring droughts has not yet been learned by the great body of farmers. The one remedy that occurs to most persons is irrigation, and yet there is sufficient rainfall in most parts of the older fruit-growing regions to provide all the needs of large crops. The difficulties are that this rainfall comes when it seems not to be wanted, and very much of it is allowed to escape by evaporation. The truth is, however, that the heavy rainfall usually comes at the best season, 
for it is the period of inactivity, when the work of the farmer and the growth of the plants are least interfered with. If farmers in the East and South were certain that there would be no rain from June till September, they would carefully husband the rainfall of the earlier months, and would suffer little loss; but when they expect rain all summer, they neglect the saving of the early precipitation, and gamble on the chance of having a rain when they need it. It often happens that the dry countries suffer least for water.

The water is to be saved by holding it in the earth. If the earth is finely divided and yet compact, the numberless pores or interstices will hold great quantities of water. If, then, the interstices next the atmosphere are broken up so that capillarity is reduced, the water is prevented from passing off by evaporation. The whole process of the saving of moisture, therefore, falls into two means: the catching and holding of it (or the making of a reservoir), and the preventing of evaporation. It is, therefore, a question of plowing and then of surface-tilling. It will thus be seen how futile it may be to try to save the water by beginning tillage late in the season, when a drought is threatened. If the land has not been well prepared, there may be no water to save by that time. It may either have run through the land into the drains, or it may have evaporated long before the farmer saw the need of saving it.

The hardpan may be so near the surface that little water can get into the land; the soil is shallow, and the early rains make mud-puddles or pass off over the surface. In such lands deep plowing is necessary, to break up the hardpan and to increase the storage-capacity. Breaking up the hardpan by means of dynamite blasting may make a useful preparation for fruit-lands. If the 
land is open and leachy, shallow plowing may be necessary, else the soil may be loosened too much. The waterstorage capacity of most soils may be increased by putting vegetable matter into them. It will thus be seen that the methods of conserving or saving moisture must be worked out-or rather thought out-by each farmer for his own farm.

The water of rains and snows is held on the surface for the time, and allowed to percolate into the soil, if the land is rough and open from recent plowing, if there is a cover of herbage, or if the surface is soft and mellow. Fall-plowing may be advisable to catch the water of the inactive season, and also to expose hard soils to weathering; and it may facilitate the work of spring. But clay lands with little humus may puddle or cement if fall-plowed, and particularly if harrowed and fitted in the fall; and in the South all rolling lands are exposed to serious gullying by fallplowing. In general, it is not advisable to plow fruit-plantations in the fall, however, not only because it may too greatly expose the roots to the weather, but because it prevents the ameliorating of such lands by the use of some incidental or catch-crop sown after the summer tilling is past. The winter covering is efficient in holding the precipitated water, and the other advantages of it are invaluable (as explained in Chapter IV).

Any body or substance interposed between the air and the moist soil will prevent the evaporation of the moisture in that soil. The ground is moist underneath a board, a layer of sawdust or ashes; and so it may be underneath a layer of 2 or 3 inches of dry earth. It is expensive and difficult to haul this dry earth to the land, and, moreover, it soon becomes hard and dense, and is no longer a mulch. It is better to make the mulch on the spot by shallow til- 
lage, and to repair the mulch as soon as it becomes hard and crusted. The orchardist, therefore, will till as often as the land needs it, however frequent that may be; but as a general statement it may be said that fruit-lands ought to be tilled every ten days and soon after every rain.

USE OF THE VARIOUS TOOLS IN RELATION TO MOISTURESAVING (adapted from L. A. Clinton)

Many special tillage tools have been designed for fruitgrounds practice. The primary office of these tools is to provide the soil reservoir, to comminute the surface, to keep down the weeds; and all this has important relations to moisture. Figs. 16 and 17 show some useful forms of tools.

\section{Plowing to save moisture.}

The first step in the saving of moisture must be the preparation of the land so that the rain will sink down, and not be carried off by surface drainage. In many regions, especially in the southern states, the great handicap to agriculture is the surface-washing of the land. Owing to shallow plowing and shallow tillage, the water is unable to settle into the hard soil with sufficient rapidity, and is carried along the surface, producing the destructive gullies.

The improvements in the plow have done much toward remedying these defects, but there is still much ignorance as to the proper use of this implement. As a tool to be used in the preparation of the land for the reception of moisture, it stands preëminent. Good plowing does not consist-as ordinarily supposed-in merely inverting a strip of earth, but in pulverizing and fining it and burying the sod or refuse that may be on the surface. The quantity of water 
that a soil is capable of holding depends directly on the fineness of its particles. Then that plow which will break and pulverize the soil most thoroughly is the one best adapted to fit the soil for holding moisture. This point is well illustrated by King, who says: "Since each independent soil-grain of a moist soil is more or less completely surrounded by a film of water, it is evident that, other conditions being present, the largest aggregate surface area may retain the most water per cubic foot. Now, a cubic foot of marbles 1 inch in diameter possesses an aggregate surface of 27.7 square feet, while if the marbles were reduced in diameter to one-thousandth of an inch, then the total area per cubic foot is increased to 37,700 square feet." From this it is evident that the total quantity of water capable of being absorbed by a soil that is cloddy and lumpy is very slight in comparison with the quantity when the soil is in a finely divided state; and not only is its absorbing power less, but its power of holding moisture is also greatly reduced.

\section{Harrowing to save moisture.}

The harrow, besides pulverizing and fining the soil for the seed-bed, is most efficient in making an earth-mulch. The spring-tooth harrow is in reality a cultivator. When used as an instrument to conserve moisture, the teeth should penetrate to the depth of about 3 inches, and to produce the best effect the ridges left by it should be leveled off by a smoother, which can now be purchased as an attachment to the harrow. The tillage of orchards by the harrow is now practised extensively, and nothing short of irrigation will so nearly meet the demands of trees for moisture, particularly in the heavier soils.

The Acme harrow is a most excellent implement on 


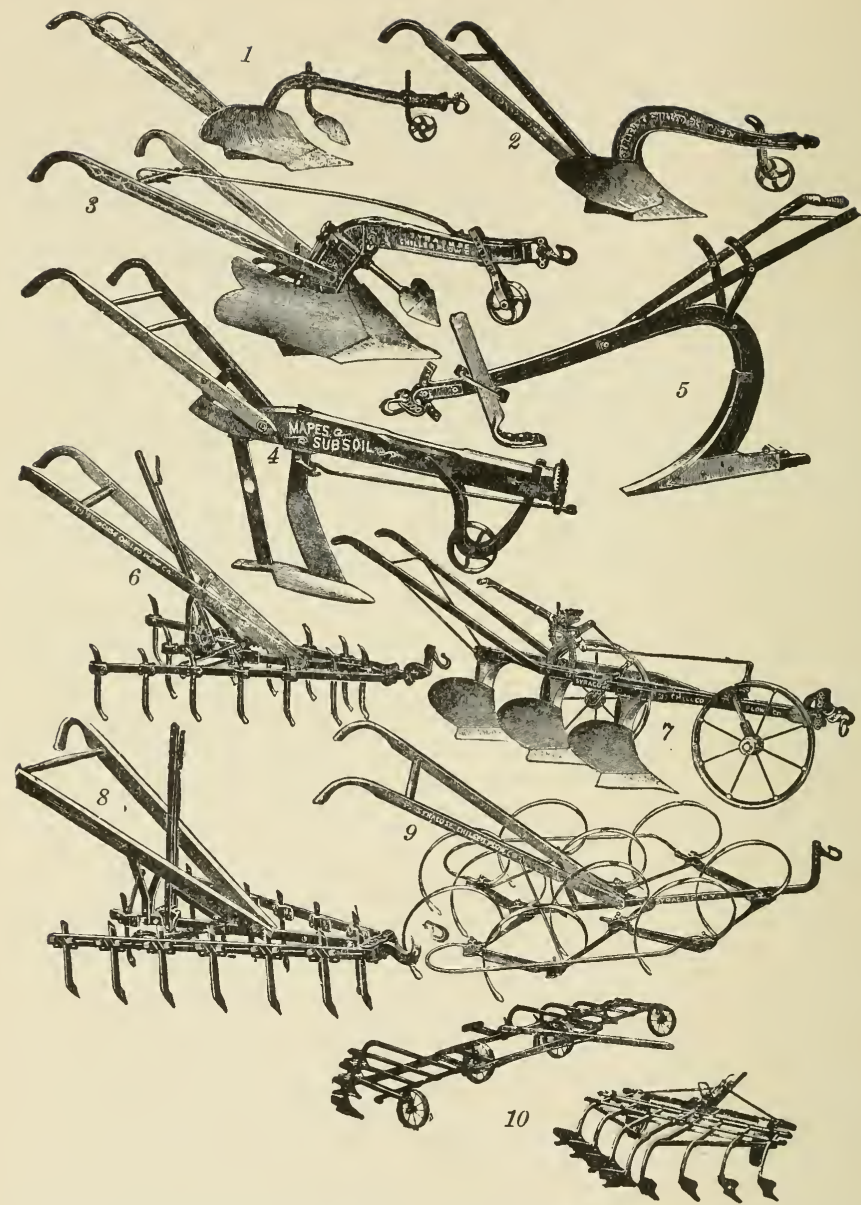

Fig. 16. Various tools adapted to tilling of fruit-plantations. (1) Robert's form of an ideal plow; (2) vineyard and garden plow; (3) swivel plow; $(4,5)$ subsoil plows; $(6,8)$ spike-tooth cultivators; (7) gang-plow; (9) spring-tooth cultivator with side-guards; (10) an orchard gang-plow. 


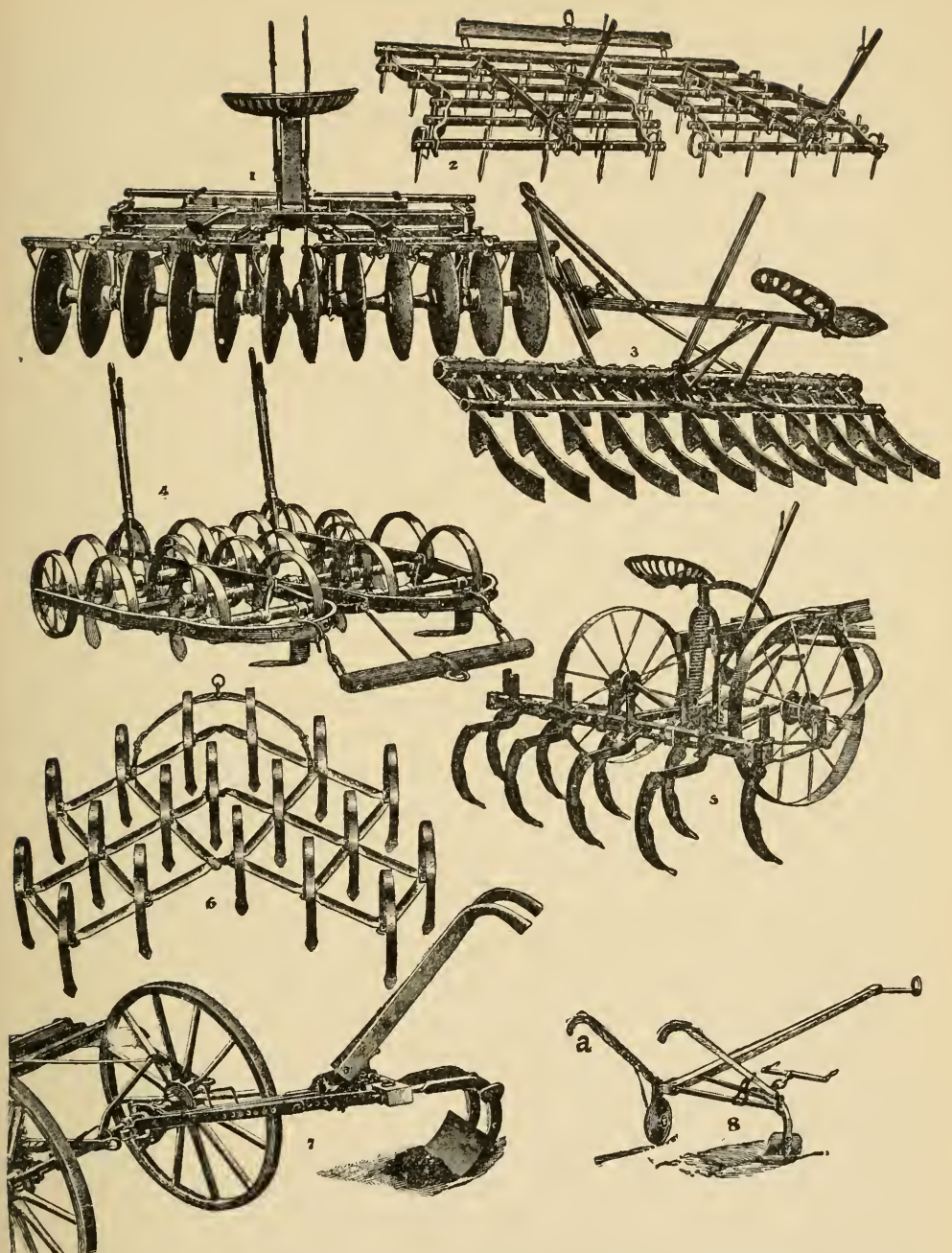

FIG. 17. Tools adapted to surface-tilling of fruit-lands. (1) disc-harrow; (2) spike-tooth harrow; (3) Acme harrow; (4) spring-tooth harrow with side frames; $(5)$ riding cultivator; $(6)$ spring-tooth harrow; $(7,8)$ grape-hoes. In 8 , the handle $a$ serves as a rudder or guide. 
lands that are comparatively free from stones and rubbish. The plow-like action of its blades serves to pulverize the soil, to spread the mulch evenly, and it leaves a most excellent seed-bed.

The cutaway or disc-harrows may be either beneficial or positively injurious. If the discs are so set that they cover but a part of the surface with the mulch, they leave a ridge exposed to the action of the wind and sun, and the rate of evaporation is greatly increased. The discs should be set at such an angle that the whole surface shall be stirred or covered. Their chief value lies in the cutting and pulverizing action on clay soils, but as conservers of moisture they are inferior to the Acme or the springtooth. Soils that need the disc-harrow to pulverize them should usually be gone over again with some shallower tool.

The mellower the soil, the lighter should be the work done by the harrow. On most heavy orchard soils, it will be found necessary to use the heavy tools, like the springtooth and disc-harrows, in the spring, but if the land is properly handled it should be in such condition as to allow the use of a spike-tooth or smoothing-harrow in summer. This light summer harrowing should be sufficient to keep down the weeds, and it preserves the soil-mulch in most excellent condition. With such a tool and on land in good tilth, a man can harrow 10 or more acres a day.

\section{Cultivators and moisture-saving.}

The action of cultivators is not materially different from that of the spring-tooth harrow. The size of the teeth should be regulated by the work to be performed, an implement with many small teeth being preferable to one with a few large teeth when the object is to conserve moisture. 
It must be borne in mind that in a dry time the less surface exposed the less will be the evaporation. If a large-toothed implement is used to destroy grass and weeds, then it should be followed by a smoother to reduce the ridges and prevent loss of moisture.

Ridge culture is allowable only when the object is to relieve the soil of moisture on bottom lands where the water comes very near the surface, or for some special crops with which a high degree of warmth is required early in the season; but even then the ridges should be slight. Nothing could be better calculated to dry out a potato-field or a corn-field than throwing the ground up on high ridges, leaving a large surface exposed to the action of sun and wind. In fruit-plantations in a proper state of tillage, unless very heavy clay, a small-toothed or even spike-toothed cultivator will be found sufficient to maintain the surface mulch.

The roller, in its relation to soil-moisture.

The roller is an implement whose value depends largely on special conditions. There is no tool that requires more judgment as to proper use. On light, loose, sandy or gravelly soils, where every effort must be made to solidify and pack the particles closely together, the roller may be used repeatedly. The difficulty with such soils is that the spaces between the grains are so large that the water is permitted to pass through freely, and is lost by percolation. The capillary openings are so large that there is very feeble rise of the water to take the place of that used by plants and lost by evaporation. The roller lessens the size of these pores in solidifying the soil, and the capillary force is then strong enough to draw the water to the surface. If, now, the soil is left in this condition, it has been 
put in the best possible form for parting with its moisture into the atmosphere, unless prevented by a surface mulch. In seeding land in a dry time, the soil should be rolled in order to bring sufficient moisture to the seeds to insure germination.

When circumstances will permit, the roller should be followed by a smoothing-harrow, that the surface mulch may be restored and the moisture stopped before reaching the atmosphere. On clay lands, the roller must be used with much caution. If used immediately after grain is sown and if a heavy rain follows, there is danger of the soil becoming so compact on the surface that the tender shoots are unable to get through, and the most direct connection is established between the soil-moisture and the air. A good

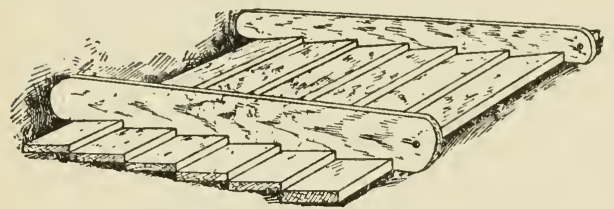

Fig. 18. One form of planker or float. method of treatment for clay is to roll before the seed is sown, then harrow and make a good seed-bed, and then drill in the grain. After the plants are well up, the roller may be used again, which will bring the water to the surface, where the growing plants can make use of it before it passes off by evaporation.

Various kinds of plankers or floats may be used in the place of the roller to smooth and compact recently tilled lands. A good tool of this kind is shown in Fig. 18. "To make this cheap and easily-made adjunct to good cultivation, take two hardwood planks, $2 \times 8$ inches and 7 feet long, and notch them as in the cut, boring a hole at the upper end to hitch to; the notches should be 8 inches apart and 2 inches deep; now nail cross-planks on the two 
notched bed-pieces, using the same-sized pieces, $2 \times 8$ and 6 or 7 feet long; let the cross-planks project 1 foot at each end over the bed-pieces. If more weight is needed to fine the clay lumps, the driver can ride the float, or weights can be placed on it."

\section{SUGGESTIONS FOR THE TILLING OF FRUIT-LANDS}

The foregoing discussions should now be put into practice. The standards of excellence should be well understood and be constantly in mind, even.though it is not possible always to apply them as completely as one would desire.

\section{Preparation of the land.}

Lands that enjoy perfect natural drainage are particularly desirable for fruit-growing, because they are not only warm and give up their fertility easily, but because they also allow of very early tillage, which is an important requisite in the management of fruits. If this perfect natural drainage does not exist, tile-drainage should be employed until the land is brought into the best possible condition. Many hard and wet soils make excellent pear and plum lands when thoroughly tile-drained. It is a common opinion that only flat lands need draining, but there are rolling lands in which the subsoil is high and hard and holds the water like a dishpan. Hillsides are often springy and boggy, needing careful attention in underdraining. Judicious draining not only carries off the superfluous water, but it also loosens the subsoil and allows it to retain its moisture better in times of drought. An attempt should be made to bring the land in the various parts of the orchard into conditions as uniform as possible, 
so that the same tillage and treatment may be applied to the entire area. All hard and "sour" spots should receive particular care in drainage and subjugation, or they should be left outside the plantation.

Lands with hard and impervious subsoils should be plowed very deep before trees are put on them; and in some cases, as for dwarf pears, it may pay well to use the subsoil plow. It should be borne in mind, however, that the subsoil plow is not always a fundamental corrective of hard subsoils, for it does not remove the cause. The subsoil may gradually settle back into its old condition, and land cannot be completely subsoiled after it is planted to trees. In the case of strawberries, raspberries, and other short-rotation fruits, the subsoil plow may be used at frequent intervals; but in lands to be planted to orchards, the tile drain is a more perfect ameliorator of the subsoil than is the subsoil plow. Yet even the one subsoiling may serve a useful purpose in sending the roots downward at the start, and this advantage will be the greater when the superfluous water removes itself rapidly from the hardpan. Good tile underdraining may modify the hardpan.

The land should always be in a thorough state of tillage at the time the trees are planted; that is, whether in sod or in hoed crops, the land should be in good "heart" and physical condition, fertile, and free from both very hard and very wet places and pernicious weeds. There are exceptions to this in the case of certain rocky or steep lands on which it is desired to set apples; but for all orchards planted directly for commercial results, this advice has few, if any, modifications. It is usually best to put the land into tilled crops the season before the trees are set, as potatoes or corn; although sod land, if 
well fitted and naturally in good heart, often gives excellent results when turned over and set at once to orchards. Yet most soils need the previous tillage to bring them into a mellow and uniform condition. Many of the "bad places" in orchards, where trees die out the first two or three years, could have been discovered and corrected if the land had been devoted to one or several tilled crops. Lands look more uniform when in sod than when cultivated, and the farmer may be led to overestimate their value for orchard purposes. It may also be said that the familiarity with a particular piece of land, which comes of frequent tilling, enables the careful grower to judge accurately of its adaptability to particular fruits or even to particular varieties.

If the land is not in good condition, it may be well to prepare it two years or so in advance by careful plowing and tilling and the turning under of clover, alfalfa, cowpea, or other humus-maker. Speaking of new land in Colorado, to be used for the raspberry industry, Herrick and Bennett say that "Not infrequently fruits of various kinds are set in raw land that has never been plowed except in the rows where the plants were set. In such cases the plants often grow in a stunted way and never acquire the vigor that they should attain. One of the best crops for growing on raw land is alfalfa. If alfalfa has made a good growth it may be plowed under the second fall and if the soil is poor in humus it would be well to plow under the last cutting. This will do much in bettering the physical condition of raw soil. It is well to follow the alfalfa with a hoed crop of some kind, such as potatoes, corn, and so forth. This will help to do away with the weeds and leave the soil in fine condition for planting.

"Another reason why land should be cropped before 
setting out raspberries is that when raw land is first irrigated it almost always settles more or less in spots. As irrigation is necessary year after year, it is important that the land has the right slope and has a comparatively smooth surface."

\section{Subsequent tillage.}

The best tillage of planted areas is that which begins early in the season, and which keeps the surface stirred until late summer or early fall; and the best implements are those that secure this result with the least expenditure of time and labor. For the first few years, it is advisable to turn the land rather deep with a plow at the first spring working. For the subsequent tillage of the season, there are many styles of clod-crushers, spring-tooth harrows, cutaways and smoothing-harrows, which adapt themselves readily to the particular soil area in question.

There is no single style of tool best for all soils or for all years. As a general statement, it may be said that for all heavy lands the fruit-grower needs four types of harrows,- - the cutaway or spading-harrow type for hard land and the first spring work; the spring-tooth type; the Acme or clod-crusher type; and the smoothing-harrow type. The last is to be used only to make and maintain the surface mulch after the land has been put in fine tilth. In all friable or loose soils, shallow tillage is always preferable. When the land is once in good condition, little effort and time are required to run through the orchard. Crust should never be allowed to form, and weeds should be killed before they become firmly established. The entire surface of the orchard should be thoroughly stirred as often as once in ten days or two weeks while the tillage season lasts. 
In general, level culture is best. This is secured by plowing one year to the trees and the following year away from them; one year north and south, and the next year east and west. It is somewhat difficult to plow away from large trees, however, and with the cultivators or harrows now in use, it is easy to work the soil away, allowing the furrow to be thrown toward the tree each spring, particularly if the land is in good tilth; but it is always advisable, on fairly level ground, to plow the orchard in opposite directions in alternate years. Land so wet that it needs to be thrown permanently into ridges for drainage is not often adapted to fruit.

The difficulty of working close to the trees has had the effect of encouraging too high pruning. There is a tendency to start tops too high rather than too low, thereby exposing great length of trunk to injuries of sun and wind, and elevating the top beyond the reach of pickers and of sprays. For most trees the ideal length of trunk is under 5 feet rather than above it, and tillage implements now in the market allow of this lower training. Trees with low tops, or that hang low with fruit, can be reached by separating the halves of any of the double harrows by means of a long doubletree, so that the halves, when adjusted, run 3 to 5 feet from each other. A cutaway harrow rigged in this way will work the back furrows from under the trees during the season. All cultivators or harrows with high handles, wheels or levers should be discarded if orchards are worked when the limbs bend low with fruit. An implement of the grape-hoe type may be used with advantage in some cases to loosen the earth about the trees. A single-horse plow, with a set-over beam (as in Fig. 19), is also most excellent for plowing close to trees and bushes. The objection to medium-low heads 
arises from the use of the old-fashioned implements of tillage, and also from a misconception of what the plowing of an old orchard should be; for if the orchard is

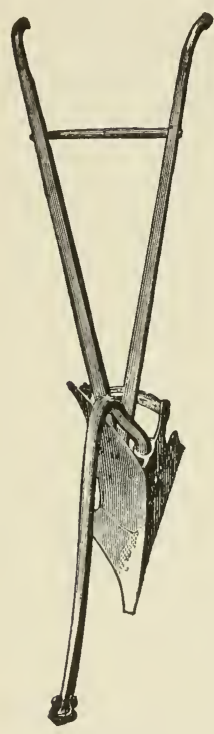

FIG. 19. Set-overbeam vineyard plow. properly cared for in its earlier years, very heavy breaking will not be needed in its later life.

This labor of working about trees is greatly facilitated by the use of harnesses which have no metal projections. There should be no hames with elevated tops, and the turrets on the back-pads should be simply leather loops. The back-pad itself should be reduced to a single wide strap devoid of wadding. Harnesses with no traces, but drawing by a single chain between the horses, have been designed for orchards, but they have not become popular with workmen.

The better the plowing and other tillage of the orchard in the first few years of its life, the easier and more efficient the subsequent plowing should be. If care is taken to keep the land friable and wellfilled with humus, it may not be necessary to turn furrows at the spring plowing after four or five years. Persons commonly suppose that an orchard must be plowed the same as corn or potato ground, by inverting the land and running regular furrows; but inasmuch as the object is only to keep the land mellow on top, and not to get a crop into it, heavy plowing is not essential. Very often some of the heavier harrows or light gangplows may be used to tear up the ground in spring, if the land has been put into proper condition when the 
plantation was young. This is especially true in light lands on which peaches are generally grown. If covercrops are to be plowed under, these remarks may not apply. In the first few years, however, it is essential to plow moderately deep to break up the earth and to send the roots down. A world of trouble with the orchard will be saved if the suggestions in this paragraph are fully understood.

Specific advice on tillage.

1. Begin to till when the orchard is planted, and till the entire surface. If trees are properly set, and if tillage is begun the first year, the roots will go deep enough to escape the plow. The roots of trees spread much farther than the tops. The illustrations give examples from trees of which the tops and roots have been carefully measured. Fig. 20 shows a standard Howell pear seven years after planting. It grew on a hard clay knoll, but with tillage. The full spread of the top was 7 feet. Two roots were laid bare, and they ran off in one direction to a distance of 21 feet. Assuming that they ran an equal distance in the other direction, the spread of roots was 42 feet, or six times that of the top; and yet it is commonly said that the spread of roots and tops is about equal. These roots were long and whip-like. The soil was so poor that they were obliged to run far and wide for pasture. Compare the upper tree in Fig. 21. This is a Fall Orange apple, of equal age, in rich well-tilled soil. Here the roots are in good pasture, and they remain at home; yet their spread is twice that of the top. The top of this tree had a diameter of 8 feet, and the roots were followed 8 feet on one side. These object-lessons enforce the importance of tilling all the land between trees. 
But these figures teach another lesson. Even at their highest point, the roots of Fig. 20 are 8 inches below the surface. They escape the plow. A like remark applies to the upper tree in Fig. 21. Compare the lower tree in Fig. 21; this tree is the same age as the others, but had always stood in sod. The roots ran 10 feet in one direction and the total spread of the top was 6 feet; but

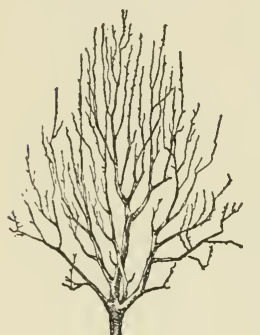
the roots lie just underneath the surface. This land could not be plowed without great injury to the tree. Let us consider the relation of this tree to moisture: the roots are in the driest part of the soil; the grass is pumping out the water and locking it up in its own tissues and sending it into the atmosphere with great rapidity; the soil is baked, and pulls up the water by capillary attrac-

FIG. 20. The long roots of a pear tree in very hard land, extending 21 feet and lying $2 \frac{1}{2}$ feet below the surface at the extremity.

tion and discharges it into the air; there is no tillage to stop this waste by spreading a mulch of loose and dry soil over the earth. If one were to sink a well under this tree and were to erect a windmill and pump, he could not so completely deprive the tree of moisture; and the less moisture, the less food.

In comparing apple trees in sod and in tillage at the close of a five-year period, Hedrick found a similar condition: "The roots of the trees in the sod-mulch plat came to the very surface of the ground. How much these 
trees suffered by the destruction of roots in the heat and drought of summer or the cold of winter cannot be said. In the tilled land the roots were found in greatest abundance at a depth of from 3 to 10 inches. The circumference of the root-systems in the tilled trees is approximately circular, but the circumference of the roots of the trees in sod is very irregular, indicating a reaching out of a part of the roots in response to a demand for more moisture, food, or air, or to escape some evil effect of the grass roots."

In young orchards, then, it is commonly best to plow rather deep-say 6 to 8 inchesin order to send the roots down. Of course, the Fig. 21. The deep roots (above) in tilled land, and the very plow should

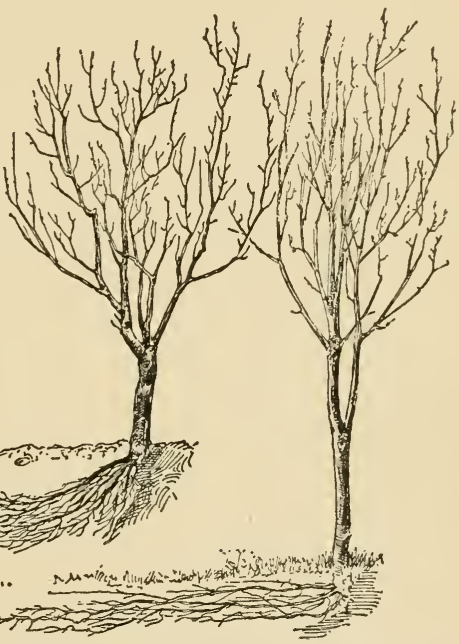
not be run deep close to the trunk of the tree. The careful plowman will turn out his plow when he comes close to the tree. This deep plowing for a few years will ameliorate the land, establish the root-habit of the tree, and obviate much of the necessity of laborious plowing in after years.

2. Tillage should be begun early in the season, in orchards. Trees complete most of their growth in length by the first of July. Early tillage saves the moisture which 
has accumulated in winter and spring; it is capable of putting the soil in fine mechanical condition, and this condition may be as important as fertility; it warms up the soil and sets the plants quickly to work; it turns under the herbage when that herbage is soft and moist and when there is moisture in the soil, so that the herbage soon breaks down and decays. All catch-crops should be plowed under as soon as the ground is dry enough in the spring, for these crops soon take the water from the soil and cause it to bake and cement together, and the longer they remain the more difficult it is to cause them to rot when turned under. Hard and woody herbage, plowed under late in the season, may remain as a foreign body in the soil all summer, breaking the connection between the upper and lower soil, and thereby preventing the upward movement of the water and causing the top-soil to dry out completely. The chief value of crimson clover, rye, or other catch-crop in the orchard lies in its fall growth and its protection of the soil in winter, not in its growth in late spring.

Few persons are aware that the season of growth in most woody plants in cold climates extends scarcely to midsummer. This is no doubt one reason why they are able to endure the winter. Plants that cease growing early, and mature their wood well, are often said to be determinate in their growth, while those of opposite habit are said to be indeterminate. It is, of course, apparent that plants of indeterminate growth are not hardy; as a rule most fruit trees are determinate.

3. Tillage should usually be stopped in late summer or very early autumn. The tree has completed its growth. It must now ripen and prepare for winter. It can spare some of the moisture that comes with the fall rains. We may, therefore, sow some catch- or cover-crop. 
The above advice follows what is practically the universal experience in the North, that the late growth of trees in autumn, particularly of the tenderer fruits as peaches, is likely to produce a soft or immature condition that may render the tree liable to severe injury by winter cold. Chandler finds, however, that one of the ways in which to avoid injury to fruit-buds by the cold "spells" of late winter and early spring in the region of south Missouri and in similar climates is to prolong the restperiod of the variety so that it will not swell its buds so early. He finds that with peaches the different varieties have rather definite rest-periods, at the expiration of which the buds start very readily. Anything that tends to make a strong late growth in the autumn has the effect of postponing or delaying this rest-period. This prolonging of the growth in fall is accomplished by pruning the trees severely either that year or the year before, and also by the use of nitrogenous fertilizers the preceding spring. These statements have reference only to the killing of the fruit-buds when they start prematurely, and probably does not affect the usual experience in regard to the winter-hardiness of the wood or tree itself. Frostinjury is again considered in Chapter VIII.

4. Operate in such way that the land shall be in uniformly fine tilth. Orchards plowed late in spring are usually in bad condition all the season, especially if the soil is clay. Fall-plowing of stiff and bare lands is likely to result in the puddling of the soil by the rain and snow, as already explained (p. 83); if there is sod on the land, this injury is less likely to follow. In general, it is best to let orchard lands pass the winter under a cover-crop.

5. Tillage may be overdone. Trees may be made to grow too much wood, and therefore too little fruit, and they 
may be sent into the winter in soft and unripened condition. If land is in good tilth, as it is when in best condition for the growing of potatoes or melons, tillage beyond that needed to conserve the moisture is useless. It is a common practice to head-in trees that are making too vigorous growth, but this practice usually aggravates the difficulty rather than corrects it. The rational treatment for such trees is to check the growth by some means, as by lessening the tillage or by withholding stimulating fertilizers.

\section{CROPPING THE PLANTATION}

It will now be asked what crops may be grown in the fruit-plantation: fruit-crops always, grain and hay never!

Any hoed or tilled crop may be used for the first few years; but it must be remembered that every crop competes with the trees for food and moisture, and whatever may befall the crop, the trees should not be allowed to suffer. As a general statement, it may be said that a space 3 or 4 feet wide should be left on all sides of the tree the first year, and this area should be enlarged a foot or two each year; and the space should continue to enlarge until the trees occupy the entire surface. Corn and some other luxuriant plants appropriate moisture more quickly than can the tree. In general, some low-growing crop that demands good tillage and comes off the land early is best. The notion that young trees should be shaded by a crop is probably erroneous for most regions. In orchards set less than 20 feet apart, the land should rarely be cropped after the third year; but apple orchards, if well cared for, may be cropped lightly for seven or eight years. In no case should the grower expect to secure as much crop on orchard land 
as on other areas; and the drier the land, the less it should be cropped. When the orchard comes to bearing age, it should have the entire land. Thereafter, the most profitable secondary crop to raise is cultivators.

In general, only those crops are allowable in a fruitplantation that demand such treatment as to improve the land for the fruit-plants. The growing of light crops is a means of keeping the land stirred when it might otherwise be neglected; and if the grower is careful to see that the physical condition of the land is improved, and adds enough plant-food to supply the loss, the light cropping of orchards for the first few years may be a decided benefit. At all events, tilled crops are better than sod. The danger is that the fruit-grower will continue the cropping too long, and expect too much from it. Strawberries and the bushfruits may be advantageously set in alternate rows with beans or potatoes, and the same tillage is required for each crop. It is well to fertilize the tilled crop liberally, for the trees will receive some of the benefit. When orchards begin to bear well, the crops should be discontinued.

The growing of nursery stock in orchards - a frequent practice in parts of the North-should be discouraged. This crop makes essentially the same demands on the land as the orchard itself, and it does not allow of those variations in cultivation and management that may be essential to the varying seasons. It may be true that enough fertilizer can be used to replace the loss of plant-food, but it is rarely added; and, more than this, the nursery stock consumes the moisture that should be used by the orchard. Nursery stock is known to be particularly hard on land, so much so that nurserymen seldom grow two crops of fruit-tree stocks in succession on the same area; but this injury to the land is an impairment of physical or other 
condition rather than mere exhaustion of plant-food. (See Chapter IV.)

Young orchards may sometimes be summer-fallowed with the very best results if the land is hard and intractable. This fallowing is clean cultivation. This is often the quickest and cheapest way of bringing such lands into fit condition for the growing of the fruit, and the longer the process is delayed after the plants are set, the more difficult and the less efficient the labor will be. This summer-fallow should be begun very early in the season and continued until midsummer, at which time some covercrop may be sown. It is a way of correcting or overcoming the lack of good preparation of the land in the beginning, or the results of subsequent neglect.

Orchard crops.

It is best to grow only annual crops in the orchard. Garden-truck is usually good, because it receives good tillage and fertilizing, and usually does not shade the fruit plants. If the farm carries live-stock, which of course must be fed, the range of crops that can be grown with profit is extended. Rowed and tilled peas, beans, roots, cabbage, tomatoes, and the like (Fig. 22), may be useful. Potatoes are good as a crop, but the digging may come at a time when it will interfere with cover-cropping or when it may constitute a too late tillage.

In all corn-growing regions, Indian corn is probably the most frequent crop in the young orchards, and it appears to give good results if sufficient space is left about the trees. Thornber makes the following summary on the use of corn in irrigated orchard lands (Lewiston Orchards Life, June, 1914): "The high price of choice fruit-land under irrigation in the Pacific North- 
west, and the cost of bringing an orchard to bearing, have compelled the fruit-growers to make a careful study of the best methods for reducing the cost of producing an orchard. Every opportunity of resource applicable to young orchards has been thoroughly tested and the effects of the crops noted upon the soil, as well as upon the young trees; and while crops have been found that will

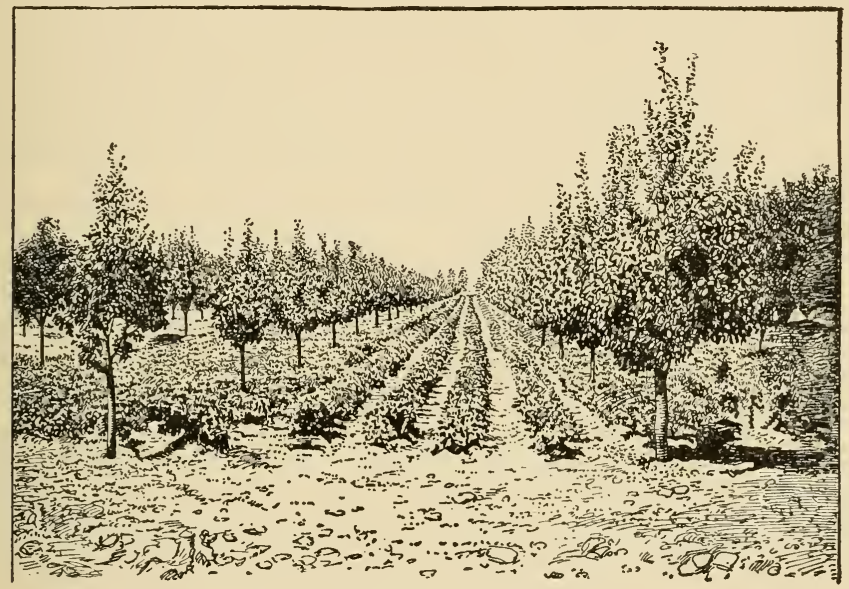

FIG. 22. Cropping a young orchard.

produce more money value per acre, none with an equal amount of labor will give a more uniform tree-growth and cause an orchard to come into bearing more satisfactorily than corn. Garden and small-fruit crops easily give greater financial returns, but require more time and labor to produce them. Alfalfa has the advantage of being a more sure crop, and one that will give larger returns per acre, but is not adapted to very young trees; however, it is more satisfactory among older trees." Care must be taken not to plant corn too close to the trees or bushes, so that they 
will be shaded; and it is well not to plant the most robust varieties.

The growing of clover, buckwheat, rye and other crops for the purpose of plowing under belongs to another line of practice. It is discussed in the succeeding chapter.

\section{IRRIGATION OF FRUIT-LANDS}

The irrigation of fruit-plantations is of two kinds, that which is necessary to the growing of the plants (as in arid and semi-arid regions), and that which is employed secondarily in a humid region to help make a particular crop. The former kind is, in essentials, the same as general irrigation, in the countries and regions in which irrigation is essential to farming; only the special applications of the water may be peculiar. The reader who intends to raise fruit in an arid or semi-arid region will perfect himself on this subject before he undertakes the enterprise.*

Supplemental irrigation for humid regions is often feasible and profitable for special crops, mostly for those that represent a high investment in capital, equipment and labor.

Irrigation in the East (C. S. Wilson).

The systems of irrigation used in humid regions may be divided into two classes: (1) surface irrigation; (2) overhead sprays.

The surface system, which is the more widely used, distributes the water by means of ditches and furrows. A ditch, which is the main, carries the water along the side or through the orchard and empties it into the furrows, by which it is distributed over the entire area. For such *Consult, for example, Paddock \& Whipple, "Fruit-Growing in Arid Regions." 
crops as fruit, grain, alfalfa, clover, and the like, the surface system is employed, and furnishes the best practicable method of applying the water.

The overhead system is employed in the humid as well as the arid sections of the country, particularly in the case of those areas intensively cultivated. It has been used mostly on such crops as cucumber, strawberry, lettuce, tomato, bean, eggplant, potato, squash, and the like-in fact all garden crops. The plan is to lay stationary pipes over the whole field, or to provide movable sections of pipes mounted on wheels. The advantages of this system are: (1) The crops are sprayed naturally whenever desired; (2) there is no waste land; (3) water is applied uniformly over the entire surface; (4) it is especially adapted to the shallow-rooted crops. The disadvantages, on the other hand, are: (1) It necessitates an expensive system of piping; (2) it requires a powerful pumping plant which gives a pressure of twenty to fifty pounds to the square inch; (3) the quantity of water wasted by evaporation is excessive; (4) the pipes interfere with tillage operations.

The so-called Skinner system of irrigation may be cited as an example of the overhead method. It consists essentially of pipes supported above the ground 40 to 60 feet apart, in which are set small nozzles at intervals of 3 or 4 feet. The pipe is turned by means of a union and handle to cover ground very near or more distant from the line. The best water-pressure is thirty to forty pounds, and a single line throws its rain-like spray about 25 feet. In addition to the advantages mentioned above, advocates of this system assert that it is a protection against frost, and an excellent means of distributing insecticides, fungicides and commercial fertilizers.

To what extent irrigation will increase in the East 
remains to be seen. Thus far, insufficient experimental evidence has been collected as to its real value. Probably it will never be used commercially to any extent for the tree-fruits, because the annual rainfall in most of the fruit-growing districts east of the Mississippi is sufficient for the plants, if the farmer practises thorough tillage. It is possible that irrigation may be beneficial in the case of the small-fruits or in certain localities where the rainfall is insufficient, and it has been so employed in a few places in eastern plantations. An abundance of water is of particular value to small-fruits at the time of ripening and it is often at this time that the dry spells come.

The grower should remember that irrigation cannot take the place of tillage; the two go together. When the soil is well tilled, the water of irrigation distributes itself better than when tillage is neglected. Moreover, when water is applied to lands not tilled, puddling is liable to result. Another difficulty connected with the application of water is the collection of alkali at the surface. This is a well-known trouble in the arid regions. The alkali of the soil, which dissolves in the water, is brought up by the moisture, and as the moisture evaporates, it is deposited at the surface. Where irrigation is continued year after year, the amount of this alkali may increase to considerable amounts.

The value of irrigation to the eastern grower should be determined by the experiment stations, and these stations are now working on the question. Until more definite results are secured, the grower should look to thorough tillage as the most economical means of supplying moisture. It seems reasonable to predict that the fruit-grower will not find it profitable to practise irrigation to any considerable extent in the East. 


\section{CHAPTER IV}

THE ENRICHING OF FRUIT-LANDS

ANY land that is fit for the growing of crops will maintain a fruit-plantation throughout its existence without the addition of plant-food, and enable the trees to produce at the same time a normal quantity and quality of fruit. But the profit in fruit-growing lies in securing the extranormal or superior quantity and quality, and this result demands every good care and often the addition of fertilizer. How much plant-food the farmer shall add to his land, if any, depends on the amount of increase or profit that can be secured. If the fruit-grower applies two tons of fertilizer to the acre and secures a profit on the investment, the quantity may be none too large; but in some cases it is a loss of the material to add anything. The successful merchant is the one who is dissatisfied with a normal and common trade, and he stimulates the demand by attracting and interesting the market beyond the point of its usual needs.

The land is to be kept at work.

Many causes contribute to the occasional unsatisfactory results of applying fertilizers to orchards, smallfruit plantations, and similar areas, but the commonest one is lack of proper tillage and preparation of the land. Poorly tilled land, not only refuses, as we have seen,. to give up its own stores of wealth, but it will delay and even preclude the good results from the plant-foods that 
may be added to it. The first thing to do, then, is to make it possible for the plant to grow. If the physical and environmental conditions are right, the addition of plantfood is capable of being felt. The plant must be made comfortable before it will thrive. A cow will not relish even the fanciest ration if she is uncomfortable.

The grower must set himself in line with natural methods. He must see that the soil has a good supply of humus or organic matter (from crops turned under, dressings of stable-manure, muck, and the like), and that it usually has some cover. Early in the season, this cover is the surface mulch of tilled soil, and later it is the covercrop of rye or crimson clover or something of the kind.

Bare land becomes unproductive land. Its elements must be unlocked and worked over and digested by roots. The surface must be covered to catch the rains and to hold the snows, to retain moisture, and to prevent the baking and cementing of the soil. The plant tissues add fiber and richness, and make the land amenable to all the revivifying influences of sun and rain and air and warmth. The plant is co-partner with the weather in the building of the primal soils. The lichen spreads its thin substance over the rocks, sending its fibers into the crevices and filling the chinks, as they enlarge, with the decay of its own structure; and finally the rock is fit for the moss or fern or creeping vine, each newcomer leaving its impress by which some later newcomer may profit. Finally the rock is disintegrated and comminuted, and is ready to be still further elaborated by corn and ragweed. Nature intends to leave no vacant or bare soils. She providently covers the railway embankment with quack-grass or willows, and she scatters daisies in the old meadows where the land has grown sick and tired of grass. If one pulls up 
a weed, he must quickly fill the hole with some other plant, or Nature will tuck another weed into it. Man is yet too ignorant or too negligent to care for the land, and Nature must still stand at his back and supplement the work which he so shabbily performs. She knows no plants as weeds. They are all equally useful to her. It is only when we come to covet some plant that all those which interfere with it become weeds to us. If, therefore, we are competent to make a choice of plants in the first place, we should also be able to maintain the choice against intruders. It is only a question of which plants we desire to grow.

We must keep the land at work, for it grows richer and better for the exercise. A good crop on the land, aided by good tillage, will keep down the weeds. The weeds do not "run out" the sod, but the sod has grown weak through some fault of our own, and thus the dandelions and plantains find a chance to live. So the best treatment for a weedy lawn is more grass. If the farmer occupies only half the surface of his field with oats, the other half is bound to be occupied with mustard or wild carrot or pigweed; but if his land is all taken with oats, few other plants can thrive. So, a weedy farm is a poorly farmed farm. But if it does get foul and weedy, then use a short quick, sharp rotation. Keep the ground moving or keep it covered. No Russian thistle or live-forever or jimsonweed can ever keep pace with a lively and resourceful farmer.

This attitude is as important in fruit-growing as in general farming. The land must be kept active and at work, which means that the fruit-grower must be active and at work. When this is accomplished and the fruitplantation is still unproductive, other means must be 
considered; and one of these means is to apply plant-food materials.

The lesson of nursery lands.

The injurious effects of leaving soils bare, and of tilling at untimely seasons, are well illustrated in most nursery plantations. The best nursery lands are the "strong" lands, or those containing a basis of clay, and these are the ones that soonest suffer under unwise treatment. The nursery land is kept under clean culture, and it is, therefore, deeply pulverized. There is practically no herbage on the land to protect it in the winter. When the crop is removed, even the roots are taken out of the earth. For four or five years, the land receives practically no vegetation that can rot and pass into humus; and moreover, the trees are dug in the fall, often when the soil is in unfit condition, and this fall digging amounts to a fall plowing. The soil, deeply broken and robbed of its humus, runs together and cements before the following summer; and it then requires three or four years of "rest" in clover or other herbage to bring it back into its rightful condition. This resting-period allows Nature-if man grants her the privilege - to replace the fiber in the soil, and to make it once more so open and warm and kindly that plants may find a congenial root-hold in it.

Chemical analyses of nursery stock show that the amounts of potash, phosphoric acid and nitrogen that such stock removes are really very small, and less than those removed by a similar bulk or weight of corn or wheat. Experiments with the addition of concentrated or chemical manures to heavy nursery lands seem not to have shown very important results; but there are greater hopes from the sowing of crimson clover and other cover-crops in the 
nursery rows, and in the use of stable manures. There are examples of excellent results following the addition of stable manure to nursery lands between the trees in autumn. One piece of land so treated has grown excellent plum trees for twenty consecutive years.

\section{COVER-CROPS}

The vegetable matter or fiber may be supplied by herbage plowed under and by the addition of stable manures or similar amendments. We may first consider the growing of herbage for the amending of the land.

A cover-crop is used for the particular purpose of securing its mulching and physical effect on the land in the intervals between the regular fruit crops or the normal seasons of tillage. A sowed crop in the orchard may be valuable in two ways: by affording a cover to the land, and by improving the soil when it is plowed in. As a cover, it may keep down weeds and protect the land from injurious effects of frost. As a green manure, it may add fiber to the soil, and thus augment its power of holding fertility and moisture, and it may add directly to the plant-food. This late crop catches and holds the nitrates which the tree-roots utilize earlier in the season. Taken as a whole, the cover-crop may be said to improve the soil as follows:

1. It protects the land and directly improves its physical condition:

Prevents hard soils from cementing or puddling;

Holds the rains and snows until they have time to soak away into the land;

Holds the leaves from blowing away;

Dries out the soil in spring, making early tillage possible;

Sometimes serves as a protection from frost;

Prevents washing in winter. 
2. It improves the chemical condition of the soil:

Catches and holds some of the leaching nitrates;

Adds humus;

Renders plant-foods available;

Appropriates nitrogen, if it is leguminous.

As a rule, crops grown for cover alone should be sown not earlier than midsummer. The most thorough tillage can then be given early in the season, and the benefits of the cover may be secured for early autumn, winter and spring. It is usually advisable to grow a crop that answers

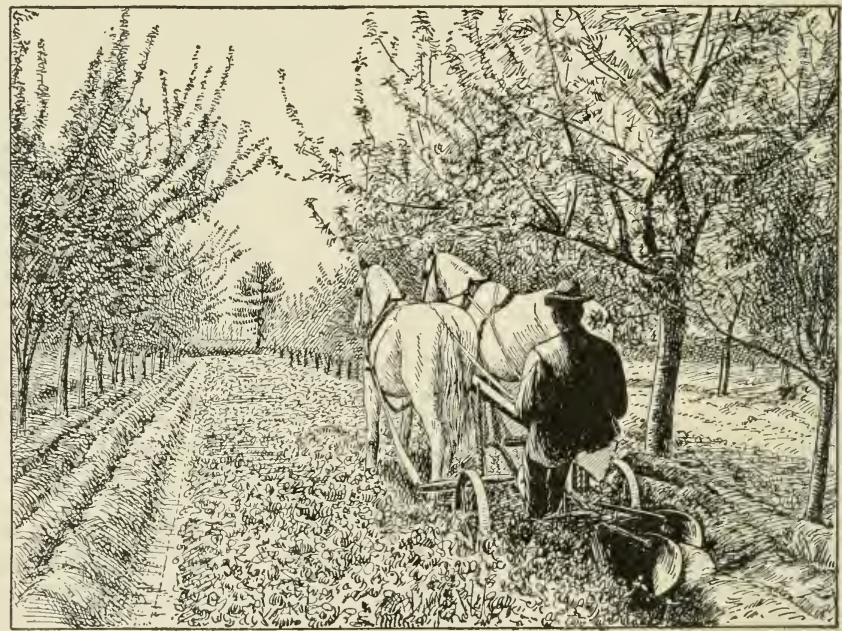

FIG. 23. Plowing under a cover-crop in spring.

for both cover and green manure, although it is possible to make the soil too nitrogenous for some fruits by the extravagant use of the legumes. It will also be observed, from the above enumeration of the benefits arising from cover-crops, that crops killed by the winter may still be 
very useful. The reader must also be reminded that much of the value of the cover-crop depends on its being plowed under very early in spring (Fig. 23).

It is probably not often that one secures too rapid growth of his fruit-plants by the use of leguminous covercrops, and yet it seems to be a common opinion among growers that this may occur. The experience of George T. Powell, in eastern New York, has been much quoted. In a pear orchard he grew three very heavy successive crops of crimson clover and plowed them under, with the result that the trees grew too heavily and bore too little. An analysis of the soil was made by Cavanaugh and also of the same character of soil from a neighbor's field just across the fence, with the following results:

\begin{tabular}{|c|c|c|}
\hline & $\begin{array}{c}\text { Three crops } \\
\text { crimson clover } \\
\text { Per cent }\end{array}$ & $\begin{array}{l}\text { No clover } \\
\text { Per cent }\end{array}$ \\
\hline 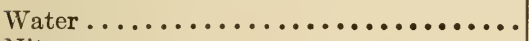 & 15.00 & 8.75 \\
\hline 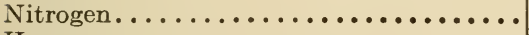 & .21 & .12 \\
\hline 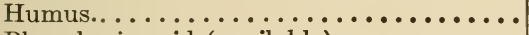 & 2.94 & 1.91 \\
\hline Phosphoric acid (available)........... & .015 & .008 \\
\hline
\end{tabular}

These percentages are calculated to the acre, estimating $1,500,000$ pounds of fine soil to the acre-foot $(3,000,000$ pounds is the average weight of an acre-foot, but in this case about 50 per cent of the soil was sufficiently fine to be included in the analysis); the increase in percentages, as computed to pounds or tons to the acre, is as follows:

Water........6.25 per cent $=46.875$ tons to the acre.

Nitrogen ....... .09 per cent $=1,350$ pounds to the acre.

Phosphoric acid.. .007 per cent $=105$ pounds to the acre. 
There is much confusion in the popular mind as to the relation of cover-crops to moisture. Some contend that any crop which shades the ground will keep the surface moist and conserve moisture, whereas others, knowing that all plants exhale water, consider that any crop tends to make the land dry. Both these opinions are in part correct. A crop that occupies the land the entire season, and that does not allow of tillage, will make the land dry, whereas one sown late in the season on land that has been thoroughly tilled during May, June and July, does not seriously rob the soil of moisture. At all events, there need be little fear of drying out the soil by sowing a late crop, for the serious injury by drought is usually effected before such crops are established, and rainfall is then becoming abundant; and the trees may need to be checked rather than stimulated, at this season, by the transfer of the nitrates and moisture to other plants. The most marked way in which such crops conserve moisture is by means of the fiber and humus that they add to the land when plowed under; but even this humus cannot compete with cultivation as a retainer of moisture. Both humus and tillage are essential for best results.

\section{The kinds of cover-crops.}

It should be said at the outset that the choice of the proper crop for the covering of an orchard is a local matter, the same as is the method of tillage or the kind of fertilizer. There is also no one best cover-crop for all purposes and all circumstances. The grower must study the condition of his trees and his land, and then judge as best he may what course he shall pursue. Nature's covercrops, at least on farms, are weeds, and these may be use- 
ful if allowed to grow in autumn after the tillage is completed. The difficulty is that they cannot always be relied upon to cover the land at the time when they are wanted, most of them do not live through the winter, and they are very likely to become a serious nuisance. It is best, therefore, to substitute some other plant for the weeds. Red clover is a stand-by, but it often fails to "catch" if sown late in the season, and it should stand on the land an entire season in order to contribute its full value. On good and well-tilled lands and in favorable seasons, considerable herbage can be secured for turning under in the spring if clover is sown the preceding August or September; but in general it is unreliable as an annual crop, and is not adapted to fruit-lands. Mammoth clover is considered to be better than the common red.

In approaching the question of the choice of covercrops, the grower must understand that there are two great classes in respect to their supposed power to gather nitrogen. The one class is non-leguminous, comprising those plants that take only such nitrogen as has already been worked over into available form by plants or animals; the other class is the leguminous, comprising those plants that have the power of appropriating and utilizing free nitrogen through the action of root-nodules. For purposes of cover and protection, the non-leguminous crops may be just as good as the nitrogen-gatherers, and when the fruitplants are growing very vigorously they may be decidedly better than the others because, by not adding nitrogen, they do not over-stimulate the growth.

A rotation of cover-crops will nearly always be found to be important. Some of the most useful cover-crops will not thrive on hard and intractable land, and in such cases a rougher and coarser crop must be used. 
The golden scale of cover-crops for orchards begins with rye and ends with crimson clover. Lands that are very sandy and leachy, as well as those that are hard and lumpy, are usually not adapted to the growth of crimson clover, especially in the North. Such lands must be gradually ameliorated by the use of other plants, and, as a rule, the best plant to begin with is rye.

Rye thrives on a great variety of soils, it demands little preparation of the land, the seeds are large and germinate at a low temperature, it grows early and strongly in spring, it may be sown late in the season after tilled crops are removed, and it is exceedingly hardy. Rye may be sown at the very moment of the freezing of the land, and it will sometimes germinate the following spring. It is ordinarily best, however, to sow it about a month or six weeks (or even two months) before the land is expected to freeze; and for the purpose of securing cover, not less than one and one-half bushels should be sown to the acre when orchards are young. When the trees have begun to shade the ground, a less quantity may suffice.

Indian corn, is sometimes used to begin the amelioration of intractable lands, sown broadcast very thickly, six weeks or two months before killing frost. Although it does not withstand the winter, it nevertheless affords an excellent cover and supplies a large quantity of herbage.

Buckwheat may be used for the same purpose, sown so late in the season that it will reach its full height but will not go to seed. There is danger, however, of using buckwheat too much; only an occasional crop of it should be sown and on orchards growing on the hard types of land.

Turnips and rape are also to be recommended in certain 
cases. Turnips sown late in July in the North make a complete cover of the land, and furnish so much bulk and moisture as greatly to improve the character of the land when they are plowed under the following spring. Turnips are especially good to begin the process of improvement in certain hard lands that are much inclined to be dry. They contain much potash. The large cowhorn turnips are usually preferred for cover-crop work, although the smaller turnips may be sown with them. Dwarf Essex rape furnishes much herbage at little cost.

Oats, wheat, barley, millet, and various other quickgrowing crops may be utilized as covers, but they are less adapted to the purpose than those that have been mentioned. In order to impress the different qualities on the mind, it may be well to say that rye and corn, and the like, are to cover-crops what pigs and mules are to domestic animals.

Leguminous crops comprise the various kinds of peas, beans, vetches, and the clovers and their kin. If it is desired to grow a leguminous crop on hard and dry land, it will be necessary to choose those with large and quickgerminating seeds, as the beans and the field peas. Common field beans may be sown broadcast late in the season, and if they can have six weeks of uninterrupted growth, will make a good cover before killed by frost. Canada peas are not injured by the early frosts of fall, and therefore may be sown later. In New York, peas sown as late as the 20th of September reached a height of about 6 inches, and were large enough to afford a fairly good cover, if they were sown very thick. But, in general, in the northern states, it is advisable to sow not later than the last of August or the first of September.

The cowpea (Vigna sinensis) may often be used to 
the greatest advantage, especially in the middle and southern states where the long seasons allow it to make a most luxuriant and satisfactory growth. It is probably destined to fill the office in the southern states that red clover fills in the North, and, if properly used, can no doubt be made the means of filling the burned-out soils of the South with fresh life and vigor. It is killed by the earliest frost, and is, therefore, not advisable at the North, unless sown early or on land that is "quick."

Vetch or tare (Vicia sativa) as a cover was brought forward by the Cornell Station, in 1892. It is a leguminous plant of strong growth. If sown in the northern states in late July, it makes a dense cover that is killed by hard frosts and mats down like a carpet before spring. The seeds are large and start readily. Its great drawback is the cost of the seed, and about thirty to fifty pounds should be sown to the acre on open lands.

Winter or hairy vetch (Vicia villosa) withstands the winter and grows in spring. The seed is likely to be expensive; thirty to fifty pounds are required to the acre. It thrives on rather poor as well as on rich soils.

Sweet clover or melilotus (Bokhara clover) is sometimes mentioned as a cover-crop, particularly for hard and dry lands and those on which it is difficult to secure a catch of clover; but further experience is needed with this plant.

Crimson or scarlet clover was brought prominently to the fore as a cover-plant for orchards by the Delaware Experiment Station in 1892. It is an excellent cover-crop in the northern states, and in Nova Scotia (Sears, Rept. N. S. Agric. 1904). It will not thrive on hard or poorly tilled land. It must be sown in midsummer or a trifle after, when the ground is likely to be dry. The seeds are small and oily, and the grower is likely to fail in secur- 
ing a "catch." On the better tilled lands, however, crimson clover may be expected to succeed as often as any other plant of its class. Growers have made a mistake in expecting too heavy growth of herbage in the crimson clover. It is an annual plant, normally completing its entire growth in a single season. When sown at midseason, therefore, it should not be expected to yield a very heavy crop. If it should arrive at that stage when it nearly or wholly covers the ground with a thin close mat, it will have reached its most profitable condition. If the crimson clover passes the winter and grows in the spring, much will be gained; but if it should not pass the winter, nothing will be lost. If it is sown very early (that is, before the first of July in New York), it is likely to become too large and ripe, and be killed by the winter; if it is sown too late (after the middle of August), it will ordinarily not attain sufficient foothold to be able to withstand the heaving by frost. Crimson clover may be sown among Indian

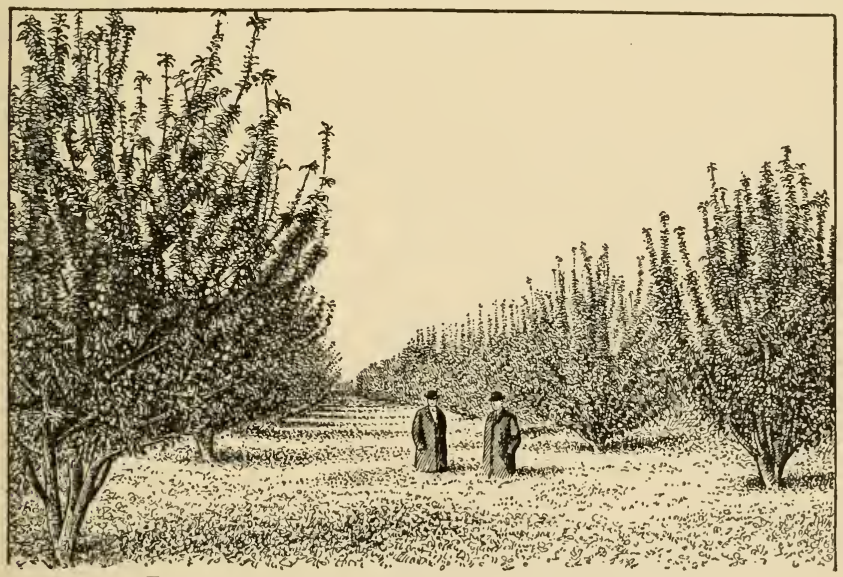

FIG. 24. Cover-crop of alfalfa in a western orchard. 
corn at the last cultivation, but in orchards it is ordinarily sown from the m:ddle of July to the middle of August in the North, on a well-prepared seed-bed, and is then lightly dragged in. In old orchards, six quarts to the acre is sufficient seed; in the open lands, about eight quarts is the quantity required.

Other plants are used as cover now and then or in particular regions, as alfalfa, velvet bean and beggarweed in the South, soybean, oats (mostly in mixture), cabbage. In the North, the soybean should be sown early and tilled for a time. Alfalfa is sometimes used as a cover in orchards (as in Fig. 24, from the Lewiston-Clarkson region). If irrigation is available, it may be an acceptable crop for providing abundant herbage to plow under. Under usual conditions, it is likely to be kept too long on the land.

Paddock gives chemical analyses of cover-crop plants, showing also date of seeding and taking samples, yields of green crops and air-dry roots to the acre:

\begin{tabular}{|c|c|c|c|c|}
\hline & $\begin{array}{l}\text { Cowhorn } \\
\text { turnips }\end{array}$ & Rape & $\begin{array}{l}\text { Crimson } \\
\text { clover }\end{array}$ & $\begin{array}{l}\text { Red } \\
\text { clover }\end{array}$ \\
\hline Seed sown. & July 22 & July 22 & July 22 & July 22 \\
\hline 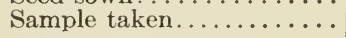 & Nov. 15 & Nov. 16 & Nov. 22 & Nov. 22 \\
\hline Pounds green tops........ & 11297 & 26620 & 18800 & 6909 \\
\hline Pounds air-dry roots....... & $* 20522$ & 864 & 413 & 1212 \\
\hline Total yield ............ & 31819 & 27484 & 19213 & 8121 \\
\hline Pounds nitrogen- & & & & \\
\hline In tops.......... & 64.4 & 116.2 & 128.2 & 69.8 \\
\hline In root. . . . . . . . & 45.1 & 13.2 & 6.2 & 33.2 \\
\hline Total............ & 109.5 & 129.4 & 134.4 & 103.0 \\
\hline Pounds potash- & & & & \\
\hline In tops...... & 80.3 & 148.2 & 84.0 & 46.5 \\
\hline In roots........... & 62.3 & 13.1 & 4.2 & 9.9 \\
\hline 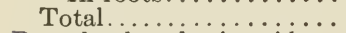 & 142.6 & 161.3 & 88.2 & 56.4 \\
\hline Pounds phosphoric acid- & & & & \\
\hline 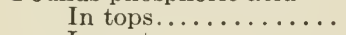 & 14.3 & 41.8 & 59.2 & 18.9 \\
\hline In roots............ & 11.7 & 5.1 & 2.0 & 10.1 \\
\hline Total......... & 26.0 & 46.9 & 61.2 & 29.0 \\
\hline
\end{tabular}

The turnip roots were weighed in their natural state just after being dug; this is therefore, not air-dry weight. 


\begin{tabular}{|c|c|c|c|c|}
\hline & Alfalfa & $\begin{array}{l}\text { Hairy } \\
\text { vetch }\end{array}$ & Cowpeas & Soy-beans \\
\hline Seed sown. . & July 22 & July 22 & July 22 & July 22 \\
\hline Sample taken............. & Nov. 20 & Nov. 19 & Nov. 7 & Nov. 11 \\
\hline Pounds green tops........ & 5430 . & 13150 & 5933 & 10952 \\
\hline Pounds air-dry roots....... & 1980 & 600 & 394 & 756 \\
\hline Total yield............. & 7410 & 13750 & 6327 & 11708 \\
\hline Pounds nitrogen- & & & & \\
\hline In tops....... & 54.8 & 108.0 & 65.2 & 130.9 \\
\hline In roots......... & 40.4 & 13.2 & 4.3 & 9.3 \\
\hline Total ............ & 95.2 & 121.2 & 69.5 & 140.2 \\
\hline $\begin{array}{l}\text { Pounds potash - } \\
\text { In tops...... }\end{array}$ & 322 & 784 & & \\
\hline In roots......... & $\begin{array}{r}32.2 \\
9.5\end{array}$ & $\begin{array}{r}7.4 \\
7.1\end{array}$ & $\begin{array}{r}47.4 \\
2.4\end{array}$ & $\begin{array}{r}40.2 \\
1.8\end{array}$ \\
\hline Total .............. & 41.7 & 85.5 & 49.8 & 48.0 \\
\hline Pounds phosphoric acid- & & & & \\
\hline In tops $\ldots \ldots \ldots \ldots \ldots$ & 13.1 & 22.5 & 16.6 & 37.8 \\
\hline In roots $\ldots \ldots \ldots \ldots$ & 8.5 & 4.7 & 2.3 & 2.4 \\
\hline 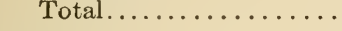 & 21.6 & 27.2 & 18.9 & 40.2 \\
\hline
\end{tabular}

In considering this table, the reader will observe that rape contains the most nitrogen of any of the plants and that turnips are richer in this element than is red clover. This excess is due to the greater tonnage, and it is all taken from the land. In the case of clover and similar plants, some of the nitrogen-content is usually new, since a part may be taken from the air.

Lists, and Rates of Seeding, of Cover-crop Plants.

\section{Leguminous-}

Alfalfa.

Beans of all kinds.

Beggarweed.

Clovers of all kinds.

Cowpea.

Peas of all kinds.

Soybean.

Sweet clover.

Vetches of all kinds.
Non-leguminous-

Barley.

Buckwheat.

Cabbage.

Corn.

Millet.

Oats.

Rape.

Rye.

Turnip.

Weeds of most kinds.

Wheat. 
Withstanding the winter (in the North) and growing in spring.

Alfalfa.

Clovers

Rape.

Rye.
Sweet clover.

Turnip (more or less).

Vetch, winter or hairy.

Wheat.

Average quantity of seed to the open acre (modified from C. S. Wilson).

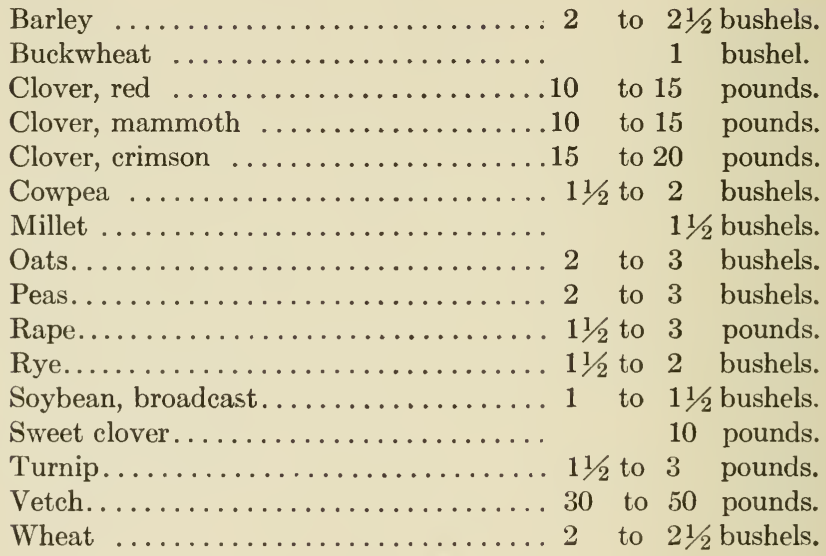

As all the desired features are seldom found in a single crop, combinations are desirable. Thus buckwheat, which makes a quick growth, does not live through the winter as does the slower-growing rye, so the two combine well. Following are suggestions:

1.

(Clover, red or mammoth, ...........10 pounds.

Winter vetch..................

Oats.................... 1/2 bushel.

Cowhorn turnips................ 1/2 pound.

(Rye......................... 1 bushel.

2.

Cowhorn turnips................. 2 pounds.

Crimson clover.........................

Vetch............................ pounds.

May be sown in August, in the North. 
Buckwheat..................... 1/2 bushel.

3.

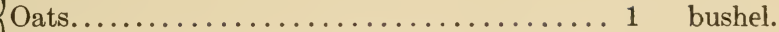

Rye.......................... 1 bushel.

4. $\left\{\right.$ Oats.......................... $1 \frac{1 / 2}{2}$ bushels.

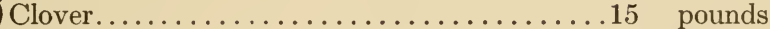

5. $\{$ Buckwheat.................... $3 / 4$ bushel. Oats ......................... 1 bushel.

6. $\{$ Oats.......................... 11/2 bushels.

$\{$ Rye........................ 1 bushel.

Many combinations may be made of the plants listed above, to meet special conditions; for rather hard lands that need both humus and nitrogen, a suggested combination is buckwheat or cowhorn turnip, rye, Canada peas or vetch; or a leguminous crop may be added to 3, 5 or 6 above.

Other successful mixtures are reported in Delaware by Close (Bull. No. 60), as follows:
1. $\left\{\begin{array}{l}\text { Hairy vetch } \\ \text { Rye....... }\end{array}\right.$
40 pounds.
2. $\{$ Hairy vetch.
30 pounds.
2. $\{$ Cowpeas or soybeans
20 pounds.
3. $\left\{\begin{array}{l}\text { Hairy vetch } \\ \text { Turnips..... }\end{array}\right.$
45 pounds.
4. $\left\{\begin{array}{l}\text { Hairy vetch...... } \\ \text { Mammoth clover. }\end{array}\right.$
20 pounds.

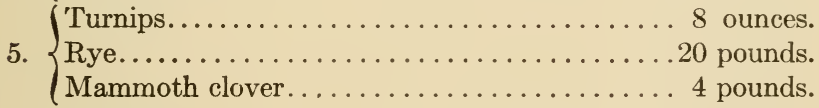

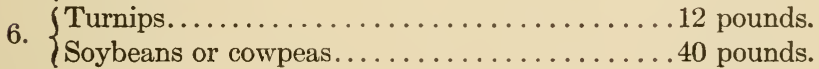

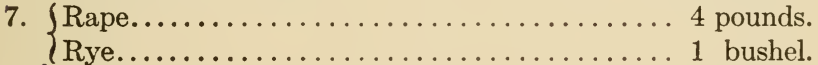

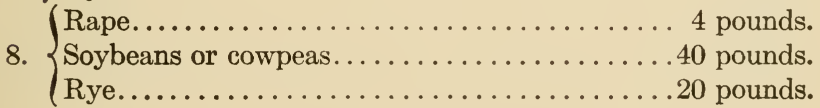 12 ounces. 20 pounds. 8 pounds.

Weights of the seeds of cover-plants.

Following are the customary seedsmen's weights to the bushel some of the seeds contained in the above lists (Edgar Brown): 
Clover, alsike, crimson, mammoth red...... 60 pounds. Cowpea........................56 to 60 pounds. Millet, barnyard................. Millet, common, German, Hungarian.......48 to 50 pounds. Millet, Pearl................. 48 to 56 pounds. Pea, field ................... 60 pounds. Rape.......................50 to 60 pounds. Soybean....................58 to 60 pounds. Sweet clover, hulled................ 60 pounds. Velvet bean.................. 60 pounds. Vetch, hairy or winter.............50 to 60 pounds. Vetch, spring.................. 60 pounds.

\section{ROTATION OF PLANTATIONS}

It is accepted that the rotation or at least the diversification of crops in orchards and other fruit-plantations is a desirable practice as a means of conserving productivity of the land. It is also accepted that strawberries would better not follow strawberries or cane-fruits follow cane-fruits; but there is little real planning for the rotation of plantations of the longer-lived fruits, and yet such rotation must be very important. The following discussion may be suggestive (Bailey, Cyclo. Amer. Agric. II).

The grower usually does not not lay out a plan of land management, one item in which is the growing of orchards. In the case of apples, the life of the orchard is so great, that the grower feels that he is planting for a lifetime, and he leaves succeeding questions to those who may come after him. Even apple orchards may be retained too long for profit, however; and peaches, plums and some other fruits are not too long-lived to form part of a rotation plan. The rotation farmer may lay out a course that is not expected to mature within twenty years. Small-fruits are well adapted to rotationing. In fact, careful rotation is the very best means of keeping in check certain difficult dis- 
eases and pests of strawberries, raspberries and blackberries. The rotation may be between different kinds of fruits themselves, or between fruits and field-crop courses. The point is that fruit-growing practice ought not to be completely isolated from general farm-management plans.

Rotation between the fruit-plantations themselves, may be very desirable in some cases. If one has a 100 -acre farm on which he wishes to make a specialty of peaches, he might set aside six fields of 10 acres each, and set them in twelve-year rotations or blocks, planting a new orchard every three years. In this way there would always be a new orchard coming into bearing, the grower could apply the experience of one orchard to the succeeding one, and he could prepare the land thoroughly in advance of each setting, and he would have some land left for other crops.

On small farms, such a plan could not be applied, except for small-fruits. Neither would it be adaptable to farms presenting very different or various conditions; for many properties are broken into irregular fields by creeks, gulches, slopes, forests or hills, and only a part of such natural subdivisions might be adapted to fruit.

The following display shows how this plan would work out. The heavy figures show orchards in bearing; it will be seen that there are always three orchards in bearing after the plan is in full working maturity. It is assumed that six years intervene between the plantings on the same ground. The letters $a, b, c$ show how the elements in a three-course crop-rotation would combine with the orchards, if it is assumed that it would be safe or desirable to crop the orchard lightly for the first three years. The blank or treeless years would be used in general field-crop practice. This plan is not recommended, but is given to suggest a line of study: 
Rotation Scheme of Peach Orchards

Heavy figures represent bearing years

\begin{tabular}{|c|c|c|c|c|c|}
\hline $\begin{array}{l}\text { First } \\
\text { orchard }\end{array}$ & $\begin{array}{l}\text { Second } \\
\text { orchard }\end{array}$ & $\begin{array}{l}\text { Third } \\
\text { orchard }\end{array}$ & $\begin{array}{l}\text { Fourth } \\
\text { orchard }\end{array}$ & $\begin{array}{l}\text { Fifth } \\
\text { orchard }\end{array}$ & $\begin{array}{c}\text { Sixth } \\
\text { orchard }\end{array}$ \\
\hline $\begin{array}{l}1900 a \\
1901 b \\
1902 c \\
1903 \\
1904 \\
1905 \\
1906 \\
1907 \\
1908 \\
1909 \\
1910 \\
1911\end{array}$ & $\begin{array}{l}1903 a \\
1904 b \\
1905 c \\
1906 \\
1907 \\
1908 \\
1909 \\
1910 \\
1911 \\
1912 \\
1913 \\
1914\end{array}$ & $\begin{array}{l}1906 a \\
1907 b \\
1908 c \\
1909 \\
1910 \\
1911 \\
1912 \\
1913 \\
1914 \\
1915 \\
1916 \\
1917\end{array}$ & $\begin{array}{l}1909 a \\
1910 b \\
1911 c \\
1912 \\
1913 \\
1914 \\
1915 \\
1916 \\
1917 \\
1918 \\
1919 \\
1920\end{array}$ & $\begin{array}{l}1912 a \\
1913 b \\
1914 c \\
1915 \\
1916 \\
1917 \\
1918 \\
1919 \\
1920 \\
1921 \\
1922 \\
1923\end{array}$ & $\begin{array}{l}1915 a \\
1916 b \\
1917 c \\
1918 \\
1919 \\
1920 \\
1921 \\
1922 \\
1923 \\
1924 \\
1925 \\
1926\end{array}$ \\
\hline
\end{tabular}

Aside from a rotation of fields, it is often advisable to lay out a rotation of crops in the orchards themselves when the trees are young. Such rotation practice would reduce the great amount of tillage labor by keeping part of the area always in clover or other sod, would correct the faults of a continuously recurring treatment, would guard against neglect, and would allow of a somewhat definite plan of work for some years ahead. The rotation should be short and should contain the maximum of tilled crops. A three-year course might fit the conditions well, for it 
would be adapted to the varying early stages of orchards, and would correspond with normal strawberry rotations and even with the best practice in raspberry-culture. One to four three-year courses could be run in orchards before the trees are large enough to interfere, depending on the land, the kind of fruit and the distance apart. A threeyear course for young orchards should preferably have two tilled crops and one legume or sod crop: as (1) potatoes, roots or truck-crops, (2) corn, (3) crimson clover or vetch in fall or spring; or, again, as (1) corn, (2) cotton, (3) cowpea or velvet bean. Sometimes it may be allowable to run only one tilled crop, in which case the potatoes-wheat-red clover may be useful. Care must be taken to see that first attention is given the trees, and this should call for manure or fertilizers with one or more of the courses.

\section{STABLE MANURES}

The kinds of fertilizing applications are of two types, -stable manures and concentrated or commercial plantfoods. The stable manures exercise a most important effect on the physical character of the land, and, in fact, this is often their greatest value. In this respect, stable manures may answer much the same purpose as greenor cover-crops, particularly if they are applied in fall or early winter. When manure is not sufficient to cover the entire plantation, it should be applied to the hardest and driest spots only, these spots being observed and noted the previous season. Lands so hard or dry that even rye will not catch may be got under way for the cover-crops by liberal applications of barn manures. Rotation in the use of fertilizers may be found to be as useful as in the case of cover-crops. A soil that has had a liberal 
application of stable manure one year, may profit more by some chemical fertilizer the next year.

In thoroughly tilled orchards the use of barn manures should sometimes be discouraged, for the chief element of fertility in them-if they are not leached-is usually nitrogen. This advice is particularly applicable to vineyards, and all other fruits that run very strongly to wood. In such cases, it is better economy to apply the manures to the annual crops of the farm. The old, neglected apple orchards of the country, however, may receive barn manures with safety; yet, even here it is a question whether economy would not dictate tillage and late green manures to supply the nitrogen, except, perhaps, for a season or two when an attempt is making to rejuvenate a plantation. Mulching a sod orchard with manure, or with hay cut on it, often gives fairly good results in cases in which the land cannot be tilled; but better results in the way of fertilizing and in freedom from weeds and insects may be secured by pasturing closely with sheep or swine and adding chemical manures.

All stable and barn manures should be carefully protected, saved and utilized: where they should be applied -whether on annual crops or on fruit-plantations - only the grower himself can determine; it is certain that the fruits will profit by them.

In blackberry, raspberry and strawberry plantations, stable manures may be used moderately as a mulch, and the leachings will be of service; and if the material finally is plowed under, double results will be secured.

In general, the same principles cover the application of manures-as to when and how-to fruit-lands as to general farm lands, and this subject may not be discussed here at any length. The applications are usually made in 
the dormant season,--from autumn till early spring. In mature plantations, it is best to apply manure to the entire area rather than to pile it close to the trees or vines. Plowed under in early spring, the barn manures should have a marked effect in ameliorating the land and improving the thrift and stamina of the plantation.

\section{CHEMICAL FERTILIZERS}

Presumably, fruits profit by the application of fertilizer to the land because they use the kinds of materials that fertilizers contain. The standard computations of Roberts, from analyses, show the following values of nitrogen, phosphoric acid and potash taken from an acre by apple trees (the trees 35 feet apart) in twenty years, counting in ten crops of fruit:

Total in fruit for twenty years............\$147 00

Total in leaves for twenty years............... 16051

Total in wood for life of tree..................... 7000

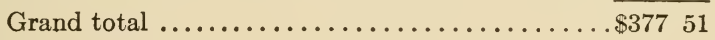

"The value of nitrogen, etc., in any given case is so indefinite and variable that stress should not be laid on values as given, but on the total amounts of plant-food used by the orchard, as follows:

"The total amount of nitrogen, exclusive of that used in the growth of the trees, is $1,336.8$ pounds, of phosphoric acid 310 pounds, and of potash 1,895.4 pounds. To restore the potash alone, as above and that used by the growth of the tree, it would require 21.69 tons of high-grade ashes containing 5 per cent of potash. To restore the nitrogen as above would require 16.19 tons per acre of a commercial fertilizer containing 5 per cent of nitrogen. 
"How much of this plant-food is usually furnished to the orchard by leguminous plants and by feeding supplementary foods to animals which graze upon it, and how much by the fallen leaves and apples which are not blown or carried off, cannot be told."

Another calculation by Roberts shows the amount of plant-food that may be expected to be carried away from an acre in the fruit, and blown off in the leaves (not computing the amount in the wood), for the period between the ages of thirteen and thirty-three years of apple trees:

\begin{tabular}{|c|c|c|c|}
\hline & $\begin{array}{l}\text { Apples } \\
\text { Lbs. }\end{array}$ & $\begin{array}{l}\text { Leaves } \\
\text { Lbs. }\end{array}$ & Value \\
\hline $\begin{array}{l}\text { Nitrogen } \ldots \ldots \ldots \ldots \ldots \ldots \ldots \ldots \ldots \ldots \ldots \ldots \\
\text { Phosphoric acid } \ldots \ldots \ldots \ldots \ldots \ldots \ldots \ldots \ldots \ldots\end{array}$ & $\begin{array}{r}498.60 \\
38.25 \\
728.55\end{array}$ & $\begin{array}{l}456.75 \\
126.00 \\
441.00\end{array}$ & $\begin{array}{r}\$ 143.30 \\
11.50 \\
52.63\end{array}$ \\
\hline Total value...... & & & $\$ 207.43$ \\
\hline
\end{tabular}

"While the above results are reached by assuming a given amount of apples and leaves a year in a bearing orchard, and while the facts in any given case at any given time may vary widely, yet it is believed that they are valuable as they furnish a means of measuring in any given case, with a great degree of accuracy, the amount of soil-exhaustion."

He also "shows that five bushels of apples remove in round numbers eleven pounds of nitrogen, nearly one pound of phosphoric acid and sixteen pounds of potash, and that the leaves of a tree large enough to produce the apples would contain ten pounds of nitrogen, nearly three pounds of phosphoric acid and ten pounds of potash, or a total of twenty-one pounds nitrogen, three pounds phosphoric acid, twenty-six pounds potash." 
"As a clearer comprehension is had by comparing unfamiliar things with familiar things, a table follows which gives in brief the soil-exhaustion which is likely to occur from a continuous twenty-year wheat-production. Here, again, an average yield has been assumed which, while approximately correct for New York, may be wide of the mark in some states where the average yield of wheat falls to eight or ten bushels an acre.

"The following tables show the amounts and values of the fertilizing ingredients removed by wheat (grain and straw) in twenty years' continuous cropping, assuming an average yield of fifteen bushels an acre and seven pounds of straw to three pounds of grain:

"Composition of Wheat and Straw

\begin{tabular}{|c|c|c|c|c|}
\hline & $\begin{array}{l}\text { Water } \\
\text { Per cent }\end{array}$ & $\begin{array}{r}\text { Nitrogen } \\
\text { Per cent }\end{array}$ & $\begin{array}{l}\text { Phos. acid } \\
\text { Per cent }\end{array}$ & $\begin{array}{l}\text { Potash } \\
\text { Per cent }\end{array}$ \\
\hline 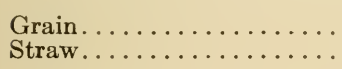 & $\begin{array}{l}14.75 \\
12.56\end{array}$ & $\begin{array}{l}2.36 \\
.559\end{array}$ & $\begin{array}{l}.89 \\
.12\end{array}$ & $\begin{array}{l}.61 \\
.51\end{array}$ \\
\hline
\end{tabular}

"Amounts and Value of Plant-food Removed in One Year AND IN TWENTY Years

\begin{tabular}{|c|c|c|c|c|}
\hline & $\begin{array}{l}\text { Nitrogen } \\
\text { Pounds }\end{array}$ & $\begin{array}{l}\text { Phos. acid } \\
\text { Pounds }\end{array}$ & $\begin{array}{l}\text { Potash } \\
\text { Pounds }\end{array}$ & $\begin{array}{l}\text { Total } \\
\text { value }\end{array}$ \\
\hline $\begin{array}{l}\text { Grain, one year.......... } \\
\text { Grain, twenty years...... }\end{array}$ & $\begin{array}{r}21.24 \\
424.80\end{array}$ & $\begin{array}{r}8.01 \\
160.20\end{array}$ & $\begin{array}{r}5.49 \\
109.80\end{array}$ & $\begin{array}{l}\$ 3.99 \\
79.86\end{array}$ \\
\hline $\begin{array}{l}\text { Straw, one year............ } \\
\text { Straw, twenty years....... }\end{array}$ & $\begin{array}{r}11.74 \\
234.78\end{array}$ & $\begin{array}{r}2.52 \\
50.40\end{array}$ & $\begin{array}{r}10.71 \\
214.20\end{array}$ & $\begin{array}{r}2.42 \\
48.37\end{array}$ \\
\hline
\end{tabular}

Total value in wheat, grain and straw for 20 years... $\$ 128.23$

Total value in apple, fruit and leaves for 20 years... 207.45

"The above table shows that the orchard requires, if fruitful, plant-food equal in value to about $\$ 80$ more 
than the wheat. No one would think for a moment of trying to raise wheat, even on our best New York land, for twenty consecutive years, even though the soil was fitted in the best possible manner yearly."

\section{Apple-orchard experiments.}

Yet, as explicit and striking as are these calculations, the results of experiments in the fertilizing of apple orchards are very contradictory.

This is perhaps to be expected. It probably represents undetermined differences in the lands under experiment. Inasmuch as we do not possess sufficient knowledge to enable us to harmonize the results, some of the most prominent findings are given here for such guidance and information as the reader may be able to secure from them. Hedrick reports the conclusions of a fifteen-year experiment on the fertilizing of apples by the New York (Geneva) Experiment Station in part as follows (Bull. No. 381):

"Current recommendations for fertilizers in orchards are unreliable because there have been few investigations of the subject which have furnished trustworthy information. Present practices are largely based on the fertilization of field and garden crops, but the needs of apples cannot be compared, in the least, with the needs of herbaceous crops because of the great difference in the habits of growth of the two kinds of plants. Fertilizing apples is a difficult problem, too, for, beside variability of plant and environment to contend with, as with all plants, it is necessary to take thought of the tree and of the crop of the future.

"This experiment has to do with apples-not apples and grass. Attention is called to this fact because most of the investigations of fertilizers for apples have been carried on with trees in sod. In all such experiments the interactions of soil, apples, grass and fertilizers are so complicated that a crucial test is impossible.

"The experiment under discussion was carried on in a station 
orchard. the soil of which is a clay loam too heavy for a good orchard soil and not better than the average clay soil in the farm lands of western New York. The orchard has been given the care it would have received in a commercial plantation.

"There are twelve plats in the experiment. The fertilizers applied each year are as follows:

\section{Average to the Tree}

Plats 1 and 9. Pounds

Plats 1 and 9.-Stable manure............... 415.15

Plats 2 and 8.-Acid phosphate............. 12.66

Plats 6 and 10.-Muriate of potash.......... 7.26

Acid phosphate.................... 12.60

Plats 4 and 12.-Muriate of potash........... 7.26

Acid phosphate..................... 12.60

Nitrate of soda.................... 3.67

Dried blood...................... 12.84

"An important consideration is that the fertilizers were put on only underneath the branches of the trees so that a tremendous excess of each has been used and the experiment, therefore, throws light on the question as to whether excessive fertilization is deleterious to trees.

"The apple in the experiment is the Rome top-worked on Ben Davis, the Rome buds all having come from one tree and the stocks having been selected carefully. These precautions were taken to exclude individual variations. Cross-pollination is provided for, there being over a hundred other varieties separating and bounding the plats.

"From the data at hand there seems to be but one interpretation of the results of this experiment. An analysis of the soil before the experiment was begun shows that at that time there was, in the upper foot of soil, enough nitrogen per acre to last mature apples trees 183 years; of phosphoric acid, 295 years; of potash, 713 years. From this well-nigh inexhaustible storehouse, tillage, cover-crops and good care have made available all the plant-food these trees needed. It may be necessary to fertilize some apple orchards in New York. Such cases will be found on sandy and gravelly soils, on lands very subject to drought, on very shallow soils and on soils quite devoid of humus. Some soils may require one of the chief elements of fertility; some, though few, indeed, need the three which usually constitute a complete fertilizer. 
"A fruit-grower may assume that his trees do not need fertilizers if they are vigorous and making a fair amount of new wood. If the trees are not vigorous the drainage, tillage and sanitary condition of the orchard should be looked to first and the fertilization afterward if then found necessary. Lastly, before using fertilizers the fruit-grower should obtain positive evidence by experimentation as to whether an orchard needs fertilizers, and what ones."

Similar results had been previously reported by the New York Station in a test to determine the effect of woodashes and acid phosphate on the yield and color of apples (Bull. No. 289). The trees were forty-three years old when the experiment was begun. "The results as to color of fruit lack uniformity and were not decided enough in a sufficient number of the twelve seasons to enable us to state that the fertilizers applied improved the color of the apples. The influence on color was most marked in the seasons when the climatic conditions were unfavorable to the development of the fruit.

"This experiment shows that fifty-seven years of orchard cropping has not reduced the soil of the station orchard to the condition where it needs a "complete" fertilizer. The fact that plowing under leguminous crops gives beneficial effects in the orchard shows that the soil is having a one-sided wear. It needs nitrogen and humus rather than potash and phospho:ic acid."

These results are practically confirmed in a five-year experiment by the New Hampshire Station. Gourley reports that "Up to the present time (1913) we have not received any cash return for the fertilizer that has been used in this orchard. The size of fruit has been increased by the use of fertilizers, especially by the use of excess nitrogen and potash, as shown by the percentage of No. 1 apples. Both the area and weight of the leaves were increased by the use of fertilizers in the year 1913, no 
records being taken of these factors previously. Lime had no appreciable effect on any of the factors considered. Color of fruit has not been increased by any combination of fertilizers employed."

On the other hand, opposite results have been secured by the Massachusetts and Pennsylvania Stations. The Massachusetts test had been continued for twenty years or more, when it was reported that "The experiment shows most decisively that apple trees must be fed to grow well and bear well."

"No one selection of materials," the report declares, "can always be best. The manure in this experiment is apparently furnishing too large a proportion of nitrogen. The combination of bone-meal with low-grade sulfate of potash has produced good results. It seems probable that, especially in soils poor in lime, basic slag-meal might wisely be used in place of the whole or a part of the bone; but should this change be made, a legume should be grown as a cover-crop to furnish nitrogen. Experiments upon a larger scale to test some of the questions raised by the results of this are now in progress.

"The orchard is divided into five plots, equal in area (about $1 / 3$ acre). Each plot contains twelve trees, - three each of Gravenstein, Baldwin, Roxbury Russet and Rhode Island Greening. After one year's preparatory cultivation, two-year-old nursery trees were set in 1890 . This orchard produced but little fruit previous to 1900 . The location is a hillside with moderate slope. The soil is a strong gravelly loam which naturally produces mostly chestnut and hemlock.

"Each plot has been continuously fertilized in the same way since 1889. The actual rates per acre are as follows:

Plot $1 .-$ Barnyard manure (about $31 / 2$ cords) ........20,000

Plot 2.-Wood-ashes.................... 2,000

Plot 3.-Nothing.

Plot 4.-Bone-meal..................... 600

Muriate of potash................. 200

Plot 5.-Bone-meal...................... 600

Low-grade sulfate of potash (sulfate of potash

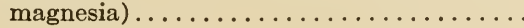


"The orchard was cultivated for the first five years. Since then it has been continously kept in grass. The crops were made into hay and carried off until the trees began to bear freely in 1903. Since then the grass has been cut, usually twice each season, and left on the ground. The hay crops each year paid for the manures used from 1894 to 1902.

"The fruit was usually ranked in color and general attractiveness in the following order: Plots 5, 4, 1, 2 and 3. In size, plots 5, 4, 1, 2 and 3.

"One of the most significant results of the experiments is the great superiority of plot 5 as compared with plot 4 . The trees are much larger and they have produced a much greater amount of fruit. Both plots have annually received equal amounts of bone-meal and equal amounts of actual potash, 100 pounds per year. The plot receiving potash in the form of low-grade sulfate has produced much better results. This may be due in part to the magnesia which the low-grade sulfate supplies, although it is possible that there was a natural difference in the soil of the two plots, or that the sulphuric acid combination with potash is better suited to the trees than the hydrochloric acid of the muriate."

Extensive apple-orchard tests have been made by the Pennsylvania Station, involving ten soil types, twelve locations, upward of 2,600 trees and 34,000 bushels of fruit in a period of five years. Some of the conclusions to 1913 as given by Stewart (Buli. No. 121) are:

"The experiments of this station have shown that the fertility needs of an orchard may be the most important check on its production. Variations in fertilization alone have resulted in average differences ranging from 50 to 460 bushels an acre annually for the past four or five years, depending on the experiment. These results were accompanied by similar differences in the growth and general vigor of the trees.

"The time required for results to appear has been surprisingly short in all cases where fertilization has proved to be really needed. In such cases, both the value of fertilization and the kinds needed were clearly evident by the middle of the second season, and no material changes have occurred since.

"Lime also has failed in most cases, although it may have some 
value in aiding growth. In addition, it may have some indirect value in facilitating the growth of leguminous intercrops, and also in correcting a possible toxic action possessed by the basic radicals of a number of salts, some of which are present in commercial nutrients.

"At present, the high-grade sulphate in our experiments is showing no superiority over the muriate as a carrier of potash, but the reverse is usually true. The lower cost and easier handling of the latter therefore give it the preference. It is possible that the lowgrade sulphate, or the 24 per cent 'double-manure salt,' as it is often called commercially, may be superior on account of its magnesiacontent, but this has not yet been fully demonstrated.

"The influence of proper fertilization is not transient. The gains from it have been greater in the sixth and the last year of some of our experiments than at any time before. In one case, these gains have exceeded 1,100 bushels an acre. Where the crops of the full years are not too high, the yields usually have been greatly steadied by proper fertilization.

"In all our experiments, the action of manure has proved to be practically identical with that of a commercial fertilizer rich in nitrogen and phosphorus. Their successes and failures have coincided with but two exceptions, and in those cases moisture rather than plant-food was apparently the controlling factor. The commercial nitrates and blood have acted more quickly than the manure, and the potash in the latter has apparently been less effective than that in the commercial forms.

"In general, the influences that have materially increased the yields have also increased the growth. This is true generally, unless either occurs to an abnormal extent. The phosphates seem to be a partial exception to this rule, and mild injuries also may stimulate yield at the expense of growth.

"Manure and potash are the only fertilizing materials that have shown a consistent benefit on the average size of the fruit. This is doubtless associated with their favorable relations toward available moisture, which is the chief determiner of fruit-size. Above a rather indefinite point, however, the size of the crop on the tree becomes the dominant influence on fruit-size. Proper thinning and moisture conservation, therefore, are the most important means of improving the average size of fruit.

"The red colors in apples can not be increased materially by any 
kind of fertilizer applications, though potash and possibly phosphates may be of some slight assistance. These colors are directly dependent upon sunlight and maturity, with the latter occurring preferably on the tree. Late picking, open pruning, light soils, sod culture and mildly injurious sprays, therefore, tend to increase the reds in fruits, while opposite conditions decrease them.

"The retarding influence of nitrogenous fertilizers or manure on color makes it advisable to use them less freely on some of the red varieties, especially those in which the color comes on rather tardily, such as the York Imperial. On the lighter soils, or in localities with the longer growing seasons, this precaution is less important.

"It has been noted that the fertilizing elements found effective in certain experiments were not so in others. In one of our experiments, no form of fertilization has yet shown a profitable response, and in two others such responses have come only from manure and mulches. It is evident therefore that the actual fertilization of a given orchard is still largely a local problem.

"It is possible, however, to indicate the more prominent characteristics of orchards that are in need of fertilization, and to formulate a general fertilizer, based on present experimental results, that may be used in such orchards until more definite local data can be secured. (See page 143.)

"Present evidence indicates that the nitrates, or other specially soluble plant-foods, are best applied somewhat after the fruit has set. In addition to greater effectiveness, this delay enables the rate of application to be varied somewhat in accord with the amount of fruit set, making the applications heavier when the crop is heavy and vice versa. In the long run, this plan should steady the yields and get maximum benefits from the fertilization applied."

What to do.

There is every reason to expect, from the nature of the case, that orchards profit by liberal fertilizing. Whether added plant-food is needed under every set of conditions is quite another matter, and it is a problem that must be answered by tests made on the place. Whether special treatments are needed in fruit-plantations to correct toxicity of the soil, or to accomplish other results, is also 
as yet undetermined. It should not be difficult to make fertilizer tests, for the results on a few trees should soon be apparent. In the case of peaches and berries, there is evidence enough of the value of fertilizing, and the same principles should apply to apples and pears, particularly on the less responsive or less retentive lands. If the trees are doing well and if the annual crops are also thrifty and satisfactory, the plantation may need nothing more than good care; but if the results are not satisfactory or if there is indication of a let-down, the grower should be alert for a remedy.

Having studied the matter carefully in reliable writings, and having observed his plantation from day to day and year to year, the grower should be able to discover about the treatment needed. An orchard in sod and not doing well should be plowed and tilled. One that is tilled and is not doing well may be benefited by seeding down, or it may not. If the growth is strong and rapid, and the trees or vines seem to be going to wood at the expense of fruit, then some check may be necessary. This check may be given by seeding down for a time, by giving somewhat less thorough or prolonged tillage, or by the use of rather more mineral fertilizers and less nitrogenous materials. In all cases in which the growth is not sufficient and the leaves are yellow and drop early, it is probable that either more nitrogen or more moisture is needed, or both. As a general principle, it may be said that nitrogen is to be had in sufficient quantity by thorough and judicious tillage, by the use of leguminous covercrops, and by stable manures. In some cases, however, quicker and cheaper results may be had by the direct addition of nitrogenous materials, as nitrate of soda, sulfate of ammonia, or some of the animal compounds. 
The grower should also remember that the plants need all the elements of plant-growth, and not one of them alone. For example, a heavy application of nitrogen to soil deficient in potash and phosphorus cannot be expected to give useful results. Similarly, the application of potash to soil that is very poor in nitrogen or phosphoric acid would be comparatively unavailing. The heavy loamy or clay lands usually contain abundance of potash and phosphoric acid in a more or less unavailable condition, and much of these materials may be liberated to the plant by careful tillage and the incorporation of humus. However, it is nearly always advisable, in bearing orchards, to add these materials in manures or concentrated fertilizers. The quickest results following the use of fertilizers will be seen in the sandier lands. Two or three years often elapse after the application of chemical fertilizers to heavy lands before any decided results are observed. In other words, clay lands ordinarily show quicker results from tillage than from fertilizers.

While all this may seem to be wholly unsatisfactory to the man who wants recipes and rule-of-thumb directtions, nevertheless it is impossible to do more than to suggest and to give advice. The uncertainty will seem less to the actual practical grower, however, than to one who reads about the situation and is not yet hard against the problem. The actual grower, if he is acute, arrives at a judgment from experience and observation that is not far wrong. He talks with his neighbors, visits other plantations, attends the meetings, hears lectures, reads, and asks questions. All good farm practice is guided by such means.

Individual plants. - It may not be necessary to treat the plantation as a whole. The soils and other conditions may differ widely in different parts. If single trees or 
plants are unthrifty, they should be given separate treatment. The experienced orchardist picks out these trees at a distance by the lighter shade of green, the sparser leafage, and the lesser growth. The first inquiry should be for borers, collar-rot, canker, sun-scald, mice injury, or other special attacks or difficulties. If the trouble does not lie here, or in the union at the graft or bud, or in over-bearing, he may assume that soil conditions are at fault. Digging up the soil about the tree or bush, or applying a good top-dressing of manure or a liberal supply of nitrate of soda, is likely to give positive results. Sometimes the difficulty is unusual dryness, on a hard or leachy spot, and the application of water may help immediately, and the incorporation of vegetable matter and the reshaping of the surface to catch the rains may help permanently.

Recommendation for apples.-Stewart gives "a general fertilizer recommendation for apples" as follows, for preliminary use in orchards that are apparently in need of fertilization:

Nitrogen (N) 30 pounds, carried in 100 pounds nitrate and 150 pounds dried blood, or in 150 pounds ammonium sulphate.

Phosphoric acid $\left(\mathrm{P}_{2} \mathrm{O}_{5}\right) 50$ pounds, carried in 350 pounds acid phosphate, or in 200 pounds bone-meal, or in 300 pounds basic slag.

Potash $\left(\mathrm{K}_{2} \mathrm{O}\right) 25$ to 50 pounds, carried in 50 to 100 pounds muriate, or in 100 to 200 pounds of low-grade sulphate.

The amounts are for an acre of bearing trees; for young orchards, reduce these amounts in proportion to the area covered.

"This formula means that a fertilizer carrying about thirty pounds of actual nitrogen, fifty pounds of actual phosphoric acid $\left(\mathrm{P}_{2} \mathrm{O}_{5}\right)$, and twenty-five to fifty pounds of actual potash $\left(\mathrm{K}_{2} \mathrm{O}\right)$ should be applied on an acre of 
bearing trees. Where potash is not known to be lacking, the smaller amount may be used, or after a little testing it may even be omitted entirely. With the smaller amount of potash, the essentials of the present combination are carried in 500 pounds of a $6-10-5$ fertilizer or its equivalent. In the usual ready-mixed fertilizers, the nitrogen is likely to be carried in ammonium sulphate, with which some liming may be necessary if many applications are made, and especially if leguminous cover-crops or permanent covers are desired. In special or in home-made mixtures, the various elements may be carried in any of the materials indicated."

Other suggestions for apples and pears.- "When the stage is passed in which extended cropping between the trees is possible, and the burden of fruit becomes great," Wheeler advises, "special care should be taken to apply an abundance of potash and phosphoric acid annually, and only enough nitrogen from legumes or fertilizers to insure adequate foliage, satisfactory wood-growth, and abundant fruit-spurs. For this purpose a suitably compounded complete fertilizer may be employed. If legumes are found to supply enough nitrogen one may employ annually from 200 to 600 pounds an acre of acid phosphate or basic slag meal, and from 50 to 400 pounds an acre of the muriate or high-grade sulfate of potash. If the double manure salt is used as the source of potash instead of the muriate or the high-grade sulfate of potash, the total application should amount to approximately twice as much an acre, because of the lower potash-content of the latter.

"The nitrogen for the orchard may be supplied in one, or on light, open soils, in two applications of nitrate of soda at such a rate that the total application for a season will not exceed from 100 to 300 pounds an acre, dependent 
upon the slowness of the growth of the trees. It is usually much simpler to make a single application of a complete fertilizer in which the nitrogen is present in nitrates, ammonium salts, soluble organic compounds and in less quickly available organic forms than to apply nitrates at two or more different times. When such complete combinations are used the danger of loss by leaching is greatly lessened and a satisfactorily continuous but properly decreasing supply of nitrogen for the trees is assured. The fertilizer application should not be made later than just after the time the fruit has set. Many good authorities even advise waiting until this time in order to gage the application according to the probable yield and requirement of the trees."

As to lime, Wheeler states that "apple trees, as a rule, respond to liming rather better than pear trees; nevertheless, on very acid soils there are several good reasons for liming even pear trees. An occasional application of magnesian lime may be desirable, but if used it should be alternated with applications of purer lime."

A test plat for apples.- Stewart also gives advice for "determining the actual needs of an orchard," or for making a test:

"The general fertilizer formula just indicated (page 143) is for use only until the exact needs of the particular orchard can be determined. In other words, it is intended only to meet the immediate demands. If in the meantime one wishes really to answer the question of how to fertilize his own orchard, he can do so by following the plan outlined in the following table. This plan is especially adapted to the needs of commercial orchardists and to 'community' tests on the part of the smaller growers." This may require some work, but the results should be worth it. 
Plat 1.-Check (unfertilized). Pounds

Plat 2. -Nitrate...................... $21 / 2$

Dried blood...................... $31 / 2$

Acid phosphate.................. 10

Plat 3.-Nitrate....................... $21 / 2$

Dried blood...................... $31 \frac{1}{2}$

Potash.......................... 2

Plat 4.-Acid phosphate.................. 10

Potash....................... 2

Plat 5.-Check.

Plat 6.-Nitrate........................ $21 / 2$

Dried blood..................... $31 / 2$

Acid phosphate................... 10

Potash...................... 2

Plat 7.--Same as Plat 6, plus lime........... to 25

Plat 8.-Manure......................400

Plat 9.-Check.

"The quantities are pounds for a mature tree in bearing. "This test should be located in a typical part of the orchard, and should include not less than five average trees of the same variety and age, in each plat. All the trees should be labeled and carefully measured at a fixed point on the trunk, and definite records of their growth and yields should be kept for at least three years. Frequently good indications of the orchard's needs may be obtained in less time than this, but at least this time should be allowed and more should be used when necessary."

Peaches.-Wheeler says that "peach trees are less in need of lime than apple trees, yet liming is nevertheless often desirable, even for its indirect benefits. The fertilizer demands for peaches are much greater than for apples for the reason that the trees grow far more rapidly and bear early and abundant crops. On poor soils generous fertilization must be provided from the outset, but if the land is very rich or heavily manured, fertilizer may be omitted for the first year or two. If the soil is very poor, 
it should receive at the outset from 300 to 500 pounds an acre of a fertilizer containing a moderate amount of nitrogen derived from appropriate materials, a fair quantity of available phosphoric acid, and a generous amount of potash in muriate of potash. On soils in which potash is naturally very abundant, the supply can be greatly !essened.

"When the peach trees come into bearing, more nitrogen will be required than at the outset, and the total quantity of fertilizer may then be increased one-half, or even more than doubled. In the case of peach trees, constant watchfulness is required to make sure that neither too little nor too much nitrogen is used. An excess of nitrogen will prevent proper ripening of the fruit, and of the wood in the autumn, whereas too little will mean abbreviated crops, loss of vigor, and at the same time the lack will create conditions favorable to disease. In any case, ample supplies of phosphoric acid and of potash, as muriate, should be provided to meet any possible need. If a little extra nitrogen is required in the spring, it may be applied in nitrate of soda, or, if the soil is properly limed, sulfate of ammonia may be substituted for the nitrate of soda if desired."

Plums, apricots and cherries probably require about the same treatment as peaches except perhaps not so heavy, although sweet and sour cherries and plums are said to need much more liming.

Quinces are reported as responding to lime in about the same degree as cherries and plums.

Grapes.-Field experiments by the New York (Geneva) Experiment Station gave confusing and unsatisfactory results not only with commercial fertilizers but with stable 
and green manures. Hedrick sums up the work thus far (Bull. No. 381) as follows: "From the data obtained in these experiments it is evident that the fertilization of vineyards is so involved with other factors that only longcontinued work will give reliable results. From the work done, however, several suggestions may be made to grapegrowers:

"First, fertilizers cannot be profitably applied in vineyards poorly drained, suffering from winter freezes or spring frosts, or in which fungi or insects are uncontrolled, or where good care is lacking.

"Second, it is probable that most vineyards have a one-sided wear, there being few plantations indeed where more than one or two of the elements of fertility are lacking. Nitrogen is probably most frequently the element needed. Each grape-grower should try to discover which of the food elements his particular soil needs, if any.

"Third, maximum profits cannot be obtained in many vineyards of the Chautauqua belt because of the lack of uniformity in vineyard conditions. Grape-growers should strive by every means possible to secure an equally vigorous and healthy growth over the entire area cropped. "Fourth, the steps to be taken in restoring a failing vineyard are, in the usual order of importance, (1) give good drainage; (2) control insects and fungi; (3) improve the tillage and general care; (4) apply such fertilizers as may be found lacking."

Wheeler makes the following general statement: "Grapes may show some gain from the use of lime under certain circumstances, but they do not require it in even approximately the same degree as the cherry, plum, currant, and gooseberry. The chief need of this crop is available phosphoric acid and potash. If nitrogen is used, the 
quantity must be carefully regulated, and in Europe slowacting forms of organic nitrogen are in special favor. Basic slag meal or bone-meal may be used as sources of phosphoric acid when the grapes are set, but later, superphosphate is to be preferred, especially if it is not most thoroughly worked into the soil. Sulfate of potash is often considered preferable to the muriate of potash for grapes, for it is alleged to give a better quality of fruit."

Berry bushes respond readily to the fertilizer treatments applied to general field and garden crops. The roots are relatively shallow and therefore submit to surface tillage and applications, and the life of the plantation is short enough to allow of definite tests and also of rotation. Wheeler writes that "The blackberry is especially at home on very acid soils and a very light application of lime will meet all possible requirements of the plants, if indeed it is needed at all. The blackcap raspberry is more likely to be helped by liming than the blackberry, although it is well adapted to moderately acid soils. The Cuthbert raspberry is appreciably helped by liming on quite acid soils, and the same is probably true of most or all of the red and yellow varieties. The gooseberry and currant, including the white and various red varieties, are greatly benefited by liming. As much as two to four tons of ground limestone an acre, or its equivalent of slaked lime, are often very helpful to these plants. Raspberries, in particular, thrive well on a heavy, freshly rotted sod, as for example, on old grass land plowed the autumn before the plants are set. In many cases all that is required on such land is to supply an adequate mixture of an available phosphate and a potash salt, but whenever the cane-growth is weak and unsatisfactory, or, when gooseberries and currant bushes do not show satisfactory growth, a moderate 
amount of complete fertilizer containing a fair amount of nitrogen in gradually available forms is likely to be beneficial. The use of heavy applications of nitrogen for raspberries, currants and gooseberries is not advised, for it will induce too great a growth of canes and foliage and interfere with the maturing and ripening of the fruit. The plants will also be rendered more readily subject to mildew."

The cranberry, according to Wheeler, "thrives better at the outset, even on certain very acid soils, than after the acidity has been lessened by liming. If more nitrogen is needed than that naturally available from the humus of the bog, it is usually recommended that it be applied in small quantities, preferably in nitrate of soda, although it is possible that sulfate of ammonia may sometimes answer as well; and nitrate of potash may even be preferable to either. The chief need of the cranberry vine is usually phosphoric acid and potash. The phosphoric acid for top-dressing may be in superphosphate, but if applied just before the plants are set one may employ bone-meal, or, if on very acid peat or muck soil, even raw rock phosphate." When the soils are very wet, he warns against the use of nitrates, "owing to their ready reduction to nitrites, which may be poisonous."

"In case spring applications of fertilizer are made, it must not be expected that they will always affect the cranberry yield of that season so much as the yield of the crop which follows. Such applications should ordinarily be made after the water is drawn off and the land has dried out to a reasonable extent. Some growers advise applying the fertilizer just after the crop is harvested, but if nitrogenous fertilizers are used spring applications are better.

Strawberries give quick response to fertilizers, manures, mulches and tillage. They may be likened in these regards 
to annual crops. The special requirements, as given by Wheeler, are "moderately acid to very acid soils, and if lime is used the application should be light, rarely exceeding 1,000 to 2,000 pounds of ground limestone an acre.

"An important point to be recognized by strawberrygrowers is, that weak plants are not likely to be heavy bearers the next year. In consequence, the plants when set should be supplied with a fertilizer reasonably rich in available nitrogen. This fertilizer should usually be applied at the rate of 1,000 to 1,500 pounds an acre at the time of setting, and in the later years, just after picking the crop of fruit, fertilizer may be scattered in a furrow turned away from each side of the bed, after which the furrow may be turned back again. Early each spring fertilizer should be applied broadcast over the beds. This should contain liberal quantities of soluble phosphoric acid and potash but only enough nitrogen to promote reasonable growth. This nitrogen should, however, be largely in readily soluble and available forms. If too much nitrogen is used in the spring the fruit will lack color, and it may be soft and unsatisfactory, especially for distant shipment. It may even be necessary to omit all nitrogen in the spring, if the soil is exceptionally rich in humus or has been well manured previously. This can be decided only by the observant grower.

"On many soils, superphosphate is preferable to basic slag meal as a source of phosphoric acid for strawberries, for the reason that too much lime is to be avoided, and, furthermore, the phosphoric acid is largely soluble and better adapted to top-dressing. On an exceedingly acid soil the use of basic slag meal may be permissible for application at the time of setting, for the action of the soil aids in rendering it available to the plants." 
How to apply.-In general, fertilizer is broadcasted in fruit-plantations. In young orchards, it may be applied near the trees if they are to receive the immediate or chief benefit, although it should never be placed against or very close to the trunk. Sometimes it is applied in drills with potatoes or with other catch-crops. Usually it is preferable, however, to treat the entire area for the benefit of all the crops that are to be produced.

The fertilizer may be applied in autumn or in spring. Old trees do not receive the benefit of surface applications at once, and if the roots are deep and the soil retentive they may never receive much help from such applications. Wheeler states that "in some European countries the fertilizer for orchards is placed from 4 to 5 inches deep in holes 20 inches apart, at the rate of about an ounce and a quarter in each hole. This method is, however, probably too expensive to employ in this country, although it may be especially effective for orchards in sod. If the work were capable of being done by machinery or by some suitable implement the method might possibly prove of economic value." Materials that are rich in nitrogen should be applied cautiously, if at all, in autumn, at least before growth ceases, as it promotes late growth. There is likely, also, to be considerable loss of nitrogen.

The general unskilled farmer would better apply readymixed fertilizers. As the fruit-grower begins to understand his problem, however, and becomes discriminating, he will find himself buying the separate ingredients and applying them as he thinks best. 


\section{CHAPTER V}

\section{THE PLANTS AND THE PLANTING}

We now come to the concrete and interesting work of actually making the fruit-plantation. The subjects that one naturally considers when about to begin the planting of a fruit-area fall into five categories-the choice of the varieties, the securing of the trees or plants, the actual setting of the stock, the laying out of the area, and the records of the plantation. These matters may now be considered, the two last in the succeeding chapter.

\section{THE CHOICE OF VARIETIES}

The most personal problem connected with the actual making of a fruit-farm is the choice of varieties. This is the one subject about which most questions are likely to be asked, and also one on which little specific advice can be given in a book. The choice of varieties depends primarily on the personal preferences of the grower, the purpose for which the fruit is to be grown, and the locality. Without knowing these three elements, it is impossible for any person to give satisfactory direction as to varieties. The grower who has no personal preferences for varieties has not yet mastered the first essential to successful fruitgrowing,- - the setting for himself of a specific ideal. In the greater number of cases one may answer questions on what varieties to plant by asking the questioner what he wants to plant. He will commonly answer his own question fully. The intelligent question about varieties is that 
which asks for specific information; as, for example: What is the best red fall apple for southern Ohio? What is the earliest raspberry? What is the hardiest apricot? What is the largest plum? What is the best strawberry for caning? Such questions as these indicate that the questioner has classified his own ideas, and that he is driving straight to the point for information; and they are usually capable of rather definite answer.

A few general rules or precepts may be stated to aid the intending fruit-planter in the choice of varieties:

1. So far as possible, the planter should follow his personal preferences,- - the type of fruit he likes best or in which he takes most interest. These types or kinds are the ones with which he will be most likely to succeed, other things being equal.

2. He should develop a clear and specific conception of the purpose for which the fruit is to be grown,-whether for dessert, for canning, for a local market, for export, for evaporating, and the like. Then the varieties best suited to meet these desires may be looked up and chosen.

3. The planter should not covet a variety because it is eminently successful in another region. Varieties have distinct adaptations to geographical areas. If a given variety is a universal success in the plains regions, the probabilities are that it will not thrive equally well in New England. The farmers of the East have learned that they cannot compete with those of the West in the growing of wheat, and they should know that one region may not be able to compete with another in some particular variety of fruit, even though the variety thrive well in both. It is a question whether the northeastern states can compete with the mid-western states in the growing of the Ben 
Davis apple. The South and mid-South have been planted extensively to the Kieffer pear, largely because it thrives better over a large area than most other varieties. It is doubtful, then, whether it is wise to plant it extensively in the North, where other pears will thrive that do not succeed in the Kieffer region. Probably in every state or province certain varieties are considered to be especially adapted to certain regions, as the Rome Beauty apple to southern Ohio. Such adaptations should be considered. Any region should grow most freely that type of fruit which it can grow best and which other regions cannot grow so well. The lists of fruits recommended for different regions by the American Pomological Society are very suggestive in this regard.

4. The choice should consider the local conditions, as the adaptation of the variety to the particular climate, to the probable length of season, to distance from market, and to the system of husbandry. The adaptation of varieties to soils is an important consideration, and one that demands closer attention as cultivation becomes more intense and perfect; but the question is yet imperfectly understood, except perhaps with strawberries and few outstanding varieties of other fruits. As a rule, the finer the variety in quality, the less able it is to thrive equally well under diverse and particulariy under careless methods of treatment. It is partly for this reason that dessert fruits are commonly regarded as unreliable and difficult to grow. One can scarcely hope for success in the best horticulture unless he gives particular study to the adaptations of species and varieties to soils.

5. One should seek to determine the best varieties for a given purpose by experimenting, by diligent inquiry of neighbors, pomologists, nurserymen, marketmen, and by 
keeping in touch with discussions in societies, articles in the rural press, and publications of institutions.

6. To a certain extent, one may improve one's varieties by breeding, particularly in the fruits that bear early or young, as the berries, grapes, and even peaches and plums. If one does not care to go to the trouble of raising seedlings of known parentage, one should at least be on the lookout for interesting variations, and should exercise discrimination in the taking of cuttings and cions.

Self-sterile varieties.

Choice should be made also with reference to interpollination. It is known that some varieties of fruits are self-sterile,- - that is, they are not fruitful with their own

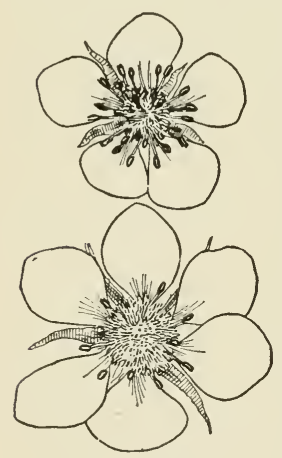

Fig. 25. Strawberry flowers modified by weather. pollen and when planted alone. This sterility may be due, as in the case of the strawberry, to imperfect (or unisexual) flowers, or, more commonly, to pollen that is impotent on the pistils of the same flower. This infertility or self-sterility is largely a varietal characteristic, yet it is no doubt modified by seasonal and environmental conditions. It is probable that varieties may sometimes be self-fertile and at other times self-sterile. The strawberry flowers in Fig. 25 show the marked influence on pollen-bearing that is exerted by different conditions. The flowers are of the same variety, and were grown under glass. The lower one shows the small development of stamens in a long cloudy spell, and the upper one the profusion of stamens that appeared in other flowers after a few 
days of sunshine. It is probable that pollen is more potent in some years than in others.

There is yet insufficient positive knowledge of the inter-pollination of fruits, and no subject connected with pomology is in greater need of further study. We know that many of the most productive orchards are of many varieties, and that some varieties sometimes refuse to fertilize themselves. The most positive knowledge on the impotency of pollen amongst our common fruits is in connection with the plums of the Wild Goose type, with sweet cherries, and with many grapes. The safest practice, in all fruits, is to plant only a few rows of any one variety together of fruits in which self-sterility is a frequent characteristic. The chief point to be observed in choosing the varieties is that they shall bloom together.

Strawberries often lack stamens altogether, while others have so few and so poor stamens that they are practically self-sterile. Ordinarily, there should be a row of a perfect-flowered variety for every two rows of a pistillate or infertile variety of strawberry.

Some kinds of red raspberries are only partially selffertile, and should therefore be grown in mixed plantations. Cuthbert is apparently strongly self-fertile and is probably a good pollinizer.

The early experiments in this subject by Waite and others gave the following lists of self-sterile and self-fertile fruits:

Pears.-Varieties more or less self-sterile.-Angouleme, Anjou, Bartlett, Boussock, Clairgeau, Clapp, Columbia, De la Chène, Doyenne Sieulle, Easter, Gansel. Bergamotte, Gray Doyenne, Howell, Idaho, Jones, Kieffer, Lawrence, Louise Bonne, Mount Vernon, Pound, Sheldon. Souvenir du Congres, Superfin, Wilder, Winter Nelis.

Varieties usually self-fertile.-Bosc, Brockworth, Buffum, Diel, 
Doyenne d'Alençon, Flemish Beauty, Heathcote, Le Conte, Manning Elizabeth, Seckel, Tyson, White Doyenne.

Apples.-Varietis more or less self-sterile.-Bellflower, Chenango (Strawberry), Gravenstein, Tompkins King, Northern Spy, Norton Melon, Primate, Rambo, Red Astrachan, Roxbury (Russet), Spitzenburg, Tolman (Sweet), Willow Twig, Winesap.

Varieties mostly self-fertile.-Baldwin, Ben Davis, Codlin, Fallawater, Rhode Island Greening, Oldenburg, Rall Janet, Red Astrachan, Smith Cider.

Plums.-Varieties more or less self-sterile.-Coe Golden Drop, French Prune, Italian Prune, Marianna, Miner, Ogon, Peach, Satsuma, Wild Goose and many cther native plums.

Varieties mostly self-fertile.-Burbank, Bradshaw, De Soto, Green Gage, Lombard, Robinson, Damsons.

"The quince seems to fruit nearly as well with its own pollen as with that of another variety."-Waite.

Grapes (Beach).-Unfruitful (or usually so) when planted by themselves.-Black Eagle, Brighton, Eumelan, Massasoit, Wilder, Gaertner, Merrimac, Requa, Aminia, Essex, Barry, Herbert, Salem. •

Able to set fruit of themselves.-Concord, Diamond, Niagara, Winchell or Green Mountain, Rogers' Nos. 13, 24, and 32, Agawam, Delaware.

Some of the self-sterile varieties mentioned have fruited well when planted with pollinizers as follows: Bartlett with Nelis, Flemish, Easter; Kieffer with Le Conte, Garber; Coe Golden Drop with French Prune, Fellenburg; Satsuma with Abundance, Burbank, Red June; Miner with De Soto, Forest Rose, Wild Goose; Wild Goose with De Soto, Newman, Miner.

Fletcher finds that self-sterility is the rule in Kieffer and Bartlett pears. For planting with Bartlett, the Anjou, Lawrence, Duchess and Kieffer were good pollinizers, although in some seasons Bartlett and Kieffer do not bloom simultaneously. For planting with Kieffer, the LeConte, Garber, Lawrence, Bartlett, Duchess, Anjou and Clairgeau 
were satisfactory, although in some years the bloom of some of these may not be simultaneous although it overlaps.

Grapes of the muscadine type are strongly self-sterile, having imperfect flowers. (Cf. Reimer and Detjen, Bull. No. 209, N. C. Exp. Sta.) Beach finds (Bull. No. 223, N.Y. Exp. Sta.) that varieties of grapes self-sterile or nearly so have shown about as little ability to fertilize other selfsterile sorts as they have to fertilize themselves; and also they have usually failed to fertilize self-fertile varieties. Indications were found, however, that the pollen in some instances is not altogether impotent, but that its own pistils are less congenial than those of some other varieties. Further investigation is needed to learn whether this selfsterility is because the pollen is deficient in amount, is not well developed, or is uncongenial to its own variety.

For Oregon conditions, Lewis and Vincent have found (Bull. No. 104) gains in size of fruit of self-fertile apples to result from crossing, as well as marked benefits from crossing self-sterile kinds. Of eighty-seven varieties of apples under test, fifty-nine varieties were found to be self-sterile, fifteen varieties self-fertile, and thirteen varieties partially self-fertile. "Many varieties of apples naturally tend to be self-sterile, when limited to their own pollen. Results indicate that cross-pollination is the rule and self-pollination the exception. In some instances the immediate effects of pollen on the color of the fruit were perceptible. With an increase in the weight of the crossed apple, there was a proportional increase in the weight of the seeds. The action of foreign pollen on the Yellow Newtown, a self-fertile variety, was very pronounced. Many of the self-fertile varieties of apples, when self-pollinated, were found to be seedless, or devoid of plump seeds. Wind is a poor agent in transferring pollen from tree to tree. 
Bees and insects appear to be the principal pollen distributers. Climatic conditions influence, to a certain degree, the relative blooming periods of the different kinds of fruits. In frosty localities, varieties can be selected with reference to their time of blooming, thus partially eliminating the difficulty of a failure of fruit. We found that pollen was capable of maintaining its viability for three weeks, provided it was not allowed to ferment. The length of time different kinds of fruit remain in blossom at this station are as follows: Apples thirteen days, pears eleven days, and cherries ten days."

In a conclusive study, Gardener has found that all Oregon varieties of sweet cherries are self-sterile, although in all cases the pollen germinates in nutrient solutions. $\mathrm{He}$ also found that many varieties are inter-sterile; thus, Bing, Lambert and Napoleon planted together with no other variety are all sterile, although Black Republican and Black Tartarian will fertilize each of them. Sour cherries do not seem to be self-sterile so far as preliminary studies in New York indicate.

It is not yet known how constant in different regions or under unlike conditions are the attributes of self-fertility and self-sterility in varieties of fruits, or how much of the barrenness of orchards may be due to impotency of pollen. Some cases of barrenness attributed to this cause may be due to other and unrecognized deficiencies. Some of it is attributable to frost or wind at blooming time, to neglect and other causes. It is certain, however, that impotency or inefficiency of pollen is one of the prime factors in fruit failures, and it should be taken into account in all orchard plans by avoiding solid blocks of varieties. It is safer to plant not more than five or six rows of one variety together unless the variety is known to be abundantly self-fertile. 
Scoring the varieties.

If the grower puts the points of excellence in tabular or organized form, he may then scale or score the merits or demerits of a given variety; he may need to inquire of those who are well acquainted with the variety, if he does not have personal knowledge of it, before he is able to score or grade it intelligently. Sears has made a useful scorecard (Agric. of Mass., 1909, p. 44) for commercial apples:

Score-Card for a Commercial Variety of Apples

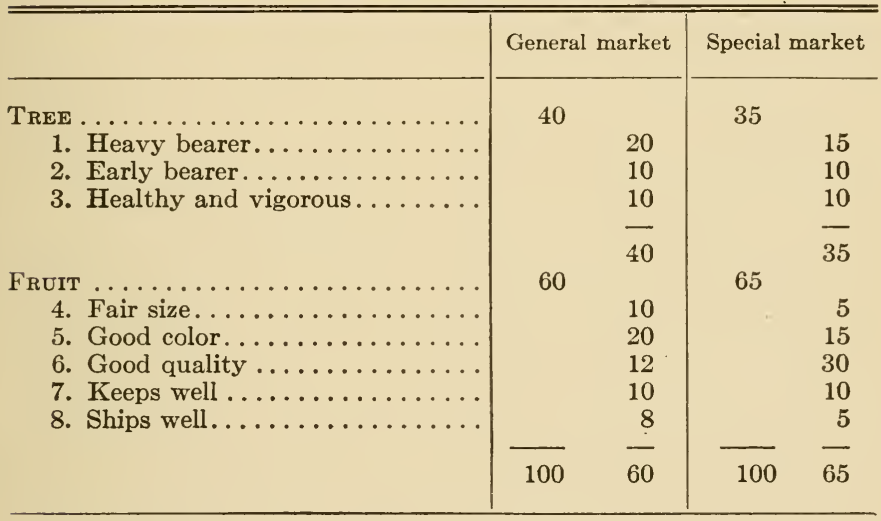

Applying score-card points to apples for Massachusetts, Sears makes tables contrasting the desirable and the undesirable, four of which are given by way of illustration:

\section{BALDWIN}

Good points:

1. Well known.

2. Long-lived tree.

3. Good bearer.

4. Uniform grade of fruit.

5. Good color.
Bad points:

1. Rather slow in coming into bearing.

2. Overbears in alternate years.

3. Not high quality.

4. Cankers. 


\section{Rhode Island Greening}

Good points:

1. Well known.

2. Productive.

3. Good quality.

4. Fine cooker.
Bad points:

1. Sometimes scalds in storage.

2. Color.

3. Scabs.

4. Not so hardy as Baldwin.

\section{Wealthy}

Good points:

1. Bears very early.

2. Hardy tree.

3. Good quality.

4. Uniform grade.

5. Good color.
Bad points:

1. Drops badly.

2. Ripens unevenly.

\section{Gravenstein}

Good points:

1. Fine quality, cooking and eating.

2. Handsome appearance.

3. Tree needs little pruning.

4. Well known.
Bad points:

1. Shy or biennial bearer.

2. Winter-kills.

3. Collar rot, rank grower.

4. Fades in storage.

5. Sun-scald and canker.

How did the varieties of fruits originate?

Systematic breeding has not yet made very extensive contributions to fruit-culture, although many interesting experiments are now maturing. The importance of being on the lookout for choice chance seedlings is as great as ever. It may be well to consider how the existing varieties of fruits have come into our practice.

It seems to be next to impossible to enlighten the public mind on this question, for whatever detailed explanation one may give seems to leave the questioner still unsatisfied and perhaps uninformed. The real cause of this dissatisfaction is that persons assume that there is something mysterious about the process of the origi- 
nation of varieties; and so long as the mind makes a mystery of a subject it is impossible to elucidate the subject. We have also been taught that like produces like, and therefore that any unlikeness between two plants-as between the parent and its offspring-calls for instant explanation. The fact is, that it is not in the nature of domestic productions for like to produce like, but rather for similar to produce similar. That is, there are certain type or family characteristics that pass over to the offspring, but there are normally very many unlikenesses in the details. Apples give rise to apples, and sometimes there is a closer reproduction of the parent in tribes like the Fameuse apples and the Crawford peaches; but there is seldom or never an exact duplication of parental features. Considering that this is the rule in nature, the wonder is that plants should ever reproduce the variety with approximate exactness. In other words, rigidity of generation may be the thing to be explained rather than the elasticity of it. In kitchen-garden vegetables this rigidity has come about, but it is the direct result of a long effort at selection and breeding until the elasticity of the type has been largely bred out. In the vegetables, invariableness has been bred.

Those persons who are always wondering how the varieties of fruits have come should consult the records. History is capable of enlightening them. If the origins are traced, it will be found that in the greatest number of cases the variety was simply discovered, and that some one began to propagate it because he thought it to be good. A tree springs up along a roadside, in the fence-row, back of the barn, in a thicket, and bears acceptable fruit. It is the product of a chance seed dropped by a bird or thrown there by an urchin. A thousand, perhaps ten thousand, seeds 
produce trees that bear poor or indifferent products when only one bears superior fruit. This one good tree is cherished, and all the others are forgotten, or perhaps are never seen; and then we wonder why so many more good varieties originate in the half-wild places than in the garden. It is only because more seeds have been sown there, and as we do not covet the ground, the failures pass unnoticed. If we should secure the same results in the garden by the sowing of only half the number of seeds, we should consider the experiment to be a costly one. It is probable that a seed will produce the same character of fruit, whether the tree springs up in a fence-row or in the garden; and the half-wild areas are, therefore, most useful and prolific places in which to allow nature to carry out her various kinds of plant-breeding. And if man has been willing to be relieved of all effort in the matter, it is fair to assume that he will long continue of the same mind, and that this exploration for new varieties will be a passion of the adventurer until every copse and tangle has been razed into cultivated fields.

It is not the province of the present book to discuss the fundamental reasons why plants vary and new forms arise. These reasons are obscure at best, but the greater part of them are probably not past finding out. It is enough for this occasion to say that nearly all the varieties of fruits were seedlings found in some waste place, or in a nursery row or a garden; and they were propagated.

\section{THE SECURING OF THE PLANTS}

It is first necessary, in choosing the plants for fruitgrounds, to determine what first-class stock is. The nurseryman contends that he grows the varieties that the 
planters want-those for which there is a demand. In fact, however, he largely forces the demand by magnifying the value of varieties that are good growers in the nursery. The nurseryman's business ends with the growing of the young tree, and the tree that makes the straightest, most rapid and cleanest growth is the one that finds the readiest sale. But it by no means follows that the variety which is the cheapest and best for the nurseryman to grow is the best for the fruit-grower to plant. Probably every apple-grower is now ready to admit that the Baldwin has been too much planted, while Canada Red and various other varieties that are poor growers in the nursery-row have been too little planted.

The blame for this condition of things does not rest wholly with the nurseryman. The difficulty lies in the fact that our conception, and, consequently our definition, of what constitutes a first-class tree is at variance with the truth. We conceive a first-class nursery tree to be one that grows straight and smooth, tall and stocky, whereas we know that very many-perhaps half-the varieties of apples and pears and plums will not grow that way. In order to make our conception true, we grow those varieties that satisfy the definition, and, as a result, there is a constant tendency to eliminate from our lists some of the best and most profitable varieties.

All this could be remedied if growers were to be taught that varieties of fruit-trees may be just as different and distinct in habit of growth as they are in kind of fruit, and that a first-class tree is a well-grown specimen that has the characteristics of the variety. A tree may be first-class and yet be crooked and slender, if it is the habit of the particular variety to grow that way. The emphasis should be placed on health and vigor, and not on mere shape and 
comeliness. Why may not a nurseryman give a list of varieties that are comely growers, and another list of those that are wayward growers?

It is usually best to buy first-class trees,-those of medium size for their age, vigorous, shapely in body and head, stocky, with clean trunks and abundant roots, not stunted, that are free of borers and other injuries, and, in the case of budded trees, those in which the union is very near the ground; and the tree should show the natural characteristics of the variety. It is important, also, that trees of apples and pears have several good limbs that do not arise close to each other; for the main scaffold limbs of a mature tree should be some distance apart to avoid splitting. In dwarf pears, especially, it is important that the stock, to be first-class, shall be budded very low. It is often thought that large size is of itself a great merit in a nursery tree, but this is an error. Vigor, cleanness, stockiness, firm hard growth, are much more important than bigness. The toughest and best trees are usually those of medium size. The very small extra expense incurred in buying the best trees is commonly a good investment. It is often said that second-class trees may be chosen with good roots and that the grower can form the top to suit himself. This requires more time and care, and is very doubtful economy; and, moreover, one is likely to lose in uniformity, which is an important feature in an orchard. In an acre of apple trees, the difference in cost of first-class over second-class trees may not be more than a dollar or two, but the difference in results is often great.

The age of plants at purchase must be governed by circumstances and by species. The general tendency is to buy trees too old rather than too young. When varie- 
ties are new and scarce, it may be economy to buy very young stock. Some of the freer-growing apples and pears are large enough when two years old, if grown from buds; but these fruits are usually set at three years from the bud or graft. Dwarf pears may be set at two or three years, preferably at the former age. Quinces are set at two and three years. Peaches are set at one year from the bud; plums and cherries at two and three years. Strawberries are set only from new plants (that is, those that have not borne); gooseberries and currants preferably from two-year stock; raspberries and blackberries from stock not more than one season old; grapes one and two years, preferably the latter.

One does not save time, in serious orchard work, by buying very large and old trees. It is best to depend on the standard sizes and ages of good commercial stock.

Dwarfs vs. standards.

Whether standard or dwarf trees are the better to plant, is a personal problem, and cannot be answered for another any more than the question as to whether peaches are more desirable than plums. Dwarf apples and dwarf pears are of a different type of fruitgrowing from the standards, or free stocks, and the intending grower must weigh the evidence for and against as best he can. As a general thing, the standards are the safer and more reliable; but persons who are willing and competent to give the extra care that dwarfs need, who have the proper location, and who have access to extra-good markets, may often grow the dwarfs with profit.

The growing of dwarfs is a special practice. The only fruits that have regular commercial standing in this 
country as dwarfs are pears. The pear is dwarfed by working it on quince stock. Usually, dwarf pears are not profitable. The apple is dwarfed by working it on apple trees of small stature, as on the doucin and paradise races; these races are of themselves bushes or only very small trees. There are no other well-recognized dwarf fruits, although the cherry is more or less dwarfed by working it on the mahaleb, and the plum by working it on the peach.

The general fruit-grower would better avoid the planting of dwarfs for commercial purposes. They require more care, are subject to more difficulties and hindrances. It is only when they receive extra attention in pruning and otherwise that they succeed. They may be used as fillers in standard orchards, but this is doubtful policy. It is better to grow them by themselves, where they can receive the care that they need. They may not bear profitably much in advance of standards.

Dwarf apples are interesting and excellent for the home garden, where one wants a good range of choice varieties in small space. The extra attention that they receive in spraying, pruning, thinning and otherwise, produces fruit of excellent size and form. The yield to the acre is not large for the capital and labor invested. One cannot afford to grow barrel apples on dwarfs, but only the choice and exceptional varieties.

\section{Pedigree plants.}

It is probable that trees sometimes fail to bear because propagated from unproductive trees. We know that no two trees in any orchard are alike, either in the amount of fruit they bear or in their vigor and habit of growth. Some are uniformly productive, 
and some are uniformly unproductive. We know, also, that cions or buds tend to reproduce the permanent characters of the tree from which they are taken. A gardener would never think of taking cuttings from a rose bush or a chrysanthemum or a carnation that does not bear flowers. Why should a fruit-grower take cions from a tree that he knows to be uniformly unprofitable?

Much of the variation in fruit plants is associated with temporary, local or fortuitous conditions, - as the character of the land in the spot where the plant stands, the exposure, injuries it may have received; such modifications are probably not perpetuated in the cions. Trees propagated from heavy-bearing parents cannot be expected to give good results if they are grown under neglect; and undoubtedly trees grafted from unproductive parents may be made to outyield their ancestry if given exceptional care. And yet it is reasonable to expect that parentage counts even in bud-propagation. The question is difficult of determination because many factors enter into it and every generation of plants is grown under its own conditions. Other things being equal, pedigree stock is to be preferred; but there always remains the question as to whether the pedigree means anything in any particular case.

Stocks.

The tree-fruits are multiplied by grafting and budding. The tree (or root) on which they are grafted is the stock.

In most of the fruits, one may have a choice of stocks, and this requires some knowledge of them. In the purchase of nursery trees, however, one does not know the particular stock, and the goods are commonly purchased without reservation or requirement. In practice, planters 
concern themselves very little with the kind of stocks on which their trees are worked.

The stock, because of its naturally small stature, may dwarf the tree (see page 168); some stocks are particularly adapted to given soils; others escape certain injuries; others make poor or short-lived union with the cion or top.

The apple is budded or grafted on French crabs, which are apple seedlings imported from Europe, or on seedlings grown from American cider-mill seeds. The American stocks are raised mostly in the Middle West, and are often preferred to the foreign stocks, but most nurserymen seem to prefer the imported stocks. If it is desired that the apple trees shall be dwarf, they are worked on stocks that themselves never make large trees, as the doucin and paradise types; these stocks are imported from Europe.

In severe northern climates, apples are worked on seedlings of Russian apples, and also on Siberian crab.

Pears are grown on imported French seedlings. The supply of pear seed is so limited in this country that growing the seedlings on an adequate scale cannot be attempted; and the risk from pear-blight is also too great.

The peach is adapted to a variety of stocks. It is preferable to have peach on peach stocks, in most cases; but the peach root is specially liable to root-knot far south and another stock may be necessary in that case, and plum may be used,- the Marianna probably being best for light lands. The myrobalan plum is used for peach stock, but has a dwarfing effect, and it is not suited to all varieties. There is a choice even of peach stocks, it being considered that seedlings from southern pits are better than those from the northern canneries. 
Plums may be worked on peach for light soils. There are several kinds of plums used as stocks, and there is much difference of opinion as to their merits. Seedlings of the common orchard plum are probably to be preferred, except that the varieties of native plums should be grown on native or wild stock. The myrobalan is much used, but is probably inferior. French stocks of the St. Julien type are also imported to some extent.

There are two prevailing cherry stocks, the mazzard and mahaleb. The latter is much used by nurserymen because of its cheapness and ease of working, but it is inferior. Sour cherries are likely to be very unsatisfactory on mahaleb. The native dwarf or sand cherry is used to some extent in the northern plains region as a very hardy stock; it also has a dwarfing effect.

There has been little critical study of the hardiness of the different stocks. Chandler, however, reports that "roots of the French crab used as a stock seem to be more tender than roots which come from cions of an average variety of apple. Marianna plum roots are certainly more hardy than myrobalan roots, and mahaleb cherry roots seem slightly more hardy than mazzard roots."

Stock for top-working.

If one is to plant hardy stocks and then work them over with selected cions, he should usually plan to graft or bud them after they have stood in the orchard one year. Good results sometimes follow grafting in the very year in which the stock is set, but this is the exception.

Some persons have proposed to sow seeds in the very spot where the trees are to stand, and thereby to raise stocks for top-working without transplanting them; but the labor and uncertainty of the method make it imprac- 
ticable. It is cheaper to grow trees in the nursery-rowthe same as it is cheaper to buy trees of a nurseryman than to attempt to grow them-and the trees also receive better care. Again, seedlings vary, and the poor and weak ones should be discarded the same as they are discarded by the budder in the nursery-row who finds them to be too small or too scrawny to bud. Well-grown stock of a strong-growing variety usually gives more uniform results than a lot of home-grown seedlings.

Stocks for reworking are sometimes employed for the purpose of securing straight and strong bodies for weak and poor growers, as for the Canada Red and Jefferis apples. Any straight, vigorous, free-growing, hardy stock may be chosen. In the northeastern states, Northern Spy is much used for this purpose.

Buying the trees.

It is best, when it can be done, to order trees late in summer or early in autumn. Buy where the best trees can be obtained, and where there is good reason to expect reliable stock and honest dealing. It is usually advisable to buy at the nearest nursery at which the desired stock can be secured, for the buyer has more personal knowledge of the nurseryman, he can visit the nursery, he saves freight, and he may be able to secure his stock in fresher condition; but trees of equal excellence thrive equally well when transported from long distances, if they arrive at their destination in equally good condition. Southerngrown stock gives good results in the North if it is strong, healthy and well-matured.

Nursery stock should never be purchased simply because it is cheap. Poor stock is dear as a gift. Yet farmers who annually plant a few trees and who buy of agents, 
often pay exorbitant prices. In a certain town, when farmers were paying 28 cents each for peach trees in lots of a dozen, any reliable nursery would have been glad to have supplied the same varieties at $\$ 18$ a hundred, at the nursery. Plums that should have sold for 15 cents to 20 cents each were selling to farmers for 50 and 60 cents. The man who expects to plant an orchard for profit will not be led by agents into any glowing scheme or into the purchase of wonderful varieties. He will usually buy directly of the nearest nurseryman who can supply the desired stock and varieties at the prices that suit him. Some nurserymen employ regular and reliable agents, and such agents carry a certificate from the firm they represent. But while these salesmen may be perfectly straightforward, and may be the best channels through whom small orders can be secured by those who are uninformed in pomological matters, all persons who expect to go into fruit-growing seriously should buy directly of the nurseries. Yet we must remember that the tree agent has been one of the means of clothing the country with fruit trees, and thereby of adding much to the contentment of farm life.

The buyer should make up his mind just what varieties he wants, and then find the nursery that has them, and order early enough to get them. There is then no occasion to consider the vexed question of substitution of varieties. If the varieties are not in market, buy stocks of some strong-growing staple variety, and after these are established-usually the spring or summer of the next yearbud or graft the tops to the desired varieties.

It is better to have the stock delivered in autumn and plant it or heel it in over winter than to trust to the uncertainties of spring delivery and the disadvantages of cellared stock. 


\section{THE SETTING OF THE PLANTS}

Fruit plants sometimes live and thrive under very careless handwork in setting, but these cases are exceptions and due to unusually favorable seasons or soil conditions, and they are not to serve as guides to practice. The only recommendable procedure is one of care-taking at every stage of the work.

\section{When to plant.}

There is much difference of opinion as to the relative merits of fall and spring planting. The writer's opinion is that fall planting is generally preferable to spring planting on thoroughly drained and settled lands, particularly for the hardy tree-fruits, like apples, pears and plums; and if the ground is in good condition and the stock well matured, peaches may sometimes be set in October, even in the northern states, with success. The advantages of fall planting are several. The trees become established in the open weather of autumn, and they usually make a start in spring before the ground is hard enough to allow of spring planting. This early start means not only a better growth the first season, but, what is more important, trees that get a very early hold endure the droughts of midsummer much better than trees planted in spring. Planting is nearly always better done in the settled weather and workable soil of autumn than in the capricious days and in the hurry of springtime; and the orchardist is free to begin cultivation at a time when he would otherwise be planting his trees. Again, it is commonly better to buy trees in the fall, when the stock of varieties is full and when the best trees are yet unsold; these trees must be kept until planting time, and it is about as cheap and fully as safe 
to plant them directly in the field as to heel them in until spring.

In fall planting, however, the trees must be thoroughly well matured. In order to move stock quickly, it is the practice of some nurserymen to "strip" the trees before the growth is completed; that is, the leaves are taken off, the growth stopped, and the trees are put on the market for September deliveries. This process weakens the trees, and many failures in young plantations are probably attributable to this cause. Such trees may die outright, especially if set in the fall and a hard winter follows; or they may live to make a dwindling growth for the first few years. Like early-weaned calves, they lack vitality and push. If one were setting an orchard in autumn, one should place the order for trees in August or September, if possible, with the express stipulation that the trees should stand in the nursery-rows until the leaves begin to die and fall. In the meantime, the land should be fitted and the holes dug, so that when the trees arrive they may go directly into their places without delay or without the expense of heeling them in. Trees are mature enough to dig late in September or early in October in the northern states, depending on the season, soil and variety. When the tree is fully mature, some of the leaves will still hold on the vigorous shoots, and these are stripped off; but this stripping does no harm, for the young growth is then mature and it has a thick, strong, brown appearance very different from the slender, soft and green branches of early-stripped trees.

There are many good planters who consider fall planting hazardous, especially in the North. It is true that unless the conditions are right, spring planting is the safer course; and farmers who have many fall crops to 
harvest will also probably find more time for trea-setting in the spring.

If trees are secured in autumn for spring planting, they should be heeled-in on well-drained land and preferably where the snow will not blow off. They may be stood upright in furrows, or laid down (Fig. 26, adapted from Blake), the latter preferred. Open the bundles and place

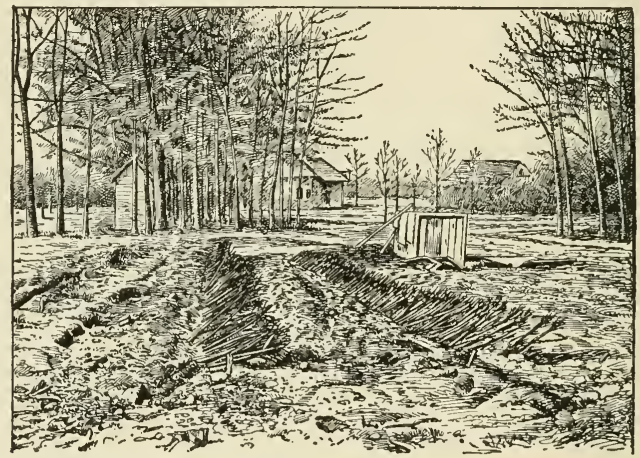

Fig. 26. Peach trees pruned and heeled-in.

each tree by itself, so that the earth will lie on all sides of the root. Pack the earth. It is well to cover the earth with straw or bedding; but watch must be kept that mice are not attracted by this material, for they are likely to gnaw the trees.

\section{Distance apart.}

Fruit plants are oftener set too close together than too far apart; in fact, the latter error scarcely exists. Trees, especially, are wide feeders, and the best results are secured when each tree stands far enough from its neighbors to allow it to possess an individuality all its 
own. An additional reason for sparse planting has lately become important,- the necessity of spraying for insect and fungous pests; and for this reason, as well as to allow of better tillage, the outside rows should not be set close to fences. The distance at which trees may be set depends much on the system of pruning. If heading-in is followed vigorously and systematically, trees may be set a third nearer than if allowed to take their natural form. Heading-in should always be practised with dwarf trees, and many of our best growers pursue it regularly with peaches, plums and quinces. Wide planting is the safer rule for the generality of cases. The following table may be supposed to represent the outside average limit for the planting of fruits in the northeastern states, when the plants are allowed to take their natural form:

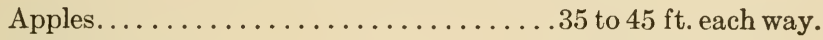

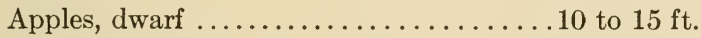

Pears, standard ................20 to $25 \mathrm{ft}$.

Pears, dwarf... ............. $12 \mathrm{ft}$. to 1 rod.

Quinces ........................ 1 rod.

Peaches and nectarines $\ldots \ldots \ldots \ldots \ldots 20 \mathrm{ft}$.

Plums ......................20 ft.

Apricots ................... $20 \mathrm{ft}$.

Cherries, sour ...............20 ft.

Cherries, sweet............... $30 \mathrm{ft}$.

Figs ............................. to $25 \mathrm{ft}$.

Pecans .....................40 ft.

Grapes......................

Currants ....................

Blackberries .....................

Raspberries ...................

Strawberries .................

Cranberries ................. or $2 \mathrm{ft}$. apart each

These are safe distances. In certain cases, however, when the soil is strong and the grower makes thorough 
work of tilling, pruning and fertilizing, these distances may be reduced somewhat with profit, except, perhaps, in the case of apples.

Double-planting; fillers.

These remarks on the proper distances call for discussion of the question as to whether it is good policy to plant shorter-lived trees, as peaches, between apples and pears.

The trees will thrive under such planting; but whether it is advisable depends on the man and the economic situation. In general, it should be discouraged; but if the orchardist gives the very best attention to fertilizing and cultivating, plantations may be mixed with good results (as in Fig. 27). It is usually best to plant each species

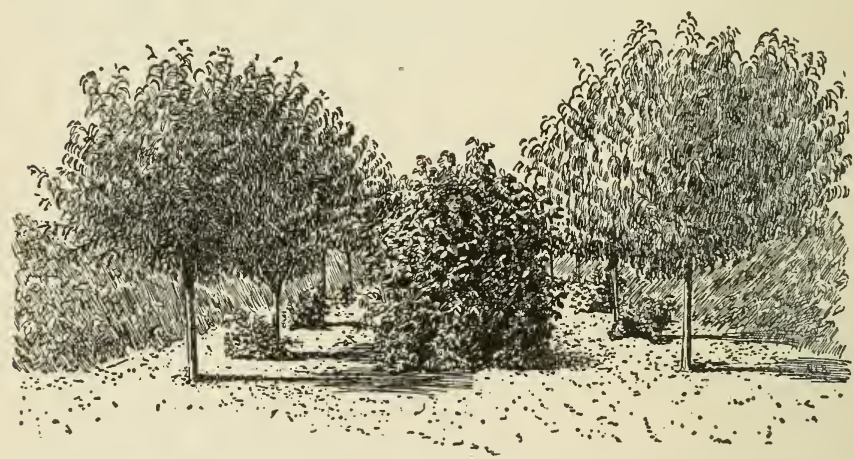

Fig. 27. Double-planting.-Bush-fruits between orchard trees.

by itself, that it may receive its own treatment, as peaches in a peach orchard, apples in an apple orchard, and quinces in a quince orchard.

Another form of double-planting, now much in the public mind, is to place early-fruiting varieties of the 
same fruit between the regular rows, with the idea of securing a quicker return. These "fillers" are to be removied as soon as the regular plantation requires the room. For this purpose, Wagener or Ben Davis apples may be planted as fillers in an orchard of Baldwins, Spys or Greenings. This means more care and expense in tillage and other attention, and more fertilizing. If the party is an intensive fruitgrower, the effort may pay; but it is a special practice and it always carries the burden of proof. The price of land and labor is an important factor. It will probably pay best when land is limited or highpriced. It may be better,

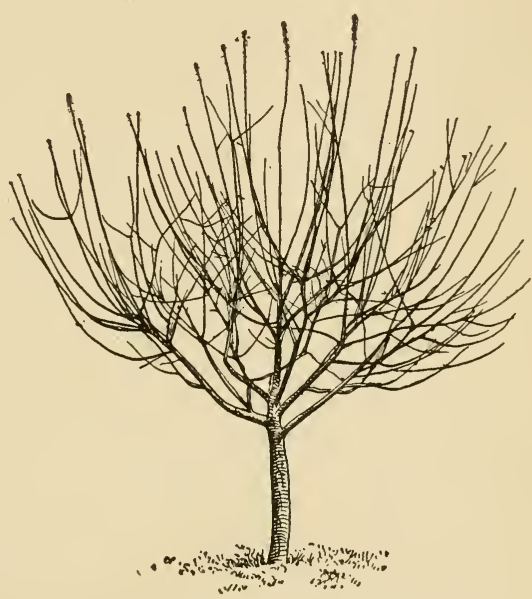

Fig. 28. A well-shaped tree. This tree was grown in an orchard without fillers. Compare with Fig. 29.

in a given case, to cover more land and expect less yield to the acre. Only the best cultivators, with sufficient help and equipment, should attempt double-planting of fruit trees; and these are the persons, also, who will see that the fillers are removed at the proper time.

"Many of the Connecticut fruit-growers," says Jarvis (Bull. No.62), "have the necessary intelligence and courage to handle successfully an orchard on the filler system. But there are undoubtedly some who, for the sake of earlier returns, are likely to favor the fillers at the expense of the permanent trees and for the sake of getting one or two 
additional crops, are likely to injure seriously the shape of the trees of the main planting (Figs. 28 and 29). The growers of the latter class are advised to set their trees at moderate distances and to grow among them

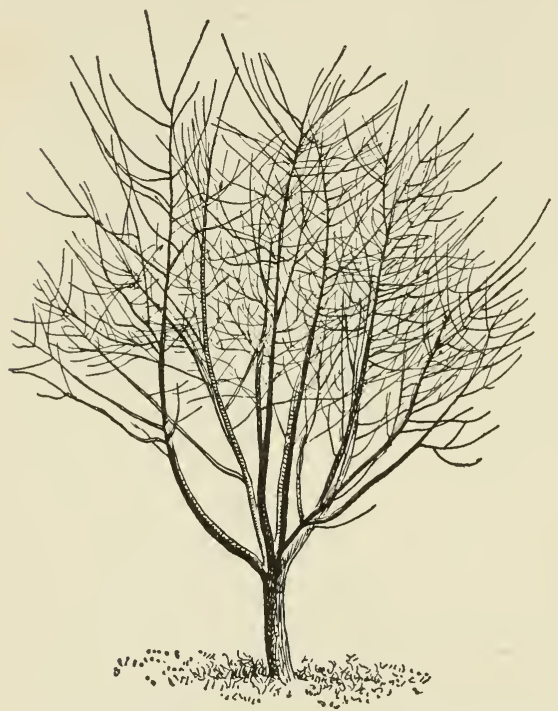

Fig. 29. A thirteen-year-old apple tree injured by leaving fillers in the orchard too long. Observe the long, slender, upright branches.

some kind of crop such as potatoes, corn or vegetables that require cultivation during the early part of the summer. Even then, there is danger of growing these crops too near the trees and of not supplying the necessary plant-food to make up for that removed from the soil by the secondary crop."

Speaking for Washington State conditions, Thornber writes: "Whether or not it is advisable to use fillers in an orchard depends entirely upon the ability of the planter to remove them before they do serious if not permanent injury to the trees. Fillers never do any damage in an orchard until they begin to contend with the permanent trees for food, moisture, sunlight or space. This being true, it is possible to grow fillers in an orchard for several years and do no injury, and at the same time harvest good crops of fruit that will help maintain the necessary 
expenses. Many growers have been able to pay for their land and all expenses of caring for the orchard by means of the fruit from the fillers before the permanent trees came into full bearing." Thornber diagrams "a good planting plan" (Fig. 30) in which the fillers are placed in the rows and also between the rows.

Of course some of the small-fruits may be planted in

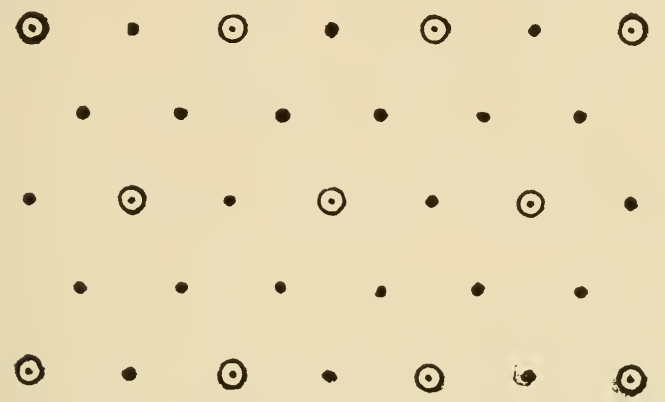

FIG. 30. The placing of fillers (represented by dots) between the permanent trees.

orchards with the very best results. Strawberries are practically an annual plant, and are much better for orchards than is any kind of a sowed crop. This, however, belongs with the cropping-scheme for orchards rather than with the subject of fillers.

How to plant.

Plow the land and fit it well. As all orchards should be put into tilled crops for at least the first two years after planting, it will usually be found advisable to plow the entire area before the place is set, rather than to plow strips where the trees or plants are to go, for the land can then be better shaped with reference to surface drainage and general convenience. 
Trees should be set neither in dead-furrows nor on back-furrows. Level culture should be adopted from the start, unless it is known to be necessary to displace surface water; and in that case it may be questioned whether the land is fit for fruit plants. In all ordinary lands, holes are dug by hand for the tree-fruits. Plowing out a deep furrow in the line of the rows may lessen the digging and aid in getting the trees in line. Peaches on light lands are often set in furrows made for the purpose.

The hole should be broad and ample; and the harder the soil the larger ought the hole to be, for in that case the loose dirt that is filled in must give the tree its start. In loose and deep soils, the hole need be no larger than the spread of the roots. Chop up the earth in the bottom of the hole, or throw in a few shovelfuls of loose surface earth.

No hardpan should be left immediately under the tree. It should be broken by heavy tools or blown out with dynamite (page 82).

Trees should be set an inch or two deeper than they stood in the nursery, for the loose earth will settle and wash away in the course of the season, even if it is well packed when the trees are set. Dwarf pears should be set 3 to 6 inches deeper than the bud. The roots are trimmed, as explained farther on.

Every care must be exercised to get the soil thoroughly firmed in about the roots-which are straightened out in approximately their natural position-and especially under the crown or fork of the roots, in order that no airspaces may be left to dry out. This dirt can be best placed by fingering it in, moving the tree gently up and down at the same time. Once or twice in the progress of filling the hole, the earth should be stamped down. Fill the hole to 
a little more than level full if there is danger from surface water, but be careful that no hollows are left close about the tree into which water can settle, especially when planting in autumn. Stamp or pack the earth firmly about the tree before leaving it, for the double purpose of securing moisture and of holding the tree against winds. Small stuff, like nursery stock and small-fruit plants, may often be well planted by means of a dibber or spud. All this operation of planting can proceed to perfection only when the earth is dry enough to crumble. Stock should not be planted in wet and sticky soil.

If trees are set according to these directions, and the tops are cut back as explained farther on, there will rarely be any necessity for staking and tying the trees to keep them plumb.

Mulches of straw or manure are sometimes advised for newly set trees. For trees planted late in spring and in droughty lands, a light mulch about the tree may be advised; but in other cases it is not necessary. If mulches are applied to fall-planted trees, care must be taken to tramp them down well, or they may become a nestingplace for mice, which may girdle the trees. There are those who favor placing a forkful of manure in the bottom of the hole, but this is a practice of doubtful value; and, at all events, the manure should be well mixed with the soil to prevent drying out. There is often discussion as to whether it is desirable to place the mulch on the surface or to place it an inch or two below the surface and cover it with earth. No positive assertion can be made for either method, although, of the two, the former is probably more generally advisable. But a mulch of tilled earth is more desirable than one of straw or manure in general fruit-planting. 
Puddling the roots is a good practice when trees are to be shipped any distance or when they are likely to be unduly exposed, and it is a common practice among nurserymen. The operation consists in sousing the roots in a thin mud or paste of clay.

\section{Trimming the trees.}

There is much difference of opinion as to the best way of trimming trees when they are planted. So far as the root is concerned, it is advisable, in the North, to cut away only those roots that are broken or badly torn. These should be cut off just back of the injury. It is the custom to cut off the ends of all roots of the size of a lead-pencil or larger, for a clean smooth wound is supposed to heal more quickly than a ragged one, although the experiments at the Woburn Experimental Farms (England) showed that bruises and rough ends healed very rapidly (Ninth Rept., 1908). When the tree is planted, all the roots should be straightened out to nearly or quite their normal position. If it is found that one or two roots run off to an inordinate length, they may be cut back to correspond somewhat with the main root-system.

Perhaps half the root-system of the young tree is left in the ground when it is dug. It is therefore evident that the top should be cut back to a corresponding extent. In fact, the top should be more severely shortened-in than the root, because the root, in addition to being reduced, is also dislodged from the soil, with which it must establish a new connection before it can resume the normal activities. Trees that carry too much top when planted may fail to grow outright; or if they start, they are likely to be overtaken by the droughts of summer. Even if they live, the growth is usually small and uncertain, and the 
tree may fall a prey to borers or a victim to high winds. On the other hand, trees may be trimmed too severely when set. Except possibly in the case of peaches, it is probably unwise to trim the trees to a mere pole; and with peaches, it may be better to leave spurs with at least one bud than to trim to a whip. There should be a number of fresh bright buds left on the top, for these are the points where early and active growth begins. These buds are on strong branches. If they are removed, the weaker or half-dormant buds on the main trunk or low down in the crotches, must take up the work, and these start slowly and often feebly.

There are two general methods of trimming the tops of young trees at planting time. One method cuts back all the branches to spurs of one to three buds; or sometimes, particularly with dwarf pears set when two years old, the side branches may be cut entirely away, leaving only the buds on the main stem or trunk. The tree, therefore, "feathers out" the

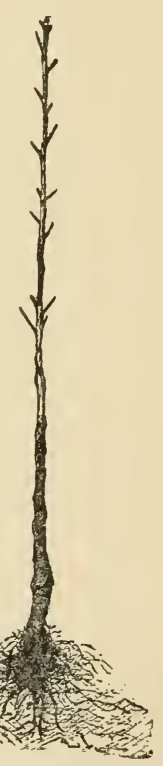

Fig. 32. Peach tree pruned.
FIg. 31. Yearling peach tree, for planting.

first season; that is, it makes many small shoots along the main trunk. The following autumn or spring, the top is started at the desired height. Fig. 31 shows a peach tree as received from the nursery, and Fig. 32 the same 
tree, trimmed in this way, ready for planting. This method is the one usually best adapted to the peach, which is always set when one season old from the bud; but for other fruits unless the trees are slender and without good branchy tops, it is doubtful whether it is the best practice. If the bodies are thought not to be stiff enough, this way of trimming may be used to good advantage. The

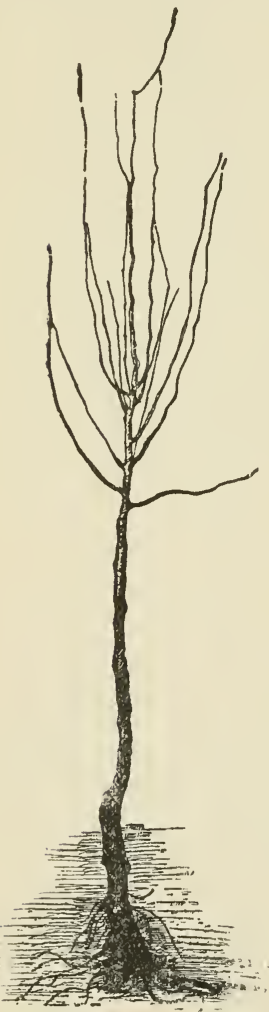

FIG. 33. Three-year-old pear tree. main shoot should usually be headed back in this as in all styles of trimming, to make the trunk stocky.

The second method aims to start the top at the required height when the tree is planted. It is adapted only to strong and well-grown stocks that have a more or less branching and forking top. From three to five of the best branches are left, and these are headed back to a few buds each. Fig. 33 shows a pear tree, trimmed in Fig. 34 , and the illustration may be considered to represent a good example of its class.

It is, of course, evident that there is no one method of pruning young trees that is all wrong, nor any other that is all right. The method must always be modified by the age and shape of the trees, by the climate (or part of the country) in which the plantation is set, by the species of plants, and especially by the standard that the grower has set for himself. In general, it may be said that the 
younger the stock the more nearly to a whip it may be pruned.

It may be said, then, that peach trees and other small or slender trees should be well headed back and spurred

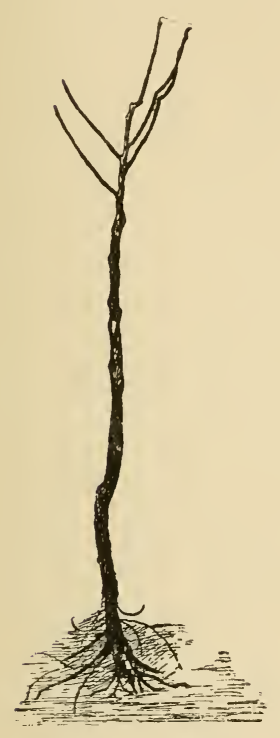

Fig. 34. Pear tree pruned for planting.

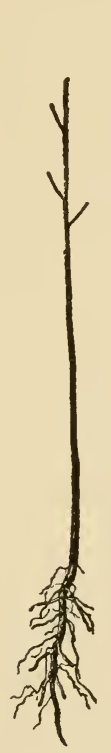

Fig. 35. Young plum tree, pruned.

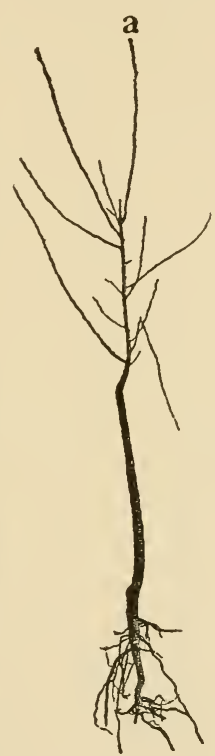

Fig. 36. Secondclass apple tree, with leader at $a$.

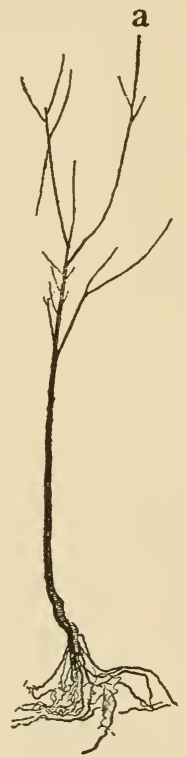

FIg. 37. Secondclass tree, with leader at $a$.

(Figs. 31, 32); but that strong well-branched trees may have the head started at the desired height at the time of planting, all the branches being well headed back (Figs. 33 and 34). Fig 35 shows a small plum tree cut to spurs, and the roots have also been properly dressed. Figs. 36 and 37 show second-class apple trees. In these trees, the tops are not well formed, and it might be best to trim to a whip, allowing the branches $a$ to become the 
leaders. Such whips may look very crooked and scrawny, but they will straighten as they grow. Fig. 38 shows three apple trees before and after shaping (Jarvis, Conn. Bull. No. 62). The lines in Fig. 39 show where a grape plant should be pruned. The top should be cut at $a$ and $b$,

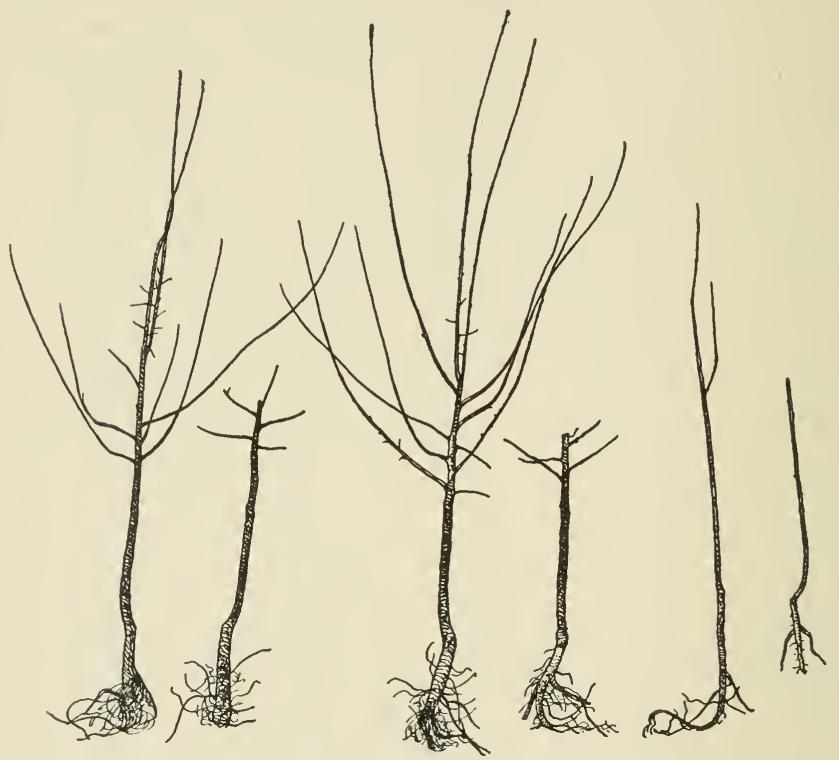

FIG. 38. Tree tops unpruned and pruned.

the upper roots trimmed off at $c$ and $d$, and the main roots cut in from $e$ to $f$.

The trees may be trimmed before they are planted, although it is usually better to trim just after they are set, especially if the tree is trimmed after the method of Fig. 34, for one can then better estimate the proper height, the operation is more easily done, and there is no further danger of breaking off the limbs by the handling of the 
tree. One foot is planted firmly at the base of the tree, and then with one hand the branch to be removed is bent upwards and with the other hand the knife is applied to the under side and the cut is made neatly and easily (Fig. 40). Never cut downwards on a limb, for a ragged wound nearly always follows.

In fall-set trees it is sometimes thought to be inadvisable to prune before spring because the cut surfaces are liable to dry out. It has been shown by Howard, however, that the evaporation from wounds is not so great as from the branches of unpruned trees; and fallpruned trees in his investigations started to grow better the following spring and made more growth in the summer than unpruned trees.

In shaping or starting the future top, care should be taken

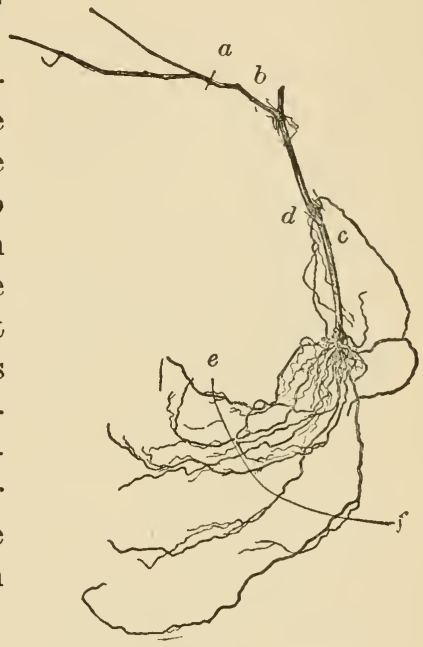

FIG. 39. Trimming the grape at planting.

to avoid crotches or the joining of branches at the same level, for the tops are likely to split later on, with ice or fruit. The framework branches should alternate on the trunk and should start at different levels and preferably several inches apart.

The height at which to start the top is largely a matter of personal preference. In the East, apple and other trees have undoubtedly been started too high, and the tendency is now to start very low. Three to 4 feet of trunk for grown trees is the author's preference for apples east of the 
Great Lakes. Jarvis (Conn. Bull. No. 62) writes as follows on this subject for New England conditions: "During recent years the difficulty of getting properly shaped trees has been greatly lessened, for the nurserymen are now heading their trees much lower. The low-headed tree is

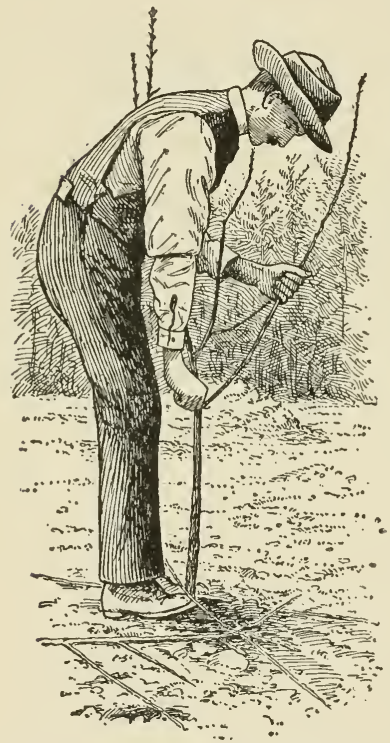

FIG. 40. Pruning the newly set tree. now generally preferred. For most varieties the head should be formed about 2 feet above the ground, but with those varieties like Rhode Island Greening and Tolman, that are naturally spreading, the head may be started higher, and with varieties like the Yellow Transparent, that are naturally upright growers, the head may be started much lower." Fig. 41 shows a tree that Jarvis considers to be started too high. Fig. 42 shows what has been the prevailing type of stout longbodied American nursery tree.

In the country west of the Great Lakes, low heads are advised. "For Iowa conditions," according to Erwin and Bliss, "a low-headed tree is to be desired for a number of reasons. The fruit is much easier to pick, the spraying can be done more thoroughly, there are less windfalls, and the tree is also less liable to sunscald. The first branches should be formed 20 to 24 inches above the ground. If the tree is headed too high when it comes from the nursery it can be cut back." 


\section{CHAPTER VI}

\section{THE LAYING OUT OF THE PLANTATION}

Arrangement of the plants in the plantation may now be considered. Berry fruits, grapes, cranberries and similar things are set in rows at small distances apart and the land is all utilized quickly. Little need be done in the placing of the plants except to line out the area accurately and to set the plants along the lines. The matter is not so simple in the case of orchards, however, for the distances are greater, the trees do not occupy the land quickly, and means must be found of utilizing the area to the best advantage. Rarely can an orchard of any size be satisfactorily set merely by following lines for separate rows; the entire area is to be laid out geometrically in advance. It is much satisfaction to have an orchard as well laid out as that shown in Fig. 43. It is not only a matter of looks, but of easy handling.

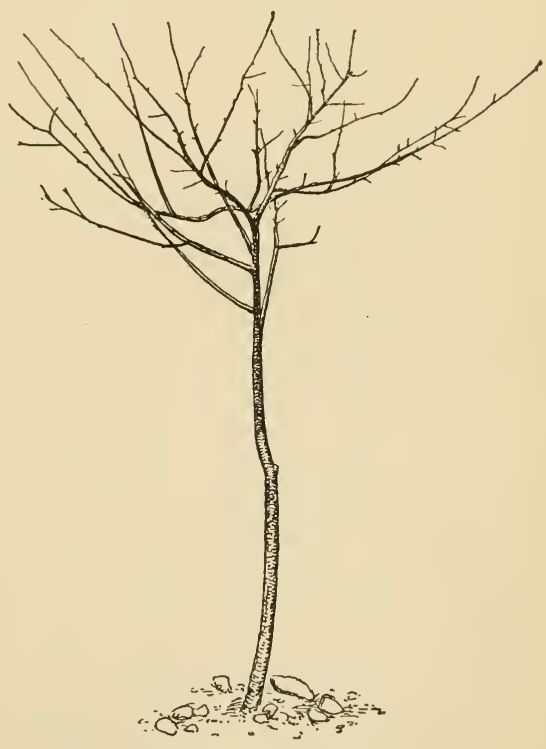

Fig. 41. Poorly-shaped young tree, with the head started very high. 
Contour planting.

On steep lands it may be desirable to plant the trees on the contours, following the grades around the hill or along the face of the slope. This facilitates tillage, tends to prevent disastrous washing, and allows of more easy

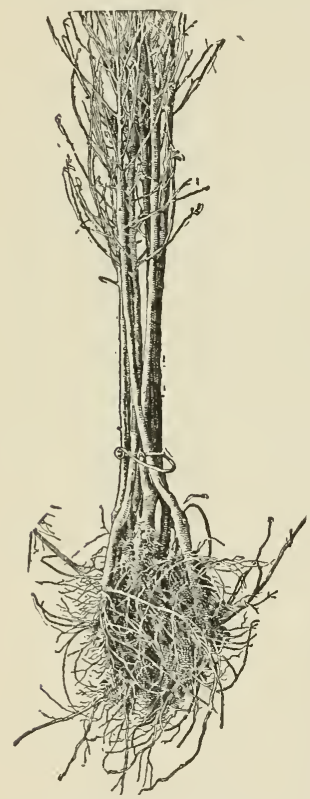

FIG. 42. First-class apple trees, with stout high trunks. access to the plantation by team and wagon. The utility of the geometrical systems is most marked on level lands.

Orchard systems.

It is possible to plant the trees in many geometrical patterns, but the main or prevailing systems are three, with variations. These (Fig. 44, from Martin, Cornell Bull.) are as follows:

1. Rectangular, the most usual and the simplest form, in which the trees occupy the four corners of a rectangle. The rectangle is usually equal-sided (i.e., square). 2. Quincunx, in which a tree is set in the center of the rectangle to economize space. This system is particularly well adapted to the use of fillers. 3 . Equilateral triangle, known also as triangular and hexagonal, in which the field is so laid out that all the trees stand at equal distances.

Theoretically, the quincunx and equilateral triangle are most to be desired because the land is most uniformly and completely utilized. It is a fair question, however, whether it may be desirable to utilize all the land in this way, or whether, in fact, the practical working out of the 
business confirms the advantages of the paper plan. The roots forage far and wide and the so-called unoccupied places may be the very areas in which they forage to best advantage. It is also well to have broad open spaces of sunshine, to facilitate the ripening and coloring of the fruit; and free spaces are needed for the easy handling of large spray rigs, heavy tillage tools, harvesting apparatus, and for use in the packing of fruit and the piling of boxes and barrels.

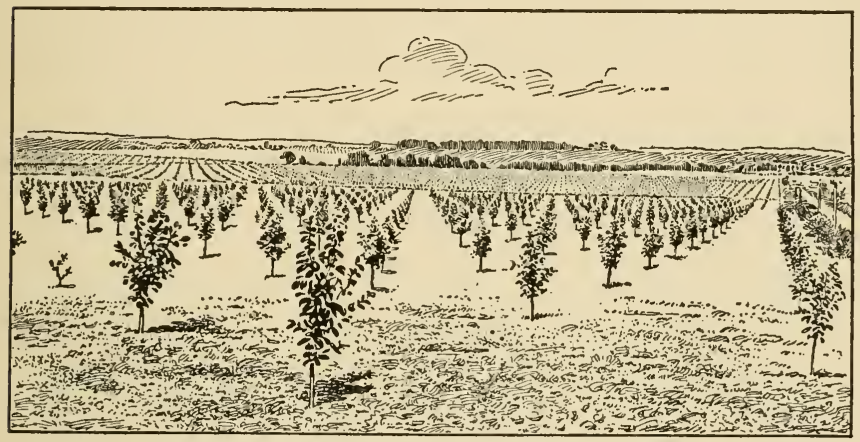

FIG. 43. A well-laid-out young orchard. Oregon.

If land is high-priced or limited in extent, it may be desirable to space all the trees at equal distances; but such systems demand good land, heavier fertilizing, more care in pruning, and they entail extra labor to the tree in spraying when the trees begin to cover the ground. For the general run of orchards, the rectangular or square form of planting is undoubtedly to be recommended.

Experiments at Woburn, England, with plums grown eleven years on the square and hexagonal systems, and also on a rectangular arrangement with double the distance between the rows as between the trees in the row, the same number of trees being grown in a given area, gave 
an increase in growth of 1.7 per cent in favor of the hexagonal planting, all the trees having been lifted and weighed. This is a small gain, and probably does not offset the cultural advantages of the square planting.

\section{Making the rows straight.}

It is difficult to make the rows straight in large areas and to place the trees at proper intervals, particularly on
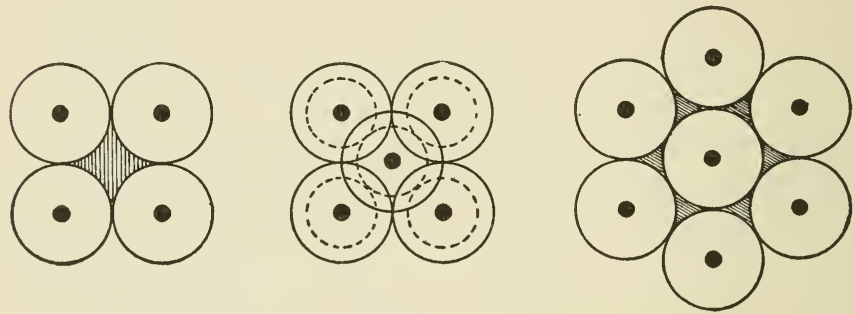

FIG. 44. The diagonal, quincunx and hexagonal systems.

rolling ground. Persons who have had areas regularly surveyed with chain and compass, and a stake set for every tree, may have found the orchards to be as crooked as others set with much less care. The surveyor sets his stakes by sighting across the field from certain fixed points; but it is difficult for the planter, when the stake is removed and the hole dug, to stand the tree in the exact place of the stake. It is better to regard the trees as stakes and to set them by sighting. The area can be "run out" on two or three of the sides, a conspicuous stake being set at the location of each tree on these outside rows. If the field is large or rolling, it may be necessary to set one or two lines of stakes across the center of the field also. For areas of a few acres, a garden-line stretched across the place will be a great help and save much time. This line is moved 
at either end to the adjoining row, as soon as one row is set alongside it. Persons sometimes tie strings on the line at the given intervals, expecting to set a tree at every knot, but with the stretching of the line, and other errors, it is difficult to get the cross-rows straight in this way.

On comparatively level fields, especially if the land is in good tilth, the plantation may be laid out with a cornmarker. If the planter keeps his back to the row of trees and sights ahead to the marked line or furrow, he will get his rows straighter than if he sights by the trees. Two men

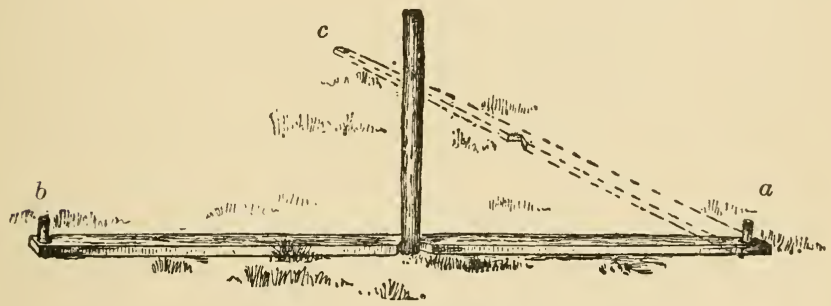

FIG. 45. Planting-board.

are better than one when setting plants, for one usually attends to the sighting while the other puts in the plants. There are various devices for locating the position of the orginal stake, after the hole has been dug. One of the best consists simply of a thin board 3 or 4 inches wide and 6 or 7 feet long (Fig. 45), with a notch at its center, and a stationary leg or pin at one end $(a)$. The other end (b) is provided with a hole to receive the top of another stake or pin. The notch is set against the stake, the legs at each end of the board being thrust into the ground at the same time. The end $(b)$ is now raised off the pin or leg, and the board is swung around out of the range of the hole. When the hole is dug, the end $(c)$ is swung back and dropped over the pin, and the tree is set in the notch. On 
the practical use of this device, Stuart writes as follows (Vt. Bull. No. 141): "When each tree stake has been located, the setting board is brought into play. This consists of a board some 6 feet in length and 4 to 5 inches wide, having two holes bored some 3 or 4 inches from either end and a notch in the center. The notch of the setting-board is placed against the tree stake and two

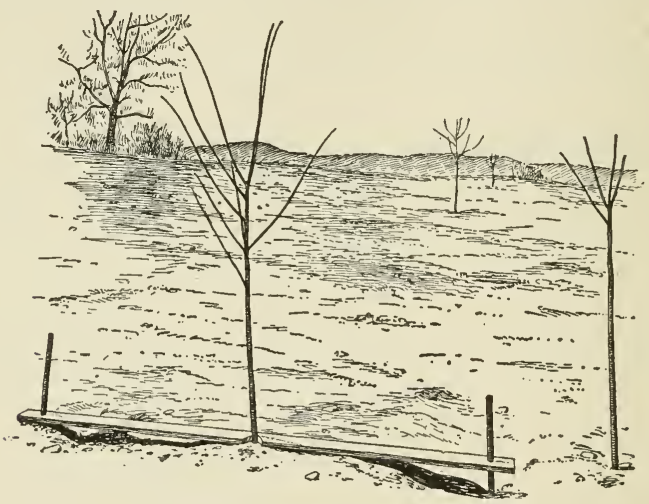

FIG. 46. The planting-board in use.

smaller stakes are set through the end holes, after which the board is removed. The central stake is then removed and the hole dug. In setting the tree, the setting-board is again brought into play by being put over the two smaller stakes, the center notch determining the position of the tree (Fig. 46). By being careful always to work in the same direction with the setting-board, and observing the same precaution while setting the tree, one should succeed in planting each tree in perfect alignment, in both directions, with every other tree in the row, without the necessity of sighting. This method of course cannot be recommended for large operations." 
Another form of planting-board, described by J. C. Moore, is the equilateral triangle. Three laths or narrow pieces of timber are fastened together so that they form a triangle with the ends projecting, as shown in Fig. 47.

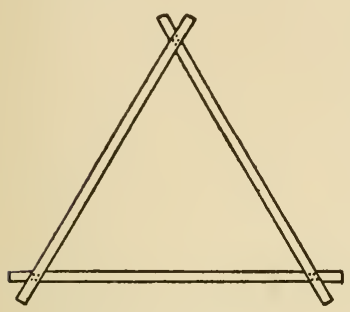

FIG. 47. The triangle, for placing the tree.

Care should be taken to have the distance between each two adjoining corners equal, as this will relieve the necessity of replacing the triangle in the same position. One projecting end is put over the tree stake, and the pins placed in the others. This marks the location of the tree after digging the hole.

The trees may be planted in furrows, as explained farther on (page 200). Blake writes (N. J. Circ. No. 14): "If the land is well furrowed out where the trees are to be planted, it will only be necessary to move from two to four shovelfuls of soil in order to make a hole of sufficient width and depth to receive each tree. One man should then hold the tree in place while the other shovels in some of the loose, moist surface-soil about the roots. The trees should be set at sufficient depth to bring the point where the trees were budded just below the surface of the soil. The man holding the tree can make the soil firm about the roots with his feet and hands, and at the same time keep the tree in line both ways. If the line method previously described is used he will only be obliged to sight one way to make sure that the tree is in place. The last one or two shovelfuls of soil should be thrown about the tree loosely and not tramped down. If the land has been properly and thoroughly prepared, as described, a threeman planting gang should be able to set fifty trees an hour 
without difficulty upon the sandy soils after the outside rows have been established. Upon the stony mountain soils or upon the red shale, more time will be required to set the trees." Figs. 48, 49, 50, show Blake's method.

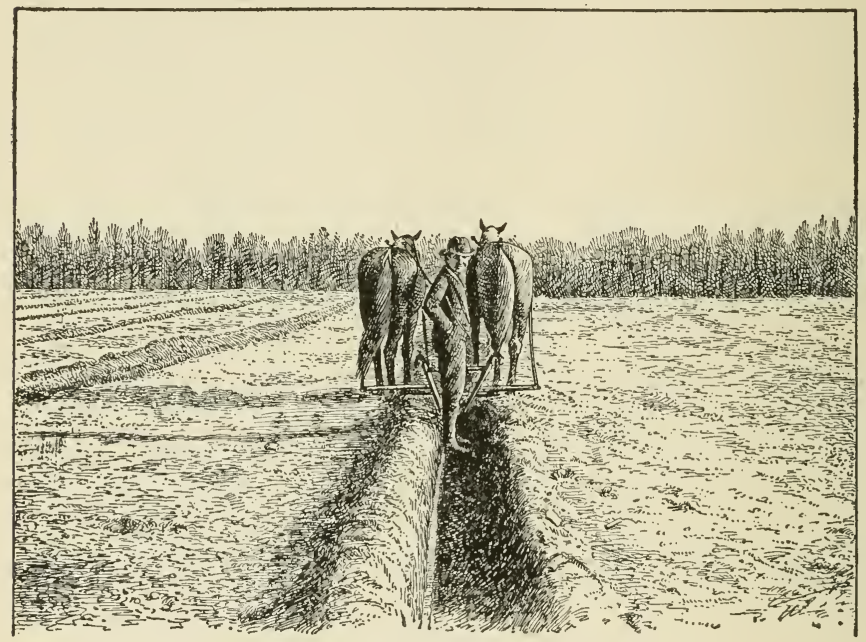

FIG. 48. Furrowing for the planting of peach trees.

How to get the rows straight may be discussed here in more detail. Three ways are quoted from H. E. Van Deman:

"To lay out with the plow.-Before doing anything, one must decide which style or arrangement of the trees is to be followed and the distance apart to plant them. This having been decided, the first thing to be done is to establish a base line, which should be along a fence, road or some other permanent border of the tract to be planted. Prepare enough small split stakes, that may be easily seen, to put at each end of every tree-row; that is, enough to go entirely around the tract. Then, set a stake firmly at a spot which shall be the first established corner of the outside limits of the orchard. It must, however, be set at a spot which shall also be the end of 


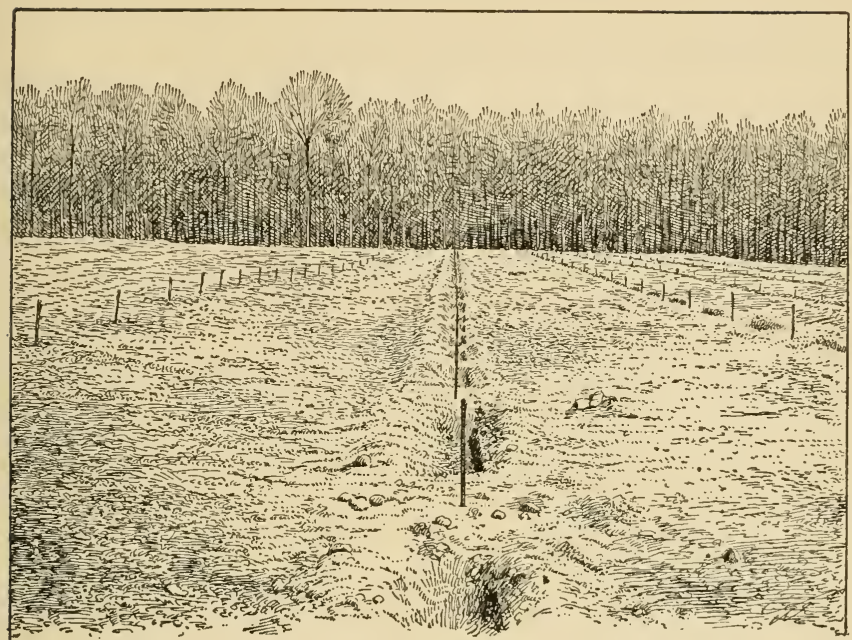

FIG. 49. The orchard immediately after trees are set.

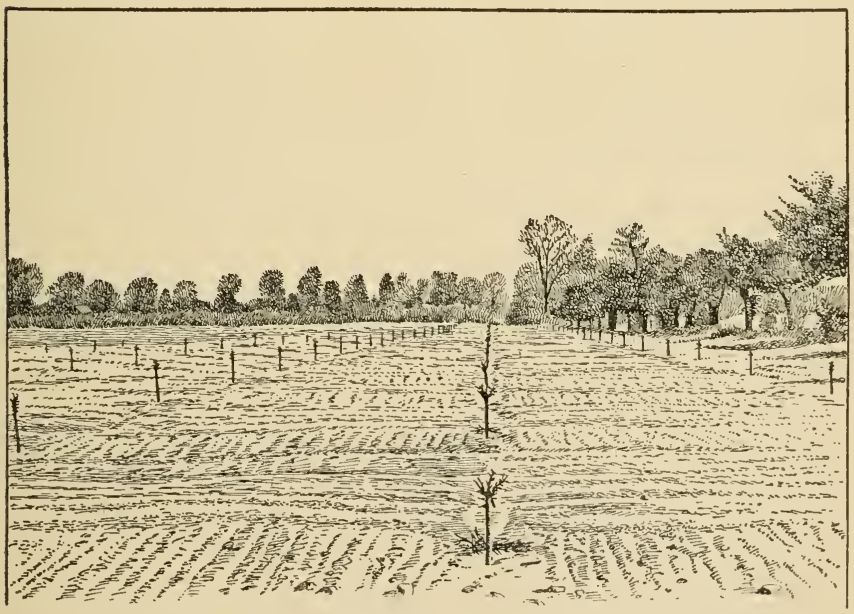

FIG. 50. Newly planted orchard, prepared for a crop of corn. 
another line running exactly at right angles to the base line. In the West, where the farms are nearly all laid out in perfect squares or rectangles, the fields are apt to be rectangular. In the absence of a surveyor's transit, a carpenter's square may be used to establish the lines, by sighting along its edges when laid on the tops of three stakes at the corner. Set a stake at the farther end of each of these lines. From this first corner stake, measure along the base-line 15 feet, or as far as it is thought best to have the width of the margin between the trees and the fence, and there set a stake. Next, measure along the base-line from this second stake the distance that the trees will be apart, and set a stake. Measure along the entire length of the baseline, setting a stake at every $16 \frac{1}{2}, 20,25,33$ feet, or whatever distance may have been decided upon. This line of stakes being only the ends of the transverse rows and not the places for trees, they need not be set absolutely in a straight line, but should be nearly so. Then, go back to the original corner stake and measure 15 feet at right angles to the base-line and set a stake, which determines the width of the border next the base-line. Now, measure and set stakes along this other side of the orchard site, up to the stake at the farther end. The two remaining sides should be measured and staked in the same way.

"Provide several tall stakes with a white rag tied at the top of each, to use as sight poles at each end. If one can run a straight line with a plow without intermediate sight poles, that is, with only one at each end, these will be enough; but I have found that it pays to have an extra line of stakes set a few rods from each end, and a guide pole to be set at each in turn, as the laying-out progresses.

"We are now ready for the plow. Some like one horse, but two make the plow run steadier, and it is easier for the plowman to sight between two horses than over the head of one. My plan is, first to mark out crosswise to the way I intend to plant, and to make but a single shallow furrow. This being done, we are ready to make the furrows in which to plant. If these run up and down the slope they will act as a drain to the trees, in some measure. By plowing two rounds and finishing with a dead-furrow or trench on the line, and then subsoiling in the bottom of it, there will be very little work for the spade in preparing to set the trees. It is by no means difficult to set them in the checks, with a little sighting, so straight that no one would know but that they were set by a line. After setting the trees, hitch one horse to a plow with a very short singletree covered with 
rags at the ends to prevent injuring the trees, and fill up the trench at two rounds. Then plow the space between the rows. One thing must be very carefully figured out the very first thing, if the hexagonal style is used, and that is, the distances between the rows at right angles, and not diagonally from tree to tree, and then accurately measured and staked on the outer lines. The great Wellhouse orchards, in Kansas, were laid out with the plow. J. H. Hale substituted a 60 -cent per day darkey and a mule for a $\$ 6$ surveyor and transit, in laying out his rows for planting his 600 -acre peach orchard in Georgia.

"Laying out with a line.-For small orchards of an acre or two, I have often practised a method of laying out in the hexagonal style, which is very quickly and easily done. As many stakes are provided as there are trees to be set. A wire is prepared of the exact length that the trees are to be apart, and a ring or loop twisted in at each end, by which to hold it. A base-line is established by setting stakes just where each tree will be in the first row. One person (A) slips a finger through one ring, and another (B) takes the other end of the wire and runs a small stick through the ring. A holds his end exactly at stake 1 , and $B$ steps to where he supposes the first tree of the second row will come, and with the point of his stick marks a small segment of a circle on the ground. He remains there while A goes to stake 2 and holds his end exactly to it. B describes another are on the ground, and where it crosses the first one he sets a stake, and moves to the place for the next stake. There he makes a mark, and A then goes to stake 3 of the base-line and holds the wire as before, while $\mathrm{B}$ finds the crossing of the marks and sets another stake; and so on to the end of the row. When the second row is complete it is used as a base-line from which to make a third, and so on. If the work is done carefully the stakes will be found to be in very straight rows every way. I have tried it on some of the roughest hills in northern Michigan, where, in newly cleared places the stumps were very thick, and planted nice orchards that are now over twenty-five years old, that look to-day as if the trees might have been set by a compass and chain. On level ground, free from obstructions, it is fun to lay out an orchard so.

"Another line method.-Another cheap and handy method is, to mark and set by a wire long enough to reach entirely across the field. It should be stretched tightly between two stout stakes that have been firmly driven into the ground, and exactly on the line of the 
first row to be planted. Directly over the place for the first tree or vine, wrap a small wire two or three times and twist the ends tightly, so it cannot slip. Measure along the wire to the next place and fasten another wire coil, and so on to the end. If these little coils were soldered fast they could not move. A little piece of bright cloth should be tied over them, that the places may be easily seen. Now, dig the holes and plant the first row while the wire is in place. Then move the wire and stakes to the second row and stretch as before, being very careful to have the first mark exactly where the first tree should be. Proceed to dig and plant as before. Move the wire to the third row, and so on throughout. This obviates all necessity for marking off upon the ground, except the distances between the rows and a starting-point on each row."

Staking methods.- There are so many methods of staking out an orchard, that it will interest the reader if one of the best of them is described. The Yeomans plan is as follows: "In connection with the accompanying diagram, is explained an easy, simple and accurate way of marking out the ground and planting the trees without putting any stakes where trees are to be planted or removing any while planting. The stakes not only show where to dig the holes, but when the planting is to be done the same stakes indicate the precise place where the trees are to placed, always sighting only by the stakes in setting, without any regard to the trees planted. Thus all the stakes will be standing when the last tree is planted, showing the accuracy of the work done.

"The outside line of the diagram (Fig. 51) represents the ground to be planted; the dots are stakes, by means of which the location of each tree can readily be found without any measurements; but none of them stands where trees are to be planted. The ground being properly prepared for one hundred trees, provide sixty lath as very suitable stakes-light, straight and of proper lengthlay them on the ground or a board, and whitewash on each side about a foot or more at one end, by which they can readily be seen at a distance and distinguished from any other stake or object. Let two men with a tape-line start at the corner of the ground at $\mathrm{D}$, and measure 25 feet along the east side to 1 and then set a stake; thence measure 40 feet to 2 , setting a stake, and continue to 10 , putting a stake every 40 feet to $\mathrm{C}$, setting all stakes as perpendicularly as possible. 
"Then with ten stakes start at B and measure the same distance toward A, sticking a stake first at 25 feet, and after that 40 feet, to correspond with those on the east side. And on the same plan and in the same manner, stick ten stakes 40 feet apart along the north and south bounds of the orchard, and entirely outside of where any

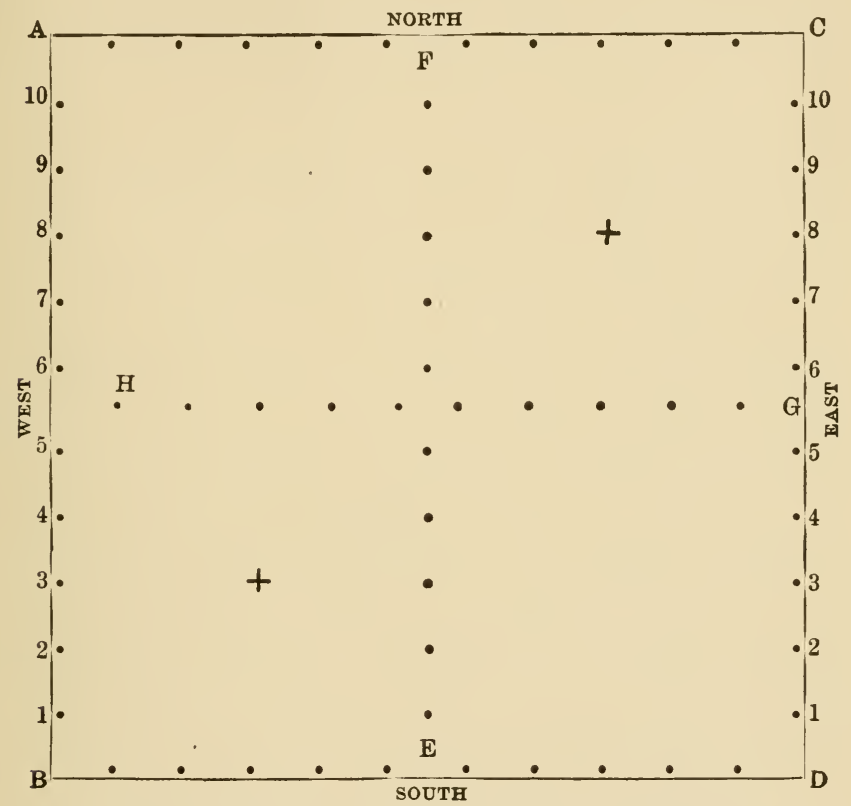

FIG. 51. Diagram to illustrate the planting of an orchard.

trees are to be planted, being particular that no trees shall be planted nearer than 25 feet to the fences surrounding the orchard, for the reason that when the trees become large, as much as 25 feet of space will be necessary to allow a spraying wagon and fixtures to pass in spraying the trees properly, and to place ladders about the trees for gathering the fruit.

"The stakes being set around the orchard ground at proper distances, the tape-line is no longer needed, as the cross intermediate rows of stakes are to be set by sight. Now let one man take ten of 
the white-top stakes and go about to $\mathrm{E}$ (at bottom of diagram), and another man go to the first stake north of $\mathrm{D}$, and sight the man at $\mathrm{E}$ precisely where to stick a stake in line with the two stakes on opposite sides of the ground; then move northward to 2, and stick a stake between 2 and 2 ; and thus continue from south to north and from east to west, through and not far from the middle of the field, being careful not to place either of these intermediate rows where a row of trees is to be planted. These rows need not be straight, but each stake must be in line with the corresponding stakes at the right and left.

"With the stakes thus placed, a person moving anywhere about the ground to be planted can readily find, by looking in the direction

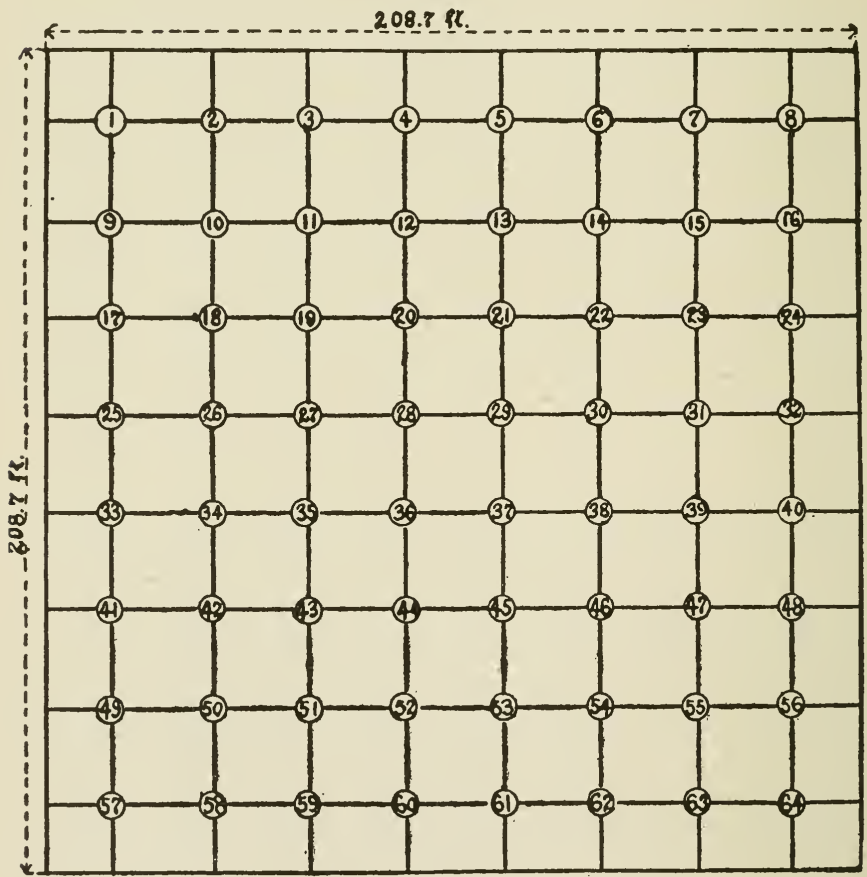

Fig. 52. Square system. The above plat represents an acre of land with the trees 25 feet apart. (Figs. 52-58 from N. O. Booth.) 


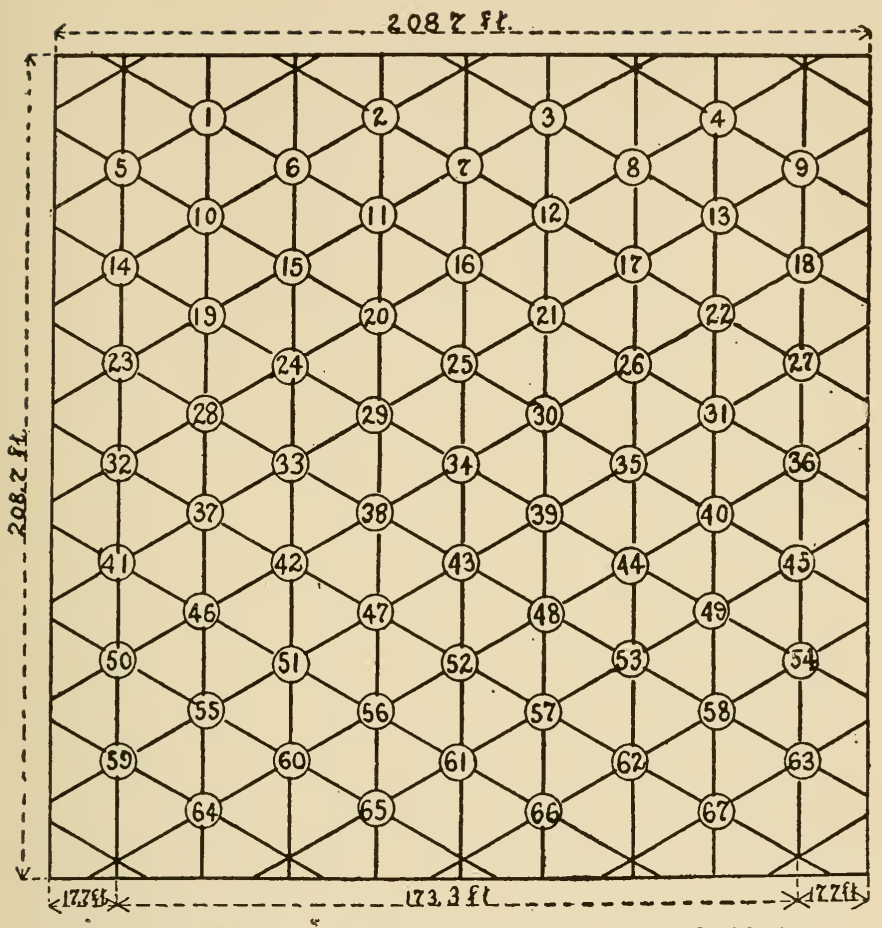

Fig. 53. Hexagonal or triangular system. One acre of land with the trees 25 feet apart.

of two stakes in two directions at right angles, precisely where a tree is to be planted. Thus, a person standing at either $X$ is at a point where a tree must stand, and at either of those points will see two stakes in a line with him in two directions at right angles; and so of every point where a tree is to be planted. If men are to be employed to dig the holes, who are not capable of setting a stake in line with two other stakes already standing (there are such men), let some one who can do so go through the field, and with point of stake or other thing, mark where the holes are to be dug.

"With this arrangement no stakes are placed where the trees are to be planted. Any number of men can go on with the work of dig- 
ging the holes and planting in any part of the orchard without reference to any other trees in any other part. The writer has planted about 150 acres of apple and 100 acres of peach orchard on this plan, and has furnished many persons brief descriptions of same for planting; has planted rows 30 to 40 rods long of nice trees, so straight in

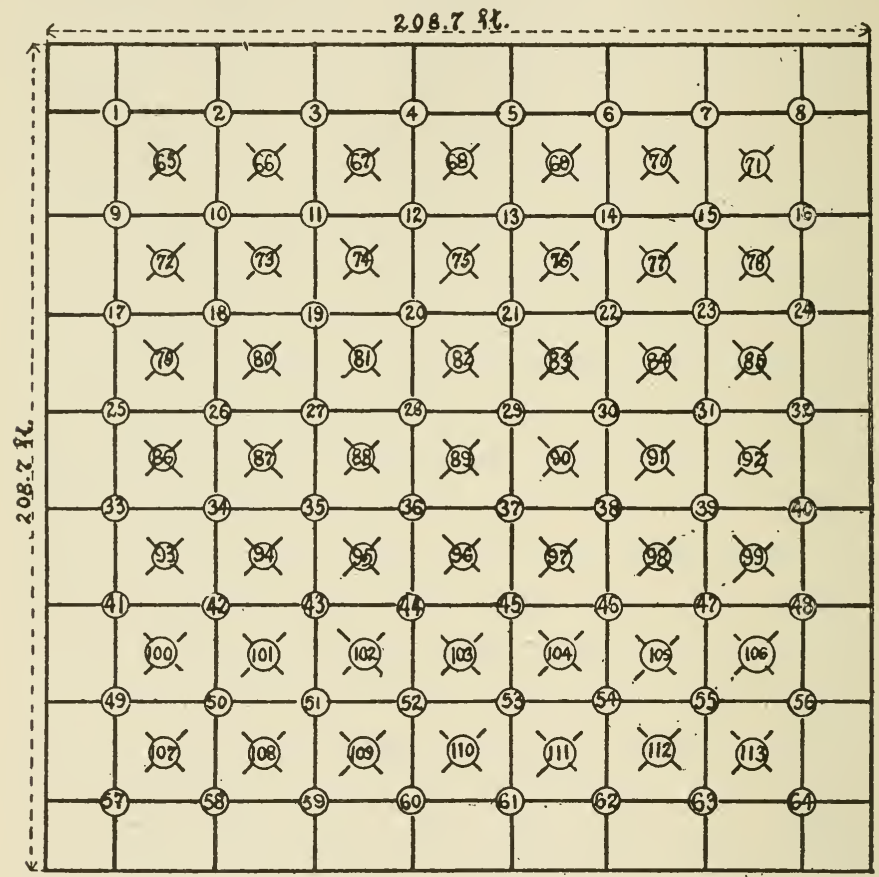

FIG. 54. Quincunx system. One acre of land with the trees 25 feet apart in the row, but only about $141 / 2$ feet diagonally across, or from any tree to its nearest neighbor.

line that a stake 2 inches in diameter set up in the row would hide every tree from view, looking from the end thereof."

Details of orchard lay-outs.

A further exact discussion of the systems of orchard-planting, with diagrams (Figs. 52-58), will aid the intending planter. Booth 
writes as follows on the subject (Okla. Exp. Sta. Circ. No. 20): "From the standpoint of the number of trees contained on an acre we find: That planted by the square system, with trees 25 feet apart, an acre will contain sixty-four trees. This leaves, however, about $163 / 4$ feet around the sides between the last row of trees and the outside line, instead of $121 / 2$, as would be intended. When the acre is planted by the triangular or hexagonal system it will be found to

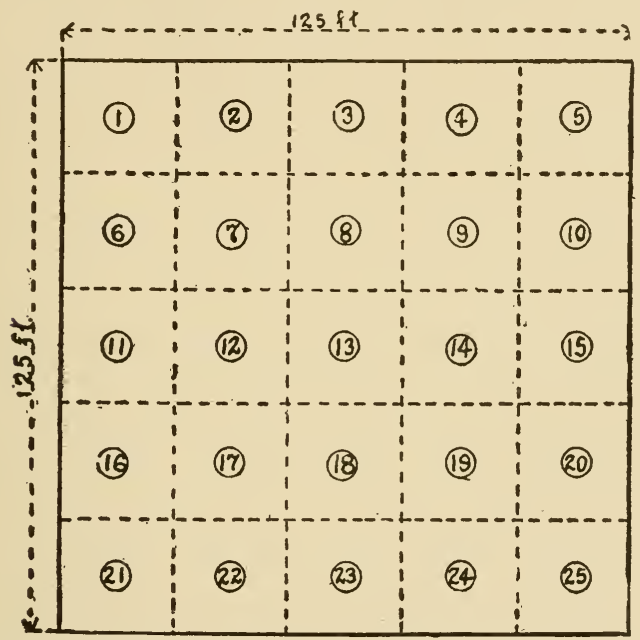

FrG. 55. Twenty-five trees planted according to square system. Dotted lines indicate feeding-area assigned to each tree.

contain sixty-seven trees. Here again, however, in planting the single acre, the trees do not fit the plat, and there is a margin left over on two of the sides of $16 \frac{4}{5}$ feet, instead of $121 / 2$. It is difficult to say how many trees may be planted on an acre by the quincunx system on account of the difference of meaning as to what is intended. Usually in comparing this system with others they are compared with the trees the same distance apart in the rows. This is not a fair comparison, however, for when trees are planted by this system the nearest tree to any given tree is not the next tree down the row, but the next tree diagonally across. Taking it in the sense in which it is generally used, an acre of land planted according to 
the quincunx system contains 113 trees. Here, as in the square system, a $163 / 4$ foot margin is left instead of the intended $121 / 2$ feet.

\section{"Number of Trees to the Acre Planted 25 Feet Apart}

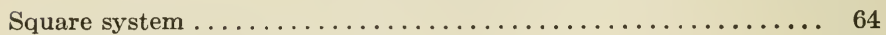

Hexagonal or triangular system................... 67

Quincunx system (trees 25 feet apart in the row, but only about

$14 \frac{1}{2}$ feet from any tree to its nearest neighbor)......... 113

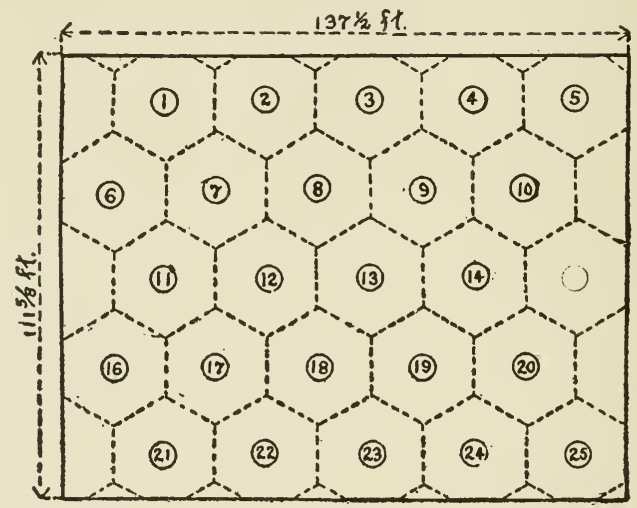

Fig. 56. Twenty-five trees planted according to hexagonal system. Dotted lines indicate feeding-area of each tree.

"Approaching the subject from another standpoint, we find that if we desire to plant twenty-five trees 25 feet apart, we have the following space required for the different methods of arranging: By the square system it will require a plat of land 125 feet square, with an area of 15,625 square feet. By the triangular system it will require a plat of land $1371 / 2$ feet one way, by 111.62 the other, with an area of 15,345 square feet. By the quincunx system, as the meaning is usually accepted, that is with the trees 25 feet apart in the rows, the twenty-five trees occupy a tract of land 100 feet square, with an area of 10,000 square feet. By the quincunx system in the more correct sense of having the trees with 25 feet from any tree to its nearest neighbor, twenty-five trees require a tract 131 feet each way with a total area of 17,161 square feet. 
"Length Breadth and Total Area Required to Plant Twenty-Five Trees 25 Feet Apart, By Different Systems

\begin{tabular}{|c|c|c|c|}
\hline & $\begin{array}{c}\text { Length } \\
\text { (feet) }\end{array}$ & $\begin{array}{c}\text { Breadth } \\
\text { (feet) }\end{array}$ & $\begin{array}{l}\text { Total area } \\
\text { (sq. ft.) }\end{array}$ \\
\hline Square system. & 125.0 & 125.0 & $15,625.0$ \\
\hline Hexagonal or triangular system. & 137.5 & 111.6 & $15,247.7$ \\
\hline $\begin{array}{l}\text { Quincunx system (trees } 25 \text { feet apart in } \\
\text { row) } \ldots \ldots \ldots \ldots \ldots \ldots \ldots \ldots \ldots \ldots \ldots \ldots \ldots\end{array}$ & 100.0 & 100.0 & $10,000.0$ \\
\hline $\begin{array}{l}\text { Quincunx system (trees } 25 \text { feet apart in } \\
\text { diagonal row) } \ldots \ldots \ldots \ldots \ldots \ldots \ldots\end{array}$ & 131.0 & 131.0 & $17,161.0$ \\
\hline
\end{tabular}

"It will thus be seen that there is a certain gain in the amount of land required to plant twenty-five trees, by using the triangular rather than the square system of planting. This gain is evident for

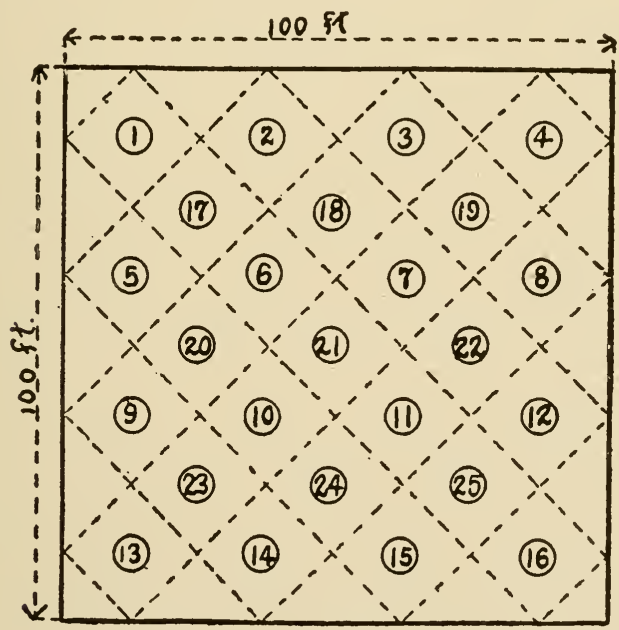

FIG. 57. Twenty-five trees planted according to quincunx system.

even so small a tract of land as that required for twenty-five trees; and since it is evident that there is a slight loss by the triangular system on the outside rows, the gain would be greater, proportionately, with a larger area. 
"It appears to be doubtful if there is any gain in using the quincunx system rather than the square system. In the small plat of twentyfive trees there is no gain, but a decided loss, when the trees are planted the same distance apart. There is, however, an evident and great gain when an extra tree is added to the center of each square. To any person with the most rudimentary notion of geometry it is evident, that there is no essential difference between the quincunx

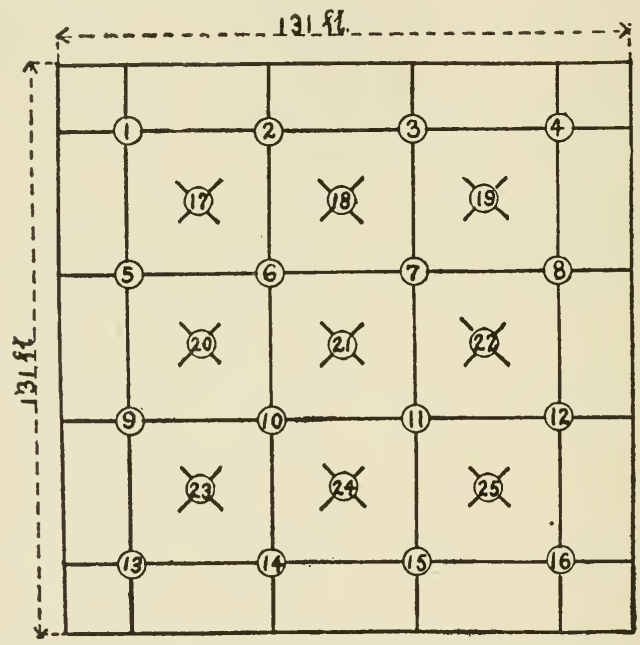

FIG. 58. Twenty-iive trees planted according to quincunx system.Trees are 25 feet from nearest neighbor.

system and the square system. In the first case, the rows run diagonally with the outside boundary, while in the second, they run at right angles, or parallel with the outside boundary. In both cases the trees are arranged in squares. Any one with an orchard planted on the square system can change it to the quincunx system by cutting off the corners until the outside boundary again becomes a rectangle with lines diagonal with the original boundary lines. It is thus evident that any gain in the number of trees put on a given area, by the quincunx rather than the square system, must be made either by closer fitting in the margin of the field, or else by putting the trees closer together. An examination of Fig. 57, where an equal feed- 
ing-area is assigned to each tree, shows that there is an absolute loss on the margin. In other words, the whole space is not so equally divided among the different trees by the quincunx system as by the square system. An examination of Fig. 56 shows that the same thing is true of the hexagonal or triangular system."

Diagrammatic representations of the three leading systems are given in Fig. 59, redrawn from Moore, Bull. 201, Wis. Exp. Sta.; and the alternate plan is also shown. The alternate system, according to Moore, is designed to correct the difficulties arising in the quincunx plan, these difficulties being, "that unless the rows are more than 30 feet apart, setting a tree in the center of the rectangle would so reduce the

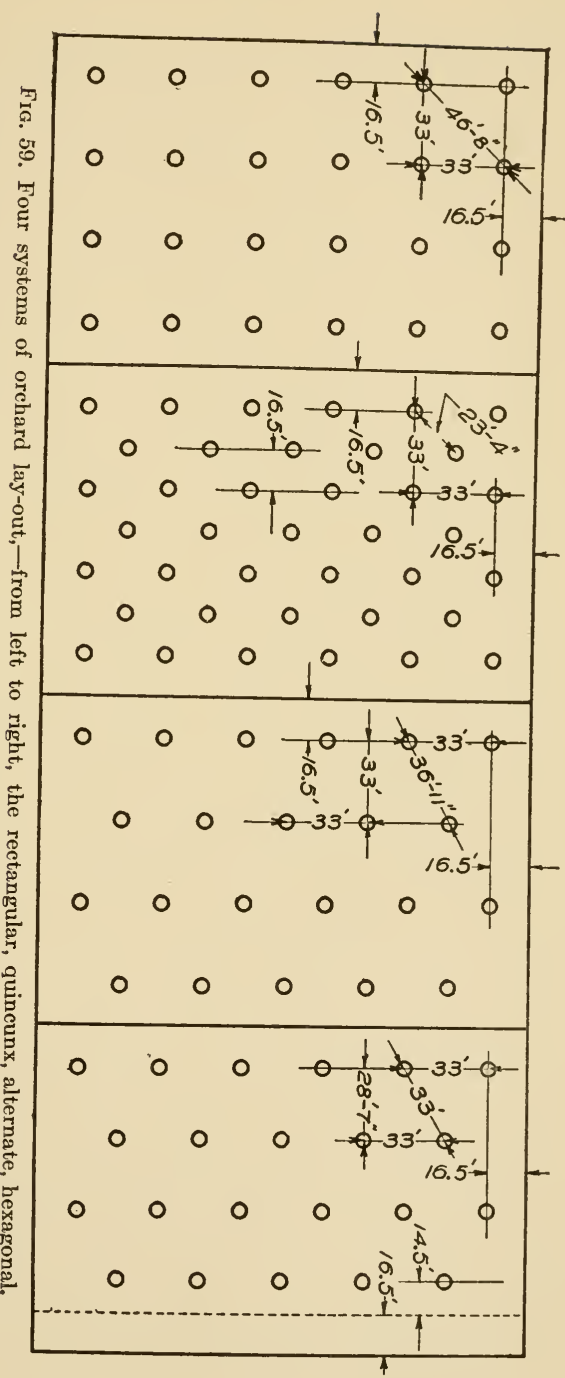


distance between the rows that difficulty would be encountered in orchard operations." The alternate plan differs from the quincunx "essentially in widening the distance between the rows, maintaining the same distances between the trees in the row, and is therefore better adapted to planting under 40 feet. The first tree of each of the even rows is midway between the first and second trees of the odd rows. The rows are placed far enough apart so that the diagonal distance between trees of adjoining rows is greater than the distance between trees in the row, and the perpendicular distance between rows is more than one-half the distance between trees in the row. In the alternate plan, with trees 30 feet apart in the row, the rows can be placed much closer together without reducing the space between the trees in adjoining rows so much as to interfere with orchard operations. By this method, the number of trees to the acre may be increased, the land better distributed among them, and inconvenience in orchard operations avoided.

"The alternate system is frequently used in close plantings. In an orchard with rows 20 feet apart, set by the alternate system, it will be found much easier to get between the trees than if the rectangular system is employed, for the distance between the nearest trees of the adjoining row will be approximately 22 feet 4 inches, or over 2 feet more than when set by the rectangular. Set at this dis-

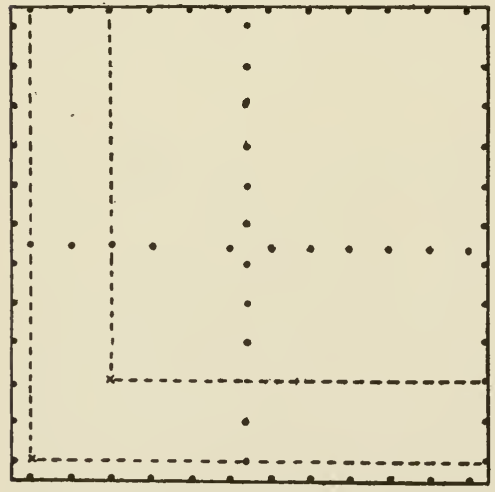

Fig. 60. Staking the orchard, by not placing the stakes where the trees are to stand. tance the space between the trees of adjoining rows would be approximately the same as when planted 32 feet apart by the quincunx."

Moore also describes two good additional methods for placing the trees, as follows:

"Lining-in method (Fig. $60)$.- A method very commonly used in setting an orchard by the rectangular system is the 'lining-in' method. Stakes are set on both sides and ends of the 
area to be planted. Laths serve the purpose very well. The first stake should be the proper distance from the fence, and the others at intervals equal to the distance between the rows. Two rows of stakes are run through the center of the area at right angle to each other, care being taken not to have them come on the line of the row, which is easily done by starting between two of the stakes on the end. These stakes should be in line with the stakes running parallel to them. The man setting trees now has two stakes in each direction by which to line-in his trees. By this method all intermediate stakes and the planting-board may be dispensed with.

"Wire-compass method (Fig. 61).Another method is

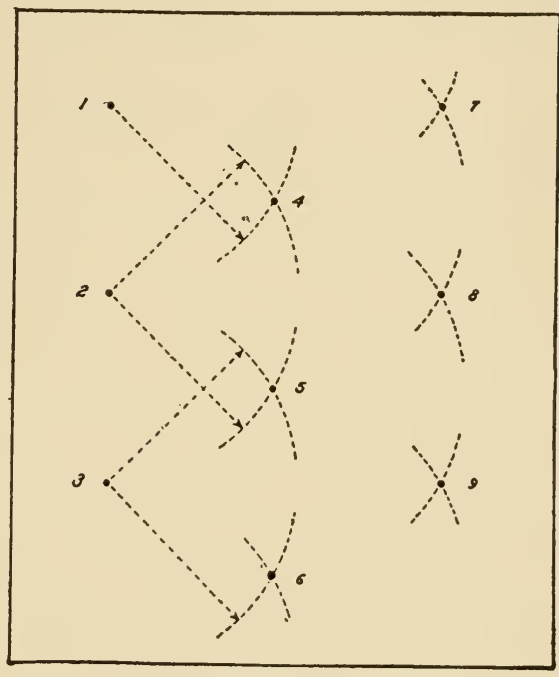

FIG. 61. Wire-compass method of staking out a hexagonal orchard.

frequently used in staking out the hexagonal orchard. The first row is located with reference to the fence and becomes the base-line. Beginning at the desired position of the first tree, stakes are set at the desired distance between trees, a wire the length of the distance between trees is then used for the location of the remaining trees. It is convenient to have a ring at each end of the wire as this facilitates handling. If the rings are used, the length of the wire should be considered as extending from center to center of the rings. One ring should be fitted with a marking pin, this end to be used by the man locating the position of the trees.

"In locating the trees, A holds the center of his ring over the first stake of row 1, while B takes the marking end and strikes an arc at what he thinks is the location of the first tree of the next row. A 
walks to the second stake of the first row, and B again strikes an arc. At the intersection of these ares he sets a stake, locating the position of the tree. B then strikes an arc where he thinks the location of the second tree will be. When all the trees of row 2 are located, it becomes the base-line from which to locate trees of row 3 . If the ground be uneven, a plumb-bob should be used so that the wire may be kept

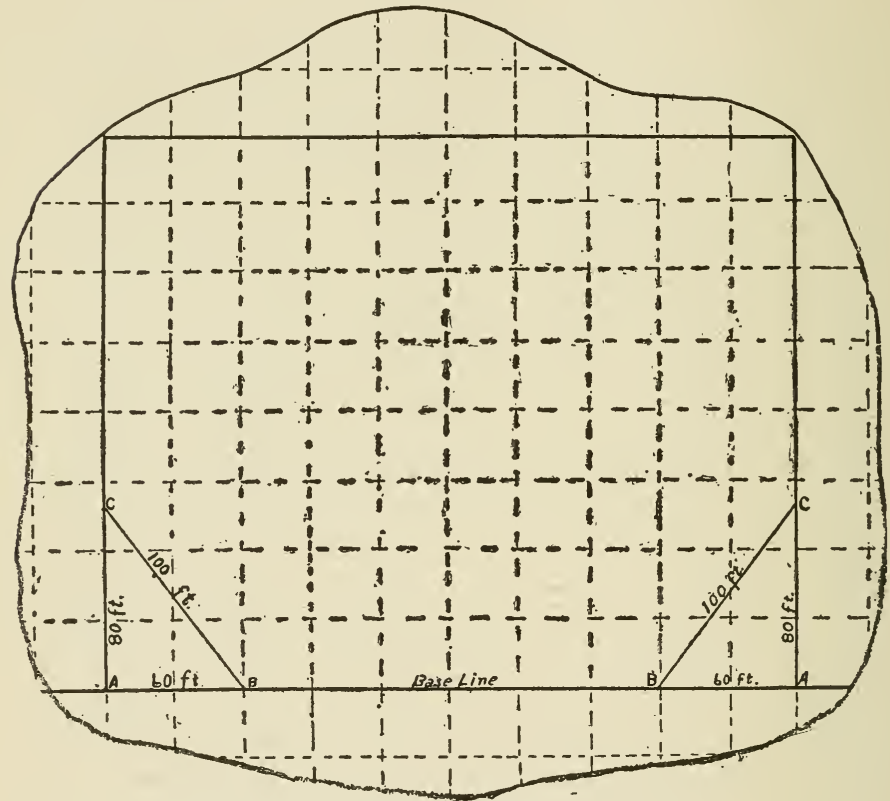

FIG. 62. A method of squaring an irregular field.

horizontal. In locating the end tree there is frequently but one stake from which to strike an arc. The location is easily determined, however, by locating the second tree first, and then using it as the point from which the arc is struck. After four rows have been located by the arcs, others may be lined-in."

The method of squaring a field for orchard-planting is described again by Jarvis (Conn. Bull. No. 62): "Before attempting to lay out a field that is irregular in outline, it must first be squared off in 
such a way that the rows running across the field will be at rightangles to the rows running the other direction. A base-line running along a straight side of a field is first chosen. If there is not a straight side, a straight line running along the longer side of the field may be established. At right angles to this straight line and near each end, may be projected two other lines. On small areas this may be done with two straight-edges and a carpenter's square, but on large tracts this method is not sufficiently accurate. The best and most reliable method is that described in Fig. 62. At the desired point (A) on the base-line a stake is set, and exactly 60 feet from this on the same line another stake (B) is set. By stretching a string 80 feet long from the first stake (A) and another string 100 feet long from the second stake (B) and by bringing the two ends together at (C) the position of the third stake may be determined. Then the desired line is drawn from A through $\mathrm{C}$ to the other side of the field. The same operation is repeated near the other end of the field. The distance between the rows, one way, may be marked off on the projected lines and the distance between the rows the other way, may be indicated on the base-line and also on the line parallel to it on the opposite side of the field. The rows in both directions can be extended to the margin of the field.

"On hilly lands it is often very difficult to get the trees lined up properly. In such cases, telephone wire is sometimes employed to stretch across the field. To indicate the position of the trees a smaller wire may be wound around and soldered to the larger one at the required distances. The telephone wire is stretched tightly, and a stake set at every point indicated by the soldered wire. In the hollow places, where the wire is far above the ground, a plumbbob may be necessary to find the exact position where the stake should be set. Twine, on account of its stretching character, is unsuited to this purpose."

Another variation for the laying out of a hexagonal tract is given by Fisher (Mont. Bull. No. 77): "A base-line is established along a fence or permanent road, running east and west and marked off at intervals at which the trees are to be planted. From the stakes thus established, lines can be run across the field at an angle of $60^{\circ}$ with a surveyor's transit or other instrument that will measure angles. These lines are then marked off at intervals at which the trees are to be planted. If an instrument for measuring angles is not available, a steel tape or wire about 360 feet long should be provided. 
This tape should be marked off at intervals at which the trees are to be planted. If the trees are to be set 30 feet apart in the rows, the tape should be about 370 feet long, with marks at every 30 feet. This will leave 5 feet at either end for pulling while stretching the tape.

"A line parallel to the base-line is then established 311.76 feet distance either north or south and marked off at intervals of 30 feet, the same as the base-line. One end of the tape-line is then held in

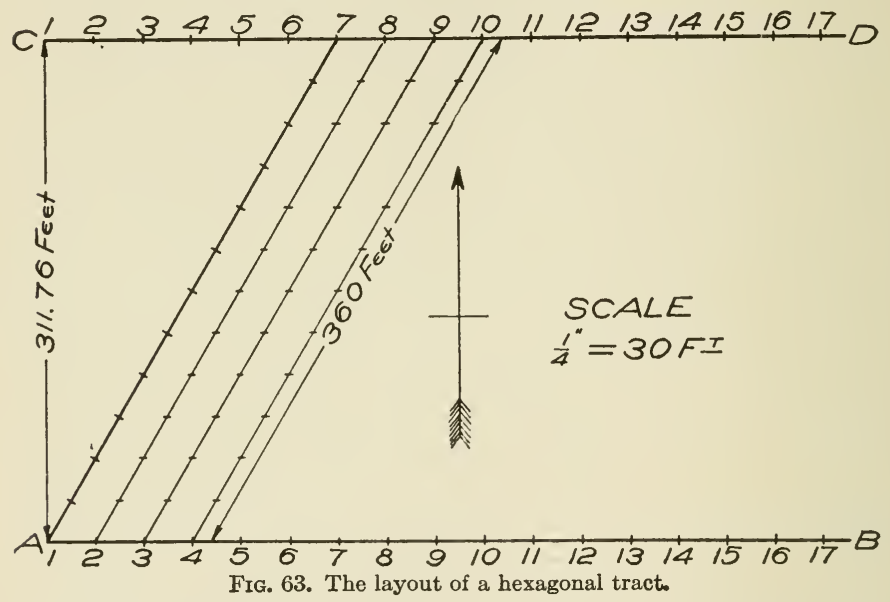

peg No. 1 (see Fig. 63), in line AB, and the other end of the tape is held at stake No. 7 in line CD. The tape-line or wire should be pulled taut. Stakes are then placed at every 30 feet along the tape-line. When this is done the tape-line is stretched between peg No. 2 in line $\mathrm{AB}$ and peg No. 8 in line CD, and pegs placed at each 30 -foot mark. This process is repeated until the length of the field has been gone over, when there will be a triangular space at each end that is not marked off, but which can be easily marked off by sighting the stakes in. Two men and a boy can mark off 10 or more acres a day by this method."

Hutt describes the following method of planting small-fruits in an orchard: "The bushes were arranged so 
that cultivation may be given both ways with a minimum amount of hand hoeing. The accompanying plan (Fig. 64) shows the arrangement of the trees and bushes. The trees are planted on the hexagonal plan, the rows being 30 feet apart and the trees 35 feet apart in the rows, the trees in one row alternating with those in the next. By this method of arrangement, 15 per cent more trees can be planted to the acre than by the ordinary method, and yet not be any more crowded. The bushes are 6 feet apart one way by 5 feet 10 inches the other. At present no trees are nearer than 9 feet to the apple trees. As the trees increase in size, those bushes within the circles,

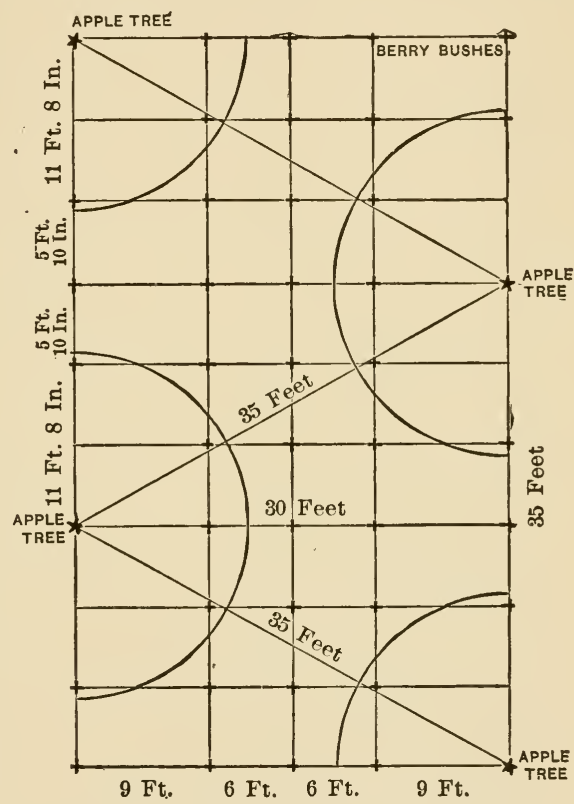

Frg. 64. Setting small-fruits in an orchard. as shown on the plan, will be the first to be removed."

\section{THE FAMILY FRUIT-PLANTATION}

It is impossible to give much specific advice for the plan of a family fruit-garden, because tastes are so personal, and the amount and character of land at disposal 
are so various. One can only say that the varieties should be chosen for best dessert and culinary qualities, for succession through the season, and the area so

10 Rods

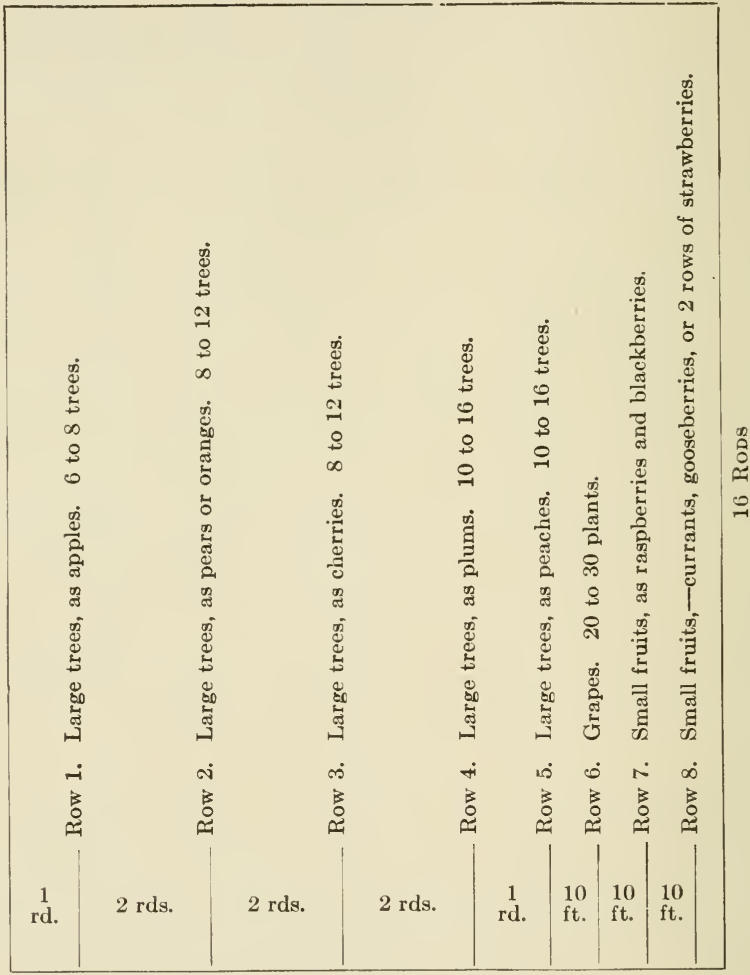

FIG. 65. Suggestion for a fruit-garden of one acre.

planted that the rows run the long way of the land to allow of easy cultivation with a horse. In general, it will not be necessary to provide for cultivation both ways. The accompanying diagram (Fig. 65) suggests how an 
area of 1 acre may be laid out in a fruit-garden for the home supply. For a number of years, other plants-as veget ables, small-fruits, or dwarf apples or dwarf pears may be grown, not only between the rows, but between the trees in the row.

The dwarf apples and pears find a special and advantageous use in the home garden, although, if there is room, a few trees of standards should be grown to lessen the chances of failure and to supply some of the staple varieties in larger quantity.

The vegetable-garden and fruit-gar-

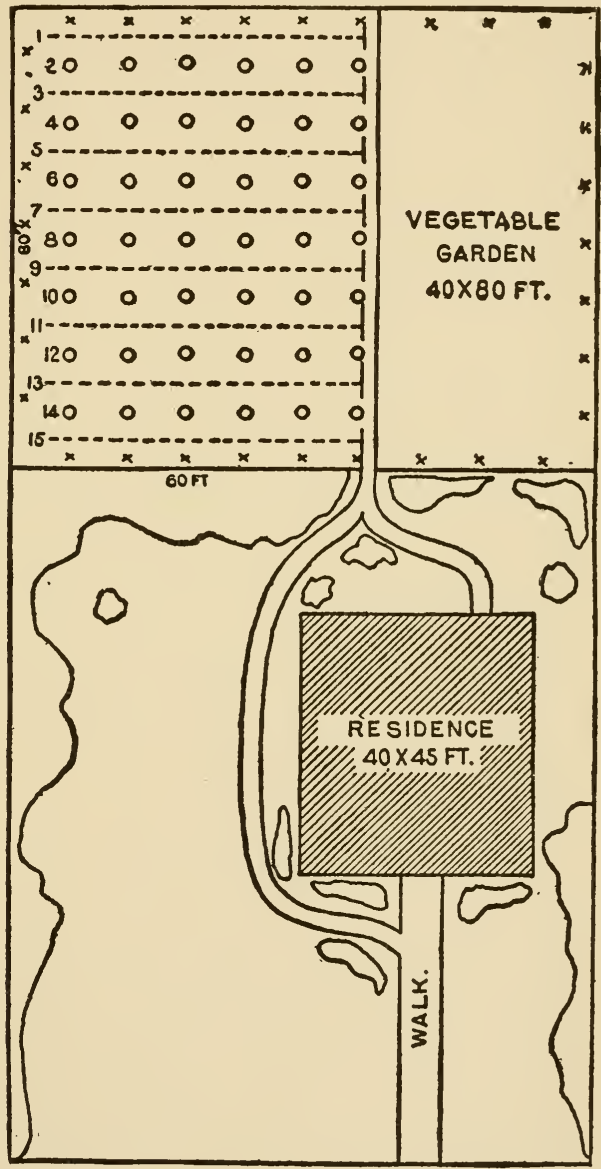

SCALE. 20 FEET.

FIG. 66. Plan for home grounds that comprise a fruit-garden. 
den may be combined when the available area is small. Corbett says that an area 60 by 80 feet will accomodate 442 fruit-bearing plants, and that an area 40 by 80 feet will be sufficient for a good variety of vegetables. $\mathrm{He}$ gives a diagram (Fig. 66), and the following key:

Fruits.

Thirty-two grape-vines, dispersed at intervals of 10 feet around the entire garden.

Three rows, each containing six trees, dwarf pears, eighteen specimens in all (rows Nos. 2, 10, 14).

One row, six specimens, peaches (row No. 4).

One row, six specimens, cherries (row No. 8).

One row, six specimens, dwarf apples (row No. 6).

One row, six specimens, plums (row No. 12).

One row, twenty specimens, blackberries (row No. 1).

Two rows, forty specimens, blackcaps (rows Nos. 3 and 5).

Two rows, forty specimens, red raspberries (rows Nos. 7 and 9).

Three rows, 300 specimens, strawberries (rows Nos. 11, 13 and 15).

\section{Vegetables.}

One row, one-half row rhubarb, one-half row asparagus (occupying 4 feet).

One row, salsify ( $1 \frac{1}{2}$ feet).

One row, parsnips ( $11 \frac{1}{2}$ feet).

Two rows, beets (3 feet).

One row, eggplants-plants set 18 inches apart-two dozen (3 feet).

Two rows, tomatoes-plants set 2 feet apart— two dozen (6 feet).

One row, summer squash, 12 hills, 3 feet apart (3 feet).

Two rows, cucumber, 24 hills, 3 feet apart (1 foot).

Two rows, early cabbage, 4 dozen plants, set 18 inches apart (4 feet).

Two rows, late cabbage, 4 dozen plants, set 18 inches apart (4 feet).

One row, early celery, 6 dozen plants, set 6 inches apart (2 feet).

Eight rows, peas, plant in double rows, 4 inches apart; follow by six rows late celery, thirty-six dozen plants (16 fæet). 
Two rows, lima beans, four dozen hills, 18 inches apart (4 feet).

Six rows, bunch beans; in succession sow seeds in drills, placing seeds about 6 inches apart in the row; follow by late cabbage, turnips or spinach (12 feet).

Two rows, radishes, four sowings, planted in double rows 6 inches apart (3 feet).

Two rows, lettuce, two sorts, adapted for early and late use (3 feet).

One row, parsley and peppergrass ( $11 / 2$ feet).

The space occupied by the last three plants may be given over to winter squashes by planting these before other crops are off the ground.

The satisfactions in a home fruit-garden are not to be measured by the money costs. It cannot be said that fruit can be bought more cheaply than it can be grown in the garden, for the market does not supply the varieties or the quality that one may secure from his own plantation.

It is desirable that a fruit-garden be made a part of a landscape design of a place, as regularly as the flowergarden, vegetable-garden, garage, or recreation areas. (Page 34.)

The condensed fruit-garden requires the best of fertilizing and of care.

\section{MAPS AND RECORDS}

One of the most annoying parts of fruit-growing is keeping track of the varieties that inevitably accumulate in plantations to which the owner gives much loving thought, and making a record of the performance of individual trees, vines and bushes.

The best means is a systematic plat, map or diagram of the plantation, in which every tree or every row of small-fruits is given a number. It is well to designate the rows in orchards by letters, and then to number each 
tree in the row, beginning with number one; or, some prefer to number all the trees in the plantation consecutively. It is an excellent plan for the grower to devote a large blank-book or record to each plantation, entering the plan of the area in the earlier pages, and then recording the yield of each tree or each row on consecutive pages devoted to the different years. Such a book would be to the orchard what the Babcock test is to the dairy,-a means of determining the profitable and unprofitable individuals. If such a record were kept, it would not be many years before the orchardist would be experimenting with a goodly number of his trees in order to determine how to make them as productive as are the best ones.

Labels.

Of labels there are endless devices, but no label can be expected to last in good condition more than six or eight years. For temporary or annual plants, where little horse work is done, the commercial garden stakes, 12 by $1 \frac{1}{4}$ inches, are excellent. These cost, when painted and made of soft, clear pine, $\$ 5$ to $\$ 6$ a thousand. For a more permanent stake label, one cut from clear pine, 2 feet long, $31 / 2$ inches wide, $11 / 2$ inches thick, and sawed to a point, is one of the best. These are given two thin coats of white lead, care being taken not to pile them on their faces until thoroughly dry, to avoid a rough surface for the pencil. The record may be made by a large, soft pencil, like a carpenter's pencil, or by a brush and black paint; but for all annual crops the pencil will be found more serviceable. At the end of the season, or when the record becomes dim, a thin shaving is taken off the face of the label, it is repainted, and used again. The label is thick enough to allow of many annual dressings, while the 
lower part is not reduced, and it therefore lasts for many years and is strong enough to resist the shocks of cultivator and whiffletrees. For ornamental bushes, this large label is too conspicuous, and for this purpose a pine label $1 \frac{1}{2}$ inches wide, $1 / 2$ inch thick, and 18 or 20 inches long is excellent. The lower half is soaked in a strong solution of sulfate of iron (copperas), and, after drying, in lime-water, to preserve it.

A great variety of labels has been recommended for trees, but it is doubtful whether we have yet found the ideal tally, although some of those here described seem to satisfy most needs. Many persons like zinc labels (No. 11, Fig. 67), cut in narrow strips from a sheet of the metal. The record is made on the zinc with a soft leadpencil, and the label is then wound about a branch. Very often the record is indistinct on the zinc, but the chief fault is the inconspicuousness of the label itself. It requires much searching to find a zinc label in a large tree, and this objection holds with almost every practicable tree label that has been introduced, even with the 3- or 4inch pine labels that are common in the market. Patent zinc and copper labels, cut from very thin metal, so that the record can be made by the impression of a sharp point or style, have been tried. These pretty and so-called indestructible labels are furnished with an eyelet through which the wire passes. They are soon broken by the wind, and in a year nothing is likely to remain of them but a hole hung on a wire.

A good label is the device shown at No. 3, in the illustration (Fig. 67). This is the pine "package label," used by nurserymen, 6 inches long and $11 / 4$ inches wide. These are wired with stiff, heavy, galvanized wire, much like that used for pail bales, and not less than 18 inches 


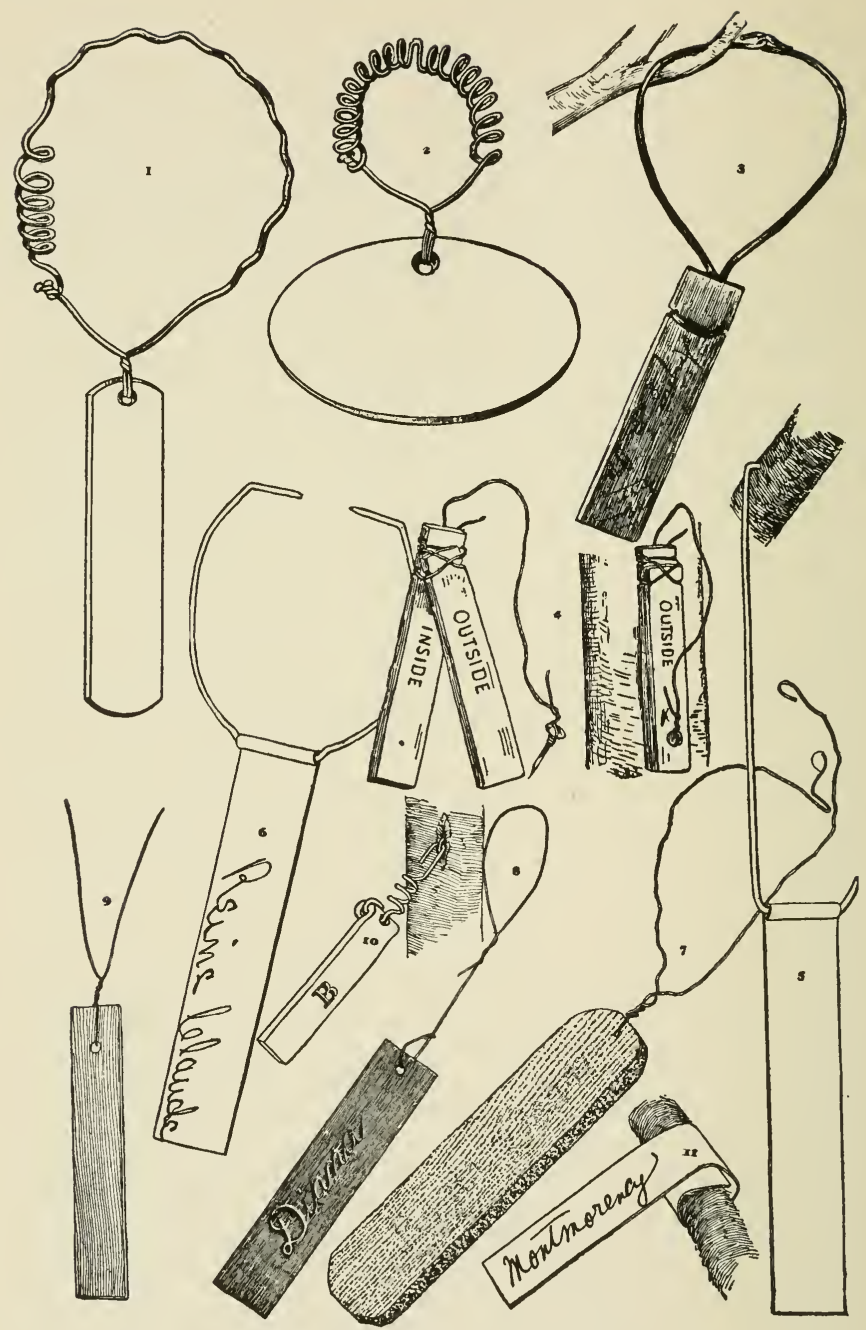

FIG. 67. Various types of tree-labels. 
is used with each label. Hooks are turned in the ends of the wires before the labels are taken to the field. A pail of pure white lead, well thinned with oil, is taken to the field with the labels. The record is made with a very soft pencil, the label is dipped into the paint, the wire is placed about a conspicuous limb, and the hooks are joined with a pair of pliers. The paint at first almost completely obscures the writing, but some of it drips off and the remainder dries in, so that the record becomes bright, and the soft pencil marks are indelibly preserved, while the label remains white. If the paint is brushed on, the soft writing will be blurred. If in the future the wood becomes gray, the label may be brightened by immersing it in a pot of white lead, without removing it from the tree. The large loop of wire allows of the growth of the branch, and the label hangs so low that it can be seen at a glance. The heavy stiff wire insures the safety of the label against boys and workmen. It cannot be removed without a pair of pincers. The label is large enough to allow of a complete record of the name of the variety, the place of purchase, age, and other matters; and it is readily found.

The various labels shown in Fig. 67, are as follows: Nos. 1 and 2, German labels, made of glazed earthenware, with the name colored blue and sunken. Strong copper wire, coiled, to allow of the growth of the limb, holds the label to the tree. No. 3, Cornell label, described above. No. 4, double wooden label, consisting of two common wooden labels fastened together. The name is written on the double label, as in any other label, but it is also written on the inside to insure permanence. When the outside writing is worn off, the label is opened and the inside is still bright. The label is secured to the tree by a tack or small nail, as shown in the cut at the right. The label is seen opened in the picture at the left. Nos. 5 and 6, zinc labels, used at the New York State Experiment Station, Geneva. The wire is driven into the tree, and the name is written or printed on the zine with black paint. No. 7, common hand-made 
wooden tag, taken from an old tree in the test orchard of the late Charles Downing, Newburgh, N. Y. No. 8, thin copper label, with the name indented into the metal by the use of a hard-pointed instrument. Some metal labels are liable to tear out at the hole when exposed to winds. No. 9, common painted pine label used by nurserymen, and costing (without the copper wire) about 50 cents a thousand, for the common size, which is $3 \frac{1}{2}$ inches long. No. 10, Lodeman's label, consists of a tag of sheet lead securely fastened to a coiled brass wire. The wire is secured to the body of the tree by a staple or screw-eye, and it is expected that the wire will become imbedded in the trunk as the tree grows. No. 11, common zinc label or tally, described on page 223.

The Fig. 68 is Paddock's vineyard label (designed by W. Paddock then of the State Experiment Station, Geneva, N. Y.). The label is a strip of heavy zinc secured to a stiff galvanized wire. This wire or shank is provided with a hook at the lower end and a half-hitch near its middle, so that it may be securely adjusted to the wires of the trellis, holding the label well above the foliage.

Much is said about the importance of giving attention to the behavior of individual trees and bushes in a fruit planta-

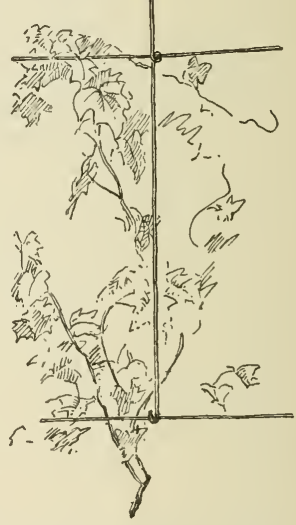

Fia. 68. A good vineyard label. tion, yet there is seldom any available record of them. With the refinements of the fruit-growing business, attention must be given to this subject; and maps and labels will then be indispensable. 


\section{CHAPTER VII}

\section{SUBSEQUENT CARE OF THE FRUIT-PLANTATION}

Now that the property is planted, we may consider what to do with it. The main general practice is tillage. This is to be the basis of the prosperity of the enterprise, but it will not be necessary to repeat the discussion in Chapter III.

It is a common opinion with fruit-growers that very heavy growth is opposed to fruitfulness; and yet the plants that are vigorous and strong and make rapid growth from the start are usually the most productive. They are largest, and should have most bearing surface, and the fruit should be large. Just where lies the danger to productiveness of too rapid growth, if the danger exists, is not easy of statement. Very heavy pruning of old trees is reported as not breaking the fruit-bearing habit, but it is commonly supposed to have the effect of reducing the set of fruit. There are probably many conditions and circumstances that modify the results.

We remember that if the roots are made to strike far into the land by deep plowing for the first few years, it may not be necessary to plow heavy furrows in the plantation in later years, except to turn under cover-crops. This can be accomplished even with hard clay land. Two orchards on very hard clay of uneven surface, in six years from the setting of the trees, were in such condition that heavy plowing was no longer necessary, and the spring fitting of the land was done with spading-harrows and spring- 
tooth harrows, and the subsequent tilling partly with a light spike-tooth harrow. Of course, this means that there must be no delay in the spring work in the orchard, and no years of neglect. Weeds are not allowed to appear; but if a patch should get a start now and then, it can usually be destroyed with the cultivator. Perhaps once or twice in the season it may be necessary to send a man through the orchard with a hoe to take the weeds away from the trees, but the space that needs such hand labor will not exceed 2 feet in diameter, and it is usually very much less. This has been accomplished by exercising great care to plow the clay when it is in such condition that it pulverizes when it is worked, and by the incorporation of one or two cover-crops.

It will be necessary now and then to grow cover-crops, and the land will then be regularly plowed in spring to turn the crop under; but even so, it may not be the desire to secure a heavy growth of cover-crop, and the spring plowing need not necessarily be deep and laborious. If, however, it seems to be necessary to plow 5 or 6 inches deep, there will be no hesitation in doing so, for the roots are deep enough to escape the plow if the plowman is

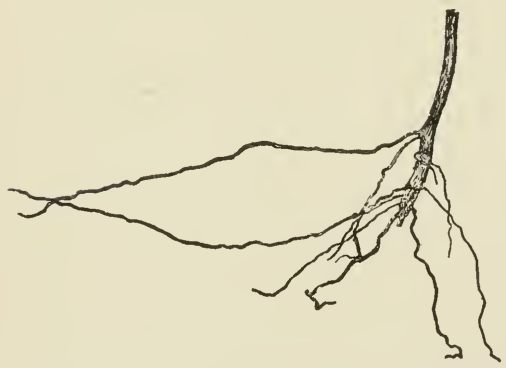

FiG. 69. A broken grape-root renewing its connection with the earth. ordinarily careful about the trees.

It is not necessarily a misfortune to cut the smaller roots with the plow, providing only a few are cut in any year. In other words, it is no doubt safer to sever a good many roots $1 / 2$ inch, or sometimes even 1 inch, 
in diameter, than not to plow the orchard at all. The severed roots usually send out numerous branches near their ends, and these branches increase the foraging power of the roots in soil normally laid under small tribute. Figs. 69 and 70 are drawn from actual specimens of roots that were broken by the plow. It would seem as if the absorbing area of the root had been actually increased, for the many small roots present more

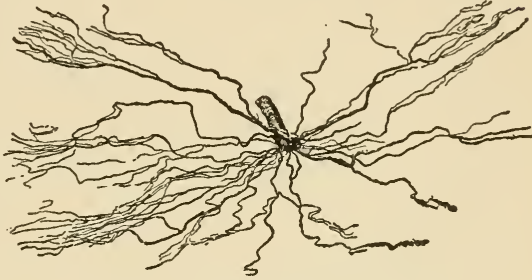

Frg. 70. The branching of a broken apple-root. surface than did the main shaft of the root. It must be remembered, however, that the real surface of the original root extended far beyond the present point, and there is no way of telling whether the adventitious roots actually present more surface than the whole of the original root. This breaking of the small roots is not recommended, but it is not necessary to take great pains to avoid it.

The particular methods of caring for plantations of small-fruits can scarcely be discussed in a general work on fruit-growing, but it may be said that a deep tillage with a spring-tooth cultivator (No. 9, Fig. 16, page 86) is usually sufficient for breaking up the ground in spring among bush-fruits, if the land is clean and in good condition. If the land is soddy or infested with bad weeds, however, a regular plowing may be necessary. A handy plow for such plantations is one of the type shown in Fig. 19 , page 96 , managed by a single horse. The management of the land in small-fruit plantations does not differ in principle from the management of orchard lands, and the tools are of the same general kind, except smaller 
and usually adapted to a single horse. If the rows are far enough apart, however-as they usually are in blackberries and black raspberries-it may be necessary in hard lands to hitch two horses to such a tool as the spring-tooth cultivator.

It is commonly a matter of a few years thoroughly to learn one's soil and climate, after moving to a new farm. The farmer has a local and personal problem to apprehend and to solve. He should not be discouraged, therefore, if he does not secure the desired results from the treatment of his land within the first two or three years. He must look after the work himself. Even though he have a perfect understanding of the subject and the intention to do the best by his plantation, he will very likely fail of satisfactory results if he leaves the management of the work to others.

Aside from the general practice of tillage, there are many special and incidental practices, some of which may be discussed briefly, after we have considered such essentials as pruning, thinning and frost-protection.

\section{PRUNING}

The subject of pruning cannot be understood until the essential principles of the practice are clearly apprehended. It is often said that pruning is unnecessary; this is true if one desires to grow brush. If he desires to grow fruit, and particularly good fruit, he must bring about the proper conditions for it; and one of these necessary conditions is a plant properly thinned and under control.

The only proper pruning is one that is applied in something like the same proportion every year, and that 
begins the very year in which the plants are put into the ground. Trees alternately neglected and heavily pruned are kept in a condition of upset that is likely to interfere with the best satisfaction in fruitgrowing.

The aim in pruning is to keep the top open, to remove superfluous and interfering parts, to maintain a size and shape that admits of easy spraying and fruitgathering and other labor,

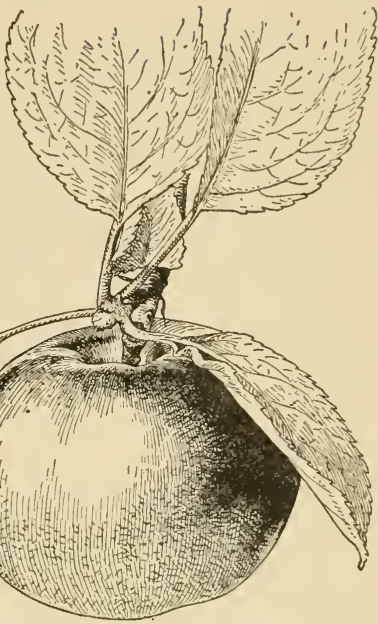

FIG. 71. Fruit-spur forming at the side. to eliminate diseases and injured branches, to encourage the fruit-bearing wood. How to accomplish these results is to be determined by practice. A good pruner has "an

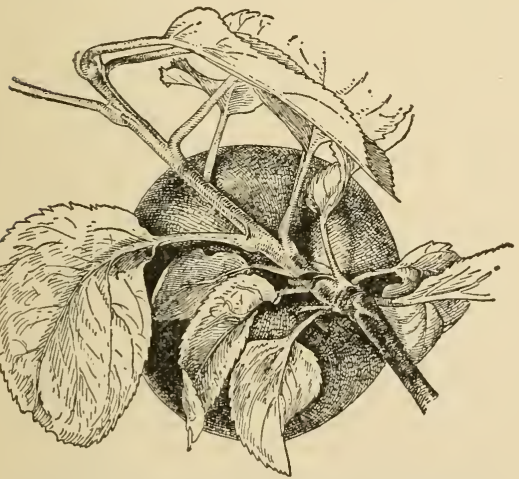

Fig. 72. Shoot grown too long for probable fruit-bearing. There will be an alternation of fruit-bearing on this spur. eye" for the work, and he undertakes it carefully as an artisan skilled in the operation. Pruning is not carpentering.

It is easy to overdo pruning. It is not primarily the removal of wood, but the working out of a purpose. Pruning is mostly for training in young trees, and "as the 
twig is bent the tree's inclined." "Pruning for fruit" and "pruning for wood" are refinements of the art that find little place in the usual commercial plantation.

\section{The bearing wood.}

Pruners should always understand how the fruit-bearing wood is borne. In the cane-fruits (raspberry, blackberry, dewberry), the fruit is borne on canes that grew the previ-

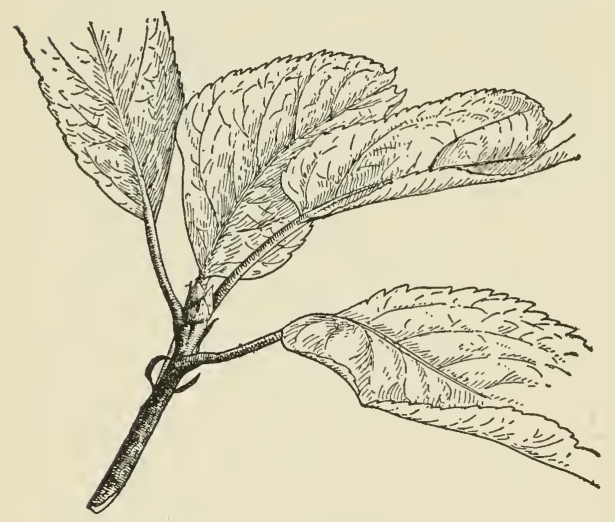

FIG. 73. Terminal fruit-bud forming on an apple shoot.

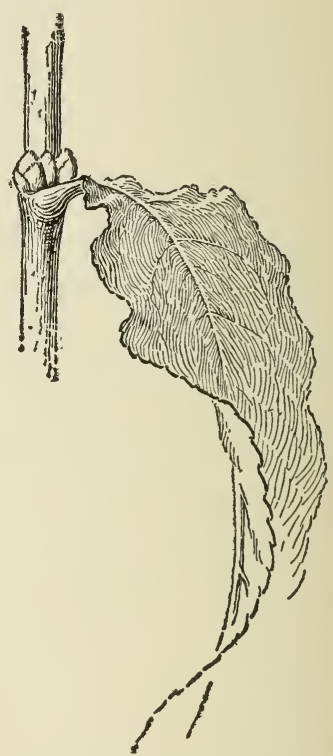

Fig. 74. Peach-buds forming in the axil of a single leaf. The central one is a leaf-bud.

ous year; and when this fruit is being borne, other cancs are growing from the crown of the plant to bear the fruit the succeeding year: therefore, the fruiting canes are removed when the fruit is off, and only a limited number of canes is allowed to grow for the next year's crop. Gooseberries and currants also bear on canes, but these canes may not bear until the second year and they continue to bear profitably for two or three years. Grapes produce 
their fruit only from canes that grew the preceding year. The tree-fruits may bear on the preceding year's axial growth or on short spurs. Most of them bear both ways, but the larger part of the fruitage of apples, pears, plums, cherries, apricots, is on spurs. Peaches bear profusely on the last year's axial or straight shoots, but they also bear on short-lived spurs. Figs. 71 to 76 show fruit-bearing in apple and peach.

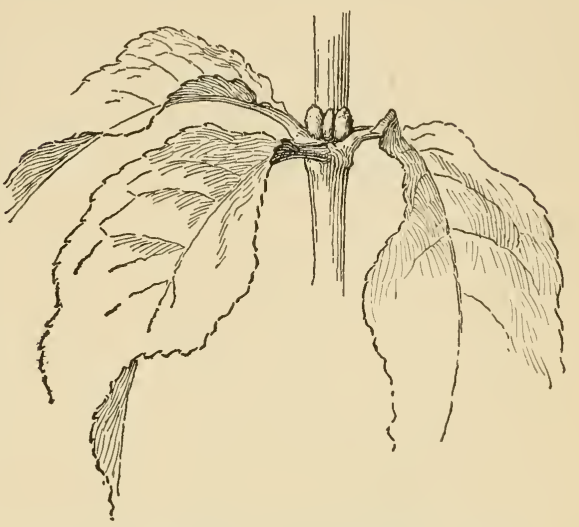

FIG. 75. Peach-buds forming with three leaves. The central bud is a leaf-bud.

In the northern states, the best time for pruning, in general, is late winter and very early spring. It is best not to prune when the wood is

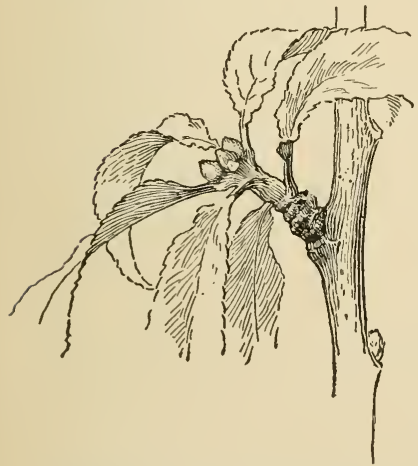

FIG. 76. A short branch or fruit-spur on peach. Central bud is probably a leaf-bud. frozen hard, although there is no physiological injury to a dormant tree thereby. The wounds should be made close to the branch or trunk, and no stubs should be left. Large wounds - of 2 to 3 inches and above - may be painted or waxed for protection. Wellmixed paint of white lead and raw linseed oil (colored, if one desires), applied after the wounds are well dried out, is 
the standard dressing; on very large wounds, it should be renewed from year to year. All wounds should be made with clean, regular cuts, without hacking or splintering.

\section{The kind of top.}

When the tree is planted, the grower must decide how high the top is to be and also what form; and then all the

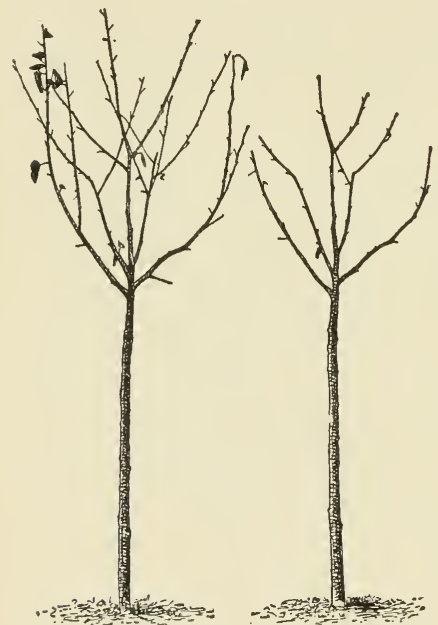

FIg. 77. An apple tree one year after planting, unpruned and pruned. subsequent pruning must be directed consistently to that end. In the old apple orchards of the East and North, the tops were often too high, - as much as 5 or 6 feet. It is just as easy to make them too low, -1 to 2 feet (see pages 189, 190).

In general structure, the tree may be open-centered with no leader, which is a favorite form for peach trees; or it may be twostoried, with the trunk continued beyond the first scaffold of branches or at least with a second tier or scaffold, which is the preferable form for pears and apples.

The illustrations show different commendable ideas in pruning. Fig. 77, from Stuart, shows an apple tree unpruned and pruned, one year after planting. Figs. 78 and 79 (Erwin and Bliss, Iowa) show a neglected young tree before and after pruning. Spreaders have been inserted to encourage a more open top. Jarvis gives 
figures (Figs. 80 and 81) of an apple tree ten years old and not pruned since planting, and the same tree after pruning to an open center. This is for New England conditions. Fig. 82 shows a good old orchard tree; and Fig. 83 what Jarvis considers to be "an ideal Baldwin apple tree," properly trained from the beginning, with a

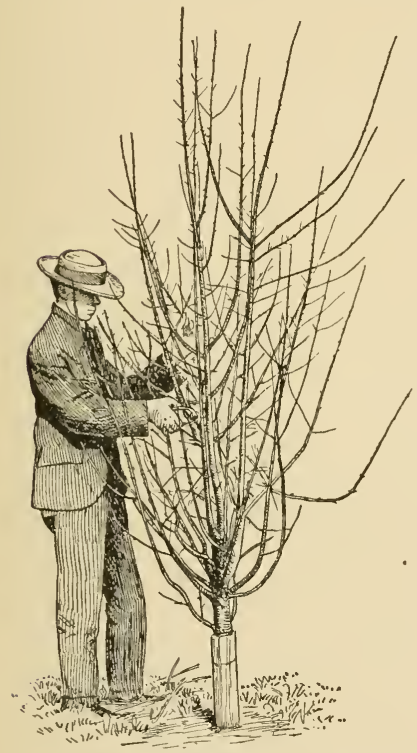

Fig. 78. A neglected young apple tree.

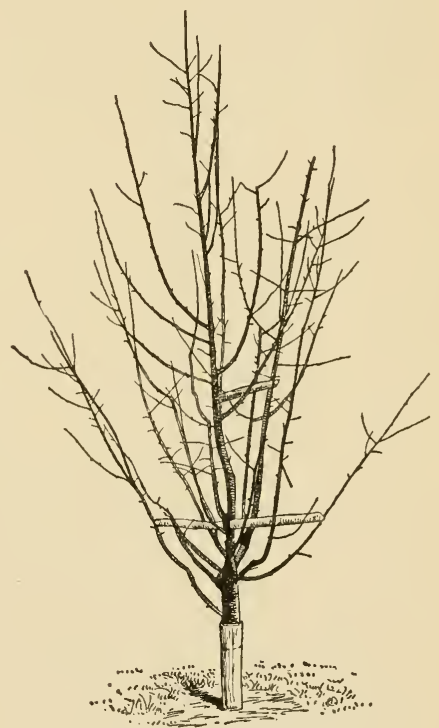

FrG. 79. The tree pruned and branches spread.

low head and broad-conical shape. Fig. 84 shows a peach tree at bearing age of good top-form, but possessing a crotch that is likely to split; and Fig. 85 shows an undesirable formation in an apple tree. Many growers are now training peaches to lower heads than in Fig. 84 . Fig. 86 represents a good Morello cherry at young bearing age; and 
Fig. 87 a sweet cherry (in bloom) but with more main branches than necessary. Fig. 88 is a successful orchard in Wyoming. Fig. 89 shows a Duchess apple orchard

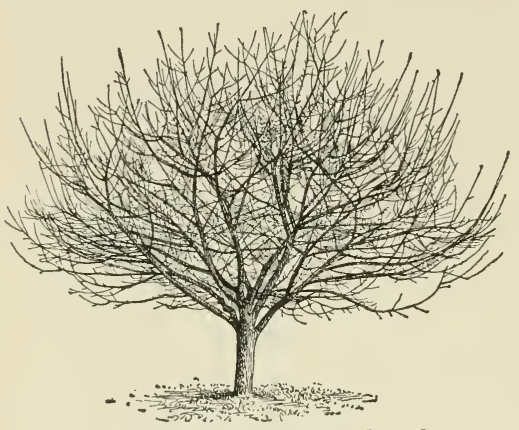

Fig. 80. Ten-year-old neglected apple tree. Connecticut. in bearing at Ottawa, Ontario.

What to remove.

The pruner should remove superfluous and unnecessary parts, water-sprouts, weak straggly limbs, diseased and badly injured limbs, at least one of the limbs when two cross and rub, hanging limbs that are much in the way, one of badly forking limbs, and some of the limbs in parts that are much crowded. Unless it is desired to thin the fruit, the fruit-spurs should be protected; and also the small healthy stocky shoots along many of the larger branches, for care should be exercised not to produce long

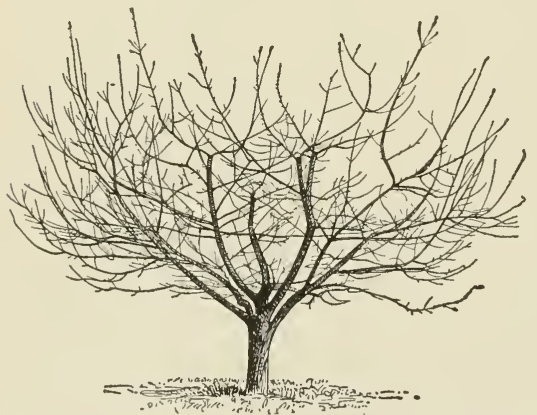

Fig. 81. The same tree thinned and pruned to an open center. and pole-like parts.

Renewing old trees by pruning:"dehorning."

Pruning is one of the legitimate means of renewing neglected orchards; but aside from this, it is often advised that very old and weak trees be rejuvenated by cutting 
the whole top off and leaving horns or stubs 1 to 3 feet long. This may work, but in most cases it is not worth the while. It takes too long, the results are too uncertain,

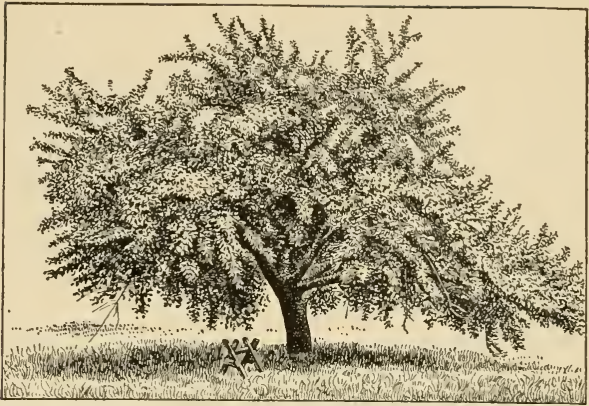

FIG. 82. A good apple tree of the old-fashioned kind, with a trunk 4 to 5 feet high.

and probably the old tree will not pay for the trouble.

The remaking of a young or middle-aged tree by such operation when it has been broken by ice or overbearing or injured by winter or by fire is another matter, and may be in every way worth the effort.

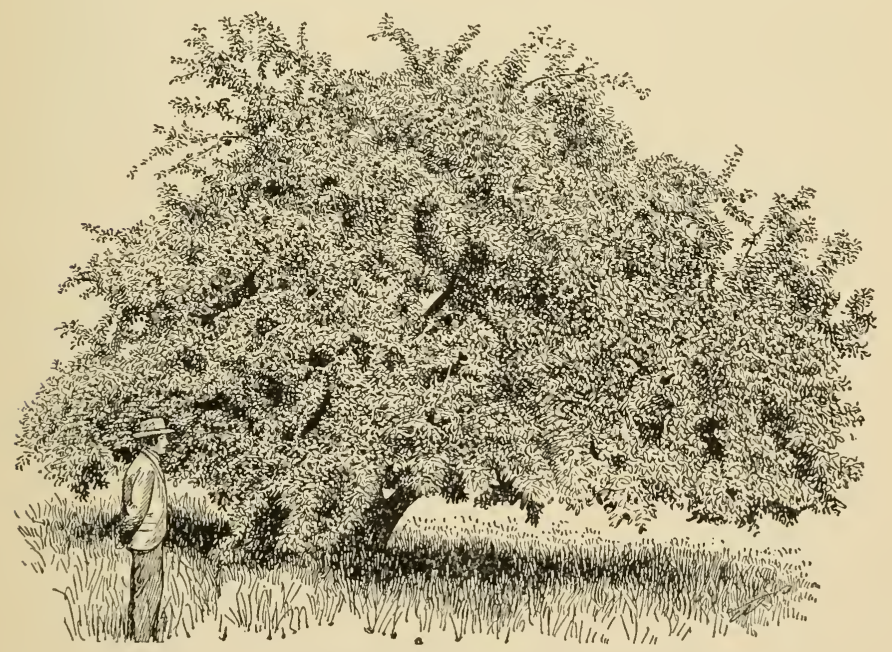

FrG. 83. A low-headed apple tree of good form and proportion. 


\section{Heading-in.}

The question of heading-in of trees is commonly misunderstood, and there are likely to be many opinions. It is a special practice. Two considerations may help the grower think out the problem for himself.

In the first place, it is largely a question of the type of training that the grower prefers; that is, every good

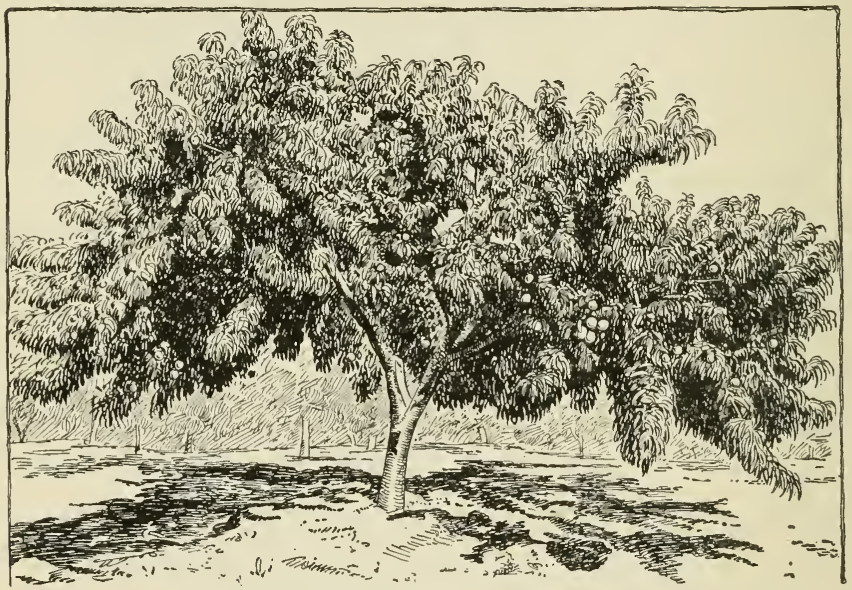

. 84. A peach tree, at bearing age, but with a bad crotch.

fruit-grower will set before himself a certain conception as to form of tree, and he will bend all his energies uniformly and consecutively to the working out of this idea throughout all the years of the plantation. If his ideal is for trees with round and dense heads, then he will, of course, head-in the stock from year to year; if, however, he sets for himself the ideal of a tree with the natural form and open head, he will not head-in, as a rule. Whichever purpose the grower sets should be worked out sys- 
tematically and logically from first to last. The heading-in ideal is always set for dwarf trees.

The other factor that chiefly determines the question of heading-in is the checking of redundant growth while the plants are young. As a rule, young trees grow more thrifty and upright than do old ones, and the grower should not be misled into thinking that his trees will keep up their present pace after they have come into maturity and bearing. Kieffer pears, for ex-

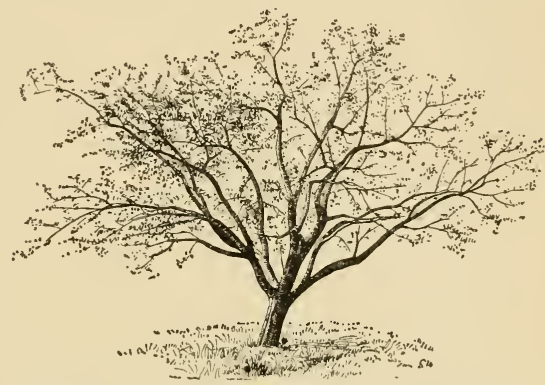

FIG. 85. A mature apple tree, showing scaffold limbs growing from same plane, and liable to split. ample, make a very tall and narrow growth for the first two or three years, as if headed for heaven (but they are not); and when the bearing time arrives, this enormous growth is checked and the tree spreads. However, in such cases, it may be advisable to head-in the tree for a time, or until the period of maturity begins to arrive. This

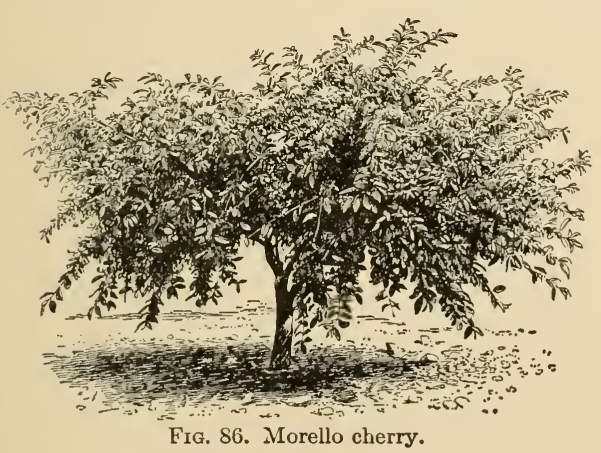
heading-in, however, is not the fundamental corrective of the difficulty; in fact, it rather augments the difficulty. It is a question, therefore, whether it is better to prevent 
redundant growth by withholding tillage and fertilizers, rather than to produce it and then to take it off.

If, therefore, the grower wants headed-in trees, he should have them. He is then able to plant his trees closer together. The habitual heading-in is practised only with plums and peaches as a rule in the northern states. The fact that relatively

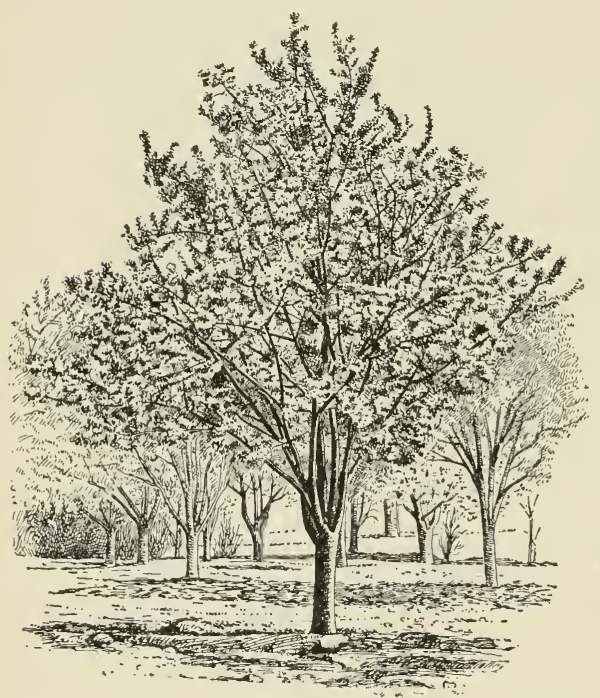

FIG. 87. A sweet cherry at bearing age. very few persons grow headed-in trees is indication enough that it is not a general practice and is not essential to success. For general purposes, the freegrowing tree is to be preferred, with only such shortening of some of the branches as will keep the plant in shape. The heading-in is performed at the same time as other pruning. If the annual growth is vigorous, perhaps one-half of it is cut away by being headed back.

Dwarf apples and pears are always kept within bounds - that is, kept dwarf-by heading-in. After the plant has reached its full height-in five to eight years-it is not allowed to grow any taller, or at least to increase in height very slowly. This means that nearly all the annual growths in length are to be removed, and the fruit-bearing is to 
depend on the spurs. The top should be thinned at the same time of weak and soft shoots, to allow the fruit-spurs room and light for best development.

\section{THE THINNING OF THE FRUIT}

The thinning of fruit for the purpose of improving that which remains is a practice much advised but too little

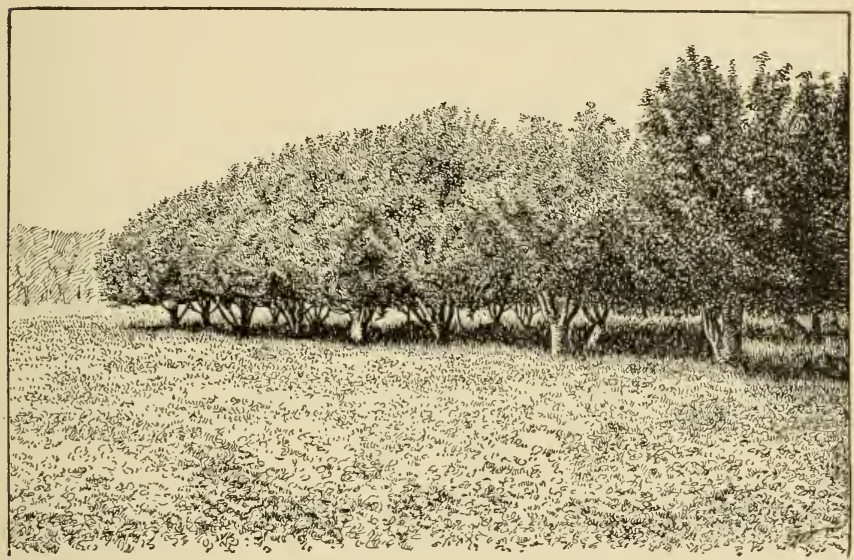

Frg. 88. A Wyoming apple-orchard, showing form of trees.

followed. It has been demonstrated time and again that no work in fruit-raising is more important than this thining, if one desires to realize the most from his fruit. It results not only in a much finer product, but it is also a means of destroying the insect-infested and diseased specimens, and of saving the energies and vitality of the tree. Persons complain that the thinning of fruit is expensive and laborious, and this is true; but it is a fair question whether there is anything worth the having of 
which the same may not be said. The fruit must all be picked sooner or later, and it does not cost very much more to pick it early in the season than to pick it late; in fact, much fruit not worth picking in the fall might have been eminently worth the labor if the trees had been

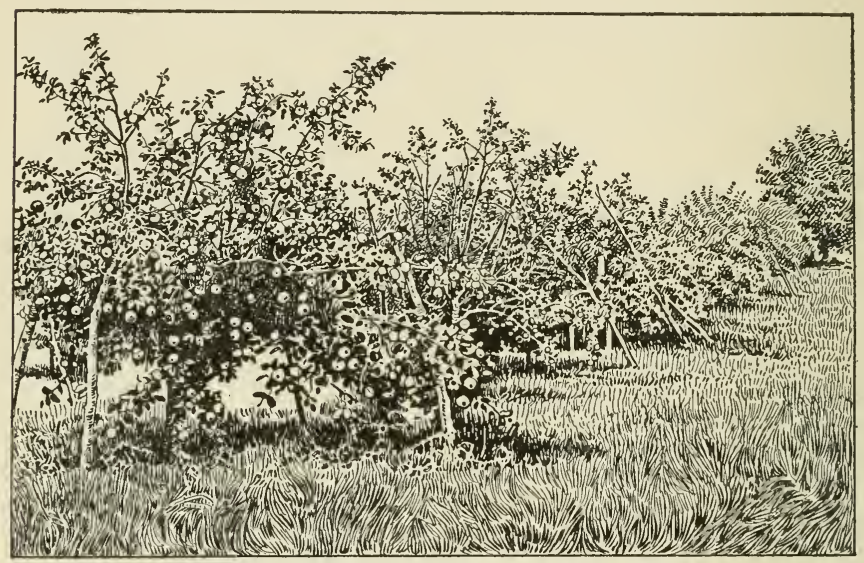

Fig. 89. Duchess apple-orchard in Canada.

thinned in the early summer. The practice is now assuming very special importance because of the rigid and highclass systems of grading fruits that are being adopted by shipping associations.

There are two general methods of thinning fruits: One is by pruning, by means of which the superfluous branches, or even the fruit-spurs themselves, are removed; the other is the direct picking of the redundant fruits. While pruning may accomplish much, it is not sufficient when the best fruit is wanted.

There is no reason in the nature of things why trees should not bear annually; but the formation of the fruit- 
spur is usually such as to preclude the production of the fruit on the same spur every year. The philosophy of the thinning of fruit, therefore, is that one spur shall bear one year, and another spur the next. This means that when fruit is thinned, it should be the object to remove it wholly from some spurs in order that they may produce fruit-buds for the following year. In those regions in which certain fruits are systematically thinned, the crop is obtained with great uniformity every year. This is especially true of peaches. There is no reason why the

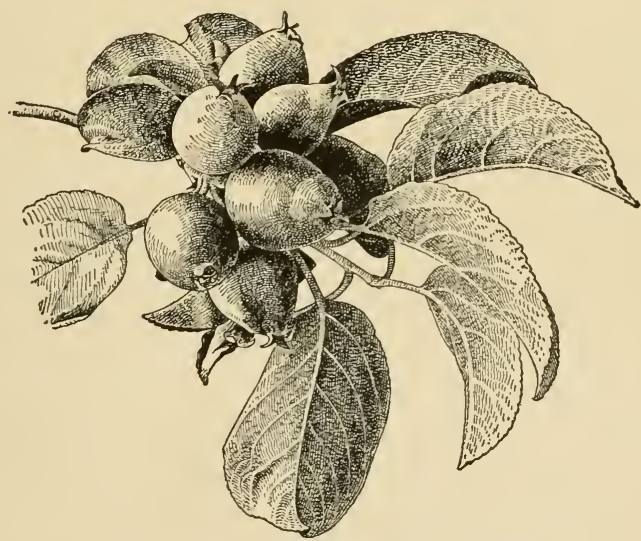

Frg. 90. Apples in a cluster; to be thinned.

same should not be said of other kinds of fruits, and for every fruit-region.

Thinning the apple.

There is no dispute of the value of thinning for peaches, dwarf pears and a few choice fruits, but it has been questioned whether the same or similar methods can be profitably applied to the apple. The boxing of apples, however, 
is forcing the question. When choice fruit is to be grown, the practice will be necessary if the set of fruit is heavy, if some of it tends to grow in clusters, and particularly

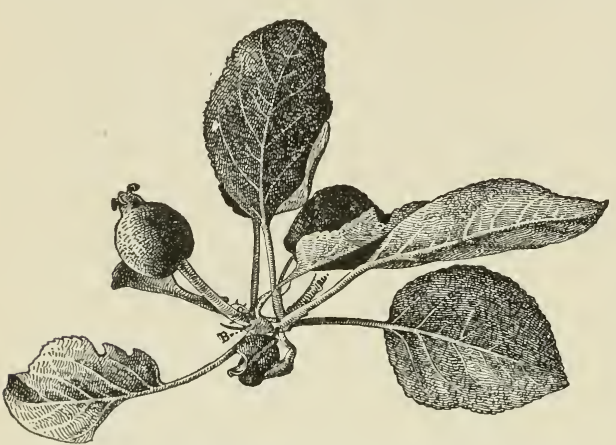

FIG. 91. Only one apple should remain of the cluster.

if fertility and moisture are not well supplied. Some varieties tend to grow in clusters, as the Chenango (Fig. 90), and these should always be reduced to one fruit (Fig. 91).

There have been no long-continued experiments in this country on the thinning of apples. One of the standard investigations is by the State Experiment Station at Geneva, New York, under the direction of S. A. Beach. He reports as follows (Bull. No. 239.):

Tests are here reported on thinning apples in June and July during a period of four years. Mature trees of Baldwin, Rhode Island Greening and Hubbardston were included in the tests. These trees stood in a good commercial orchard. They were well cared for and were all similarly treated except that some had their fruit thinned while others did not. The thinning was usually done when the fruit had grown to about $1 \frac{1}{2}$ inches in diameter. Observations were made on the effect of thinning upon the color, size and market value of the fruit and upon the amount and regularity of fruit-production. Some data were obtained for a comparison of different amounts of thinning, but the results are not regarded as conclusive.

Color.-When the trees were well filled with fruit, thinning generally improved the color. At harvest-time the various hues were heightened and tended to be more brilliant on fruit from thinned 
than from corresponding unthinned trees. Where the fruit set sparsely before it was thinned, the thinning had no appreciable influence on its color.

Size.-Whenever the trees bore well, thinning had the effect of increasing the size of the fruit. This occurred with Baldwin and Hubbardston more often than with Greening, which may be accounted for by the fact that the Greening trees did not carry any crops so heavy as the heaviest crops of Hubbardston and of Baldwin.

Market value.-The intrinsic value of the apples from the consumer's standpoint was generally increased by thinning, the thinned fruit being usually superior in size, color and general quality. The thinned fruit, as a rule, was better adapted than the unthinned for making fancy grades, for marketing in boxes, etc. Where such ways of marketing can be advantageously used, the thinned fruit should bring an increase in price corresponding to its superiority in real value. But where it must be put upon the ordinary market in barrels there is less chance for the thinned fruit to sell at sufficient advance over the unthinned to pay for thinning, especially if the thinned fruit cannot be furnished in large quantities.

Amount and regularity of fruit-production.-In these experiments the practice of thinning the fruit did not appear to cause any material change either in the amount or the regularity of fruitproduction.

Methods of thinning.-No exact rule for thinning apples should be laid down. The requirements vary with the different individual irees and with the same tree in different seasons. The amount of thinning should be suited to the conditions as shown by the age and condition of the tree, by the amount of fruit which has set, and by the distribution of the fruit on the tree. In thinning apples, all wormy and otherwise inferior specimens should first be removed and no more than one fruit from each cluster should be allowed to remain. After this is done, if there is a full set of fruit, greater improvement in the grade may be expected from thinning to 6 inches than to 4 inches apart.

Does it pay to thin apples?-The reply of Mr. Wilson, a practical fruit-grower, in whose orchard these tests were made, is in effect that where there is a general crop of apples, the set full, the chance for small apples great and widespread, it would pay to thin enough to insure good-sized fruit; otherwise not, except to protect the tree. Methods of removing the fruit.-No way of jarring or raking 
off the fruit is advised in thinning apples, since by these methods all grades are removed indiscriminately. Hand work is best. It permits selection of superior, and rejection of all inferior, specimens.

Time to thin.-The experiments in thinning apples and other fruits lead to the opinion that early thinning gives best results. Begin with apples within three or four weeks after the fruit sets, even if the June drop is not yet completed.

Cost of thinned as compared with unthinned apples.-The cost of thinning mature trees which are well loaded should not exceed 50 cents a tree, and probably would average less than that. Although a given number of fruits can be thinned faster than an equal number can be picked when ripe, it has required about as much time to thin a tree as it has to harvest the ripe fruit. Thinned apples can be graded more rapidly than an equal amount of unthinned apples. Thinned apples can be handled more economically than unthinned apples because they have proportionately less of those grades which form the least profitable part of the crop, namely, the No. 2's, the drops and the culls.

Batchelor makes the following comments on the thining of apples in Utah (Circ. No. 12, Utah Exp. Sta.):

The actual methods to be used in this operation will vary somewhat with the conditions, such as soil, age of trees, varieties and methods of irrigation and pruning. The fruit-grower should experiment and learn the best methods to follow under his conditions. Some people thin to a definite number of boxes on a certain-aged tree. This may be determined on one or two trees by actually counting the apples. These counted trees may then be used as models, so to speak, and thin the others accordingly. Other growers have learned by experience the proper distance apples should be from each other on the tree if they are to reach a marketable size. For the past two years, in thinning Jonathans to a minimum distance of 4 inches, on eight- and nine-year-old trees, there were still too many apples remaining for their maximum development. A minimum distance of 5 to 6 inches would no doubt have given better results under the existing conditions. Gano trees nine years old, thinned to one fruit on a spur, with the spurs a minimum distance of about 6 inches, gave good results.

The above experience may serve as a guide in helping each 
grower to determine the proper method to follow under each individual case. Certain thinning experiments have been carried on by the Ohio Experiment Station, in which case the fruit was left the minimum distance of 8 inches. This seemed to give the best results under the conditions. It is often suggested that pruning may be substituted for thinning. To be sure, pruning thins out the fruit-buds very materially, but it can hardly take the place of thinning. Some relief must be had for the crowded cluster on the individual branches, and again, such severe pruning as would properly reduce the crop on a bearing apple tree would likely be too severe pruning otherwise.

For the best results, the thinning operation should commence immediately after the June drop. The work should be done while the apples are 1 to $1 \frac{1}{2}$ inches in diameter. It is only natural to expect that the sooner the remaining apples are accorded the entire strength and nourishment of the tree, the better the results. Broken limbs may be averted if the thinning is done in August, but the other benefits will not be so pronounced as though the work had been done at an early stage in the fruit's development. In other words, less of the tree's energy will be thrown away and more diverted to the proper channels if the thinning is done early in the season.

Concerning tools for this work, some varieties like the Gano and Ben Davis are easily thinned by hand, while varieties with short fruit-spurs are not so readily handled this way, and the work may be hastened by the use of a small shear made especially for this purpose. In any case, care should be used not to break or injure the fruit-spurs in the operation. Very few fruit-spurs will be broken by the careful worker if the spur is grasped firmly in one hand while the apples are removed with the other. An upward and backward twist of fruit will loosen the stem from the spur without disturbing the remaining fruit or breaking the spur. One or two apples are often removed from a cluster in this way, leaving the remaining apple undisturbed. Careless workers who persist in pulling off the fruit should not be tolerated, as this practice loosens much of the remaining fruit and breaks off many spurs. A light picking ladder will hasten the work with the older trees, and the entire bearing surface may be easily reached.

The cost of this work is only slight, compared with the increased returns. The actual time in thinning will be saved at harvest time in sorting the crop. If, however, full time is charged to this thinning 
work, the cost should not exceed $1 \frac{1}{2}$ to 2 cents a box of harvested fruit. In case of the Gano variety, which is more readily thinned than some other sorts, the cost will hardly exceed 1 cent a box, on low-headed trees.

Herrick, in Colorado, also reports marked results with the Winesap (Bull. No. 170, Colo. Exp. Sta.):

Thinning of the mature Winesap tree pays in money returns the first year. The more evenly distributed the fruit on the tree, the more uniform will be the size and color of the pack. Winesaps respond to thinning by increased size and better color when thinned as late as July 20. The earlier thinning can be done, the better will be the returns from the fruit sold and the greater will be the vitality of the tree. The best results are attained in thinning an old Wine-

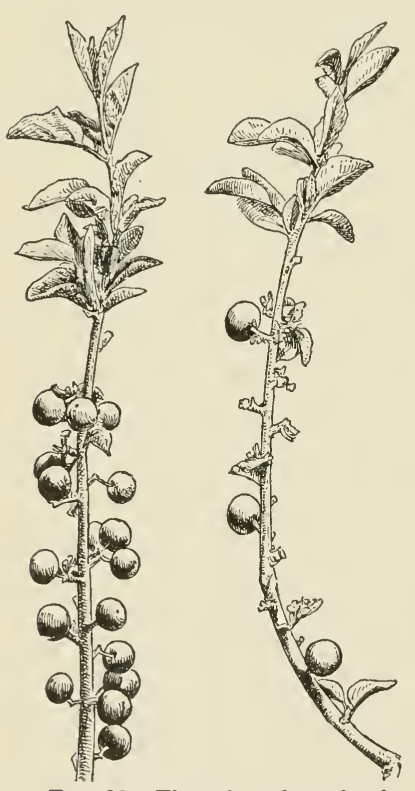

FIG. 92. Three-foot branch of Winesap before and after thinning. sap tree, by leaving the apples 9 to 10 inches apart. (Fig. 92.) Proper pruning, and keeping the trees a proper distance from each other, will facilitate thinning. Systematic, annual, uniform thinning, done from the time the trees come into bearing, should have much to do in securing an annual crop, thereby doing away with the so-called "off-year" bearing of some of the apple varieties.

Thinning other fruits.

Maynard reports experiments in thinning plums, from which there were marked gains. "A distinct advantage gained by thinning is the appreciable decrease in the ravages of fungous diseases and, to a small extent, of insect pests. This is especially notice- 
able in the case of monilia, or brown fruit-rot, which often ruins the peach or plum crop in wet seasons, while the specimens of fruit attacked by the curculio were largely removed in thining."

Good results have been reported in thinning of canefruits. Experiments at the Cornell Station with raspberries and blackberries failed, however, to give such specific results, as reported by Card: "To test the feasibility of thinning berries, rows of Cuthbert raspberry and Early Cluster blackberry were thinned by clipping off the tips of most of the clusters, and also by reducing the number of clusters, especially in the raspberry. The result was not encouraging, for the eye could detect no increase of size in the berries on thinned plants, and as the principal object was to increase the size and attractiveness of the fruit, it seems to have failed of its purpose. It should be said, however, that the season was favorable for berries, and the crop was very fine. In a very dry season, or with varieties much inclined to overbear, the result might be different. In general, however, the thining can be managed well enough and much more cheaply by regulating the amount of bearing wood at the annual spring pruning."

It is not probable that the thinning of the bush-fruits will pay as a rule, inasmuch as they are not closely graded or sold by the size of the berry. Nor are cherries thinned. Grapes grown for table use may probably be thinned with good results. If it pays to thin apples, it ought also to pay to thin pears.

\section{How to thin.}

The thinning of tree-fruits is performed in essentially the same way as the fruits are picked; that is, the fruits 
are taken off by hand, and are then dropped to the ground, where they may either be allowed to lie, or, if they are infested with insects or disease, may be raked up and burned. Methods of thinning apples have been discussed (pages 244 to 248). It is customary to thin the fruits as soon as the dangers of spring frosts and other early accidents are past, but before they have become of sufficient size to be a tax on the tree. Peaches are usually thinned when they are about the size of a small hickorynut (that is, about the size of the end of one's thumb), and apples from that size until they are twice or sometimes even thrice as large. Various devices have been suggested for the thinning of fruit, but they are mostly impracticable, because they do not discriminate between good and poor fruit, do not leave the fruit well distributed, and are very likely to break off the spurs. Some of the implements figured on page 377 may be used in special cases.

It requires more discrimination and judgment to thin fruit properly than to pick it. In the thinning of peaches, it is a good rule to allow none of the fruits to hang closer than 4 to 6 inches of each other. This means that.in years of very heavy setting, fully two-thirds of all the fruits are removed in June. In many parts of the country this thinning is systematically done, and it has in all such cases come to be regarded as an indispensable element in successful fruit-growing. No reliable estimates of the cost of thinning fruit can be given, because so much depends on the form and pruning of the tree and the quantity of fruit to be removed. The result is also greatly influenced by the character of the workmen and the price paid for labor. Full-grown peach trees may be thinned for 20 to 50 cents each. Apple trees twenty-five and thirty years old have been well thinned for 40 to 90 cents each. 
PROTECTING PLANTATIONS FROM FROST

Having considered (in Chapter II) the relations of location, site and windbreaks to cold and frost, we may address ourselves to a discussion of the means by which injury from local frosts may be averted, in case they threaten to occur. These means are of two types,- - those that attempt to enable the plant to escape injury from the frosts, and those that attempt to prevent the frost from occurring. Altogether several general means have been proposed for protecting plants from frost, and there are also combinations of the methods. The methods are mulching, covering the plants, whitewashing the plants, adding the vapor of water to the atmosphere, explosives, causing currents of air, making artificial clouds, and heating the air.

The temperatures at which the fruit-crop may be injured by frost are discussed to some extent in Chapter VIII (page 313); but O'Gara summarizes the advice as follows: "The temperatures at which the principal orchard fruits are liable to be injured cannot be accurately stated, since weather conditions previous to a freeze determine to a very great extent the ability of plants to withstand low temperatures. Not only do the different degrees of cold produce different effects on the same plant, but the same plant will often behave differently when subjected to the same degree of cold. It is well known that plants or parts of plants in active growth are more easily killed by low temperatures than the same plants or parts of plants when dormant. Actively growing plants contain large quantities of water; that is to say, the protoplasm or cell-sap is watery, and, as a rule, the larger the proportion of water contained within the plants the more 
likely they are to be injured by low temperatures. While tables giving injurious temperatures to fruit when in bud, blossom and so on, have been prepared, it is safe to say that these temperatures are not entirely reliable. This is because conditions are never the same in any frost period. It may be stated that in the practice of orchardheating the safest plan is to keep the temperature just above the freezing-point, no matter what the variety of fruit. No doubt, this will often be $2^{\circ}$ to $3^{\circ}$, or even more, higher than necessary, but the practice is on the safe side. In orchard-heating practice, the temperature should never be allowed to go much below the danger point, as it is usually difficult to bring it back without some chance of injury to the fruit."

How to predict frost.

There is no certain way of foretelling frost. Careful observation of conditions in the locality, long experience, and the use of the forecasts of the Weather Bureau are the most reliable means. Formerly the evening dewpoint was considered a reliable guide to the minimum temperature of the ensuing night. Hence, if the dewpoint say at 4 P.M., as determined by the wet-and-drybulb thermometer, or psychrometer (Fig. 93), should lie below the freezing-point, $32^{\circ} \mathrm{F}$., frost was considered likely to occur. This method of forecasting frost seems to hold good for certain localities in the western states, but has been shown by Cox and others to be wholly unreliable in the more humid eastern states. W. M. Wilson concludes (Cornell Bull. No. 316) as follows, after a study of the subject: "For the farmer who is prepared to make practical use of a frost-warning, the forecasts issued by the Weather Bureau should receive first con- 
sideration, because they may be obtained early in the day, before it is possible to secure any reliable indications from local observations as to the probability of frost. But when the warnings issued by the Weather Bureau cannot be obtained, and the farmer must rely on himself, there are no instrumental readings that will take the place of a careful observation of the condition of the sky, the direction and force of the wind, and the trend of the temperature."

"In the day, plants usually receive more heat from the sun than they give off (radiate), and consequently become warmer; but at night the process is reversed, and they radiate more heat than they receive and thus grow colder. When the surface of a plant has lost (radiated) sufficient heat to cause its temperature to fall to $32^{\circ}$ or below, frost forms. Any condition that causes increased radiation will increase the liability of frost, and conversely, whatever checks radiation $\mathrm{rr}$ supplies additional heat to

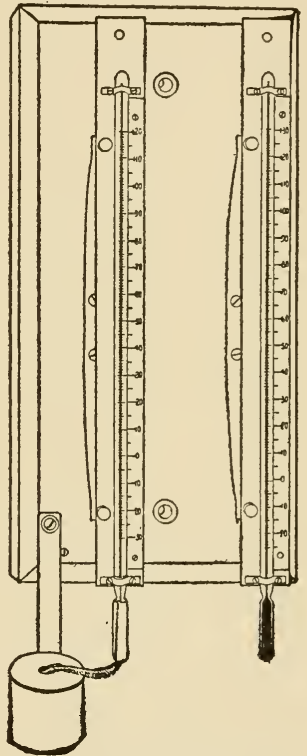

Fig. 93. One form of a wet-and-dry bulb hygrometer. the air will tend to ward off frost." Favorable conditions for frost are a clear night, a quiet or still night, a moderately dry atmosphere. The surface air is likely to be colder than that above, so that a wind may warm the surface air by mixing it with the warmer strata.

Wilson makes the following observations on weather conditions as indicating frost: 
"Preceding weather.-The character of the preceding weather is important because damaging frosts often follow an abnormally warm period. 'The weather moves over the country from west to east in somewhat irregular, but nevertheless well-defined waves. Hence, there is a strong tendency for extremes to follow each other, and such extremes are often disastrous in their effects. A light frost, particularly in spring, following an unusually warm period often will cause more damage than a severer frost preceded by cooler weather, because the warm weather forces out the blossoms prematurely and renders them more susceptible to injury. While an unusually warm period does not mean always that frost will follow, yet the fact that most frosts do follow such periods should be regarded as sufficient warning that frost is likely to occur.

"State of the sky.-Frost is not likely to occur when the sky is overcast, because the heat given off by the earth at night does not penetrate the clouds easily and is practically all retained in the air below them, which therefore remains at a comparatively high temperature. Even a hazy condition of the sky, or the thinnest cirrus clouds, have an appreciable effect in retarding the fall of temperature at the surface. But on clear nights the heat escaping from the earth passes away quickly, almost without hindrance, far beyond the limits of the atmosphere. Hence, the fall of temperature at the surface is rapid and, unless the earth has a vast store of heat, frost is likely to occur.

"Direction and force of the wind.-The direction of the wind is a reliable indication of the approach of colder weather. If, after a day or two of warm southerly winds and possibly rain, the wind changes to the southwest or west, it is an almost unfailing indication that the warm spell is over, and it is well to watch closely the conditions that follow, particularly if there are signs of clearing weather. Occasionally, a frost follows when the wind backs from east or northeast to north or northwest. In either case, the conditions to be looked for as soon as the wind changes are falling temperature, decreasing wind, and a clear sky. Frost is not likely to occur unless the air becomes quiet and the sky clear, for wind prevents the accumulation of the colder air at the surface.

"Trend of the temperature.-The rate of fall in temperature during the late afternoon or early evening is a good indication of the lowest temperature that will be reached during the night. For example, a temperature of $40^{\circ}$ at about 6 P. M., with a clear sky 
and light wind, is considered critical; particularly is this the case if the rate of fall approximates $1^{\circ}$ for each two hours, which, if continuous-as would be likely with a clear sky and light wind-would bring the temperature close to the freezing-point by early morning. A fall in temperature of $2^{\circ}$ an hour would indicate frost, even with the temperature considerably above $40^{\circ}$ in the late afternoon.

"Atmospheric pressure.-The rate of change in the pressure of the atmosphere, as indicated by the barometer, is of some assistance in forecasting frost. The actual stage of the pressure, whether above or below normal, is not important, except that a warm period with unusually low pressure is likely to be followed by the opposite extreme. The important factor is the rate of change. If the pressure is increasing rapidly, as indicated by a rapid rise in the barometer, it is a good indication that the cold period or cold wave is approaching rapidly. The change in pressure usually precedes by a short interval the change in direction of the wind, because the wind depends on the pressure; but one will have to watch the barometer very closely to gain much advantage over the indications afforded by the direction and force of the wind."

\section{Mulching to enable plants to escape frost.}

It is a general opinion that a mulch or heavy cover placed about plants on the earth when it is frozen, will retard flowering and the maturing of fruit; yet the practice appears to be often unsatisfactory, and there are reasons for supposing that the philosophy of the subject is not commonly understood. The subject is one of increasing importance, for it is essential that every means be used to escape late spring frosts. Efforts must also be made to reach the market when there is least competition from other sources, and, in the North, at least, this competition comes chiefly from early products produced in states to the southward.

If the plants are such that they can be entirely covered (as the strawberry), mulching will retard them; but the mulching of the earth does not greatly affect the blossom- 
ing of early-blooming woody plants if the tops are left exposed. Plants store up starchy matters in their bulbs or branches, to be used in the growth of the adjacent parts in early spring. The earliest bloom of spring is supported by this store of nutriment, rather than by food freshly appropriated from the earth. This is well illustrated by placing well-matured twigs of apple or willow (or other early-flowering plants) in vases of water in winter, when the buds will burst and flowers will often appear. On the 15th of one February, a branch of a nectarine tree that stood alongside a horticultural laboratory was drawn into the office through a window. This office was maintained at the temperature of a living-room. On the 6th of April the buds began to swell, and the young leaves had reached a length of $3 / 4$ inch a week later. The leaves finally attained their full size on this branch before the buds on the remaining or outdoor part of the plant had begun to swell. This experiment must impress upon the reader the fact that much of the bursting vegetation of springtime is supported by a local store of nutriment, and is more or less independent of root-action. If the ground could be kept frozen for a sufficiently long period after vegetation begins, the plant would consume its supply of stored food, and might then be checked from inactivity of the root, but this would evidently be at the expense of injury to the plant; but, in practice, it is fortunately impossible to hold the frost in the soil so long. It is evident, too, that the covering of strawberries and other low plants for the purpose of retarding fruit must be practised with caution, for a mulch of sufficient depth measurably to delay vegetation is likely to bleach and injure the young growth, and to lessen the crop. Yet it can sometimes be used to good effect, and fruiting can be delayed a week, perhaps even more. 
Some skilful strawberry-growers are able to delay fruiting on small patches as much as two weeks by means of mulches. While mulching the ground may not retard the period of bloom, and thus enable the plant to escape frost, it is possible that it may be useful in protection from frost, because it holds moisture, and, therefore, tends to raise the dew-point.

Covering the plants to protect from frost.

Covering for protection is practicable in many cases. The discussion of the mulching of strawberries to protect them from cold and from frost, as already described, really belongs here. Plants may be protected from both winter cold and spring frost by this means.

Many low-growing plants may be covered with earth. It is a practice in some places to plow a furrow or two over the strawberry rows when a frost is anticipated; fig trees, and other low or flexible-stemmed plants, are often planted on sloping land, so that they may be bent to the surface and covered when occasion requires. In parts of Russia, and other cold countries, the trees of orchard fruits are often pegged down in a similar way.

Grapes are regularly removed from the trellises and laid down in some places. The vines may be covered lightly with earth, or drawn under boards nailed together trough-shaped. Sometimes a few sods are placed on the vines to hold them in place, and the snow fills in among them and affords adequate protection.

Blackberries and raspberries are extensively laid down in cold climates, and it may be well to relate the method here, for the benefit of those who occupy bleak locations. Late in fall, the bushes are tipped over and covered. Usually three men are employed for this labor. One man 
goes ahead with a long-handled round-pointed shovel and digs the earth away 6 inches deep from under the roots. The second man has a six-tined or four-tined fork which he thrusts against the plant a foot or so above the ground, and by pushing on the fork and stamping against the roots with the foot, the plant is laid over in the direction from which the earth was removed. The third man now covers the plant with the earth or marsh hay. Earth is mostly used, and if the variety is tender the whole bush is covered 2 to 3 inches deep. Hardy varieties may be held down by throwing a few shovelfuls of earth on the tops of the canes, thus allowing the snow to fill in amongst the tops. If the grower lives in a locality where late spring frosts are not feared, the bushes should be raised early in the spring; but if frosts are anticipated, they may be left under cover until corn-planting time. If the buds become large and are bleached while under cover, they will suffer when exposed to the atmosphere; and one must watch the bushes in spring, and raise them before the growth starts. This method of laying down blackberry plants costs less than $\$ 15$ an acre, and the slight breaking of the roots is no disadvantage. Some growers dig the earth away on both sides of the row, and still others bend over the canes without any digging. Whatever method is employed, the operator must be careful not to crack or split the canes. The method may be varied with different varieties, for some bear stiffer canes than others.

The laying down of orchard trees is little practised in this country, but it must come to be better understood as the country develops and a greater interest arises in amateur fruit-growing. A method of training peach trees for laying down is as follows (method of J. T. Macomber): The trunk is trained in a horizontal position, 
and it should be 10 feet or more long to allow of its being twisted. The top is trained fan-shaped and is supported by a stake, and the bend of the trunk rests upon a block of wood. The long, horizontal trunk remains comparatively small and pliable year after year. It should be covered with an inverted board trough at all seasons, to prevent injury from the sun. The flat top is laid upon the ground each winter, by twisting the trunk, and is covered with boards; it is not lifted until all danger of late spring frosts is past. A little ingenuity applied to the pruning and training of fruit-trees will make it possible to lay them down, by one method or another, with every hope of success.

Some fruits may be advantageously protected by covering them with temporary (or even permanent) screens. This is extensively done in pineapple-culture, in which the better varieties are grown under lath or slat sheds, for the purpose of protection from frost, sun and drought; and it is now a practice with citrous fruits in parts of Florida. Small or amateur plantations of strawberries, or even of bush-fruits, may be easily covered with lath screens when frost is feared.

In the case of the cranberry, the plant may be covered with water, as explained on the next page.

\section{Whitewashing as a protection.}

The experiments of Whitten have shown that the whitewashing of trees may retard the period of bloom in early-flowering fruits, and sometimes sufficiently to allow them to escape spring frosts. The reason of this is that the white covering reduces the absorption of heat rays, since these rays are absorbed mostly by surfaces having dark colors; the tree is therefore kept cooler. Thorough spraying with lime-sulfur has a similar effect. 
Making currents of air.

Since frosts occur on still nights, it is sometimes possible to prevent them by keeping the air in motion, thereby mixing the air and preventing any part of it from lying on the plant until it shall have become frost-cold by loss of radiated heat. In small areas, as in choice gardens, it is often feasible to undertake such means. It has been suggested that windmills be set in motion by electric or other power, or that mechanical fans be installed. These methods appear not to have been applied commercially.

Adding vapor of water to the air; flooding.

An abundance of watery vapor in the air tends to check the radiation of the earth's heat, and the addition of water-vapor has an influence in raising the dew-point.

The means of adding vapor to the atmosphere are several: Spraying, flooding and irrigating, mulching and tilling. The machinery used in spraying for insects and fungi may be used for this purpose. Elaborate standpipe devices, connecting with underground pipes, have been used to facilitate the spraying of orchards. How much relief may be found from these practices is yet doubtful. The soaking of plantations to protect from frost is practicable in places where vineyards are arranged to be flooded for the destruction of phylloxera. Irrigating systems may also be used to add moisture to the soil, and therefore to the air, when frost is anticipated.

"Cranberry bogs, being always lower than the surrounding land, are peculiarly liable to damage by frost, serious loss frequently occurring when an ordinary farmer would not dream of danger, and a good supply of water is the only preventive that has been found efficient. The time of starting growth in the spring may be controlled by the 
time the water is drained off and the earlier spring frosts may so be avoided while an ample supply of water permits reflooding when a later severe frost threatens. Reflooding about the first of June, provided the water has not been withdrawn earlier than May 5 to 10, will also furnish protection from a number of damaging insects and will not injure the crop, provided care is taken that the water does not stand on any portion of the bog more than forty-eight hours. If a bog should become seriously infested with insects later in the season, it is occasionally profitable to sacrifice what remains of the year's crop and clear the bog of insects by flooding. This sometimes results in a greatly increased yield the following year. Damage from a light frost in the fall, before the berries are picked, may be prevented by raising the water in the ditches and about the roots of the vines. Protection from a heavy frost requires covering the plants with water, but this will cause immature berries to rot and should be done with great caution or the damage from water may be greater than it would have been from frost."-Elizabeth C. White, Standard Cyclopedia of Horticulture.

Explosives for frost and hail.

Explosives were first used in the vineyard districts of Austria, France and Italy, where hailstorms and frost were prevalent and were destructive to the grape-crop. Many years ago, Albert Stiger, burgomaster, WindischBriestrits (Lower Steirmark, Austria), we are informed, owned extensive vineyards on the lower slopes of the Bacher Mountains, a locality persistently visited by destructive hailstorms. He decided to drive the clouds away by the use of explosives and he established six stations on six of the surrounding mountains, a locality 2 miles in extent. The stations, built of wood, sheltered ten heavy 
mortars each, and near each station was a cabin in which powder was stored. A corps of volunteers consisting of neighbors and owners of small vineyards was trained to proceed to the stations and handle the mortars whenever there was the slightest indication of a storm. Each mortar

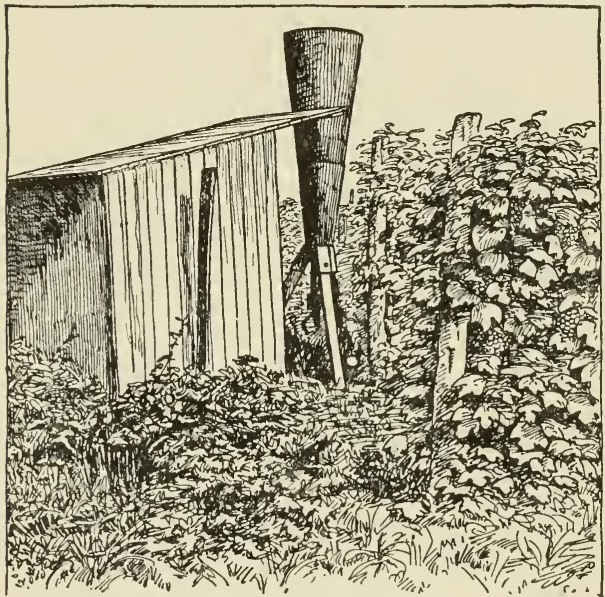

FIg. 94. Hail-gun, installed in a vineyard. The shed is only a storehouse.

was loaded with about $4 \frac{1}{2}$ ounces of powder; the firing was simultaneous and continuous until the clouds were either scattered or blown away. This also had a - tendency to break up the stratum of cold air and prevent its settling in the lowgrounds.

These experiments were practised for some time, and are said to have been successful. (G. B. Brackett, Yearbook, U. S. Dept. Agric., 1909.)

This principle of applying explosives in the upper air has received considerable attention for the prevention of hail from fruit-growers abroad and it has been introduced in the United States, but meteorologists do not look on it with favor or as being likely to produce the desired results. Fig. 94 is an illustration of one of several hail-guns now employed in New York. When hail is threatened in the vineyard, these guns are fired repeatedly, heavy charges 
of gunpowder being used. The guns are made of heavy sheet metal, and are fired from beneath. The vineyardists think that the results have been satisfactory. The subject needs investigation.

\section{The making of smudges.}

Frosts occur on clear nights. This is because the earth's heat radiates quickly into space. When clouds or fogs are present, this radiation is checked. It is possible, in many cases, to supply a blanket of smoke to check radiation; and if this cover also contains much vapor of water, its efficiency will thereby be greatly increased.

The use of smoke or smudges to protect plants from frost is an old practice. It is necessary, to secure the greatest protection, that the smudge be dense and uniform, and especially that it be maintained until all danger of frost is past. The best results are usually secured on level lands, where the smoke will not drain away, and where there are no higher lands from which the cold air may settle.

The best smudges are usually made by burning some tar-like substance. In any case, a smouldering fire is much better than a blaze. The fire should burn slowly, and attendants should keep the smudge going all night. Wet leaves, manure, sawdust, brush, grass, crude-oil and a variety of materials are in use for smudges. Some grapegrowers cut the trimmings into short lengths and pile them in vineyards, expecting to use them if frost should threaten. If frost does not occur, the piles are burned before tillage is begun. Crude petroleum stored in barrellike tanks or receptacles is sometimes conducted through the plantation in pipes, and kettles are filled (and ignited) at intervals. A mixture of one part gas-tar and two 
-parts sawdust is said to make an excellent material for a smudge.

In Europe, particularly in the vineyard regions, smudging is an accepted practice, and there are patented compositions in the way of fuels. One of the systems is that of M. Lestout, of Bordeaux: It consists of little cubical boxes, 20 centimeters (a little less than 8 inches) square,

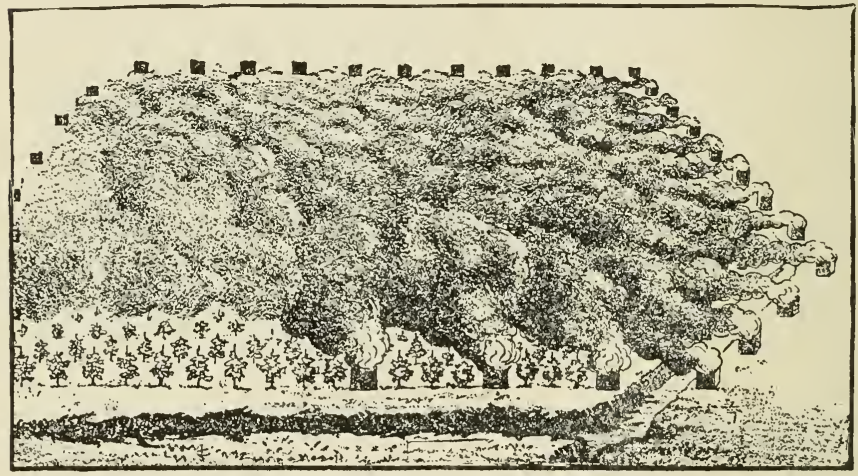

FIG. 95. Smudging a vineyard in France.

weighing seven kilos (fifteen pounds four ounces), and costing about 75 centimes ( 15 cents) apiece. These are placed around the field to be protected at a distance of 10 meters (32 feet 10 inches) apart, and are easily ignited from a torch. The fire emits a black smoke, which can be rendered more dense by pouring water upon the smudges. After a while, the columns of smoke fuse into a thick cloud, which settles upon the field, and elevates the temperature by $2^{\circ}$ or $3^{\circ}$. The fires can be instantly put out by an extinguisher. M. Lestout declared some years ago that 300 smudges, costing 225 francs $(\$ 45)$, will protect a vineyard 3,000 meters square $-i$. e., one containing 900 
hectares (about 2,200 acres) -namely, at a cost of 25 centimes (5 cents) for each $2 \frac{1}{2}$ acres. The illustration (Fig. 95) shows the Lestout method in operation. In North America, the direct heating of plantations is now gaining the ascendancy over smudging.

One of the advantages of a smudge is the utilization of it very early in the morning to protect the plantation from the sun when the night has been very cold and there is reason to think that the buds have been injured. All frosted plants should be protected from the sun on the chance that they may recover.

\section{Heating the plantation.}

It is possible and in many cases practicable to heat the fruit-plantation by means of fires, even raising the temperature as much as $10^{\circ}$. Preparation is made in advance, and when the indications point to frost, the fires are lighted. The smoke arising from the fires may combine the effects of a smudge with the heating of the air, although little dependence is commonly placed on the smoke. In very recent years, the heating of plantations has assumed commercial importance, particularly in Colorado and on the Pacific slope, and many heating devices are now on the market.

Any combustible material may be used, as wood, straw, leaves, shavings, manure, prunings from the plantation, coal and oil. The manure and straw are more useful for smudging, but the use of wood-as cordwood, old rails, stumps, and general refuse-is wholly practicable; the material to use is largely a matter of cost. The patented oil-burners are compact and effective; and it is now generally considered that crude-oil or distillate is the best and most economical material to use. 
Some of the methods in orchard-heating are here quoted and adapted from O'Gara, who has had much experience in Oregon and has written effectively on the subject.

The number of heaps or piles of home material which should be distributed in the orchard will vary somewhat, depending upon the kind of material used, about forty to fifty piles to the acre being usually sufficient. In most cases a heap or pile was placed between every four trees-that is to say, a pile every other tree row in each direction in the orchard, as Fig. 96, which illustrates the preparation in an apple orchard. Usually it will be found that only half of these heaps will have to be lighted at one time, which of course allows a large amount of reserve material that may be used in case it is impossible to keep the temperature up with only half the fires lighted. It is also well to place heaps of fuel on the outer edges or borders of the orchard, since it is often found that the outside trees may suffer where a slight breeze tends to blow the heat away. These piles should be distributed outside the last row of the orchard, and in case the temperature can not be kept up they should be lighted.

In case the temperature can not be kept up to $28^{\circ} \mathrm{F}$., a certain quantity of straw or stable manure, which will produce a dense smudge, should be placed upon these heaps before the sun rises. These smudges should be started on the side or sides from which the wind is blowing, and the material should be wet, so as to make it burn without any flame.

Experience has shown that the fires should not be large, since large fires tend to produce convective currents that are apt to bring in cold air; hence, the quantity of material for each heap need not be very great. Large fires also might scorch the blossoms. From four to five pieces of cordwood, or its equivalent in any other kind of wood or old rails, are sufficient for a single fire; very often when the low temperature is of short duration all of this material will not be consumed in a single firing. In case stable manure or rubbish was used, a larger number of heaps were placed, and the quantity of material to each heap averaged about a bushel or a bushel and a half. 
The cost of the material for firing varied greatly, depending upon how it was obtained. In some cases, where good cordwood was used, the cost of one firing was given as $\$ 2$ an acre. However, it may be stated that generally the cost to the acre for one night was between $\$ 2$ and $\$ 2.50$. In some cases the cost was estimated as high as $\$ 4$, but it is quite possible that more material than was necessary was burned, and that a higher price than usual was paid for it. When stable manure and rubbish alone were used, the cost for firing an acre was from 4 to 10 cents. This was because the material was on hand, and the only element of expense was for distributing it.

Oil-heating, however, is the most dependable means. "No matter how remote a fruit-district may be from an oil-field," writes O'Gara, "there is no question but that oil is the best fuel to be used, especiaily in large commercial orchards when the labor problem is one of more than ordinary importance. There is a great deal of difference in the oils as secured in different parts of the country. For the most part, eastern crude-oils have a paraffine base, while those on the Pacific slope have an asphaltum base. The crude-oil, or petroleum, as it comes from the wells is very rich in gases and the lighter oils, such as benzene, gasolene, kerosene and others, and therefore, is not used as such for orchard-heating. The gases and lighter oils are all removed by fractional distillation, leaving behind the heavier oils and the asphaltum or paraffine base, as the case may be. The fuel-oils on the market are, therefore, residuals, and as such are used for orchard-heating. A residual oil with a paraffine base will burn in the common smudge-pot without leaving behind anything but a little soot; but the oils with an asphaltum base do not. For this reason it is found necessary to remove the asphaltum base in so far as is practicable. Asphaltum does not burn readily in a simple smudge-pot, and therefore, remains behind after the lighter oil has burned. Upon 
cooling, it becomes very hard, and reduces the capacity of the pot for future fillings. The best oil for orchard-heating purposes is one of approximately $20^{\circ}$ Baumé test, considering the matter of cost as an item. A lighter oil up to $32^{\circ}$ Baumé may be used, but being lighter, it will burn more rapidly and reduce the effective burning time of the orchard-heater."

The equipment for orchard-heating comprises apparatus for determining weather conditions as well as devices for making and regulating the fires. For a large plantation in which heating is likely to be practised, there should be thermometers and frosi-alarm thermometers (psychrometers). the heaters themselves, devices for igniting the heaters, reservoirs for storing the oil (if oil is used), and a wagon-tank for distributing the oil.

Many types of oil-heaters are now available, some of them with reservoirs for holding an extra quantity of oil. O'Gara reports, however, that extensive experiments have shown "that the plain sheet-iron pot, holding approximately five quarts of fuel-oil is just as effective as the more complicated and expensive types. This pot is inexpensive, and, when made of No. 29 or 26 sheet-iron, will cost from 5 to 8 cents. In using a heater of such small size, the number to the acre should not be less than 100, and preferably more in districts in which periods of low temperature continue more than four or five hours. Owing to the cheapness of such pots, a very large number may be used in preference to using a few expensive heaters of the reservoir type. Many small fires give better results than a few large ones, as the heat is better distributed and convective air-currents are not produced. It must be understood that any orchard-heating device which is in any way complicated by dampers, cocks, valves and the 
like, must be avoided. At best, an orchard-heater is roughly handled and the more expensive and complicated types would find a very short existence in actual orchardheating practice. Furthermore, the matter of storage must be considered. The simple pot which will nest easily and occupy very little space will be more desirable. There is no objection to the high-priced reservoir heater providing it is not complicated; but the same results may be secured by the more simple lard-pail type, holding about five quarts, and having a burning time of four and five hours, depending upon the quality of fuel-oil used.

"The cost of orchard-heating is such a variable quantity that it is almost impossible to make a general estimate which will be of any value. Equipment, cost of fuel, length and number of firing periods, and so on, will vary in different localities and seasons. Orchard-heaters will cost all the way from 6 cents to 50 cents each, and from fifty to one hundred heaters, depending upon conditions, will have to be used to the acre. The quantity of oil will vary with the season, and the cost will be all the way from 1 to 5 or 6 cents a gallon. Usually, no less than 300 gallons an acre should be provided. At least one wagon-tank will have to be provided for each 10 acres at a cost of $\$ 25$. Lighters and torches will cost from $\$ 1$ to $\$ 2$ an acre; thermometers 75 cents to $\$ 1$ an acre. The cost of a storagetank charged to each acre will depend upon its size, but will not be far from $\$ 10$ an acre for large tracts. It is possible to get at the actual cost of fuel-oil to the acre in the following way: The quantity of fuel-oil necessary to raise the temperature $5^{\circ} \mathrm{F}$. above the surrounding air in an orchard in full bearing, with wide-spreading trees, will be approximately twelve and one-half gallons an hour to the acre. This will be true if the air remains calm or does 
not move more than 1 or 2 miles an hour. In young orchards, with the fruiting area low, practically double the quantity of fuel-oil as given will be necessary. The simple lard-pail type of heater, or, for that matter, any

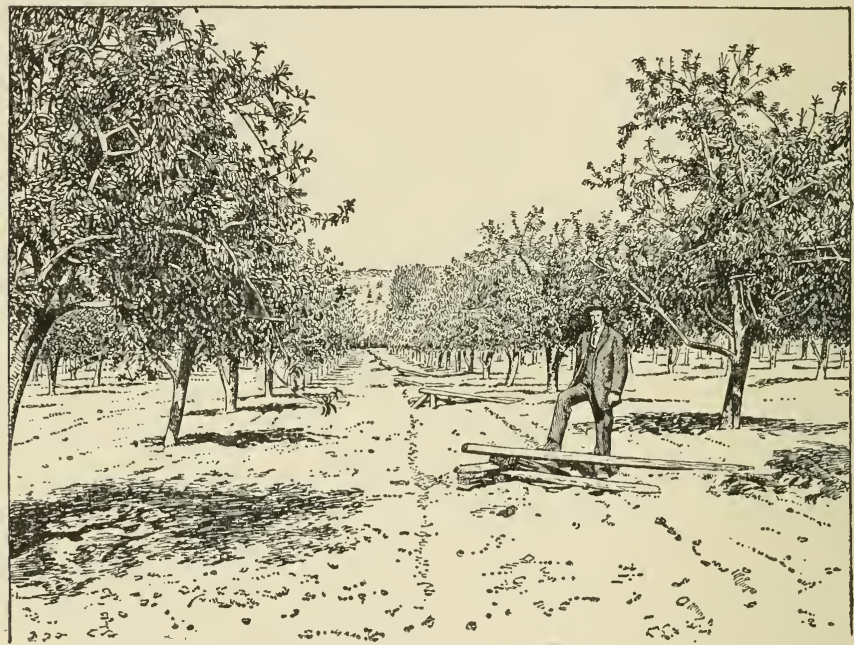

FIG. 96. The using of wood for heating an orchard,-fifty fires to the acre.

type of orchard-heater providing a burning area of about 44 square inches, will burn about one quart of fuel-oil an hour. Fifty-one gallon heaters will burn approximately twelve and one-half gallons of fuel-oil an hour and if this oil costs 4 cents a gallon, the cost an acre-hour will be about 50 cents when all the pots are burning. In other words, under the above conditions, it will cost approximately 1 cent an hour for each heater used, providing this heater does not have a burning surface greater than 44 square inches. It will require less fuel to heat an orchard in the square form than one of any other shape. The 
more the orchard-heaters are massed in the form of a square, the better the results. In fact, it is almost impossible to protect an orchard of only a few rows because there is no massing of the heat gererated on account of the lack of braking effect on air-movement." Figs. 96, 97, 98 (from Standard Cyclo. Hort.) show some of the methods in orchard-heating.

Experiments in Indiana (Bull. No. 154) lead Woodberry and Wellington to conclude that "Whether or not orchard-heating pays depends on whether spring frostinjury is the limiting factor in the production of the crop. There are probably some ơchards on sites of such a nature, and cared for so well in every other respect, that spring frost-injury is the limiting factor in crop-production. In these orchards, heating would be profitable.

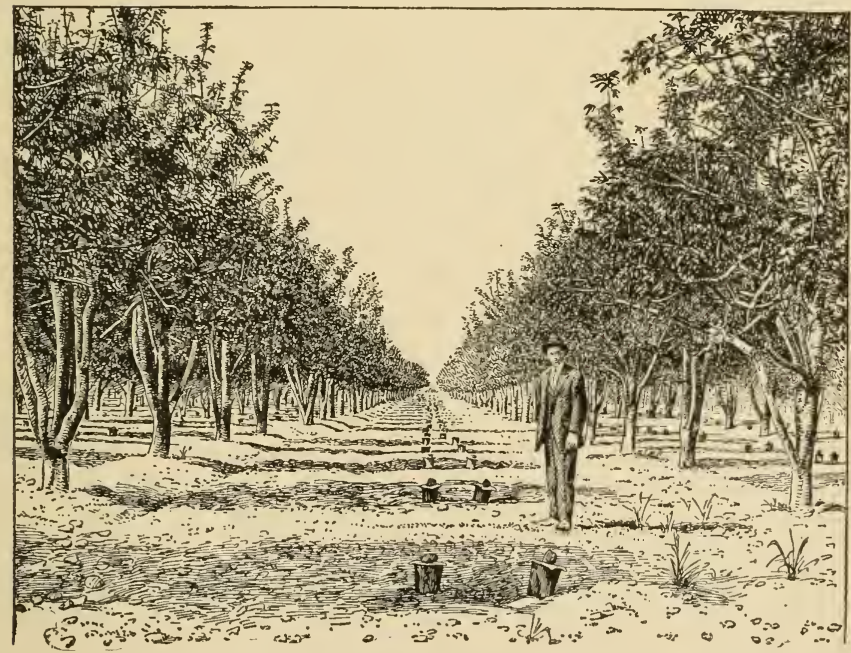

Fig. 97. Protecting the windward side of an orchard by using a double row of oil-heaters. 
In the vast majority of Indiana orchards, spraying, pruning and good management must become the rule instead of the exception before heating will pay. Considering the necessity of a reserve of extra heaters for emergency, supply of fuel for several successive nights, labor of distributing and filling heaters, and labor-cost of firing, the initial investment to prepare for protecting a 10 -acre orchard from frost-injury probably is not far from $\$ 500$."

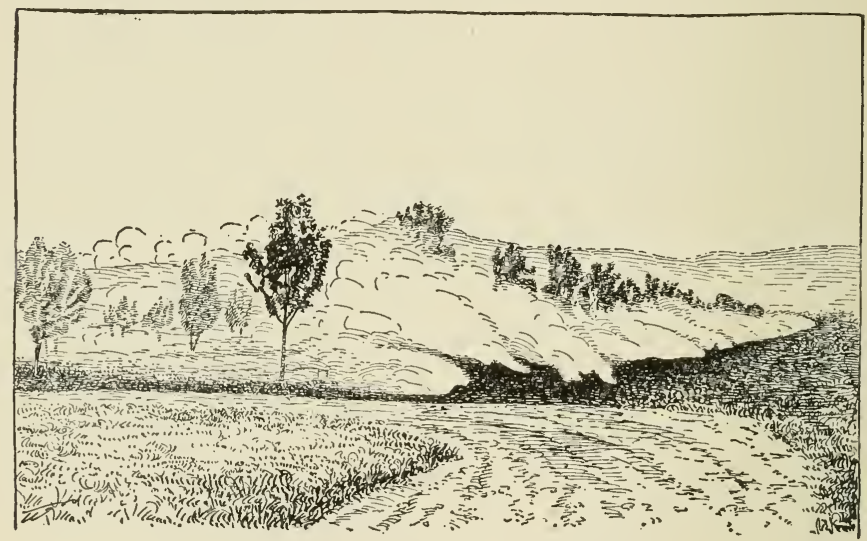

FIG. 98. Smudge in an Oregon orehard.

They found oil-heaters to give better results than coalheaters, considering the price and the quick response of the oil-burners. A maximum rise of temperature of $10.2^{\circ}$ was secured with 126 heaters to the acre. When using 80 to 100 oil-heaters to the acre, the usual temperature rise was $5^{\circ}$ to $7^{\circ}$.

In Iowa, Greene found heating of orchards to be practicable; the estimated cost for a 10-acre orchard, with 65 oil-heaters to the acre, was about $\$ 375$ to $\$ 675$ (Iowa Bull. No. 129). Church and Fergusson report gratifying 
results in Nevada (Bull. No. 79), with a good profitbalance.

All these results, together with others not here mentioned, indicate that the possibility of heating orchards to protect from spring frosts is now well beyond the experimental stage; whether it will become a generally profitable practice with deciduous fruits, however, remains yet to be determined.

\section{SPECIAL CARE OF THE PLANTS}

Many special practices, some of them local, are very important to the fruit-grower, and raise many questions. Some of these may now be briefly considered, along with other problems on which information may be desired.

\section{Staking young trees.}

If fruit-trees are stocky and well planted, and if the land is deep and in good condition, it will rarely be necessary to stake them. The staking of an orchard is usually an indication of poor trees or poor management at some point. It occasionally happens, however, that trees must be staked to enable them to overcome some accident or injury, as breaking by heavy winds or ice. When it is necessary to stake trees, it is ordinarily best to drive a stout stake on two sides and then to bind the tree firmly to each of these stakes, in order to keep it from whipping. The best bandage is of burlaps or other strong soft cloth, cut in strips 2 or 3 inches wide and firmly tied about the tree. Just as soon as the tree has recovered from its injury or weakness, the support should be removed. Trees that have blown over, but have not been broken completely off, may be severely headed-in and tied up in this way, often with the very best results. The 
wounded and broken surfaces should be thoroughly covered with some antiseptic wash or paint, or with grafting-wax.

\section{Watering.}

If the young trees or other plants are set in autumn or early in the spring and in well-prepared ground, there should be very little loss from lack of moisture to start them off well. In late spring planting, however, and if the trees are either shrivelled or have begun to start, the dry hot weather may catch them before they are well established. In exceptionally dry springs, many trees may be lost even with the best of care at the beginning. In all such cases, one good watering at the critical time may save the bushes or trees. If some of them are very slow to start, they should receive separate attention. See whether the earth has been properly firmed about them, and whether they have been sufficiently pruned. If the watering is undertaken, it should be liberal. A young tree may well receive a pail of water, so that the tissues may be well plumped up and revived. When the water has settled away about the tree, cover the place with loose earth or apply a mulch of straw or similar material. It may pay to go over a doubtful plantation with a clean spray tank and apply water to all trees that give signs of not starting.

Even bearing trees in dry places, as on thin hillsides, may be carried through a dry spell by one or two thorough soakings. Remove the fruit also, if the tree appears to be failing.

Bark-bound trees.

When a tree has been allowed to become stunted for two or three or more years, it is very likely to be hidebound, so that growth is impeded, even though the care 
of the plantation be corrected. The bark becomes very thick and dense and tight, and is likely to be dull and lifeless in color and sometimes moss-covered. The newer and fresher parts of the tree are likely to show a tendency to overgrow the lower parts. In all such cases, the bark should be softened so as to allow the trunk to expand. In general, the best means of loosening up the bark is to scrape off the outer hard layer, if it should become mossy or entirely dead, and then to wash the tree thoroughly with some soapy compound. This washing should be done with a broom, or preferably with a strong scrubbingbrush, so that the body may be vigorously scrubbed. A wash of strong soapsuds is very good. Tar soap, whale-oil soap or carbolic soap are also very useful for the purpose. These washes have the effect of softening the bark and allowing the tree to grow more readily. The effect of a good wash on orchard trees is often exceedingly marked. It is probable that the potash in the washes eventually becomes plant-food by being washed off to the soil, although the chief value of the wash is no doubt the softening and loosening effect on the bark. The washing also has the additional advantage of killing various insects and their eggs that may be in or about the bark. Spraying with bordeaux mixture, or lime-sulfur, will kill the lichen or "moss" on the trunks.

Another means of releasing the pressure in tightjacket trees is to slit the bark the entire length of the trunk or hide-bound part. This is done by thrusting the point of a knife through the bark until it strikes the wood, and then drawing the blade down the entire length of the area to be treated. When the knife is withdrawn, the slit is scarcely visible; but after a time the slit widens, as the tree begins to expand. This method is to be advised only 
as an extreme resort, for it is better to keep the bark fresh and elastic by good tillage and by the use of washes; but the slitting is of no damage to the tree, as a rule.

Scraping trees.

The outer layers of bark gradually die and peel off. This old rough bark is of no direct use to the plant, but it probably affords some protection to the tender tissues within. It also affords a lodgment for insects and fungi. Trees in good condition of growth and which are watched

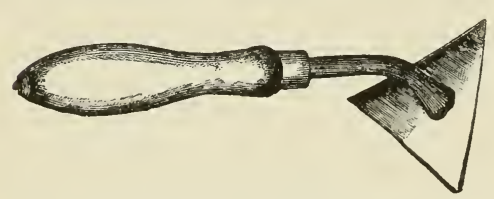

FIG. 99. Scraper for cleaning and repairing trees.

carefully, will need very little, if any, attention in the removing of the bark; but if the shaggy bark accumulates to any great extent, it is well to scrape off the loosest part. The operation should be performed when the warm weather approaches in spring, or, in fact, at almost any time in the growing season. A good tool for this purpose is an old and thin hoe, the handle of which is cut down to about 2 feet in length. This tool is grasped lightly, and is raked up and down the tree, and it removes the rough bark readily. The best tool for the purpose, however, is that shown in Fig. 99, which is a steel plate with sharpground edges, fastened securely to a bent shank. This tool may be had of hardware dealers, to whom it is known as a box-scraper. Aside from removing the loose bark from the trunks, this tool is useful in cutting out and removing diseased spots on the bodies or in the crotches. The wounds resulting from the barking of trees may be trimmed down to fresh tissue by such a tool and a knife, and all spots injured by bark-borers, spots of pear-blight, 
patches of canker, and the like, may be cut away, and the wounded surfaces are thereafter covered with bordeaux mixture or paint.

In the scraping of trees, it is advisable to take away every particle of wounded and diseased tissue, unless it extends deep into the wood. When the object is simply to take away the rough and loose bark, the tree should not be scraped down to the quick; that is, only the loose exterior part should be removed.

The scraping of trees merely for looks is to be avoided. Itinerant quacks are likely to make it appear that all the outer bark should be removed from the trunk and branches of orchard and shade trees; but, as a general practice, the bark should be allowed to remain where it grows.

Whitewashing trees.

There is probably no virtue in whitewash, unless to retard the buds in bright climates (page 259), and perhaps to keep the trunks cool and to act as a protection from sun. The whitewashing of tree-trunks is a cleansing process, particularly when the material is applied vigorously with a brush or broom. Aside from these secondary uses, the whitewashing of trees has no particular merit. It is not employed by commercial orchardists. If trunks and branches are sprayed with lime-sulfur or bordeaux mixture (as they should be), there will be little occasion for resorting to whitewash as a cleansing agent.

\section{Ringing.}

Observation of girdled branches shows that there is likely to be congestion of the parts immediately above the girdle, indicating that those parts are then overfed; that is, they receive nutriment at the expense of the parts 
below the girdle. It would seem, therefore, that intentional girdling might be made to increase the size and hasten the maturity of fruit borne beyond the girdle; and such is known to be the case. The girdling of grapes is a common practice in some regions. The girdled parts are entirely removed in the next annual pruning, and enough of the growing part is left below the girdle to maintain the roots and trunk. It will be seen, therefore, that the liability of injury to the vine is all a question of how much is left below the girdle and how much above it. Careful vineyardists are able to continue the practice year after year without apparent injury to the vine. The girdling or "ringing" is done when the grapes are about the size of peas, and a section of bark about an inch wide is entirely removed from the cane. A gain in earliness of a week to ten days may be secured by the process, but it is commonly thought that the quality of the better grapes is injured. In practice, only the very earliest varieties of grapes are girdled or ringed for commercial purposes; and it is doubtful whether the practice is to be commended.

Apples and other fruit-trees are sometimes ringed to set them into bearing. Many orchards develop a habit of redundant wood-bearing, and these are often thrown into fruiting by some check to the trees, as seeding down, girdling, and the like. Probably every orchardist has observed that the attacks of borers sometimes cause trees to bear. It is an old maxim that checking growth induces fruitfulness. This may be the explanation of the fact that driving nails into plum and peach trees sometimes sets the trees to bearing, and also of the similar influence exerted by a label wire that has cut into the bark, or of a partial break in a branch. Ringing to set trees into bearing is an old and well-known practice, but it is not to 
be advised as a general resort, although it may be allowable to employ it on one or two of the minor branches of an unprofitable tree for the purpose of determining whether the tree needs a check. One sometimes sees a tree on which one or two large limbs have been girdled, and these limbs may be bending with fruit when the remaining branches and the adjacent trees are barren.

Ringing may usually be performed with safety in spring, when the leaves are putting out. A ring of bark 2 or 3 inches wide may be removed to the wood, and entirely encircling the limb. One hears of excellent results following the simple severing of the bark-but removing none of it-completely around the tree with a sharp knife, in spring. These, of course, are only incidental operations, to be employed with caution. The treatment of trees that have been damaged by girdling is quite another subject; this is discussed on page 290.

The regulations of societies and exhibitions usually prohibit the competition of fruits produced on girdled branches with those produced normally.

\section{Top-grafting bearing trees.}

One of the important factors in the secondary care of an apple orchard is the grafting over of old trees or of worthless varieties. Whether it will pay to graft trees after they are fifteen or twenty years old depends on how profitable the trees are in their present condition. If they are bringing in no return, then nothing can be lost if they are grafted; and if the trees are strong and healthy, and not too old to make vigorous growth, there is reason to expect that much may be gained. If the operation of top-grafting is properly done, the trees ought to be 


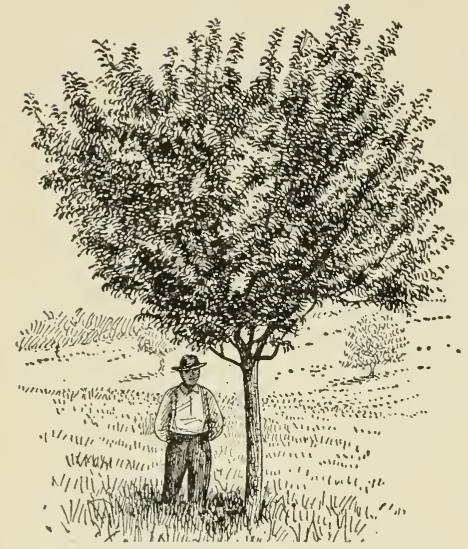

FIG. 100. Top-grafted young apple tree, after four years.

completely changed over to a new variety in three or four years (Fig. 100). It should be said, however, that the careful fruit-grower will find out whether his trees are to be profitable or not long before they reach the age of fifteen or twenty years. If there are strong indications that the varieties are unsuited to his needs, the sooner they are grafted the better.

In grafting the top of an old apple tree, it should be borne in mind that the operation at best is harsh, and that the top should be replaced as quickly as possible. Effort should be made to graft only limbs of comparatively small size (say not more than $1 \frac{1}{2}$ to 2 inches in diameter, and preferably less), and to set very many cions, even if some of them need to be cut out after two or three years. The setting of so many cions is somewhat expensive, but the orchardist should be able to do the work himself. Finally, it should not be expected that a remodeled

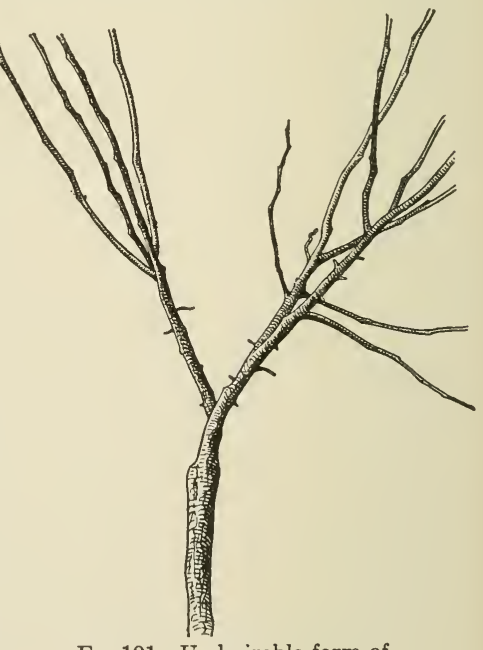

FIG.101. Undesirable form of top-grafted tree. 
old tree shall be of as good and handy shape as one that has been grown properly from the start.

In forming the new top, care should be taken to avoid bad crotches, such as are represented in Fig. 101 (from G. H. Powell, Del. Bull., as is also Fig. 100). The new scaffold branches should alternate and should spread widely. Sometimes the trunk is grafted midway, and the top taken out farther up; in such cases, the union usually remains apparent throughout the life of the tree (Fig. 102).

Graftıng-wax.

The waxes used in grafting are of two general kinds,-the resin-beeswax preparations, and the alcoholic waxes. The former kinds are hard waxes that

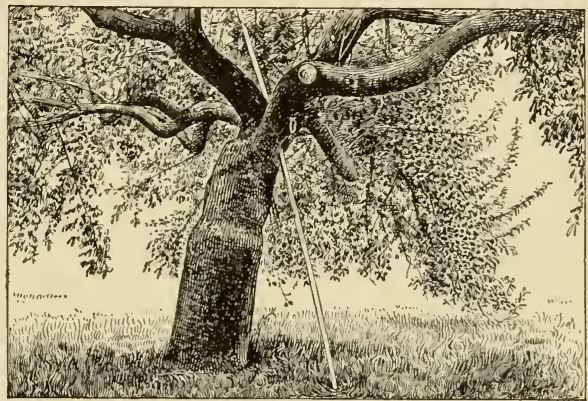

FIG. 102. The place of the graft on the trunk of an old apple tree.

must be worked up and warmed in the hands when they are applied, or sometimes they are melted and run on in a liquid state; the latter kinds are liquid or paste plastics that harden on exposure (on evaporation of the alcohol).

Standard wax.-Resin, 4 parts by weight; beeswax, 2 parts by weight; rendered tallow, 1 part by weight. Melt all together in a kettle over a stove, avoiding boiling; then pour the liquid into a pail or tub of water to harden; then work with the hands, pulling it to a grain; make up into convenient balls or skeins. It will keep for years.

Softer wax.-Resin, 4 parts by weight; beeswax, 2 parts by weight; linseed oil, 1 part or more, according as the material must be hard or 
soft. Adaptable for use in cold weather. On account of the impurities in linseed oil, this wax is now likely to be unreliable; and it may be better to use a greater quantity of tallow in the Standard wax given above.

Alcoholic wax.-White resin, 1 pound; beef tallow, 1 ounce; turpentine, 1 tablespoonful; alcohol, 5 ounces (more or less). Melt the resin; add the tallow; remove from fire and gradually stir in the turpentine and alcohol. Keep closed. Apply with brush.

\section{Bagging fruits.}

When it is desired to secure extra-fine fruit, it is a good plan to tie up the fruits in paper bags. This keeps away the insects and fungi, and protects the fruit from birds (although the whiteness of the bags is likely to attract thieves at night), and the fruit is likely to ripen later or at least to hang later, and to be of higher quality because of the warmth that the bag affords. The bagging of grapes is a frequent practice when exhibition or test specimens are desired; it is also employed in commercial work with grapes. It is customary to pin the bags on the clusters when the grapes are a third to a half grown. Bags made of mosquito netting are very useful later in the season when it is desired to secure the full color of highly colored fruit.

If it is desired to bring out the blossoms of a tree very early in the spring, it may be done by tying grocers' bags on the spurs when the buds first begin to swell.

\section{Winter preparations.}

In winter, plants are exposed to injuries of wind, snow, water, ice, mice, rabbits, and the like. Before the season closes, the farmer should see that young trees stand stiff and straight, and in order to keep them rigid and to afford good surface drainage, it is sometimes well (especially 
with newly set trees in cold climates) to bank up the trees with earth to the height of 6 or 8 inches. In making the bank, the workman should be cautioned not to leave holes, from which the earth is taken, close about the tree, for the water is likely to stand in them, and it may do harm. In small-fruit, grape and nursery plantations, it is often advisable to plow a furrow toward the plants, on either side, in the autumn. Care should be taken to provide for top-drainage if the conformation of the land is such as to hold surface water.

The protecting of bush-fruits, grapes and even trees from winter cold has been discussed on pages 257-259.

\section{RENOVATING OLD ORCHARDS}

It is impossible to give any specific method of procedure when it is desired to renovate an old and profitless orchard. The first question is, whether the orchard is worth renovating,-whether it is too old, too few trees remaining, trees too much weakened by borers and rotten hearts and other injuries, or trees so very tall and sprawly as to promise little return for the effort that must be expended on them.

If the orchard is thought to be worth it, then the next requisite is a change of heart on the part of the owner. It is then necessary to discover the causes of its unprofitableness - to diagnose the difficulty - and forthwith to go straight at the root of the evil. It must be remembered, also, that a long-neglected orchard cannot be expected to arrive at the profitable condition which trees enjoy that have received proper care from the beginning, no matter how thorough the means of recuperating it may be. At the best, one can make only an apology for long years of 
carelessness and mistakes. If the grower once arrives at a clear conception of the agencies that make for productiveness, he will readily perceive what the trouble with his orchard may be. Most neglected apple orchards need a general overhauling,--tillage, fertilizing, pruning, spraying, sometimes top-grafting, and often removal of part of the trees.

The land must be tilled. This may demand a heavy trimming up of the trees to allow a team to work; and in

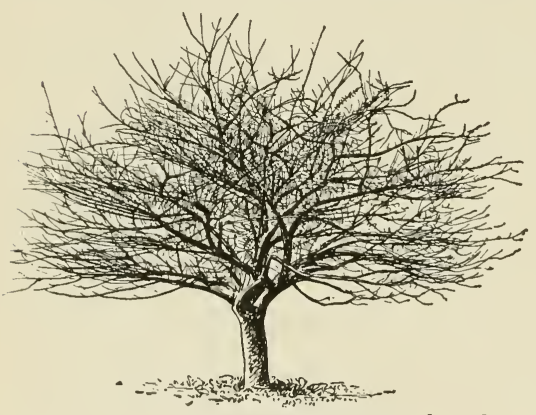

Fig. 103. A good type of neglected apple tree for renovation. many of the forest-like old orchards it may be economy to cut out a third or half the trees at the start. Perhaps the roots are so high that the land cannot be plowed. In such case, the land may be broken up in the spring, before the earth becomes hard, by means of spading-harrows, disc-harrows, spring-tooth harrows and similar vigorous tools. Or corn and other grain may be dropped freely in holes made with a crow-bar, and the hogs then turned in to root for it.

The earth-mulch once secured to save the moisture, it may next be necessary to apply plant-food, either in the form of stable manures, green crops or concentrated fertilizers, or in all these forms together.

It is probable that the trees will need heavy pruning (Figs. 103, 104, from Jarvis). But this pruning is for the purpose of correcting the results of years of neglect, not for the purpose, directly, of making the trees to 
bear. In fact, the effect of heavy pruning is likely to be the very opposite of fruit-bearing; but it must be done in most old orchards to bring the trees back into manageable shape, to produce new and fresh wood for fruit-bearing, and to thin the top sufficiently to allow the fruit to develop to something like perfection of size and quality. Weak trees may sometimes be re-invigorated by this heavy pruning alone. Severe heading-in of decrepit peach trees often accomplishes this. Tall long-armed apple trees may sometimes be headed-back severely for the purpose of establishing a new top, if the trees still retain much vigor. When the new wood is once formed and the tree has re-established its equilibrium, fruit-bearing may be expected to

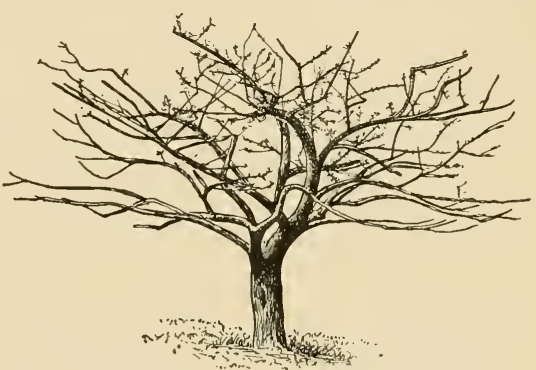
begin, if soil is good and other conditions are right.

It will next be necessary to begin hunting for borers and other squatters and campers. The trees will very likely need to be thoroughly sprayed to dislodge the army of hangers-on that has held undisputed possession of the territory perhaps for a score of years. Cut out diseased spots, fill the holes with wax or cement, remove diseased limbs, take off the shaggy hanging bark. In other words, it may be necessary to give the trees a general cleaning up.

If the trees are of the wrong varieties and are still vigorous, it will probably pay to top-graft them, as already explained (page 279), if they are apples, pears, 
oranges or cherries. Old and poor peach, apricot, plum and quince trees would better be pulled out.

Much good work has been done in the renovation of neglected orchards, particularly apple orchards, and results have been published widely in bulletin and press. These tests constitute some of the best applications of investigation to horticulture; and they also demonstrate that in existing profitless plantations the country has a latent asset as responsive to development as local mines, quarries and streams.

\section{Why are orchards barren?}

It may aid the grower to analyze the difficulty if he asks himself the above question, and then tries to answer it. The commonest reason why old orchards are barren is because they are in sod,- - that is, because they are untilled and unfed. There are men enough in the country who have taught that sodded orchards are wrongly managed orchards. They have been combatted by citations of orchards that are in sod but are still productive. They have replied that, in some cases, for a combination of reasons, orchards may do well in continuous sod, but they have still fallen back on the rationale of land management, and have said that the system is wrong, nevertheless. Time is rapidly demonstrating the accuracy of their teaching. It is a case in which a handful of philosophy is worth more than a forkful of facts.

If one asks why orchards are barren, let him fill out the following synopsis by way of review of some of the principles enunciated in this book:

The nature of the problem: Each case must be investigated by itself; teaching must be along the line of essentials, not statements of rules. The eight general factors that determine productiveness are: 
1. The Location Factor.

Improper climate, aspect, land; insufficient drainage.

2. The Plantation Factor.

(a) Age of trees, (b) the "stand,"-whether too thick.

3. The Tillage Factor.

Soil-structure. Fertility as influenced by $(a)$ fineness, $(b)$ conditions of root-hold, $(c)$ life processes, $(d)$ air-holding capacity, $(e)$ water-holding capacity.

Sod in orchards.

Cover-crops.

4. The Fertility Factor.

Conceptions of the uses of nitrogen, potash, phosphoric acid, lime, in fruit-production.

5. The Pruning Factor.

(a) The relation of pruning to wood-growth and fruitgrowth, (b) reshaping of the top to bring it within reach and to make it amenable to treatment, $(c)$ reinvigorating the tree.

6. The Variety Factor.

(a) Unproductive varieties, (b) unadapted varieties, (c) impotent varieties, $(d)$ top-working.

7. The Propagation Factor.

(a) The individuality of the tree, and its power to perpetuate its characteristics, $(b)$ poor physical union of cion and stock.

8. The Parasite Factor.

(a) Fungi, (b) insects. Spraying. 


\section{CHAPTER VIII}

ACCIDENTS AND INJURIES

WhAT may happen to a fruit-plantation is beyond the wisdom of any man to foresee. One may be sure of having difficulties that are not set down in the books. Hail, wind, frost, drought, roaming live-stock, bad places in the land, trees not true to name, are among the probabilities. Some of the prevailing injuries that may be more or less remedied are mentioned in this separate chapter.

Probably the greatest menace to the fruit-plantation is the hired man. Some men have no feeling for a tree. They will run over young trees, bark and scratch old ones, and break the limbs with no blush of conscience and with no care to bind up and mend the wounds. They are likely to work special evil in grubbing for borers, cutting more than is necessary, covering up shiftless work, and perhaps leaving the borer for bait. Discrimination in the choice of help is a prime consideration on a fruit-farm, not only in the care of the trees but also in the handling of the fruit after it is mature. Herein is one of the advantages of living in a fruit country, where most of the hired help has had some training in the business. Green and inexperienced hands should not be left alone in a fruitplantation. The only safe man for such a plantation is one who feels that the welfare of the fruit-trees or plants is his first consideration; he must like the fruit-growing business and be proud of his connection with it. 


\section{MISCELLANEOUS INJURIES}

The fruit-grower will not expect to find all his troubles explained in a book. There are some difficulties that he must solve alone and for himself. Yet some of the accidents that his trees are almost sure to meet sooner or later may be discussed briefly.

\section{Depredations of live-stock.}

Injuries of trees can be prevented in sheep pastures and hog pastures by giving the animals plenty to eat and especially plenty to drink. They are very likely to gnaw the trees for the moisture. If, however, the animals begin to injure the trees, the only recourse is either to take them out or to build wide racks about the trunks; but any sort of rack or fence prevents the proper care of the tree. Certain animals in a herd of swine may be specially vicious about trees, and they should be removed. Horned cattle (or cattle of any kind) are not in place in an orchard. If the orchard adjoins a pasture, the fences should be kept in good repair.

Birds.

The incursions of birds in cherries and small-fruits may sometimes be overlooked by planting in such quantity that the birds may get their fill without ruining the plantation. Cherry orchards may sometimes be protected by planting a number of trees of very early sweet varieties around the outside of the field. Some persons advise the free planting of mulberries to feed the birds; but they might increase the difficulty by attracting more birds to the place. In some cases, it is impossible to save the fruit unless fire-arms are used; but it is usually suffi- 
cient to fire blank cartridges a few times to scare the birds away, and thereby obviate the necessity of killing them.

Small trees and garden-plats of small-fruits may be protected from birds by means of netting manufactured for that purpose.

Rodents.

Mice and other vermin injure trees mostly in cold winters, when green food is scarce. They are likely to be especially bad in new countries. The best preventive of injuries from mice is to see that there is no material, as dead grass or weeds, close to the base of the tree, in which the rodents can nest. If the litter is not taken away, it should at least be tramped down tightly before winter sets in. The best preventive of injury by rabbits is not to have the rabbits. If the brush-piles and old fence-rows, in which the animals harbor, are cleaned away, there will commonly be little trouble; and, at all events, a smart boy who is fond of hunting will ordinarily solve the question without help, so far as the game laws allow.

If mice are very damaging, it may be advisable to put cylinders of wire netting about the trees, as elsewhere recommended (page 293). Rolls of birch bark are sometimes used in regions where the paper-birch grows. It should be considered, however, that such covers for the bodies of trees interfere with clean culture about the base of the tree, and they are likely to afford a most excellent place for the lodgment of insects.

\section{Girdled trees.}

Trees that have been girdled by rabbits, mice or otherwise should have the injured parts pared down to live tissue and the wounded surface then covered with an 
antiseptic dressing. It is also advisable to bind up the girdle with some material like grafting-wax, that will keep the wood moist and thereby allow the ascent of the sap-water; for the water rises in the tree through the young soft wood, and not between the wood and the bark. The bark is formed over the wound by material that is redistributed through the tree after it has been elaborated in the leaves; that is, the reparative tissue on the trunk is formed by elaborated sap that is on its downward course. If the woody tissue is kept soft and fresh, the tree may continue to live for years, but there will be a deposition of woody matter above the girdle, while the part below will not increase in diameter. This is well known to all observing fruit-growers. After a while the younger wood is likely to become hard and dry, preventing the upward passage of root-water, and the tree then starves to death; or, the top may become so heavy that the plant breaks off at the point of constriction. It is, therefore, necessary that the orchardist give careful attention to his label wires, to prevent them from doing great injury. It is always best to take the nursery labels from young trees when they are set, and to depend on a map record for the names of the varieties; or, if the label is left on the tree, it is best to hang it on one of the minor limbs, rather than on the trunk; or a less dangerous label may be substituted. In adjusting the label wire to the tree, it is important that only the ends of the wire be twisted together, thereby providing a large loop in which the limb may expand. The label may be held tightly to the limb by pinching the wires together with the fingers.

Trees freshly girdled in the growing time of spring may be expected to heal over before the season is past, if the girdled zone is not more than 4 or 5 inches wide, and if the 
surface of the wood, as already explained, is kept fresh. It is usually best, however, if no connection of bark remains, to bridge over the girdle by cions. These cions are of the same kind as those used for ordinary grafting. The edges of the girdle are pared down to fresh wood, and the cions are cut 2 or 3 inches longer than the width of the girdle. They are whittled to a wedge shape on either end, and these ends are inserted between the bark and the wood on the upper and lower rims of the girdle. They should be so numerous as almost to touch each other entirely around the tree. After they are inserted, a strip of cloth should be bound tightly upon the bark over their

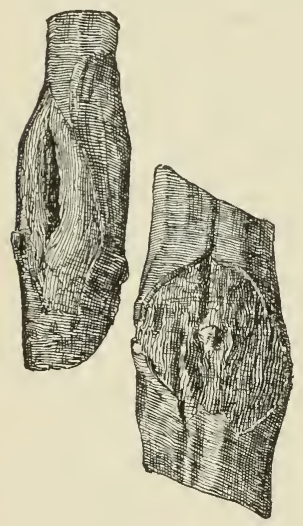

FIG. 105. Injuries by hailstones. ends, and the whole girdle should then be waxed over. It is a good plan to pour alcoholic wax over the work, allowing it to run in between the cions and cover the edges of the bark and the exposed wood surface.

Hail injuries.

The injuries caused by hail are very often confounded with those wrought by borers and other pests, and it is the delight of many persons to endeavor to puzzle the experimenters and teachers with specimens of such work. Plum limbs injured by hail-stones are shown natural size in Fig. 105. Nothing special can be done for such injuries. They soon heal.

Sun-scald.

Often it is necessary to shade the trunks of young trees to prevent sun-scald, particularly in the hot plains region. 
In the nursery-rows, the bodies of the trees are ordinarily well shaded. There are various means of providing this shade, but the best results may be expected to follow some protection that breaks the force of the sun and does not entirely obstruct it; for in the latter case, the bark does not so readily become inured to exposure to sunshine. Finely woven wire netting rolled around the tree (in more than one thickness, if necessary), is said to afford very good protection for this purpose, as shown in Fig. 106 (but preferably extending higher up the trunk). The upper part of the trunk is likely to be shaded sufficiently by the branches, although this is not always the case. These rolis of wire netting also serve a purpose in keeping away mice and other vermin. A box of boards (Fig. 107, from S. B.

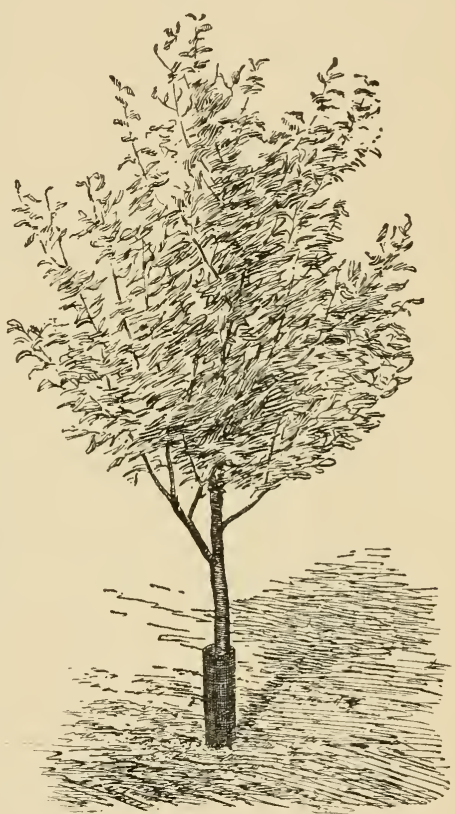

Fig. 106. Tree protected from sun and rabbits by a roll of netting.

Green) is sometimes used to protect from sun and other injuries.

Hansen writes as follows on this subject for Dakota conditions: "Trees planted and kept with stem leaning toward the southwest until the branches shade the trunk, are free from it. Some fruit-growers set a board, or two boards nailed together trough-fashion, on the southwest side; others use corn-stalks, wire netting or lath. Low- 
headed trees are best for severe locations; in more favorable sections trees may be headed $2 \frac{1}{2}$ to 3 feet high. Tall trunks suffer more from sun-scald and severe winds."

Trees are liable to injury from sun-scald after a heavy pruning, especially if they have been allowed to grow too

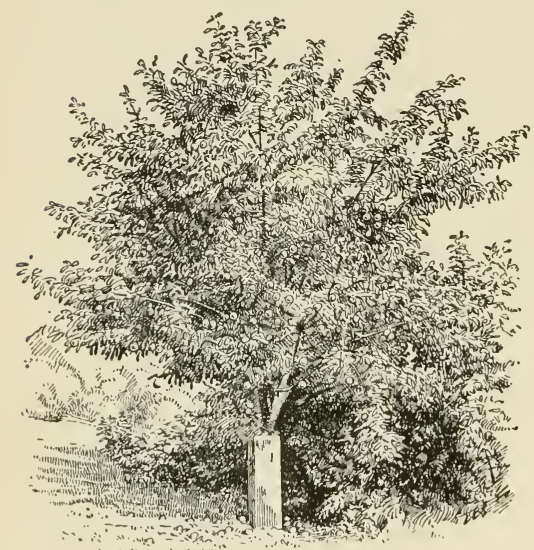

FIG. 107. A boxed apple tree. thick in the first place. Cutting out heavily from the center of the tree exposes the oblique and horizontal limbs to the intense heat of the sun, and the bark is liable to blister and be killed, after which borers are very likely to finish the work of destruction. In all interior hot regions, therefore, it is well to exercise caution in the pruning of the tops of trees. It is better to keep the top somewhat thin and open from the start, rather than to allow it to become overgrown and then to make a sudden correction.

Perhaps sun-scald is a form of winter injury due to the rapid fall of temperature when the sun leaves the southwestern side of the tree; but the above treatment applies in any case.

Borers.

The best treatment for borers and similar insect pests is to watch the plants carefully, and to dig the insects out at least twice every year. In grounds kept in clean tillage, such insects are rarely so troublesome as 
in neglected areas. This is both because the insects find places of lodgment in neglected orchards, and because the fruit-grower is so seldom present that he does not discover them in season. Orchards should be gone over every spring and autumn for borers; this is patient hand-andknee work, but it is the only sure way. The grower is certain of the borer when he has him under the knife.

Borers in the stalks of currants and raspberries are despatched by cutting the canes and burning them. The affected canes usually show lack of vigor, yellowing or wilting leaves, and are sometimes limp.

Peach trees are attacked by two very destructive borers, - the regular large borer larva, $3 / 4$ inch long when mature, and the very small borer beetle known as the bark-beetle or pine-hole borer. The treatment for the former is to dig out in spring and autumn, and at the same time to apply gas-tar or coal-tar from the roots to 1 foot or so from the ground. The bark-beetle usually attacks trees that are not in full vigor, as those that have been shattered by winter cold or lessened in vitality by other borers, lack of tillage, overbearing and general neglect. The first thing to do is to put the trees in vigorous condition; then whitewash the trunk and branches late in March, in July and in October (in the North).

Some of the protective devices or materials are more or less effective against borers in orchard trees; but the grower should not lessen his vigilance. Wire screen is good if made tight about the top and where the edges come together and if it stands far enough from the tree to prevent the beetle from ovipositing through it. Tarred paper is sometimes used, but it often injures trees if allowed to remain in warm weather. Gas-tar may be applied about the crown of peach and other trees, extend- 
ing a foot or so above the ground. Coal-tar is used with safety. Soap and carbolic washes in early summer are effective against the flat-headed borer (this borer is likely to work on the sun-scalded or injured parts of the trunk and larger limbs); probably if the trunks are well drenched with the lime-sulfur spray, the injury will be lessened. The use of axle-grease is not advisable. It is possible that no injury would result, but on the other hand if the grease should contain any of the oils, which soak into the trunk, or any turpentine, it might kill the trees. The addition of sulfur will do no harm, and also no good.

In short-generation plants, as the small-fruits, rotation of plantations is a very important means of circumventing borers and some other pests. This is specially true of the strawberry, in preventing depredations of the root-borer, root-louse and white grub. Short, sharp rotations, clean tillage, burning of rubbish about the plantation, vigorous plants, are very effective means of getting ahead of many pests.

Cankers and bad spots; wounds.

Rough and sunken places in the bark on apple trees may be cankers, produced by a parasitic fungus (the canker of the peach is produced by the same fungus that causes the fruit-rot); smooth, dead, more or less sunken spots on apples, pears and quinces may be due to pear-blight. There are other kinds of bad spots in the bark, the cause perhaps unknown. In some cases they may be due to the work of the flat-headed borer or to sun-scald (page 292).

The treatment of cankers is described as follows by Jehle (Cornell Circ. 26): "Whatever the origin of cankers, their treatment is essentially the same except that in the case of an infectious disease, such as the brown-rot canker, 
the work must be done with great care in order to insure that all trace of the fungus is eliminated. Whenever the cankers occur on limbs that can be removed without detriment to the tree, it is best to remove them while pruning; care being taken to cut several inches below any visible injury, as the living fungus in the brown-rot canker extends back beyond any external evidence of the disease, and if allowed to remain will continue to infect healthy wood. If the cankers occur on limbs that it is desirable to save, they should be cleaned out by removing all the diseased wood a short distance back of any visible evidence of the disease. The diseased wood and bark can be readily detected by its brown color. In the brown-rot cankers it is very important to remove all this discolored tissue, as it is in this tissue that the fungus lives and if it is not removed the disease will spread. The amount of bark that it is necessary to remove depends on the extent of the diseased part. Sometimes the fungus has extended so far beyond the healthy callus that it is necessary to remove it entirely; while at other times the fungus may have extended but slightly into the upper and lower extremities of the callus and it is necessary only to remove a small part. It is always well to leave as much of the callus as possible, to facilitate healing. All the dead bark and twigs should be removed. It is not necessary to remove any of the solid wood except to smooth the treated part. The wound should be pointed at the upper and lower extremities and the bark should be cut at right angles to the wood. As soon as the wound has dried out it should be coated with gas-tar. The gas-tar acts as a disinfectant and preservative, and no other treatment is necessary. Trials have been made in order to determine this point, and it is now evident that the use of corrosive sub- 
limate or lime-sulfur solution in addition to the gas-tar is unnecessary."

The collar-rots are infections, or winter injuries, about the base of the tree. Often they girdle the trunk. Some varieties seem to be particularly liable, as the Tompkins King among apples. Whether there are specific organisms for these collar-rots seems not to be known. Sometimes they may be cankers, or general infections following the "barking" of trees, or in windshakes. In any case, the remedy is to cut away the infected parts and to paint the area as for cankers. Very bad wounds should be bound up, to prevent evaporation and to afford protection. If the rot is discovered before it has made great headway, it may sometimes be stopped. Badly infested trees show yellowing and general loss of vigor.

Similar treatment may be given to "barked" trees, where they have been hit by the whiffletree or plow; but as these places are not infected if the wound is fresh, no other treatment may be required than to pare down the ragged bark and to bind up the wound in any material that will prevent drying out and protect it from weather. The best material is soft adhesive grafting-wax, wound over tightly with a cloth. Clay and cow manure are sometimes used. See that the codlin-moth does not pupate in the bandages, and that the strips do not become a harbor for other insects.

Rotten places in limbs and trunks may be gouged out to fresh wood, the interior painted, and the cavity filled tight with cement.

Root-galls.

The roots of many fruit trees and brambles are very likely to be affected with large tuber-like swellings 
or galls, that have been the subject of much uneasiness with fruit-growers; these galls are contagious, being produced by a soil bacterium. The "hairy root" of apples and pears is a form of the same disease. The organism attacks many kinds of plants. It is now thought they do not often produce great injury in the orchard, but they are always to be avoided, and trees with galls would better not be planted.

The root-knot of the southern states and of greenhouses is a wholly different trouble, and is the work of a nematode worm. There is also a root-swelling or gall on raspberries, due to the work of an insect. The nematode galls are commonly smaller and softer swellings, and occur on the younger or smaller roots, and appear not to be found in the open in regions where the ground freezes deep.

\section{WINTER-KILLING}

There are two distinct types of injuries to fruit-plants by cold,--true winter-killing (or the injury of the tree or buds when perfectly dormant, by the low temperature of winter), and the killing of the growing or swelling parts by the "cold snaps" or frosts of late spring and early fall.

\section{Winter-killing of the wood.}

Three factors chiefly appeal to the fruit-grower in the winter-killing of trees,--positive cold, very dry or very wet soil, and heaving of the land by frost. The subject of "dry freezing" has already been mentioned in Chapter I as a danger in the mid-continental country. The heaving of the land is prevented by drainage, by proper methods of tillage, and by the judicious use of cover-crops. The 
degree of cold may be somewhat averted, as we have already found, by exercising judgment in the selection of site and exposure, and by the careful employment of windbreaks; and the danger of winter-killing is much enhanced when the plants make a late autumn growth and go into the winter with immature wood. Yet, winterkilling must always be one of the gravest risks of the fruit-grower.

Winter-injury to the trees or plants usually appears in the form of splits or long checks in the trunks, or in the outright death of the ends of the branches or even of the entire plant, or in discoloration of the wood. For

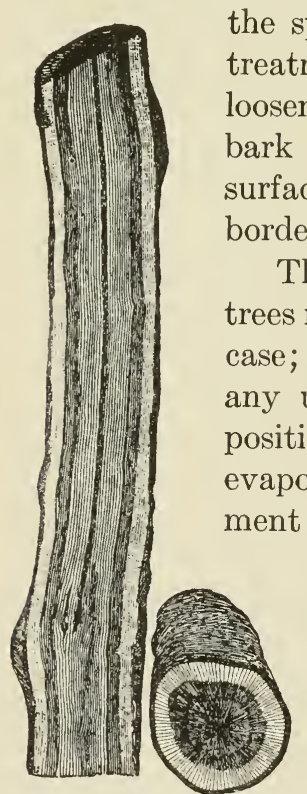

FIg. 108. The new wood formed around the core of a winter-injured stem. the splits lengthwise the trunk, the proper treatment is to pare off the dead and loosened bark to the "quick" as soon as the bark begins to spread, and to cover the surface of the wound (and the cleft) with bordeaux mixture or paint or gas-tar.

The proper treatment for frozen-back trees must be determined for each particular case; but the injured part is no longer of any use to the plant, while it may be a positive detriment by accelerating the evaporation of moisture. The best treatment for plants seriously injured at the extremities is to cut them back to fresh wood. This heading-in-sometimes to the extent of 3 or 4 feet-removes the driest and weakest parts, and concentrates the energy of the tree into a comparatively small area of top. Heavy pruning always tends toward the production of wood, and 
this wood-production is probably never more needed than in winter-injured trees, for it tends to renew the vitality of the tree.

Often the winter-injury does not appear at once on the surface, but the wood and interior bark are discolored, often so much so as to lead the observer to think that the tree is dead. But such trees may fully recover. Very much depends on the subsequent treatment of the trees. Fig. 108 shows the body of a young plum tree (in longitudinal and cross-wise sections) that was frozen black in a severe

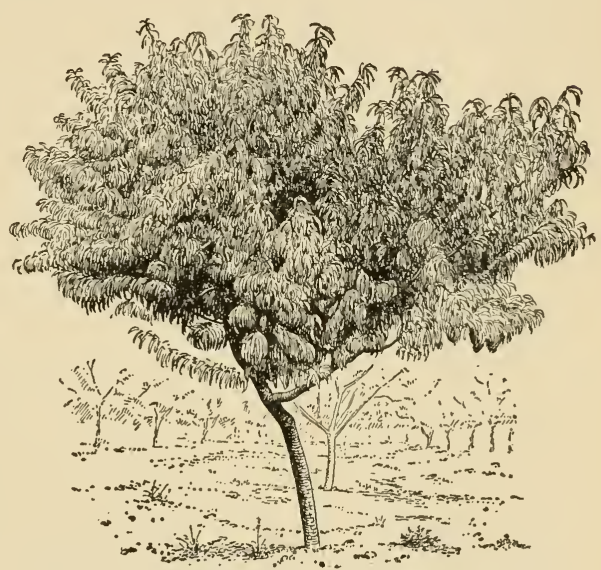

FIG._109. Recuperation of a winter-injured tree, moderately pruned in April.

winter. It was heavily pruned the following spring and in the fall had made a ring of bright new wood, amply sufficient to maintain the tree in perfect health for a long life. This appearance is common in nursery stock the year following a very hard winter, but such trees may not be permanently injured. They are to be pruned moderately, and if they are young and have much reserve vitality, they may be headed-back heavily. Sometimes heavy heading-back does more harm than good. These are cases in which the entire tree is old or otherwise weak, and when the plant seems to need the stimulus of all its buds to bring out the feeble life still left to it. Fig. 109 
(after Hedrick) shows good results from moderate pruning. It is probable that a large number of reported instances of death due to heavy pruning of winter-injured trees are of such trees as would have died or not fully recovered under any treatment.

Winter-killed plants often retain sufficient vitality to leaf out or to bloom, and sometimes even to begin growth, but when the stored vitality of the tissues is exhausted the plant perishes. This explains the phenomenon which, after a bad winter, nearly always puzzles the inobservant fruit-grower, of trees starting into feeble growth and then suddenly dying when warm and dry weather approaches. Winter-injured trees should not be allowed to bloom or to bear until they are fully recovered. Such trees are very liable to attack by the flat-headed borer, pine-hole borer and other things.

The physiological character of winter-injury is obscure, but it is probably in the nature of desiccation or the withdrawal of moisture from the cells. The greater the quantity of moisture in the tissue, the greater will be its loss under conditions of cold and the greater the injury; and this is probably the reason why a late growth of twig is likely to be so disastrous if the winter is severe. There is much that the grower can do to prevent winter-killing, as well stated by Reddick: "It is certainly advisable to recommend (1) that orchards be plowed early in the spring (not in June as is frequently the case) and receive thorough cultivation early in the season, in order to give the trees every advantage of conserved moisture. That cultivation cease not later than August 1, in order to start the trees into maturation. (3) That a covercrop, or robber-crop, be planted to take care of excess moisture in the autumn. Such a crop would seem to 
be particularly essential following an unusually dry summer. (4) That low, wet places be tile-drained, and airdrained if such a thing is possible."

It should be added that the trees are less liable to injury if they go into the winter strong and undepleted. Plants weakened by drought, lack of tillage, over-bearing, borers, San José scale and diseases, are specially liable to winter-injury.

The recent careful studies of Chandler, "The Killing of Plant Tissues by Low Temperature" (Mo. Research Bull. No. 8), have thrown much light on winter-killing. "There are several forms of injury from cold," he states, "some of them purely mechanical, such as tearing of tissue due to tension developed at low temperature, or evaporation from the surface when the conducting tissue is frozen so as to prevent the movement of water to that tissue, and killing as a result of long-continued exposure to low temperature.

"With all plant-tissues, when a certain temperature is reached very shortly after thawing, it will be found that the tissue has taken on a brown, water-soaked appearance, and evaporation from that tissue is much more rapid than from living tissue. These are characteristics of planttissue frozen to death.

"Results of many investigations have shown that during freezing (which may or may not result in freezing to death), ice forms in the tissue, generally not in the cells but in the intercellular spaces, the water moving out of the cells to form crystals in these spaces. The most commonly accepted theory is that killing from cold results from the withdrawal of water from the protoplasm. The amount of water-loss necessary to result in death varies with the different plants and different tissues." 
As to treatment, he remarks: "The killing of wood of peach trees from freezing is one of the most important determining factors in peach-growing. Little can be done to influence the amount of killing except to have the trees start into winter in proper condition of maturity. The weakest-growing trees, however, do not generally reach this condition of maturity in the most satisfactory manner. Trees one or two years in the orchard, or old weak trees, are most liable to succumb to effects of low temperature. Pruning the trees severely following a winter when the wood has been killed, although apparently in the best condition of maturity, seems to reduce the amount of killing. However, such pruning following winters when the wood has been killed on account of its not having reached the proper condition of maturity in the fall, generally due to the presence of wet weather following a drought the season before, is liable to result in greater loss than if no pruning were done.

"In the peach-growing district of south Missouri and Arkansas, and probably other similar climates, the most important factor influencing the loss of peaches from low temperatures in winter is keeping the buds from starting into growth during warm periods in winter. In that section the best means of accomplishing this end is prolonging the growth of the trees in autumn, either by heavy pruning or by fertilizing with nitrogen the spring before. Some varieties of peaches have a much longer restperiod than other varieties, and therefore are started into growth moreslowly by warm periods in winter." (Page 101.)

Frost cankers.

The effect of winter injury may appear in the form of sunken dead patches that sometimes exude gum. On 
peaches, frost cankers, according to Jehle, "are oftenest found on the main trunk of the tree, usually near the surface of the ground or at the snow line of the previous winter; in the crotches of the larger branches; or about pruned stubs. They appear after a hard winter, particularly one of extreme changes in temperature and more particularly when such a winter follows a very late growing season. The cankers appear in the spring as slight depressions. These are made more apparent as the tree puts on new growth of wood over the area not affected. Gum pockets usually form under the flattened areas and the gum often oozes out during periods of wet weather. The injured area is usually rather indefinite about the margin, and the formation of a healthy roll of callus is thereby much retarded. Fermentation of the dead tissue occurs and various fungi and insects quickly follow. One fungus, Valsa leucostoma, comes in so commonly that sometimes it has been regarded as the cause of the trouble."

As to prevention: "It is impossible to predict the character of the winters, but one can judge by the growth and maturation of the wood what the probabilities are that a tree is in good condition to withstand a severe winter. Soft, poorly matured wood is easily injured. The use of highly nitrogenous fertilizers, particularly their use too late in the season, is to be avoided. In seasons of drought followed by abundant autumn rains a second growth is not uncommon. This may be prevented or held to a suitable minimum by the use of cover-crops."

The treatment for frost cankers is the same as that for other similar wounds, as advised on a preceding page (page 296). It is difficult for the grower in some cases to distinguish between frost cankers and those produced by infection, and the subject also requires further investigation. 
Winter-killing of the fruit-buds.

In severe winters, the entire fruit-spur (in the spurfruits, as apples, pears, plums and apricots) may be killed outright, but the commoner case is the death of the bud

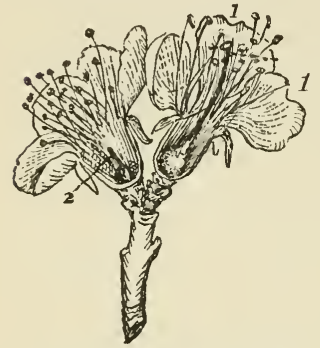

Fig. 110. Normal apricot flower (at 1), and one (at 2) injured by cold of winter. only. The bud may be entirely killed, in which case it soon turns brown throughout its entire diameter and the flower never opens; or only the pistil (the central organ, that ripens into the fruit) may be killed, in which case the flower may open and appear to be perfectly normal to the uncritical observer. The latter case is common in peaches and apricots. Fig. 110 illustrates the condition. The flower at the right was uninjured by the winter, and the pistil is seen, grown full length, at 1. In the other flower, the pistil, at 2 , is dead. We know

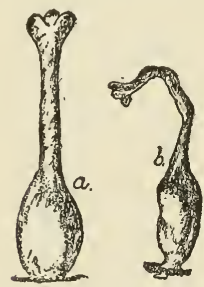

FIG. 111. Live and killed pistils.
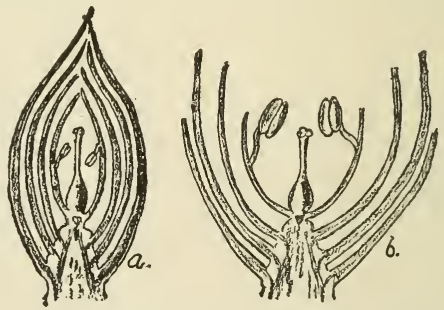

FIG. 112. Peach buds in section, to show the pistil (in the center) and the stamens. Enlarged.

that this pistil was killed before the bud began to swell, because it retains about the size it must have had in the dormant bud. If it had been killed after the bud had swollen, it would have appeared as a much larger and a more or less crumpled or withered organ, as in b, Fig. 111. 
Fig. 112 shows the structure of the peach-bud (after Halsted); at $a$ is shown a longitudinal section (enlarged) in winter, the pistil, or fruit-bearing organ, being in the center; at $b$ is shown a section of a partially opened bud.

A true fruit-bud is one in which the flower, or cluster of flowers, is present in miniature. This flower occupies the very center of the bud, and is surrounded by dense layers of scales. A healthy bud is normally green in the central part in cross-section. When the bud has been killed by the winter, in the usual way, this central part of the flower becomes prominently discolored or almost black. Fig. 113 shows a fresh or live bud at $a$, and a killed bud at $b$ and $c$. When only the pistil is killed, untrained

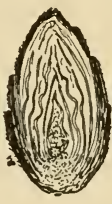

$a$

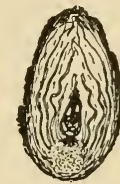

$b$

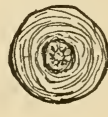

c

Frg. 113. Apricot-buds: $a$, alive. $b$ and $c$, killed by winter. Enlarged.

eyes may not detect the injury. The general run of examinations made of buds by farmers, to determine whether there is winter-injury, are of little consequence. Except in pronounced cases, the only reliable examination is made under a dissecting microscope.

There are no remedies for winter-injured buds.

\section{INJURY BY FROSTS IN THE GROWING SEASON}

Much mischief is done by "cold snaps" after the buds have begun to swell, and yet the disaster is not so easily wrought, - at least not in the North,-as is commonly supposed. Even the buds of the tenderer fruits may endure very sharp freezes after they have begun to show color. Observations were made at Cornell on buds of apricots, peaches, plums and pears (as shown in Fig. 
114) that had swollen to three or four times their normal size. The pink color of the apricot buds was distinctly visible, and the tips of the anthers could be seen in the Japan plums by looking down squarely on the buds. In this condition, the buds endured with no

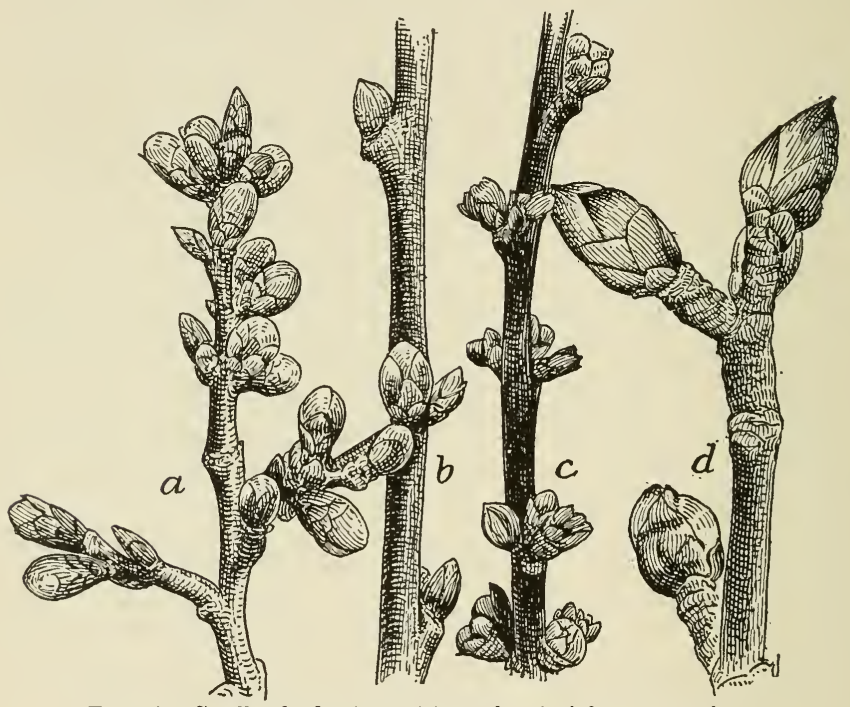

Fig. 114. Swollen buds that withstood $14^{\circ}$ of frost: $a$, apricot; $b$, peach; $c$, Japan plum; $d$, pear.

injury the following temperatures, as taken by selfregistering thermometers hung in the trees (very light snow on the ground and a wind blowing all night):

Lowest temperature

April 20, Apricot, peach, Japan plum, pear........... $18^{\circ}$

April 21, Apricot, peach, pear.................. $19^{\circ}$

April 21, Japan plum......................... $18^{\circ}$

These buds endured $14^{\circ}$ of frost without injury. On the coldest morning, the buds were stiff from freezing, and in some instances the backs and tips of some of the petals 
were permanently discolored. The buds swelled with the freezing, but returned to their previous size when thawed out, and they looked as if withered for several days,-or until active expansion began.

When the flowers have fully expanded, a comparatively light frost will destroy them. This is shown in the fact that a very slight elevation in a blackberry or strawberry patch is often sufficient to avert injury. The pistils seem to suffer first. A strawberry nubbin is shown in Fig. 115. The top of the berry (or the bottom, as it hangs) is

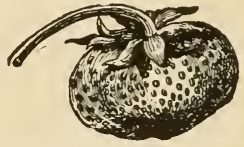

Fig. 115. A strawberry nubbin, due to frost. flattened and deformed. This is usually due to the freezing of the upper pistils in the flower, as it stood erect. Nubbins are sometimes the result of imperfect pollination, but in such cases the deformity is more likely to be on the sides than on the top, for the top pistils are the ones that are very likely to be pollinated by insects.

A similar case is reported on blackberries at Cornell. The only serious accident known to injure the blackberry crop in New York (aside from hail) is frost; and in most cases the injury is unavoidable, even though the grower has warning of its approach. In six crops grown in a certain patch, only one was injured by frost, and even this one, when the cold wave was unusually late and severe, suffered seriously only in the lowest places. Drawings of blackberry flowers were made on the spot, two or three days after the frost, and they are here reproduced, natural size. A normal, uninjured

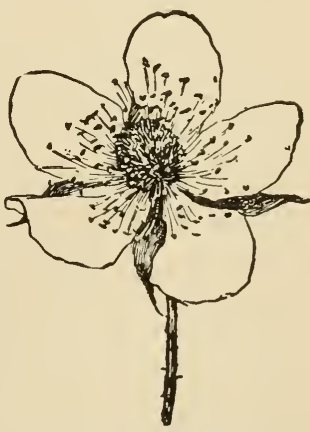

Fig. 116. Normal blackberry flower; full size. 
flower is shown in Fig. 116. Inside the five white petals are seen the numerous sprawling stamens, each one bear-

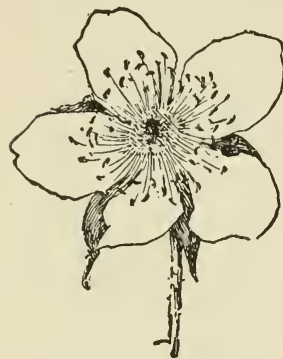

FIG. 117. Flower ruined by frost, the central or berry part wanting. ing an enlargement or anther on the end, inside which the pollen is borne. In the center of the flower is the head or cluster of pistils, each of which ripens into one of the little grains that go to make up the blackberry. The frost killed these pistils, so that the center of the flower bore only a small, black, dead column (see Fig. 117). Now and then, one or more of these pistils in the head escaped, and developed into a fruit-grain, so that the berry became a nubbin. Fig. 118 shows the dead and aborted fruits at picking time. At the top of the picture are some fruits $(n, n$,$) in which one or two$ grains or drupes are full grown, when the remainder of the drupelets making the berry failed to develop.

On the 8th of one May, temperature of $27^{\circ}$ ( $5^{\circ}$ of frost) was recorded by self-registering thermometers hung in fruit-trees at Cornell, but no injury resulted. At this time, all the petals had dropped from apricot flowers, but the calyx-ring had not yet fallen from the young fruits; peach flowers were in full bloom, but their fertilization had mostly taken place; Japan plum flowers were just

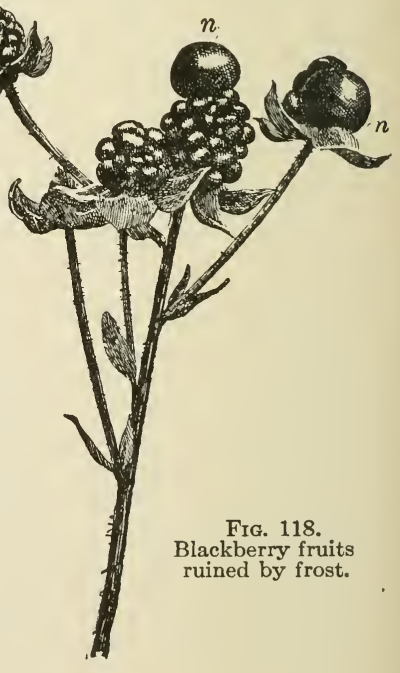


dropping; pear flowers were open, but not yet fully fertilized.

Young fruits of apples and pears may sometimes recover from a severe freeze and make perfect specimens. It is even insisted by some careful observers that they sometimes recover even if frozen solid shortly after they
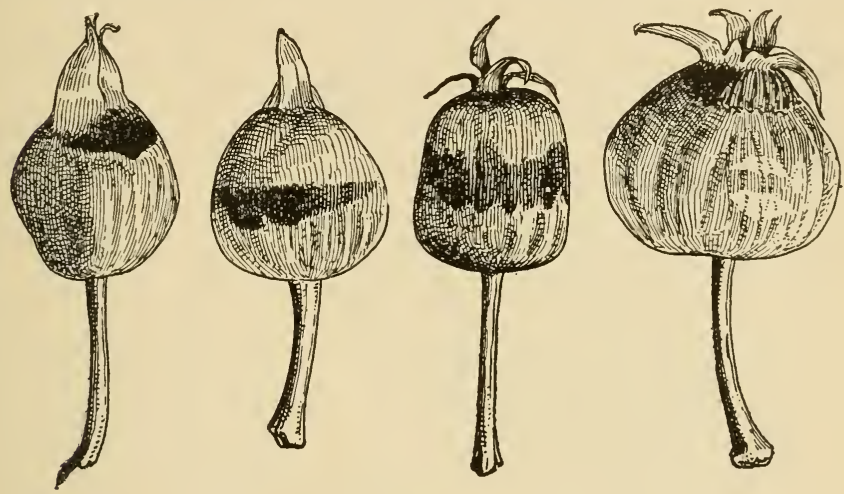

Fıg. 119. Frost injuries on young apples.

they are "set," the fruits failing to develop perfect seeds thereafter.*

Fruits simply frost-bitten,- that is, injured by a deposit of white frost,-are very likely to persist, but to show blemishes or deformities even at maturity. A common effect of very late frosts is a distinct russet zone on the fruit. This zone marks the position of the frost on the young fruit. Apples and pears are usually still erect when these frosts occur, and the dew,-which,

*"The freeze of May, 1895, froze the fruit solid. The center of each pear turned black, and yet they persisted in growing. There were eighty barrels. I doubt if there was a seed or core in the whole lot. The quality was the best that I have ever seen."-Extract from letter from Benj. F. Hawes, Oakfield, N. Y. 
when frozen, is frost,-probably settles in a ring or belt near the top of the fruit or midway down it. The exact position and conformation of this deposit of dew are, of

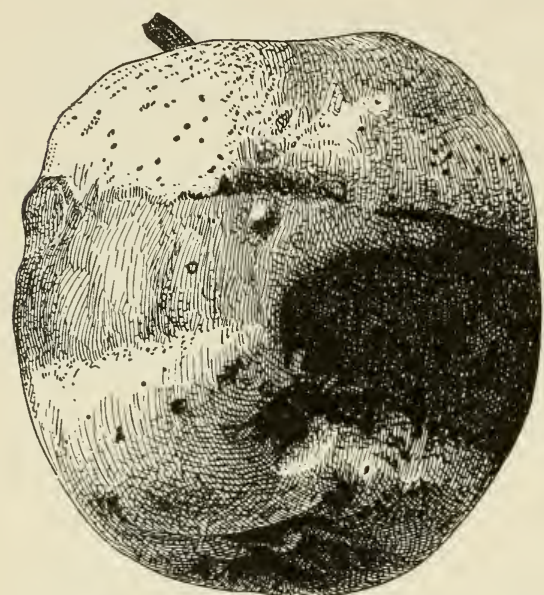

Fig. 120. Rusty frost-zone on a full-grown apple.

course, determined by the shape, position and exposure of the fruit. Fig. 119 shows the frostzones on young apples. This injured, corky tissue has the power of increasing itself by the extension of the abnormal cells, so that the zone is likely to widen with the growth of the fruit. Mature fruits, with the rusty frost marks still conspicuous, are seen in Figs. 120 and 121. In some cases, the growth of tissue in the injured zone seems to be slow, resulting in a constriction of the fruit at that point.

Among the most serious results of very late frosts in the North are injuries to vineyards. Fig. 122 shows the shoots of a grape-vine as injured by a freeze in the middle of May. In treating frozen vines, like that shown in the illustration, it must first be remembered that the injured parts are of no further use to the plants, and they are very likely to weaken the plant by causing it to lose much of its moisture. The rational procedure, therefore, is to strip off all the frozen shoots soon after the disaster, allowing the energies of the plant to divert themselves to the pro- 
duction of new shoots. When the injured parts are soft and small, it is customary to remove them by pulling them off, rather than by cutting them off. In well-pruned vineyards the cost of stripping ought not to exceed $\$ 1$ an acre.

Early autumn freezing is one of the most damaging of all forms of frost-injury, because the plant has no time in which to recuperate, and a hard winter may add to the destruction. Fortunately, such freezes before the foliage falls are very infrequent. Probably little can be done except to await the condition as it presents itself in very early spring.

It is not often that special treatment needs to be given to plants injured by late frosts; but the removal of the killed parts, or sometimes even a further heading-back, is the rational procedure. This should be supplemented by good tillage and other care.

What is an injurious degree of cold?

To this question there is no specific answer, because so much depends on the latitude, the time of year and the con-

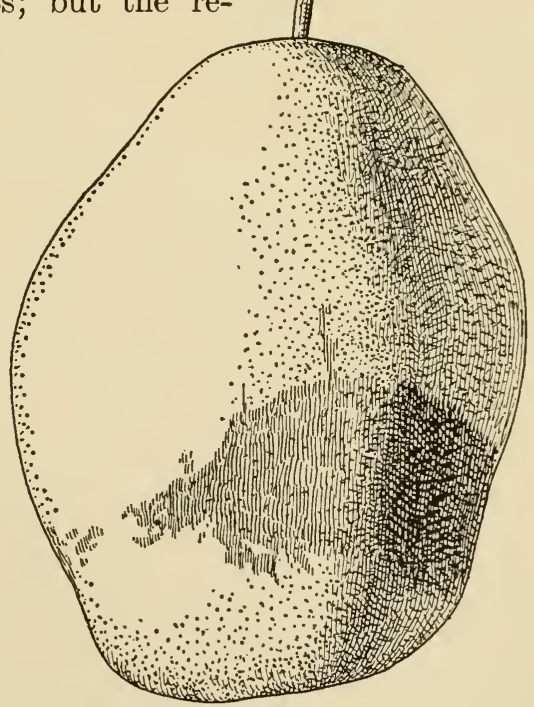

Fig. 121. Frost-blotch on a Flemish Beauty pear. 
dition of the plants. We have already seen (page 308) that at Ithaca, New York, fruits were able to endure the temperature at $18^{\circ}$, even when the buds were well swollen. Hammon gives the following figures at which plants are liable to injury from frosts, compiled from information received from horticulturists throughout the entire Pacific coast. Probably some of them are too high. The temperatures are as nearly as possible those in contact with the plant itself:

\begin{tabular}{|c|c|c|c|}
\hline Plants or fruits & $\begin{array}{c}\text { In blossom. } \\
\text { Degrees }\end{array}$ & $\begin{array}{c}\text { In setting } \\
\text { fruit. } \\
\text { Degrees }\end{array}$ & $\begin{array}{l}\text { At other } \\
\text { times. } \\
\text { Degrees }\end{array}$ \\
\hline Almonds .................. & 30 & 30 & 28 \\
\hline 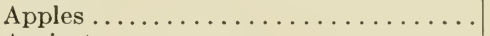 & 29 & 30 & 26 \\
\hline Apricots $\ldots \ldots \ldots \ldots \ldots \ldots \ldots$ & 31 & 32 & 30 \\
\hline 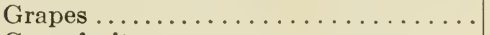 & 31 & 30 & 28 \\
\hline 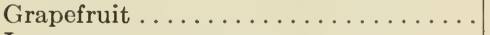 & 31 & 31 & 28 \\
\hline Lemons . . . . . . . . . . . . . . . . & 31 & 31 & 28 \\
\hline Mandarins and tangerines. . . . . . . . & 31 & 31 & 28 \\
\hline 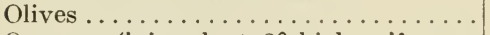 & 31 & 31 & $* 18-24$ \\
\hline $\begin{array}{l}\text { Oranges (injured at } 2^{\circ} \text { higher if con- } \\
\text { tinued four to six hours) } \ldots \ldots \ldots \ldots\end{array}$ & 31 & 31 & $\uparrow 26-29$ \\
\hline 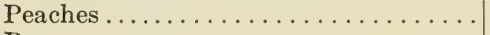 & 30 & 30 & 29 \\
\hline 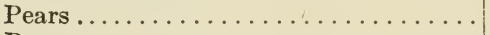 & 29 & 29 & 28 \\
\hline 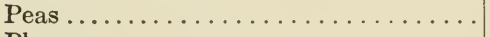 & 30 & 30 & 25 \\
\hline 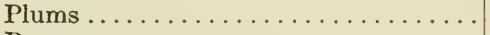 & 31 & 31 & 29 \\
\hline Prunes.$\ldots \ldots \ldots \ldots \ldots \ldots \ldots \ldots$ & 31 & 31 & 29 \\
\hline Strawberries $\ldots \ldots \ldots \ldots \ldots \ldots \ldots$ & 28 & 28 & 30 \\
\hline Walnuts, English .. & 31 & 31 & 28 \\
\hline
\end{tabular}

$* 18$ ripe, 24 green. $\quad \nmid 26$ ripe, 29 green.

Howard (Circ. No. 35, Mo. Exp. Sta.) gives the following temperatures injurious to peaches: "Fully dormant peach buds can stand $8^{\circ}$ or $9^{\circ}$ below zero. When they are appreciably swollen, zero is the danger-point. When the buds are showing pink they can stand $15^{\circ}$ above zero. When the buds are almost open, $25^{\circ}$ is the danger-point. 
When they are newly opened, about $26^{\circ}$ would be the point of danger. When the petals are beginning to fall, $28^{\circ}$ above zero is cold enough to cause uneasiness. When the petals are off, they can stand $30^{\circ}$ above zero. When the shucks (calyx - tubes) are beginning to fall off, $32^{\circ}$ above zero is the dangerpoint. The above figures will serve as a guide to the fruit-grower as showing the proper time to light the fires in the orchard."

Chandler finds that "The killing temperature of peach blossoms, when the tree is just coming into full bloom, under Missouri conditions, seems to vary from about $22^{\circ} \mathrm{F}$. to $25^{\circ}$ or $26^{\circ} \mathrm{F}$. After the blossoms are old enough that they are probably

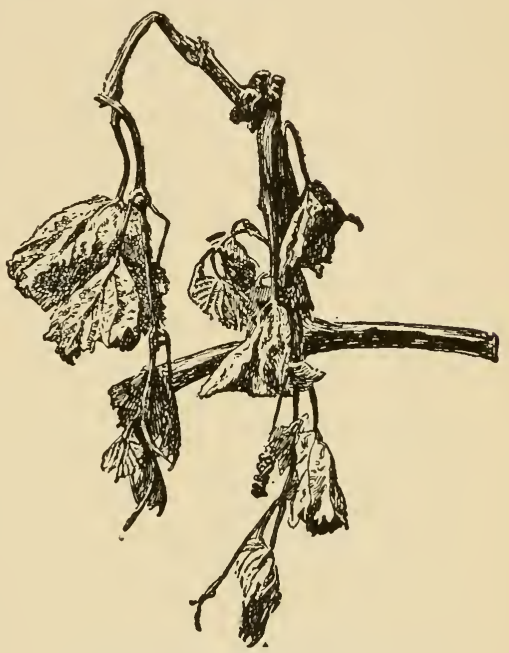

FIG. 122. Grape-shoots killed by a freeze. pollinated, and from that time on until the peaches are as large as $1 / 2$ inch in diameter, at least, they continue to become more tender until they will withstand but very few degrees below the freezing-point, the seeds of young peaches killing at a higher temperature than other peach tissue."

In New Mexico, Garcia and Rigney secured somewhat different results (Bull. No. 89):

"The data recorded at the New Mexico Station show that the fruit-buds, particularly those of the peach, at their different stages of development, - at least, in the experiment station orchard,- 
are somewhat more resistant to cold than has been reported by observers from other parts of the United States. The data further show that the degree of resistibility to frost varies with different stages of growth. The peach is least resistant when it is about the size of a pea, when the calices are falling off. Contrary to the findings of other observers, the bloom is not the most tender stage of growth. In other words, the data indicate that the newly set peach is more delicate than the newly opened blossom. In the majority of cases, a temperature of $26^{\circ}$, lasting only a short time, did little or no injury to the opening bud, newly opened blossom or newly set fruit of the peach, native plum, pear and apple; while one-half a degree below this, or $2512^{\circ}$, although lasting only a few minutes, killed a large percentage of the opening buds, newly set blossoms and young fruits of the peach, in a number of cases. In other words, $26^{\circ}$ was the danger-point and any temperature below this is liable to do more or less injury, depending on how low it gets and how long it remains at that temperature. In some cases, however, a temperature of $24^{\circ}$, lasting only a short time, left about 25 per cent of the blooms and 9 per cent of the newly set fruits uninjured.

"Three important factors that influence the amount of damage done by spring frosts are: The degree of killing temperature, the time of day at which it occurs, and the length of time the temperature remains below the danger-point. . . . As the young fruit develops, it seems to get more tender, until it grows beyond a certain size, when it seems to get hardier again; so that the later frosts which come after the young fruits have made quite a growth are liable to do more injury than the same degree of cold in the earlier part of the season, when the fruits are less developed. At this stage of growth, $261 / 2^{\circ}$ to $27^{\circ}$ would probably be dangerous to peaches. The very late frost of $25^{\circ}$ on May 4, 1912, killed practically all the peaches in the experimental orchard, while $2434^{\circ}$ on April 17, 1910, left about 30 per cent of the Elbertas.

"On the whole, apples and pears seem to be more resistant than peaches and plums."

All the studies of this subject indicate that local conditions greatly modify the effect of cold, and probably no generalizations can be made that will warrant a grower in withholding smudging or fires when the mercury indicates 
a temperature at or below freezing. See the discussion in Chapter VII (page 265).

Harm may come to fruit-setting even though the temperature does not touch the frost-point. Hedrick states that "A temperature low enough to be harmful to blossoms is usually associated with frost or rain; but a low temperature, even though it does not touch the frost-point, nor accompany rain, is often disastrous to the setting of fruit. The injurious effect is probably due to the prevention of the growth of the pollen-tubes."

\section{THE EFFECT OF RAIN ON THE SETTING OF FRUIT}

It is well known that the weather conditions may profoundly affect the fecundity of the flowers. In the forcing of winter vegetables, for example, it is of the greatest importance to keep the house dry and warm when pollination is to be effected, and better results-both in the amount of pollen produced, and in the ease with which it is discharged from the anthers-are commonly secured in bright sunshine. (See, also, page 156.) It is probable that if the flowers of fruit plants were to be kept constantly wet, very little pollination would take place. It is likely also, that dashing rains at blossoming time wash away much of the pollen, but it is doubtful whether enough of it is lost in such passing storms seriously to reduce the crop. The most disastrous storms are probably those milder ones of long duration, and which are accompanied by a low temperature. Not only may such weather tend to prevent the discharge of pollen, but it prohibits the work of insects.

It must be admitted that the above remarks are largely inferences or results of general experience. We 
have little exact knowledge as to the effect of rainstorms and other weather conditions on the setting of fruit. See the discussion of this subject in Chapter II (page 41). Hedrick thinks it "is probable that the chill of rainy weather decreases the vitality of the pollen, and an excess of moisture often causes pollen-grains to swell and burst."

Many of the injuries detailed in this chapter are beyond the reach or rescue of the fruit-grower, but, even so, he will want to understand them. 


\section{CHAPTER IX}

\section{THE SPRAYING OF FRUIT-PLANTATIONS}

IN 1886, the present author wrote in a book that "A remedy proposed of late is to syringe the trees with a mixture of paris green and water, very early in the season, while the young apples stand erect. The poison lodges in the 'blossom end' and destroys the first brood of worms. Later, when the apples turn downward, the poison is washed out by the rains. This remedy was proposed, and its entire success demonstrated, by Prof. A. J. Cook, of the Michigan Agricultural College. A tablespoonful of poison to a gallon of water is sufficient."

This statement represented nearly the sum of knowledge respecting the spraying of orchards at that time. Ten years later, the writer had part in putting before the public Lodeman's "The Spraying of Plants," which made a closely printed book of some four hundred pages. Today, the spraying of fruit-plantations is a standard practice, conducted in a large way with much skill, and involving the use of highly specialized equipment. These contrasts show how rapid has been the development of the spraying of plants to combat insects and diseases. Sometimes its importance may have been magnified out of proportion to other essential operations of fruitgrowing. Spraying has been hailed as a positive means of making orchards fruitful. In practice, however, it makes orchards fruitful only when the cause of unfruitfulness is incursions of insects and fungi. It will not correct the 
faults of poor tillage, nor of insufficient plant-food, nor of unprofitable varieties, nor of neglect in pruning. It is only one of the various elements that enter into successful fruit-growing. There is a tendency in fruit writings to give relatively too much space to spraying.

Aside from its direct and immediate importance, spraying has had a very marked secondary effect in waking up the horticulturist. It has raised the standard of intelligence. Any movement that sets a man to thinking very strongly along one line is likely to awaken his interest in related subjects. So it happens that spraying has been one of the means of rapidly diffusing a better knowledge of horticultural operations. Some of the ways in which this secondary influence of spraying has enlarged the horticultural horizon may be stated as follows:

1. The necessity of spraying calls attention to the reasons for the recent incursions of pests. Spraying was unknown in his boyhood days: why is it so imperative now? This opens a world of suggestion, and leads the questioner to consider the fact that insects and fungi are constantly changing their habits from one plant to another, as the native plants are destroyed and as the area of cultivated plants is increased, and that the continuing commerce with all parts of the world constantly exposes us to new dangers. Pests that suddenly overwhelm the plantation may have been breeding in unobserved numbers in the neglected places for many years. The ideals of the fruit-grower are also higher now. Competition has increased, demands have been refined, and the smallest blemish on a fruit is enough to throw it out of a first-class article, whereas years ago it might have passed without comment.

2. The necessity of spraying is forcing a new discern- 
ment of varieties. Those persons who grow in a large way for the general and more or less staple markets find themselves inquiring for those varieties that are least susceptible to disease- and insect-injury and which, therefore, need the smallest attention in the way of protection. On the other hand, the protection that spraying affords tends to bring back many of those good old varieties that have almost disappeared from cultivation because of disease. Those persons who are growing special kinds of fruit for particular or personal markets, or for home use, will choose the varieties of ideal qualities in spite of the liability to insect or fungous attacks.

3. Spraying demands closer study of the companionships and inter-relations of crops, fungi and insects. Certain pests follow the round of certain crops, and when the planter breaks such a rotation he also lessens the liability of attack. It also forces the use of shorter rotations, for it is a very nimble insect or fungus that can keep pace with a lively and resourceful farmer. He learns that the best treatment of the red-rust on raspberries is a short rotation rather than spraying. The best treatment with many diseases may be a combination of both; but he will find that if he reduces the number of crops to two or at most to three, and then has plantations coming on in other places, he will suffer comparatively little. The same suggestion is applicable to the cultivation of strawberries, and other short-generation fruits.

4. Spraying emphasizes the importance of better care, that the crop may repay the cost of the extra treatment. The potato bug has no doubt exercised a very pronounced influence in improving the cultivation of the potato, and it is already apparent that the San José scale is increasing the alertness in fruit-growing. 
5. The necessity of spraying must develop a greater watchfulness on the part of the fruit-grower for new pests, for they are all the time appearing from foreign countries, from adjacent states or geographical regions, or from the wild.

6. Inasmuch as every new necessity or new subject of inquiry awakens new thoughts and expands the person's relationships, so it becomes a means of enlarging and educating the man. A concentrated invasion of the armyworm is one of the very best means of waking up any farming community and of setting every man, woman and child to asking questions of every passer-by, every agricultural editor and teacher, and experiment station. The good effects of such an invasion are likely to last for a number of years. It is surprising, as one thinks of it, how easily people are scared by a bug! A strange insect, which perhaps does not weigh a grain, will set a whole community of able-bodied men agog, and may cause as much downright fear and discussion as a political revolution.

\section{The kinds of difficulties.}

There are three general types of difficulties or disorders within the view of the discussion in this chapter:

1. Attacks by insects.

(a) The injuries of those insects that eat or chew the parts of the plant, and which, therefore, are killed by the application of arsenical and similar poisons. Such insects are the whole tribe of caterpillars, worms and beetles.

(b) Attacks of insects that suck their food, and which, therefore, are destroyed by caustic applications that injure their bodies. All the 
tribes of plant-lice and scale insects belong here, and for these the kerosene emulsion, lime-sulfur washes and the like, are the specifics.

2. Parasitic fungous diseases, such as the apple-scab, black-rot and mildew of the grape, fruit-rot of the peach, leaf-blight of the plum and pear, black-knot of the plum. These diseases are characterized by definite spots, discolorations or excrescences more or less scattered over the surface of the leaf, fruit or branch. As a rule, the attacked leaves and fruits have a tendency to drop from the tree. The general treatment for these diseases is to spray with some fungicidal mixture, as lime-sulfur or bordeaux mixture. The treatment is useful in proportion as it is applied early and thoroughly. After the fungus once gets into the tissues of the host-plant, it is difficult, if not impossible, to kill it. If, however, the fungicide is on the plant before the fungus is, the parasite may not be able to gain a foothold. Even after it does secure a foothold, however, the spray may check its spread by preventing the development of its external parts and the formation of spores.

3. The physiological and bacterial diseases, or the so-called constitutional troubles. In these cases, there are rarely any definite spots, as in the attacks of parasitic fungi, but the entire leaf, or even the entire plant, or a large part of it, shows a general weakening and wilting, as if there were some cutting-off of the accustomed source of nourishment. Such diseases are a general yellowing and death of the leaf, the dying of the leaf along the main veins and 
around the edges, showing that the difficulty probably affects the entire leaf and not any one part of it. In general, there is a tendency for foliage in plants so attacked to wither and hang on the tree for a time. The peach yellows and pear blight are diseases of this kind. There are no specific treatments for these troubles. They must be approached by what physicians call prophylaxis, - that is, by methods of sanitation and prevention, and by eradication of the parts. The diseased plants or parts are cut away and burned. All conditions that seem to favor the development of the disease are removed. Varieties particularly susceptible are discarded. Careful management is often much more important than any attempt at specific treatment.

\section{SPECIFIC REMARKS ON SPRAYING}

1. Spraying is only one of the requisites to success in fruit-raising.-Trees must grow before they can bear, and this growth depends on food and proper conditions of soil, more than it does on the accident of immunity from insects and fungi. It is one of the cardinal operations for which the grower must plan in the beginning.

2. Spraying is insurance.-There are many elements of risk in the growing of fruit. It is impossible to foretell by any considerable length of time whether any or all of the difficulties liable to harass the fruit-raiser will actually appear. The owner does not know whether his buildings will burn, yet he insures them. We know that, in four years out of five, some damaging injury of insects or 
fungi may be confidently expected, and it is the part of wisdom to insure against it.

3. Spraying is of some value every year, on apples, pears, plums, quinces, grapes and various other fruits.Even in years of great immunity, nearly all sprayed orchards carry a better foliage than those untreated. So, wholly aside from the idea of insuring against risk, it is advisable to spray for those insects that are more or less abundant every year. Some insects and diseases appear late in the season, so that the spray may be needed at some epoch in the season.

4. Spray thoroughly, or not at all.-Much of the spraying is little more than a waste of time and material. Squirting a few quarts of water at a tree as one hurries past it, is not spraying. A tree is thoroughly and honestly sprayed when it is wet all over, on all the branches and on both sides of all the leaves. An insect or a fungus is not killed until the poison is placed where the pest is. It is not frightened. Bugs do not search for the poison, in order that they may accommodate the orchardist. The one spot not sprayed may be the very place where a budmoth is established.

5. Prepare in winter for next year's work.-Secure nozzles and pumps, and repair the tanks and wagons. It is especially important that the wagons be handy, and that the equipment be large enough and strong enough to do the work quickly. A break-down in spraying time is likely to be a serious matter. Pumps should be cleaned inside and out, repacked if necessary, oiled and completely repaired. If power is used, the engine should be tested, and it may need to be overhauled. All repair parts and all insecticides and fungicides should be ordered well in advance of the spraying season. 
6. The style or "make" of pump and nozzle to be used depends on the particular kind of work to be done.-The reader will now see that the advice as to machinery must depend on the specific purpose for which the appliances are to be used and the extent of operations. Apparatus devised a few years ago for the distribution of paris green may be of no value for the application of such a thick compound as the bordeaux mixture or the lime-sulfur.

Whatever the outfit chosen, the pump should be strong and powerful, with hard brass working parts, and capable of throwing much liquid with great force. In respect to nozzles, it may be said that there is no one kind which is best for all purposes. It is desirable that the liquid should reach the plant in the form of a very fine mist; but it is just as important that the nozzle should have the power of throwing the liquid to the desired point. In other words, there are two elements to be considered,- the nozzle must have carrying power and delivering power. A fine mist at the orifice of the nozzle is of no use when the nozzle is 30 feet short of the bug. With many of the modern devices, the man who holds the hose in spraying rigs may stand 8 or 9 feet above the ground, and he may use a pole 12 to 15 feet in length, which will elevate the nozzle something like 25 feet from the ground; but many apple trees are 50 to 60 feet high. It will therefore be seen that the liquid must carry itself 25 to 30 feet beyond the nozzle. For such purposes, a nozzle that distributes the liquid in a spray directly from its orifice is of small use; it must throw a more or less solid stream, and the stream should break up when it reaches its destination. Such nozzles require very strong power behind them.

For the spraying of fruits, the various disc nozzles are now most in use. They are provided with a chamber in 
which the liquid is whirled, and it is then projected through a disc with openings of different sizes. The bordeaux nozzle is also used for the codlin-moth and some other purposes. The spray liquid should penetrate the top of the tree and drench all the leaves; this requires not only a good nozzle but much force,--more than the usual handpump develops.

Remarks similar to the above may be made for pumps; that is, there is no one best pump. We might divide all pumps into two general classes,- - those that deliver the liquid by force of gravity, as some of the potato sprayers, and those that deliver it by the force of pressure. The force of gravity is not sufficient to do the work well, especially when bordeaux mixture is to be used. Of the pressure machines, there are several kinds, as those that derive their force from the suction of a piston and

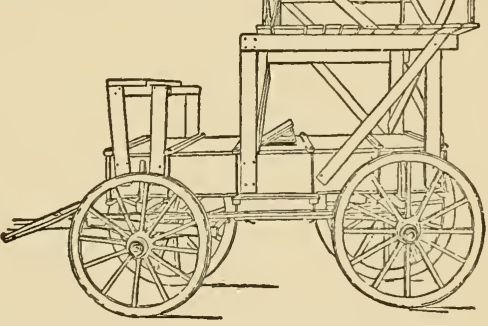

Frg. 123. Platform above a tank outfit. valves, and those that work from the force of compressed gas or air. Knapsack pumps are very efficient, not only because they are powerful for their size, but also because they enable the operator to stand very close to his work; but they are not adapted to work on trees nor, in fact, on large areas in this country, because labor is too high-priced. For small areas, for experiment purposes and the like, they are exceedingly useful and handy. The syringe and bucket pumps are very efficient for work in a small way in yards, and especially when it is desired to be extra thorough.

The force or power to drive a pump may be the arm 
of the operator, the geared wagon wheel, or an engine. The geared sprayers may be useful for small-fruits and grapes, inasmuch as they work while the team walks; but, as a rule, they are not adapted to large orchard trees,

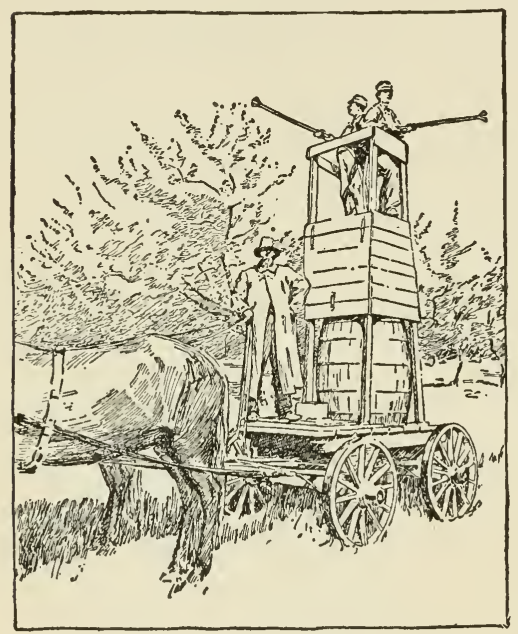

FIG. 124. Platform above a barrel outfit, now becoming obsolete for large orchards. because enough liquid cannot be thrown while the machine is passing a tree thoroughly to spray it. In recent years, very effective power sprayers have come into use, mostly employing gasolene or compressed air. In plantations of four to five acres and more, the power sprayer will probably pay, particularly if the farm grows other crops, as potatoes, that need spraying. The engine may be used at other times to drive a wood-saw, dairy machinery, silage-cutters, well-pumps and other apparatus.

In low orchards, a low truck may be needed, and in some cases a stone-boat is best; but most orchards will need some kind of high rig, to enable the operator to reach the tops of the trees. Fig. 123 is a standard rig for handpower work. The tank holds 300 gallons. The pump is placed on the front of the rig (in the seat-rack), and one man drives and pumps. The rig is stopped at every tree. Two leads of hose are used. Another good rig for hand 
power is shown in Fig. 124. In Fig. 125 is shown a power outfit, the machinery being covered for protection. Many other efficient spraying outfits are in use, but these three will serve to illustrate the kind of work that is needed. Until ten or fifteen years ago, the greater number of fruit-growers used an ordinary wagon, with box or rack, and a single fifty-gallon barrel, and this outfit may still be seen; but this is found to be both uneconomical and ineffective for large operations.

The use of long pieces of $1 / 2$-inch gas-pipe, with the nozzle attached to the end, is advisable when one is working in the tops of the trees, but they are likely to be a nuisance if one works from the ground. They are awkward if more than 10 feet long. Growers usually prefer to use a bamboo fishing-pole, and to secure the hose near its upper end, letting the lower part of the pole remain free. Most operators use insufficient hose. For work in old orchards, the run should be at least 15 feet long.

For yards and ornamental plants, a cart-like rig, like that shown in Fig 126, is handy and efficient. A home-made rig for

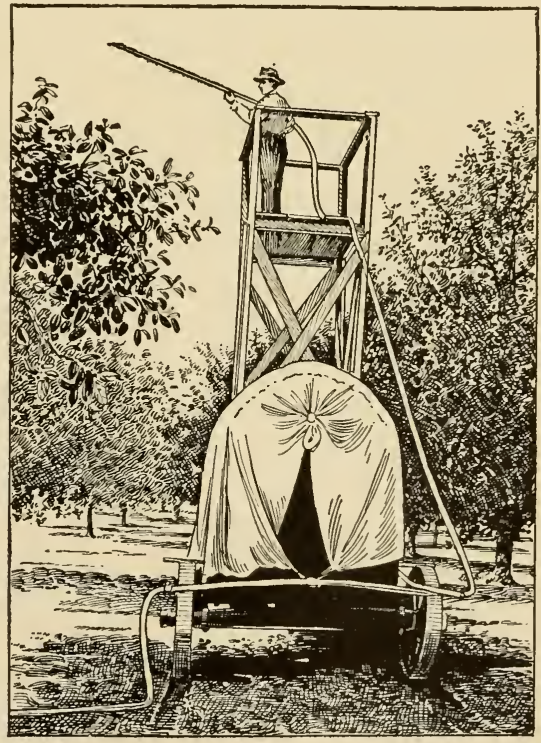

FIg. 125. Elevated platform above a power sprayer, as used on the Pacific coast. 
spraying strawberries and potatoes is seen in Fig. 127. It is a barrel-pump, mounted on wheels, with three nozzles

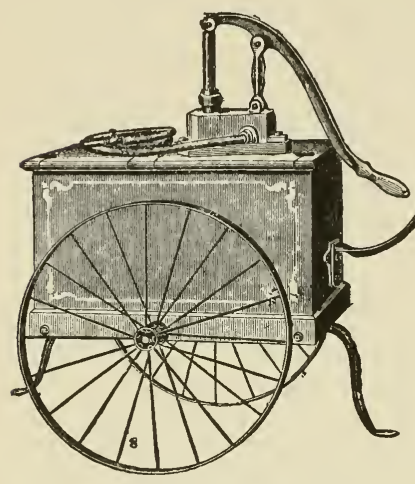

126. A convenient spraying equipment for home grounds. rigged on the tailboard, so as to cover as many rows of plants.

There are dustsprayers on the market, that apply the material in a dry powder rather than in water; but, while they have given satisfaction for particular purposes, they have not become popular for orchard work. Blodgett found (Cornell Bull. No. 340, 1914) that dust-spraying needs to be further tried as a means of controlling apple diseases. (Fig. 128.) "The use of finely ground sulfur as the fungicide in a dust mixture has given very encouraging results, and warrants further trials on a more extensive scale. The application of arsenate of lead in powdered form in the quantities applied is more effective against the common orchard insects that chew than is the same substance applied wet. The time required for dusting an orchard is much less than that required for spraying it." The cost of controlling insects and fungi is not lessened. Melander and Beattie (Wash. Bull. No. 166)

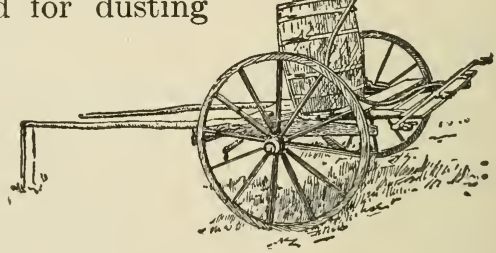

FIG. 127. One-horse outfit for spraying strawberries and potatoes. 
think that dust-spraying does not have sufficient penetrating power for orchard work.

7. The farmer should know what he wants to kill before he begins to spray. - It is still common to find a man who is going at spraying with enthusiasm, but who cannot explain a single definite object in view. He merely knows, on general principles, that spraying is useful. To such a man, spraying is spraying, whether he uses arsenicals, or bordeaux, or both, or neither one; and his results are about equal to his knowledge. There is no longer an excuse for such practice, for all the leading insects and fungi have received treatment in the publications of the government and experiment sta-

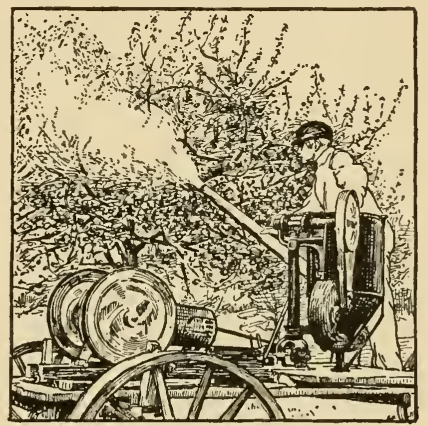

FIG, 128. Dust-sprayer. tions. Of course, the real fruit-growers are well and exactly informed, even to details; but there are some persons who need to know that:

The arsenicals are used to kill all larvæ or worms, and all those insects that chew the leaves or shoots, such as the codlin-moth, bud-moth, canker-worm, potato-beetle, tent-caterpillar, and the like. Limesulfur and kerosene emulsion are used for scale-insects and plant-lice.

Lime-sulfur and bordeaux mixture are used to prevent the attacks of fungous parasites, as apple-scab, leaf-blight of the pear, quince and plum, potato-blight and such like.

The leading poisonous insecticide is now arsenate 
of lead, although arsenate of lime is much used; the leading fungicide for most fruits is lime-sulfur, and it is also a good scalecide.

8. The time to spray must be determined for each particular case.-The grower himself must decide when and how often to spray, because he should know what enemies he desires to reach. If he has the bud-moth, he should spray with the first swelling of the buds, and if he has the plumscale he should spray in the winter. But, leaving the special insects aside, it is safe to say that for the two staple enemies-the apple-scab and the codlin-moth-at least two sprayings should be given. Spraying when the tree is dormant has an

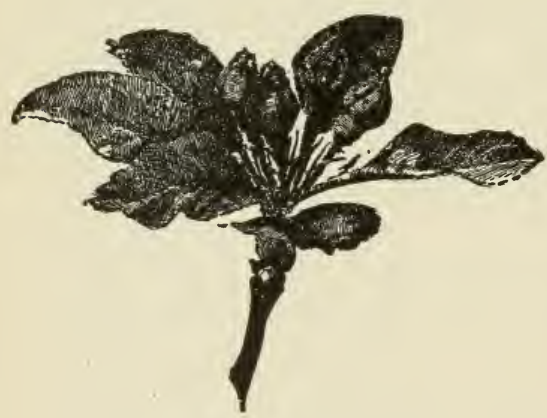

Frg. 129. Showing when apple trees are ready for the main spraying. important effect in destroying the apple-scab fungus. As a general statement, one may spray apples and pears two or three times, once when dormant, with lime-sulfur; once just as the fruit-buds break but before the flowers expand (Fig. 129) with weak limesulfur and arsenical, and again just as the last blossoms fall, with the same combination. The first spraying is for the scab fungus in particular. The second spraying (which is often omitted) is for the scab and bud-moth. The third is particularly for the codlin-moth. If scab is very bad, other sprayings may be necessary. Whether or not it is necessary to spray again will depend largely on the season. The operator must watch matters 
closely, and spray when he needs to do so, or when he is in doubt. Two sprayings are sufficient for the codlinmoth, and three are usually sufficient for the apple-scab. These two sprayings constitute the insurance that has been mentioned; thereafter, the grower will be able to see more definitely what is needed. These remarks illustrate the nature of the questions that the fruit-grower must consider.

9. Keep posted.-Every year, read the new bulletins, note the articles in the agricultural papers, keep in touch with the discussions before societies, secure the publications of manufacturers. The practice in spraying is moving rapidly, and new studies of insects and diseases are constantly being made. The practices are now well standardized, but modifications are often made and new pests appear. The grower must be vigilant.

\section{LISTS AND FORMULAS}

The marked departures in spraying in recent years have been not only in the perfecting of the mechanical devices, but in the character of the spray materials. London purple and paris green are now little used, and arsenate of lead and arsenate of lime have taken their places. Bordeaux mixture is still the standard fungicide for plants in a growing condition, although lime-sulfur is now mostly used for summer spraying of apples and pears, as well as for the winter spraying. On most plants, lime-sulfur has a serious dwarfing effect on foliage. Bordeaux is used for grapes, small-fruits, potatoes and many other things. Arsenate of lead may be combined with lime-sulfur as well as with bordeaux. 
Synopsis of the principal considerations in the choice of a power sprayer and nozzles (Melander and Beattie, Wash. Bull. No. 106):

1. General operation and efficiency.

Capacity.

Engine-

Type of motor.

Operating with distillate or denatured alcohol.

Average horse-power.

Maximum brake horse-power.

Cubic feet of piston displacement per horse-power hour.

Revolutions per minute.

Capacity of fuel-tank.

Cooling device:

Efficiency.

Amount of heating.

Ignition.

Detachability from pump for other uses.

Pump-

Belt- or gear-drive.

Number and style of cylinders.

Diameter of pump cylinder.

Length of stroke.

Strokes per minute.

Discharge per minute at 250 pounds pressure.

Maximum operating pressure.

Capacity of air-dome.

Outfit-

Tank capacity.

Filling pump: piston or rotary.

Weight.

Economy of operation.

Engine-

Time lost due to engine.

Horse-power hours per gallon of gasolene used.

Gallons of gasolene per 100 gallons pumped.

Gallons of lubricating oil per 100 gallons pumped.

Percentage of fuel-tank capacity used an hour for operation. 
Pump, etc.-

Slippage (rated capacity less actual delivery).

Uniformity of pressure.

Efficiency of pressure regulator in maintaining uniform pressure when hose is cut off or is on.

Drop in pressure between pump and nozzle.

Amount of overflow from pump to tank when working at normal capacity.

\section{Outfit-}

Efficiency of agitator.

Time required for refilling tank.

Ratio of weight to capacity.

Accessibility and convenience.

Accessibilty of working parts-

Valves: Ease of replacing valve-seats.

Drains: Engine, pump and tank.

Plunger-cups or packing; repacking stuffing-boxes (if any).

Screws; bolts; oil-cups; pressure-regulator.

Method of taking in slack between pump and engine.

Cleaning strainer on suction hose; cleaning tank of debris.

Adaptability to field conditions-

Cramping of wheels in turning.

Radius of circle required in turning.

Possibility of miring in irrigation ditches or loose soil.

Draft.

Repairs-

Possibility of securing duplicate parts.

Ease of making repairs.

2. Construction.

\section{Engine-}

General construction:

Durability; simplicity of design.

Exposure of working parts:

Freedom from danger of breaking cogs, cranks, etc.

Freedom from danger on part of operator.

Proportions of working parts; quality of materials; workmanship.

Provision for drainage.

Method of feeding gasolene. 
Pump-

General construction: as above.

Valves: composition and design.

Cylinder lining.

Provision for drainage.

Provision for supplying air to air-dome.

Reliability of pressure gauge.

Type of pressure regulator.

Outfit-

Tank: Wood or metal; location; design suited to agitator.

Trucks: Steel or wood; rigidity; strength; weight.

Wheels: Diameter; width of tires; metal or wood.

Tower:

Weight; detachability; position.

With railing or straddle.

Hose-

Quality; diameter; length; number of ply.

End couplings set in rubber and bound in place, without sharp projections to catch in operator's hands.

Extension rods-

Length; Bamboo or not; aluminum, brass or iron.

Character of end ferrules (whether they slip through the hand easily, and thoroughly grip the core). Nozzles-

Kind; quality.

Cut-offs-

Globe or ball or quarter-turn.

Anti-leak; rapidity of action.

3. Cost.

Accessories supplied: e. g., filling pump and suction hose; magneto; hose; rods; nozzles; tools; crooks; tower.

Ratio of cost to capacity and efficiency.

\section{INSECTICIDES AND FUNGICIDES}

(Adapted from Crosby and Matheson, and from Reddick.)

Of poisoning insecticides, the most widely used and effective substance is arsenic in its various forms. Arsenic is never used pure, but only when chemically combined 
with lead, lime or other substance that produces a compound insoluble in water.

White arsenic is the cheapest form in which arsenic can be obtained. It is a white powder, soluble in water, and very injurious to foliage. A cheap and efficient insecticide may be prepared from it as follows:

For use with bordeaux mixture only.-Sal-soda, two pounds; water, one gallon; arsenic, one pound. Mix the white arsenic into a paste and then add the sal-soda and water, and boil until dissolved. Add water to replace any that has boiled away, so that one gallon of stock solution is the result. Use one quart of this stock solution to fifty gallons of bordeaux mixture for fruit trees. Make sure that there is enough lime in the mixture to prevent the caustic action of the arsenic.

For use without bordeaux mixture.-Sal-soda, one pound; water, one gallon; white arsenic, one pound; quicklime, two pounds. Dissolve the white arsenic with the water and sal-soda as above, and use this solution while hot to slake the two pounds of lime. Add enough water to make two gallons. Use two quarts of this stock solution in fifty gallons of water.

As there is always some danger of foliage-injury from the use of these home-made arsenic compounds, and as they cannot be safely combined with the dilute lime-sulfur when used as a summer spray, they are now rarely employed in commercial orchard spraying.

Arsenate of lead was first used as an insecticide in 1893, in Massachusetts. For orchard work throughout the country, it has now almost entirely replaced paris green. It adheres better to the leaves, may be used at considerably greater strength without injuring the foliage, and may be combined with a dilute lime-sulfur solution or with the self-boiled lime-sulfur. Chemically, arsenate of lead may be either triplumbic arsenate or plumbic-hydrogen arsenate. The commercial product usually consists of a mixture of these two forms, the proportion depending on the method of manufacture employed. It is usually sold in the form of a thick paste, but for some purposes the powdered form is preferred. Under the National Insecticide Law of 1910, arsenate of lead paste must not contain more than 50 per cent water and must contain the arsenic equivalent of at least $12 \frac{1}{2}$ per cent arsenious oxid. The water-soluble arsenic must not exceed an equivalent of three-fourths of 1 per cent of 
arsenic oxid. In the best grades of arsenate of lead paste the chemical is in a finely divided condition, and thus when diluted for use remains in suspension for a considerable time. Arsenate of lead is used at various strengths, depending upon the insect to be killed and on the susceptibility of the foliage to injury. Four pounds in one hundred gallons can be used on the peach if combined with the selfboiled lime-sulfur; on apple, four to five pounds in one hundred gallons is usually sufficient; on grapes for killing the grape root-worm beetles and the rose-chafer, eight to ten pounds in one hundred gallons have been found necessary. The poison is more readily eaten by these beetles if sweetened by two gallons of molasses in one hundred gallons; but, unfortunately, the addition of molasses greatly decreases the adhesiveness of the poison. Some species of fruit flies may be controlled by the use of sweetened arsenate of lead sprayed on the foliage of the plants at the first appearance of the flies. They lap up the poison with their fleshy tongue-like mouth-parts and succumb before ovipositing.

Hellebore is a poisoning insecticide of recognized standing. It is a light brown powder made from the roots of the white hellebore plant (Veratrum album), one of the lily family. It is applied both dry and in water. In the dry state, it is usually applied without dilution, although the addition of a little flour will render it more adhesive. In water, four ounces of the poison is mixed with two or three gallons, and an ounce of glue, or thin flour paste, is sometimes added to make it adhere. A decoction is made by using boiling water in the same proportions. Hellebore soon loses its strength, and a fresh article should always be demanded. It is much less poisonous than the arsenicals, and should be used in place of them upon ripening fruit. It is used for various leaf-eating insects, particularly for the currant-worm and rose-slug.

Of the contact insecticides, the most important for the fruitgrower are soaps, kerosene emulsion, lime-sulfur solution and tobacco preparations.

Soaps.-The most commonly used soap solution is that prepared from fish-oil soap. The commercial brands of this soap are usually by-products and contain many impurities; further, many of them contain an excess of free or uncombined alkali, and are thus likely to injure young and tender foliage. A good fish-oil soap may be prepared by the following formula: Caustic soda, six pounds; water, one and one-half gallons; fish-oil, twenty-two pounds. Dissolve 
the caustic soda in the water and then add the fish-oil gradually under constant and vigorous stirring. The combination occurs readily at ordinary summer temperatures, and boiling is unnecessary. Stir briskly for about twenty minutes after the last of the oil has been added. There is now on the market a good brand of insecticide soap prepared from cotton-seed oil soap-stock, or from an impure grade known as pancoline.

Kerosene emulsion is the oldest of our contact insecticides. It is especially valuable for use against plant-lice and other small, softbodied insects. It is prepared by the following formula: Soap, onehalf pound; water, one gallon; kerosene, two gallons. Dissolve the soap in hot water; remove from the fire and, while still hot, add the kerosene. Pump the liquid back into itself for five or ten minutes or until it becomes a creamy mass. If properly made, the oil will not separate on cooling. For use on dormant trees, dilute with five to seven parts of water. For killing plant-lice on foliage, dilute with ten to fifteen parts of water. Crude-oil emulsion is made in the same way by substituting crude-oil in place of kerosene. The strength of oil emulsions is frequently indicated by the percentage of oil in the diluted liquid; for a 10 per cent emulsion, add seventeen gallons of water to three gallons of stock emulsion; for a 15 per cent emulsion, add ten and one-half gallons of water to three gallons of stock emulsion; for a 20 per cent emulsion, add seven gallons of water to three gallons of stock emulsion; for a 25 per cent emulsion, add five gallons of water to three gallons of stock emulsion.

Lime-sulfur solution is both insecticide and fungicide. A solution of lime-sulfur was first used as an insecticide in California in 1886. It is now the standard remedy for blister-mite, San José scale and similar scales, as well as an efficient fungicide. The lime-sulfur solution may be purchased in the concentrated form, or may be prepared as follows: Lump lime (95 per cent calcium oxid), thirty-eight pounds, or lump lime (90 per cent calcium oxid), forty pounds; sulfur, eighty pounds; water, fifty gallons. Make a paste of the sulfur with about ten gallons of hot water. Add the lime. As the lime slakes, add hot water as necessary to prevent caking. When the lime has slaked, add hot water to make fifty gallons and boil one hour, stirring constantly. Water should be added from time to time to keep the liquid up to fifty gallons. Store in air-tight hardwood barrels. Test the strength of the solution with a Baumé hydrometer, and dilute for use according to the following table: 
Dilutions for Dormant and Summer Spraying with LimeSulfur Mixtures

\begin{tabular}{|c|c|c|c|}
\hline \multirow{2}{*}{$\begin{array}{l}\text { Reading on hydrometer. } \\
\text { (Degrees Baumé) }\end{array}$} & \multicolumn{3}{|c|}{$\begin{array}{l}\text { Amount of dilution. } \\
\text { Number of gallons of water to one } \\
\text { gallon of lime-sulfur solution. }\end{array}$} \\
\hline & $\begin{array}{l}\text { For San } \\
\text { José scale. } \\
\text { Dormant. }\end{array}$ & $\begin{array}{l}\text { For blister- } \\
\text { mite. } \\
\text { Dormant. }\end{array}$ & $\begin{array}{l}\text { For summer } \\
\text { spraying of } \\
\text { apples. }\end{array}$ \\
\hline 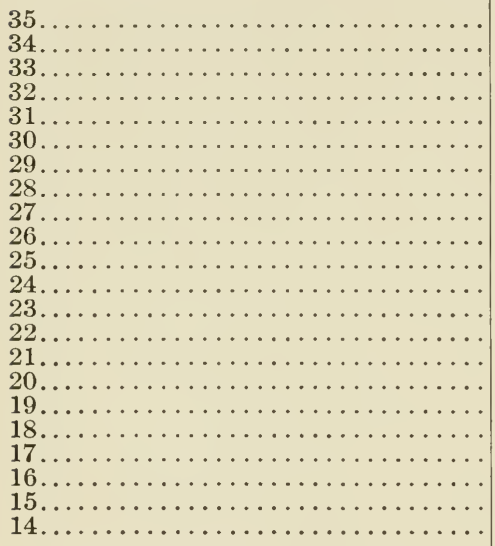 & $\begin{array}{l}9 \\
83 / 4 \\
81 / 4 \\
8 \\
71 / 2 \\
71 / 4 \\
63 / 4 \\
61 / 2 \\
6 \\
53 / 4 \\
51 / 4 \\
5 \\
41 / 2 \\
41 / 4 \\
33 / 4 \\
31 / 2 \\
31 / 4 \\
3 \\
23 / 4 \\
21 / 2 \\
21 / 4 \\
2\end{array}$ & $\begin{array}{l}121 / 2 \\
12 \\
111 / 2 \\
11 \\
101 / 2 \\
10 \\
91 / 2 \\
9 \\
81 / 2 \\
8 \\
71 / 2 \\
7 \\
61 / 2 \\
6 \\
51 / 2 \\
5 \\
43 / 4 \\
41 / 4 \\
4 \\
33 / 4 \\
31 / 2 \\
3\end{array}$ & $\begin{array}{l}45 \\
431 / 4 \\
411 / 2 \\
40 \\
373 / 4 \\
361 / 4 \\
341 / 4 \\
323 / 4 \\
31 \\
291 / 2 \\
273 / 4 \\
26 \\
241 / 4 \\
223 / 4 \\
211 / 4 \\
193 / 4 \\
181 / 4 \\
17 \\
16 \\
15 \\
14 \\
123 / 4\end{array}$ \\
\hline
\end{tabular}

Commercial concentrated lime-sulfur, as manufactured and placed on the market, is a clear amber liquid, and should test $32^{\circ}$ to $35^{\circ}$ Baumé. It costs about 20 cents a gallon retail, and comes ready to pour into the spray tank. For apple and pear diseases arsenate of lead can be used with this solution, and increases its fungicidal value.

Scott's self-boiled lime-sulfur is a mechanical mixture of the two substances, and is really not boiled, the heat being supplied by the slaking lime. In a small barrel or keg place eight pounds of good quicklime. Add water from time to time in just sufficient amounts to prevent burning. As soon as the lime begins to slake well, add slowly (preferably through a sieve) eight pounds of sulfur flour. Stir constantly, and add water as needed. As soon as all bubbling has ceased, check further action by adding a quantity of cold water, or 
pour into a barrel or tank and make up to fifty gallons. Keep well agitated. Very effective against peach-scab and brown-rot. Several other formulas have been used: $10-10-50$ and 5-5-50. Arsenate of lead can be used with this mixture. By using boiling water and allowing the hot mixture to stand for half an hour, a stronger spray mixture than the above can be secured. It cannot be used safely on peaches, but has been used successfully on grapes for surface mildew. The addition of sulfate of iron or sulfate of copper, one to two pounds to fifty gallons, has been used for apple-rust.

Tobacco is one of our most useful insecticides. The poisonous principle in tobacco is an alkaloid nicotine, which, in the pure state, is a colorless fluid, slightly heavier than water, of little smell when cold and with an exceedingly acrid burning taste even when largely diluted. It is soluble in water and entirely volatile. It is one of the most virulent poisons known; a single drop is sufficient to kill a dog. Commercial tobacco preparations have been on the market for many years. The most important of these are black leaf, "black leaf 40 ," and nicofume.

"Black leaf" was formerly the most widely used tobacco extract. It contains only 2.7 per cent nicotine and has now been replaced by the more concentrated extracts. It is used for plant-lice at the rate of one gallon to sixty-five gallons of water.

"Black leaf 40 " is a concentrate tobacco extract containing 40 per cent nicotine sulfate. Its specific gravity is about 1.25. In this preparation the nicotine is in a non-volatile form, it having been treated with sulfuric acid to form the sulfate. "Black leaf 40 ". is used at strengths varying from one part in 800 parts of water to one part in 1,600 parts. It can be satisfactorily combined with other sprays, as for example, lime-sulfur solution, arsenate of lead, and the various soap solutions. When used with water, about four pounds of soap should be added to make the mixture spread and stick better.

"Nicofume" is a tobacco extract containing 40 per cent of nicotine in the volatile form. Strips of paper soaked in this preparation are smudged in greenhouses to destroy aphids.

Tobacco is also used in the form of dust for the same purpose. It is especially valuable against root-lice on asters and other plants. Tobacco extracts can be made at home by steeping tobacco stems in water, but as they vary greatly in nicotine content and are sometimes likely to injure tender foliage, it is better to buy the standardized extracts. 
The standard fungicides for spraying purposes are bordeaux mixture and lime-sulfur. The lime-sulfur has already been discussed; we may now take up the preparation of bordeaux.

Bordeaux mixture is a bluish green copper compound that settles out when freshly slaked lime and a solution of copper sulfate (bluestone) are mixed. Many formulas have been recommended and used. The 5-5-50 formula may be regarded as standard. In such a formula the first figure refers to the number of pounds of copper sulfate, the second to the stone or hydrated lime, and the third to the number of gallons of water. Bordeaux must often be used as weak as 2-2-50, on account of injury to some plants.

To make fifty gallons of bordeaux mixture, proceed as follows:

(1) Pulverize five pounds of copper sulfate (blue-stone), place in a glass, wooden or brass vessel, and add two or three gallons of hot water. In another vessel slake five pounds of quicklime in a small amount of water. When the copper sulfate is all dissolved, pour into a barrel and add water to make forty to forty-five gallons. Now strain the lime into this, using a sieve fifty meshes to the inch or a piece of cheese-cloth supported by ordinary screening. Stir thoroughly, and add water to the fifty-gallon mark. The flocculent substance which settles is the effective fungicide. Always stir vigorously before filling the sprayer. Never add the strong lime to strong vitriol. Always add a large amount of water to one or the other first. Copper sulfate used alone would not only wash off quickly in a rain, but cause a severe burning of fruit and foliage. Lime is added to neutralize this burning effect of the copper. If the lime were absolutely pure, only slightly more than one pound would be required to neutralize this burning effect. For many purposes an excess of lime is not objectionable and may be desirable. For nearly ripe fruit and ornamentals an excess of lime augments spotting. In such cases the least amount of lime possible should be used. Determine this by applying the cyanide test (2).

(2) Secure from the druggist 10 cents' worth of potassium ferrocyanide (yellow prussiate of potash) and dissolve it in water in an eight-ounce bottle. Cut a V-shaped slit in one side of the cork, so that a few drops of the liquid can be obtained. Now proceed as before. Add lime with constant stirring until a drop of the ferrocyanide ceases to give a reddish brown color.

(3) When bordeaux mixture is desired in large quantities, stock solutions should be made. Place one hundred pounds of copper 
sulfate in a bag of coffee-sacking, and suspend in the top cf a fiftygallon barrel, and add water to the fifty-gallon mark. In twelve to fifteen hours the vitriol will be dissolved, and each gallon of solution will contain two pounds of copper sulfate. Slake a barrel of lime, and store in a tight barrel, keeping it covered with water. Lime so treated will keep all summer. It is really hydrated lime. This is often dried, pulverized, and offered on the market in paper bags of forty pounds each, under such names as ground lime, prepared lime, hydrated lime, and the like. If the paper is not broken, the lime does not air-slake for a long time. One and one-third pounds of hydrated lime equals in value one pound of quicklime. Air-slaked lime cannot be used in preparing bordeaux mixture.

Arsenical poisons can be combined with bordeaux mixture.

\section{LEADING FRUIT INSECTS AND DISEASES THAT ARE CONTROLLED BY SPRAYING}

The insects, mites, parasitic fungi, bacteria and other organisms that attack fruit plants of one kind or another are legion; but there are several prominent pests and diseases of each of the temperate-climate fruits that should be recognized by every fruit-grower. The following notes, assembled from the statements of Reddick, and of Crosby and Matheson, represent the best advice that is available at the present writing. The grower should keep himself well informed on the new practices. Only such insects and diseases are included as yield to treatment by spraying or similar practices; borers, cankers and similar troubles are discussed in Chapter VIII.

Apple.-ApHids, or Plant-Lice.-Three species commonly attack the opening buds and leaves of apple-the leaf aphis (Aphis pomi), rosy aphis (Aphis sorbi) and bud aphis (Siphocoryne aven $x$ ).

These small, soft-bodied insects may be controlled by thorough spraying with "black leaf 40 " tobacco extract, three- 
fourths of a pint in one-hundred gallons of water, adding four pounds of soap. Make the application before the leaves curl.

APPLE-SCAB (Venturia inequalis).--Olive-green, brownish or blackish scab-like spots on leaves and fruit. Scab is one of the most prevalent, as well as one of the most damaging, of the apple diseases. It appears on the leaves (Fig. 130) and also in the fruit (Fig. 131). Whetzel. The definite lesions are readily distinguished from the rusty, irregular injuries often caused by bordeaux mixture (Fig. 132, N. Y. Exp. Sta.).

Rake and burn or plow under old leaves very early in spring. Spray with lime-sulfur $32^{\circ}$ Baumé, 1-40, or bordeaux, 3-3-50: when blossom buds show pink; (2) when majority of petals have fallen; (3) three weeks after 2, depending upon the weather; (4) if a late attack is feared, spray before fall rains begin.

Apple-Curculio (Anthonomus quadrigibbus).- $\mathbf{A}$ soft, white grub, about $1 / 2 \mathrm{in}$. long, in the fruit.

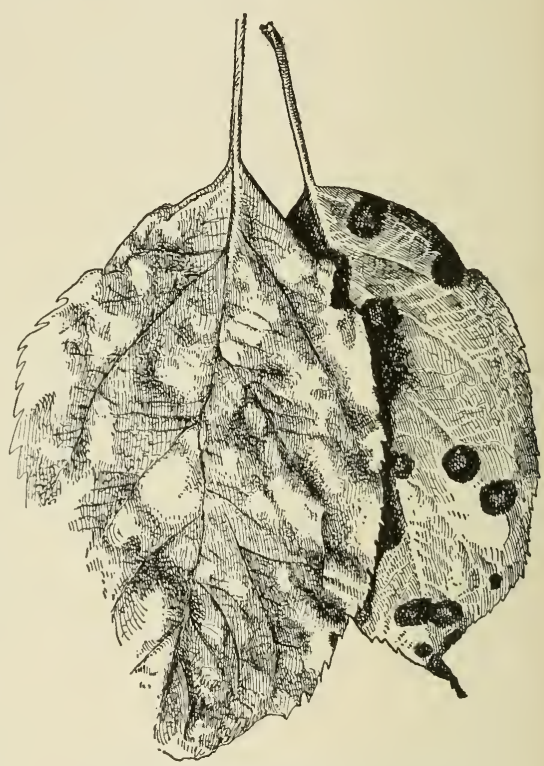

FIG. 130. The characteristic markings of apple-scab.

Clean cultivation. Rake the small, early-dropped apples out into the sun where they will dry up.

Apple Leaf-Hopper (Empoasca mali).-A slender, pale yellowish green bug; the nymphs are pale greenish and usually found on the under side of the leaves. The winter eggs are laid in blisters under the bark of the smaller branches: summer eggs, in the leaf veins and petioles. Four generations annually. The insect feeds by extracting the juices from the leaves, causing them to turn pale and curl. It is most injurious to nursery stock. 
The young nymphs may be killed by spraying with "black leaf 40 " tobacco extract, three-fourths of a pint in one hundred gallons of water, adding three to four pounds of soap. Nurserymen of ten catch the adults by the use of sticky shields.

APPLE LEAF-ROLLER (Archips argyrospila).A green caterpillar with a black head, 1 inch or less in length when mature, attacks the opening buds, rolling and webbing together the leaves, flowers and young fruit into a nest. Holes are eaten in the young apples, deforming them. Eggs are laid in

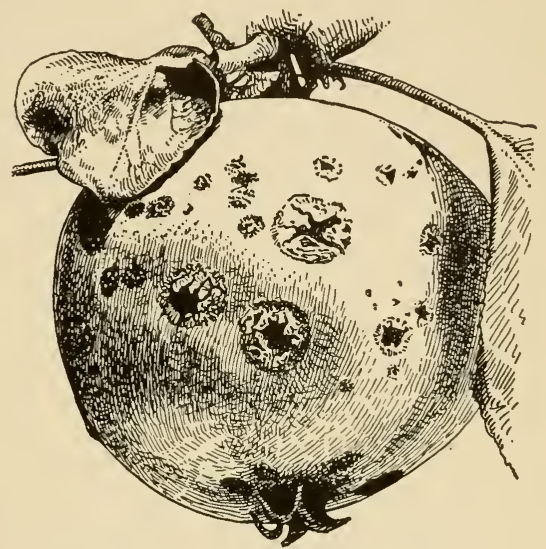

FIG. 131. Apple-scab. June in small, flat masses on the bark, and are covered with a smooth, varnish-like coating. They do not hatch till the following spring.

To kill eggs, spray with miscible oil, one gallon in fifteen gallons of water, making the application as late as possible before the buds open. If the eggs have been neglected, recourse must be had to arsenate of lead, six pounds in one hundred gallons water. Apply before the blossoms open.

APPLE-MAGGOT (Rhagoletis pomonella).-A white maggot that tunnels apples thrnugh and through, causing decay and falling of the fruit. The parent flies appear

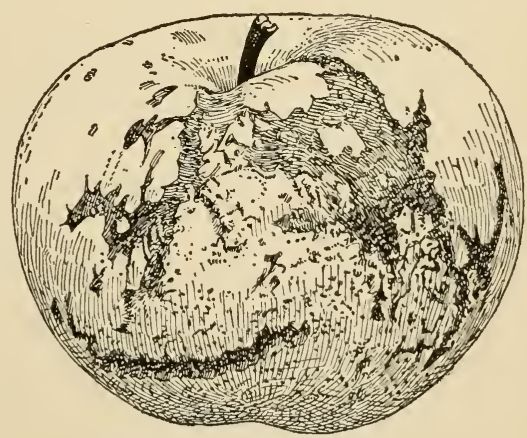

FIG. 132. Bordeaux injury. 
the latter part of June and early July, and insert the eggs under the skin of the fruit. Hibernation takes place in small puparia just below the surface of the soil. Sweet and subacid varieties are most susceptible, but others are sometimes attacked.

Clean cultivation. Spray when flies appear with arsenate of lead, four pounds in one hundred gallons of water. The addition of two or three gallons of molasses is supposed to render the poison more attractive to the flies.

Brown-TAIL Mотн (Euphroctis chrysorrhæa).-This highly destructive European insect was introduced near Boston a number of years ago, and is now rapidly spreading over New England. The snow-white moths, with a large tuft of brown hairs at the tip of the abdomen, appear in July, and deposit eggs on the leaves in elongate masses covered with brown hairs from the body of the female. The caterpillars become only partly grown the first season, and hibernate in conspicuous nests, 3 to 4 inches long, at the tips of the branches. The black-bodied caterpillars, clothed with rather long, brownish, stinging hairs, complete their growth the next spring, feeding ravenously on the tender foliage and causing great damage in orchards, parks and forests.

Cut out and burn all winter nests before the buds start. In the spring, spray with arsenate of lead, as recommended for the gipsy-moth. Prevent the ascent of caterpillars from other trees by banding the trunks with tanglefoot. Keep the bands fresh by combing the surface every few days.

Bud-Mотн (Tmetocera ocellana).-The small hrown caterpillars with black heads burrow into the buds, feeding on the opening leaves and flowers and web them together.

Spray with arsenate of lead, four pounds in one hundred gallons of water, just as the blossoms show pink, and again as the last of the petals are falling.

Canker-Worm, Fall (Alsophila pometaria).-Wingless female moths usually emerge from the ground in late autumn, crawl up the trees and deposit their eggs on the smaller branches. The eggs hatch in April or May, and the blackish, yellow-striped, looping caterpillars defoliate the trees.

Band tree trunks in the fall with tanglefoot or cotton batting to prevent ascent of moths. The young canker-worms may be killed by spraying with arsenate of lead, six pounds to one hundred gallons of water. 
Canker-Worm, Spring (Paleacrita vernata).-Habits similar to the fall canker-worm, but the moths emerge in March and April. Caterpillars are distinguished by having only two pairs of prolegs.

Same as for fall canker-worm except the bands should be applied in early spring.

CASe-Bearers.--The pistol-case-bearer (Coleophora malivorella) and the cigar-case-bearer (C. fletcherella).-The small caterpillars live in pistol- or cigar-shaped cases, about 1/4 inch long, that they carry around with them. They appear in spring on the opening buds at the same time as the bud-moth, and may be controlled by the same means.

Codlin-Mотн (Carpocapsa pomonella).-This is the pinkish caterpillar which causes a large proportion of wormy apples. The eggs are laid by a small moth on the leaves and the skin of the fruit. Most of the caterpillars enter the apple at the blossom end. When the petals fall, the calyx is open and this is the time for spraying. The calyx soon closes, and keeps the poison inside ready for the young caterpillars' first meal. After the calyx has closed, it is too late to spray effectively. The caterpillars become full grown in July and August, leave the fruit, crawl down on the trunk, and there most of them spin cocoons under the loose bark. In most parts of the country there are two broods annually.

As the last of petals are falling, spray with four pounds arsenate of lead in one hundred gallons of water, using a stiff spray to force it into the blossom end of the apple. Repeat the application three weeks later.

FALL WeB-Worm (Hyphantria cunea).-Hairy larva, about an inch long, varying from gray to pale yellow or bluish black, feeding upon the leaves of many trees, in tents or webs.

Destroy by burning the webs, or removing them and crushing the larvæ. Spray with arsenicals.

Green Fruit-Worms (Xylina sp.).-Yellowish or apple-green caterpillars, striped with cream-color, 1 to $1 \frac{1}{2}$ inches in length when mature, attack the opening leaves and blossoms and eat holes in the developing fruit. The parent moths emerge from hibernation in early spring and lay their eggs on the smaller branches. One brood annually.

Thorough and repeated spraying with arsenate of lead, six pounds in one hundred gallons of water, will kill many of the young caterpillars. Make the application when blossom clusters appear. 
Gypsy-Mотн (Porthetria dispar).-The full-grown caterpillar is about 2 inches long, dark gray in ground-color, with eleven pairs of prominent tubercles on the back, the first five pairs blue, the last six dark red. They become full grown about the first of July. They pupate in slight cocoons. The moths emerge in seven to seventeen days. The male has a light brown body, wings yellowish brown, and each front wing is crossed by four wavy, dark brown lines. In the female the body is light buff and the wings grayish white. The dark markings on the front wings are similar to those of the male. The females do not fly, but each lays its eggs in a mass about an inch in length covered with hairs from its body. Hibernation takes place in the egg-stage. The eggs hatch just as the buds are bursting.

Kill the eggs by saturating the masses with crude coal-tar creosote, to which a little lamp-black has been aded as a marker. When the young caterpillars hatch, spray the trees with arsenate of lead, ten pounds in one hundred gallons of water. When the caterpillars are half grown, use thirteen to fifteen pounds of lead arsenate. Full-grown caterpillars are very resistant to poisons. Band the tree trunks with tanglefoot to prevent the ascent of wandering caterpillars.

Oyster-Shell Scale (Lepidosaphes ulmi).-This is an elongate scale (sometimes called bark-louse), $1 / 8$ inch in length, resembling an oyster-shell in shape, and often incrusting the bark. It hibernates as minute white eggs under the old scales. The eggs hatch during the latter part of May or in June, the date depending on the season. After they hatch, the young may be seen as tiny whitish lice crawling about on the bark. When these young appear, spray with kerosene emulsion, diluted with six parts of water, or whale-oil or any good soap, one pound in four or five gallons of water. When trees are regularly sprayed with lime-sulfur, as for the San José scale or blister-mite, the oyster-shell scale is usually controlled. This is a very prevalent pest, and should be kept under complete control.

Palmer Worm (Ypsolophus pometellus).-The brownish green, white-striped caterpillars, $1 / 2$ inch in length when mature, skeletonize the tender foliage in June and eat holes in the young apples. There is only one brood a year.

Spray with arsenate of lead, four pounds in one hundred gallons of water, when the caterpillars first appear. 
Plum-Curculio (Conotrachelus nenuphar).-A snout-beetle that deforms the fruit by its characteristic feeding and egg-laying punctures. The grubs develop in the fruit and cause it to fall.

Spraying with arsenate of lead, as for codlin-moth, whenever it can be applied with a fungicide so as not to increase expense, will help to control the trouble. Thorough superficial tillage of the surface of soil during July and August will kill many of the pupæ, and is recommended. For treatment on plum, see under Plum.

RED Bugs (Heterocordylus malinus and Lygidea mendax).-The winter is passed as eggs inserted in the smaller branches. The brilliant red nymphs appear as the buds open and feed on the foliage for a time. Then they puncture the newly set apples, causing one of three things: Some drop, some dry up and remain on trees till next spring, and others mature as knotty, misshapen, worthless fruit. One generation a year.

The young nymphs may be killed by thorough spraying with "black leaf 40" tobacco extract, one pint in one hundred gallons water, adding four pounds of soap, (1) when blossoms show pink, (2) when the last of the petals are falling.

ROSE-CHAFER.-See Grape.

San Jose SCale (Aspidiotus perniciosus).-This scale is nearly circular in outline and about the size of a pinhead. When abundant it forms a crust on the branches, and causes small red spots on the fruit. It multiplies with marvelous rapidity, there being three or four broods annually, and each mother scale may give birth to several hundred young. The young are born alive, and breeding continues until late autumn, when all stages are killed by the cold weather, except the tiny, half-grown, black scales, many of which hibernate safely.

Spray thoroughly in the fall after the leaves drop, or early in the spring before growth begins, with lime-sulfur wash, one gallon in eight gallons of water, or miscible oil, one gallon in fifteen gallons of water. When badly infested, make two applications, one in the fall and another in the spring. In case of large, old trees, 25 per cent crude-oil emulsion should be applied just as the buds are swelling.

Tent-Caterpillars (Malacosoma americana and $M$. disstria).Larvæ nearly 2 inches long, spotted and striped with yellow, white and black; feeding upon the leaves. They congregate in tents or 
in clusters on the bark at night and in cool weather, and forage out upon the branches during the day.

Arsenicals, as for codlin-moth. Burn out nests with torch, or cut them out and crush the larvæ. Pick off egg-masses from twigs during winter and spring.

Tussock-Мотн (Hemerocampa leucostigma).-A handsome, redheaded, yellow-and-black tufted caterpillar, about an inch long, which devours the leaves and sometimes eats into the fruit.

Collect the frothy egg-masses in fall and winter and band the trees to prevent a reinfestation by migrating caterpillars. Spray with arsenicals as for codling-moth, taking care to cover the under side of the leaves.

Woolly ApHis (Schizoneura lanigera).-Small, reddish brown plantlice covered with a conspicuous mass of white, waxy fibers, found on the branches, sprouts, trunks and roots.

For the form above ground drench the infested parts with 15 per cent kerosene emulsion; for the underground form remove the earth beneath the tree to a depth of 3 inches, and apply 10 per cent kerosene emulsion liberally, and replace the earth. In the case of nursery stock the emulsion may be applied in a shallow furrow close to the row. Do not set infested trees.

Apricot. Diseases and insects require treatment similar to those of peach and plum.

Bramble Fruits. Blackberry Crown-Gall or Root-Gall (Bacterium tumefaciens).- Swellings, hard or soft, on roots and stem below ground.

Plow up and burn all bushes in a diseased patch. Plant clean roots in a new place.

Blackberry LeAF-Miner (Metellus rubi).-Greenish white larvæ, with brown markings, $1 / 3$ inch in length when fullgrown, causing blotch mines in the leaves.

No satisfactory treatment is known.

Dewberry Leaf-Spot (Septoria rubi).-Small pale spots of dead leaf-tissue finally becoming dotted with black specks.

No successful method of treatment is known.

RASPBERry ANTHRaCNose (Glæosporium venetum).-Circular or elliptical, gray, scab-like spots on the canes.

Remove diseased canes as soon as fruit is picked. Avoid taking young plants from diseased plantings. 
Red or Orange Rust (Gymnoconia interstitialis).-Dense, red, powdery growth on under side of leaves of black raspberries and blackberries.

Dig up and destroy affected plants.

RASPBERRY ROOT-BORER (Bembecia marginata).-Larva about 1 inch long, boring in the roots and the lower parts of the cane, remaining in the root over winter.

Dig out the borers. Destroy wild berry bushes.

RASPBERRY SAw-FLY (Monophadnus rubi).-Larva about 3/4 inch long, green, feeding upon the leaves.

Hellebore; arsenicals, after fruiting.

Red-Spider.-See Peach. Do not use lime-sulfur on raspberry foliage.

Tree-Cricket (Ecanthus nigricornis).-Small and whitish cricket-like insect, puncturing canes for 2 to 3 inches, and depositing eggs in the punctures.

Burn all infested canes in winter or very early spring.

Cherry. Brown-Rot (Sclerotinia fructigena).-The flowers decay, the leaves become discolored with irregular brown spots, and the fruit rots on the tree.

Spray with bordeaux mixture, 4-4-50, or lime-sulfur, 1-40 (1) just before the blossom buds open; (2) just after the blossoms fall; (3) one or two more applications at intervals of ten days.

APHIS (Myzus cerasi).-Blackish plant-lice infesting the leaves and tips of new growth.

Spray as soon as the first lice appear, with whale-oil soap or tobacco extract.

Black-KNot.-See under Plum; same disease.

Cherry Fruit-Fuies (Rhagoletis cingulata and R. fausta).Small maggots infesting ripening fruit. Adults are flies with banded wings and insert their eggs under the skin of the fruit.

Spray with arsenate of lead, five pounds in one hundred gallons, sweetened with three gallons of molasses to kill flies before egg-laying. Should be done when flies first appear,last of June in New York.

Cherry Tree Tortrix (Archips cerasivorana).-Tips of branches are frequently webbed into nests by colonies of lemon-yellow caterpillars.

Wipe out nests and destroy the caterpillars. 
Powdery Mrldew (Podosphæra oxycanthæ).-Leaves and twigs affected, often causing defoliation.

Spray with lime-sulfur, 1-40, or dust heavily with powdered sulfur.

Slug (Eriocampoides limacina).-Larva $1 / 2$ inch long, blackish and slimy, feeding upon the leaves; two broods.

Arsenicals, hellebore, tobacco extract.

Chestnut. Canker, or Bark Disease (Endothia parasitica).Sunken or swollen cankers on limbs or trunk. Limbs die and leaves and burs cling in winter.

Control.-Remove diseased parts and burn. Paint all wounds. Little chance of saving trees in infested locality.

WeEvils (Balaninus proboscideus and B. rectus).-Brownish beetles with extremely long, slender snouts with which they bore holes into the nuts for deposition of eggs. The grubs feed on the kernel, producing wormy nuts.

Treatment.-No satisfactory control measures known.

Two-Lined Chestnut-Borer (Agrilus bilineatus). - Slender, flattened grubs, $3 / 4$ inch long, when mature, burrowing under the bark and girdling the trees.

Treatment.-Cut and burn infested trees to prevent spread.

Cranberry. Blast, or Scald (Guignardia vaccinii).-Young flower and fruits blasted, older fruits appear scalded or watery.

Spray five or six times with bordeaux mixture, $5-5-50$, to which has been added four pounds of resin fish-oil soap. Begin just before the blossoms open.

Cranberry Fulgorid (Phylloscelis atra).-Small, broad-bodied, black, jumping insect punctures the vines, causing the leaves to turn brown and the fruit to shrivel.

"Black leaf 40 " tobacco extract, one pint to one hundred gallons of water, adding four to five pounds of soap to kill young nymphs.

Cranberry-Girdler (Crambus hortuellus).-Small caterpillar, feeding on the stems just beneath the surface of the sand.

Reflow just after picking, for a week or ten days, or reflow for a day or two about June 1.0 .

False Army-Worm (Calocampa nupera).-Green to blackish caterpillars devouring the leaves and buds.

Reflow for from twenty-four to thirty-six hours soon after the middle of May. It may be necessary to reflow a 
second time. Destroy all caterpillars washed ashore while the water is on. In dry bogs, spray early in May with arsenate of lead.

Fire-Worm, Cranberry-Worm, or Black-headed CranberryWorm (Eudemis vacciniana).-Small larva, green, blackheaded, feeding upon the shoots and young leaves, drawing ,them together by silken threads; two broods.

Flooding for two or three days when the worms come down to pupate. Arsenicals.

FrUIT-Worm (Mineola vaccinii).-Small caterpillar working in the fruits, eating out the insides.

For bogs with abundant water, reflow for ten days immediately after picking. Let the foliage ripen, and then turn on water for winter. Draw off water early in April, and every third or fourth year hold it on until the middle of May. For dry bogs spray three times with arsenate of lead during July. Burn all screenings.

Yellow-headed Cranberry-Worm (Acleris minuta).-Stout, yellowish green, small caterpillar, with a yellow head, webbing up the leaves as it works.

Hold the water late on the bog in spring to prevent egglaying. Arsenicals from the middle of May till July 1.

Currant. Wilt, or Cane-Blight (Botryosphæria ribis).-Canes die suddenly, the leaves wilting.

No satisfactory method of control is known. Cut out and burn affected plants.

Rust (Cronartium ribicola).-Brown rust pustules and brown felt-like growth on under side of leaf. Black currants espeially susceptible.

Grow at least 500 feet from white pine trees.

Currant Aphis (Myzus ribis).-Small, yellowish green lice attacking the under side of the leaves, distorting the leaves and causing them to turn red.

Contact insecticides when leaves first appear.

Currant Measuring- or Span-Worm (Cymatophora ribearia).Larva somewhat over an inch long, with stripes and dotted with yellow or black, feeding upon the leaves.

Hellebore, applied stronger than for currant-worm. Arsenicals; hand-picking. 
Currant-Worm, or Currant and Gooseberry Saw-Fly (Pteronus ribesii).-Larva, about $3 / 4$ inch long, yellowish green, feeding on leaves of red and white varieties; two to four broods.

Hellebore, applied early; arsenicals for the early brood. Treatment should begin while the larvæ are on the lowermost leaves of the bushes. Before the leaves are fully grown, the holes made by the worms may be seen. The second brood is best destroyed by killing the first brood.

Four-striped Plant-Bug (Pæcilocapsus lineatus).-A bright yellow, black-striped bug about $1 / 3$ inch long, puncturing the young leaves and shoots of many plants.

Jar into a dish of kerosene. Kerosene emulsion when the nymphs are young. Cut off the tips of the shoots in early spring to destroy the eggs.

Dewberry. See Bramble Fruits.

Gooseberry. MILDEw (Sphærotheca mors-uvæ).-A powdery mildew of the fruit and young growth of English varieties.

Spray with potassium sulfid, one ounce to two gallons of water, at intervals after leaves begin to unfold.

Gooseberry Fruit-Worm (Dakruma convolutella).-Larva about $3 / 4$ inch long, greenish or yellowish, feeding in the berry, causing it to ripen prematurely.

Destroy affected berries. Clean cultivation. Poultry.

Grape. Black-Rot (Guignardia bidwellii).--Brown circular spots on leaves, black, elongated, sunken pits on petioles, canes, etc., and on the berry a brown rot, with shriveling and wrinkling.

Spray with bordeaux mixture, 4-4-50, before rains. Spray (1) when the third or fourth leaf unfolds; (2) as soon as the blossoms have fallen; (3) when berries are size of a pea; (4) about two weeks later. Two or more applications if wet season.

Downy Mildew, or Leaf-Blight (Plasmopara viticola).-White frost-like patches on the under side of the leaf.

Same as for black-rot.

Grape-Curculio (Craponius inxqualis).-Larva small, white, with a brownish head. Infests the grape in June and July, sausing a little black hole in the skin and a discoloration of the berry immediately around it. The adult is a grayish brown snout-beetle, about one-tenth inch long. 
Spray with arsenate of lead while the beetles are feeding on the leaves. The beetles may be jarred down on sheets, as with the plum-curculio. Bag the clusters.

Grape Root-Worm (Fidia viticida).-The small white grubs feed upon the roots, often killing the vines in a few years. The adults are small, grayish brown beetles that eat peculiar chain-like holes in the leaves during July and August.

Cultivate thoroughly in June, especially close around the vines to kill the pupæ in the soil. At the first appearance of the beetles, spray the plants with arsenate of lead at the rate of eight or ten pounds in one hundred gallons of water, to which should be added one gallon of molasses.

Grape-Slug or SAw-Fly (Selandria vitis).-Larva, about 1/2 inch long, yellowish green with black points, feeding upon the leaves; two broods.

Arsenicals; hellebore.

Grapeberry-Worm (Polychrosis viteana).-Larva, about 1/4 inch long, feeding on the berry, often securing three or four together by a web; two broods.

Spray with arsenate of lead before blossoms open. Repeat after blooming and again in early July. Destroy wormy berries in August.

Grape-Vine Flea-Beetle (Graptodera chalybea).-Beetle, of a blue metallic color, about $1 / 4$ inch long, feeding upon the buds and tender shoots in early spring.

Arsenicals to kill the grubs on leaves during May and June. The beetle can be caught by jarring on bright days.

Grape-Vine Sphinx (Ampelophaga myron).-A large larva, 2 inches long when mature, green with yellow spots and stripes, bearing a horn at the posterior extremity, feeding upon the leaves and nipping off the young clusters of grapes; two broods.

Hand-picking. Arsenicals early in the season.

LEAF-Hopper (Typhlocyba comes).-These small yellowish leafhoppers, erroneously called "thrips," suck the sap from the under side of the leaves, causing them to turn brown and dry up.

Spray the under side of the leaves very thoroughly with one gallon "black leaf 40 " in 1,000 gallons of water about July 1 , to kill the young leaf-hoppers. When using tobacco 
extract, add about two pounds soap to each fifty gallons to make it spread and stick better. Repeat the application in a week or ten days. In houses, tobacco smoke, pyrethrum poured upon coals held under the vines, syringing with tobacco-water or soapsuds.

Rose-Chafer (Macrodactylus subspinosus).-The ungainly, long-legged grayish beetles occur in sandy regions, and often swarm into vineyards and destroy the blossoms and foliage.

At the first appearance of the beetles, spray with arsenate of lead at the rate of eight to ten pounds in one hundred gallons of water, to which should be added one gallon of molasses.

Hickory. LeAF-Spot (Marsonia juglandis).-Large leaf-spot, causing premature dying of leaves.

Spraying with bordeaux mixture may be of value.

Gall ApHis (Phylloxera sp.).-Yellowish green plant-lice causing hollow galls on the leaves, petioles and small twigs.

Spray with contact insecticides as buds are opening in the spring.

Peach. Bught (Coryneum beyerinkii).-A spotting, gumming and death of the buds and twigs, particularly in the lower parts of the tree. The fruit drops.

For California conditions, two applications bordeaux mixture, 5-5-50, or lime-sulfur, 1-10, (1) in November or December, and (2) in February or March.

LEAF-Curl (Exoascus deformans).-Leaves curl and wrinkle.

Spray with lime-sulfur, 1-11, before buds swell.

Brown-Rot (Sclerotinia fructigena).- - Rot on fruit and cankers on limbs.

Spray with self-boiled lime-sulfur, 8-8-50, adding two pounds arsenate of lead. Spray (1) about time shucks are shedding from young fruit; (2) two or three weeks later; (3) one month before fruit ripens.

ScAB, or Black-Spot (Cladosporium carpophilum).-Black scablike spots on fruit.

Self-boiled lime-sulfur applied as under Brown-Rot.

Black ApHis (Aphis persicx-niger).-A small black or brown plant-louse, which attacks the tops and roots of peach trees. When upon the roots it is a very serious enemy, stunting the tree and perhaps killing it. Thrives in sandy lands.

Kerosene emulsion; tobacco decoction and extracts. 
Clover Mite (Bryobia pratensis).-_Small reddish mites attacking the leaves, causing them to turn yellow.

Lime-sulfur while trees are dormant. In summer, use self-boiled lime-sulfur as a dust, or sulfur paste.

Green Peach-Louse, or Aphis (Myzus persicx).-A small insect feeding upon the young leaves, causing them to curl and die.

Lime-sulfur, kerosene emulsion or tobacco extract. After the buds open, either of the last two.

Peach Twig-Moth (Anarsia lineatella).-The larva of a moth, $1 / 4$ inch long, boring in the ends of the shoots, and later in the season attacking the fruit. Several broods.

Spray with lime-sulfur just after the buds swell. Spray trunk and larger branches in late spring to kill first brood of pupæ in the curls of bark.

Plum-Curculio (Conotrachelus nenuphar).-This insect may be successfully controlled on peach by spraying with arsenate of lead, four pounds to one hundred gallons of self-boiled limesulfur. Spray, first, when the "husks" drop from the fruit; second, ten days or two weeks later. It is unsafe to spray peaches more than twice with arsenate of lead.

Red Spider, or Mite (Tetrancyhus bimaculatus).-A small mite infesting many plants, both in the greenhouse and out-ofdoors. It flourishes in dry atmospheres, occurring on the under sides of the leaves. In some forms it is reddish, but usually light-colored and two-spotted. Common.

Persistent syringing with water will generally destroy them, if the spray is applied to the under surface. Use lots of force and little water to avoid drenching the beds. Sulfur and water. Dry sulfur. On orchard trees, flour paste.

White Peach Scale (Diaspis pentagona).-Circular gray scales with the exuviæ at one side of the center.

Same as for San José Scale. See Apple.

Pear. Blight (Bacillus amylovorus).--Flowers, young fruit, twigs and leaves turn black and die. Limbs die back, and sunken cankers form in bark. This is a widespread and very damaging disease. Some varieties appear to be more susceptible than others.

Not amenable to spraying. Eradicate all wild hawthorns, pears and apples. Inspect and remove all blighted parts of tree. Paint wounds with coal-tar. 
ScaB.-Very similar to apple-scab and demanding similar treatment.

MIDGE (Diplosis pyrivira).-A minute mosquito-like fly; lays eggs in flower-buds when they begin to show white. These hatch into minute grubs which distort and discolor the fruit. New York and eastward. Prefers the Lawrence. Introduced in 1877 from France.

Not controlled by spraying. Destroy the infested pears. Cultivate and plow in late summer and fall to destroy the pupæ then in the ground.

Pear-Leaf Blister-Mite (Eriophyes pyri).-A minute mite which causes black blisters to appear upon the leaves. The mites collect under the bud-scales in winter.

Lime-sulfur or miscible oil as a dormant spray.

Pear Psylla (Psylla pyricola).-These minute, yellowish, flatbodied, sucking insects are often found working in the axils of the leaves and fruit early in the season. They develop into minute, cicada-like jumping lice. The young psyllas secrete a large quantity of honey-dew, in which a peculiar black fungus grows, giving the bark a characteristic sooty appearance. There may be four broods annually, and the trees are often seriously injured.

Clean culture; remove rough bark from trunks and larger branches to discourage adults from hibernating; spray with "black leaf 40" tobacco extract, one pint in one hundred gallons of water, adding four pounds soap, on warm days in November or April, to kill hibernating adults. Spray with lime-sulfur, winter strength, when the blossom clusters appear, to destroy eggs.

In summer, spray with "black leaf 40 " tobacco extract just as the last of the petals are falling, to kill young. Repeat if necessary.

Pear Thrips (Euthrips pyri).-Minute insects one-twentieth inch in length, dark brown when adult, white with red eyes when young, that attack the opening buds and young fruits in early spring. They suck the sap from the tender growth, and the females lay eggs in the fruit-stems, causing a loss of the crop. The nymphs hibernate in the ground a few inches from the surface. A serious pest in California, and recently introduced into New York. 
Thorough cultivation during October, November, and December (in California). Make two applications of "black leaf" tobacco extract, one gallon in sixty gallons of 2 per cent distillate oil emulsion, the first just as the fruit-buds begin to open, the second just after the petals fall. In the East it may be controlled by timely applications of tobacco extract and whale-oil soap.

Pecan. Bud-Мотн (Proteopteryx deludana).-A brownish caterpillar about $1 / 2$ inch in length, feeding on the opening buds in early spring and on the under side of the leaves in summer.

Arsenate of lead in summer to kill larvæ of second brood. Lime-sulfur and arsenate of lead in dormant season just before buds open, to destroy hibernating larvæ.

CASE-BEARER (Acrobasis nebulella). - A small caterpillar living inside a case which it carries with it. It attacks the opening buds.

Arsenate of lead as soon as the buds begin to open. Repeat if necessary.

Plum. Black-KNot (Plowrightia morbosa). - Black tumorous swellings from 1 to several inches in length, on limbs and twigs.

Orchards thoroughly sprayed with bordeaux are not likely to be attacked. Burn all affected parts in the fall. Burn whole tree if badly affected.

Curculio (Conotrachelus nenuphar).-Larva, a whitish grub, feeding in the fruit.

Arsenate of lead, six pounds to one hundred gallons of water; apply as soon as the calyx falls, and repeat two or three times at intervals of about ten days. Jarring the beetles on sheets very early in the morning, beginning when trees are in flower, and continuing from four to six weeks, is probably the most certain procedure. There are various styles of sheets or receptacles for catching the insects as they fall from the tree. Clean culture.

San Jose Scale.-See Apple.

European Fruit Scale (Lecanium corni).-A large circular scale occurring on plum; occasionally very destructive.

Thorough spraying with kerosene emulsion, one part to five of water, in the winter. More dilute emulsion or tobacco extracts in midsummer, when the young insects are on the 
leaves and young shoots. Miscible oils when trees are dormant.

Quince. Blight.-See under Pear.

Rust (Gymnosporangium globosum).-Orange rust of fruit.

Destroy red cedars in the neighborhood, also wild apples and hawthorns. Spray as for apple-scab.

Green Aphids.-As for apple-aphids.

Quince Curculio (Contrachelus cratægi).-This curculio is somewhat larger than that infesting the plum, and differs in its life-history. The grubs leave the fruits in the fall, and enter the ground, where they hibernate and transform to adults the next May, June or July, depending on the season.

When the adults appear, jar them from the tree on sheets or curculio-catchers, and destroy them. To determine when they appear, jar a few trees daily, beginning the latter part of May. Spray with arsenicals. Pick and burn all infested fruits a month before harvesting.

Raspberry.-See Bramble Fruits.

Strawberry. LEAF-SPOT, or LEAF-BLIGHT (Mycospharella fragarix).--Small purple or red spots appearing on leaves. Leaf appears blotched.

Spray with bordeaux mixture, 4-4-50, soon after growth begins and make three or four additional sprayings during season.

LEAF-Roller (Ancylis comptana),-Larva less than $1 / 2$ inch long, feeding on the leaves, and rolling them up in threads of silk; two broods.

Turn under in the fall all old beds that have become worthless. Spray with arsenate of lead, four pounds in one hundred gallons of water, after the eggs are laid but before the leaves are folded-the first half of May in the latitude of New Jersey. ROOT-BORER (Typophorus canellus).-A whitish/grub $1 / 8$ inch in length feeding on the roots. The parent beetle is brownish, and appears in great numbers in May.

Arsenicals to kill the beetles. Plant new beds at a distance from old ones.

Root-Louse (Aphis forbesii).-From July to the close of the season the lice appear in great numbers on the crowns and on the roots of the plants.

Rotation in planting. Disinfect plants coming from 
infested patches by dipping the crowns and roots in kerosene emulsion, or tobacco extract. Fumigation.

SAW-FLY (Emphytus maculatus).-Larva nearly $3 / 4$ in long, greenish, feeding upon the leaves; two broods.

Hellebore; arsenicals for second brood.

Walnut. BLight (Pseudomonas juglandis).-Appears as a black spotting of the fruit and as black cankers on the stems. The twigs and fruit-spurs are killed.

Control.-None, except those ways mentioned under pearblight (page 357); grow immune varieties.

Anthracnose or Leaf-Blight (Marsonia juglandis). - The same disease that attacks hickory (see page 356 ).

\section{ARSENICAL POISONING OF FRUIT TREES}

In the first edition of this work, the question was asked as to what becomes of the arsenic that finally reaches the soil from the sprays. From the few studies that had then been made of the subject (Cornell Bull. No. 101) it was concluded that the arsenites do not leach from the soil, but "remain where they fall, the same as sand does, and are carried down only when there are crevices or other openings in the soil, and they go down as insoluble compounds, and, to a slight extent, by the mere mechanical action of the water." In the early days of spraying, the question of the effect of the materials on the soil and on live-stock feeding on the grass beneath the sprayed trees (as also on persons eating sprayed fruit) was much discussed. The subject of soil injury was gone over carefully by Lodeman in his "Spraying of Plants," 1896, and the experiments at that time had shown no danger following the customary use of the arsenic and the copper salts in spraying. "The only conclusion to be drawn from these extracts," he says, "is that proper applications of insecticides and fungicides will apparently never cause 
an appreciable injury either to the roots of plants or to the soil."

Recent studies lead Headden to conclude, in conditions in Colorado, that the plant may take up the arsenic, that the arsenical preparations used in spraying are watersoluble to some extent, and that the tree may be injured and killed by the action of arsenic collected about the crown or collar (Colo. Bull. Nos. 131, 157). Arsenic was found in plant tissue and soluble arsenic was detected in the soil. "Three forms of this trouble were recognized,corrosive arsenical poisoning, systemic arsenical poisoning, and arsenic-lime poisoning. The last form is considered as being produced by the joint action of lime and arsenic, because we do not find this trouble present on limestone soils in general, nor is it characteristic of arsenical poisoning produced by soluble arsenic preparations,-sodic arsenite, for example."

The subject of soil-poisoning by arsenical materials used in spraying is now again under discussion. It needs to be worked over under many conditions. Similar injuries are those of crown-rot due, perhaps, to winter injury, and there may be confusion between these injuries and those attributed to arsenic poisoning. Ball and Titus have found (Journ. Econ. Ent. III, pp. 187-197, 1910) that arsenic can be packed about the roots or trunks without injury. The subject will have increasing importance, as the arsenical materials are used more liberally and as they accumulate in the soil. Whether there is danger of injury to trees in humid regions is to be determined by investigations in many places.

It is a good commentary on the certainty and regularity of spraying, and the control of the processes, that 
practically no accidents occur to persons or to live-stock, notwithstanding the immense quantities of poisons used, the continental range of the work, and the great number of persons employed in spraying, not only of fruit trees but of street and shade trees; and yet we must look to the day when effective materials of a less poisonous nature shall be discovered for this important work and also when greater reliance than now shall be placed on securing the proper balance in nature. 


\section{CHAPTER $\mathrm{X}$}

\section{HARVESTING AND MARKETING THE FRUIT}

THE crop is now grown, and the grower is confronted with the problem of disposing of it. If he is growing the fruit for profit, he must give attention to the business situation involved in the picking, packing, storing and shipping. The actual selling of the product is an enterprise belonging to the merchantman rather than to the fruit-grower; but the grower must understand the demands of the market, and the conditions under which the salesman is obliged to work.

Marketing is rapidly coming to be recognized as a semi-public function. It is being regulated by legislation on packages and inspection, transportation, ordinances on marketing and licensing of middlemen. The producer as well as the seller must work within the law; and it is to be expected that the laws will be more specific and controlling in the future. This will impose a special obligation on the grower of fruits to raise a good product, and to grade and pack with care, for fruits are mostly shipped in separate gift packages.

Associations and exchanges for the handling of fruits have been productive of much good and have stimulated the business in many parts of the country. They are to be encouraged when the growers are ready for co-action and when the volume of business in any definite geographical region is large.

This book is devoted primarily to the growing of 
fruits; but the questions of marketing may be given brief consideration, particularly in their bearing on the work of the grower himself and on farm practices. It is not intended here to take up the larger questions of commercial pre-cooling, refrigeration, cold-storage, transportation and salesmanship.

\section{PICKING FRUITS}

If it is worth while to exercise care and ingenuity to grow the fruit, it is equally important to take pains with the finished product. It is a pity to miss the best rewards of one's labor by carelessness or inattention at the harvest.

\section{When to pick.}

Just when and how the fruit should be picked for best market results depends very largely on the species or variety of fruit, and greatly also on the distance to which it is to be shipped. The closer and better the market, the riper the fruit should be when taken from the plant. If one is fortunate enough to have a special or personal market, delivering the fruit to the consumer direct, then one may hope to retain this market only by delivering the products in the very best dessert condition. Such consumers are willing to pay a sufficient extra price for the advantage of having the fruit taken from the plant when it is in its highest state of edible quality. Most serious mistakes are constantly made in the picking of blackberries, for example. It is ordinarily considered that when the berries are black they are ripe, but such is not the case. They are fully ripe only when they shake from the bushes readily, and when they are soft and free from sharp acidity. In this condition, blackberries can be handled direct to the consumers in a local market that is only a few miles 
away; but they could not be shipped by rail. The strawberry is ordinarily picked for market when only a part of the berry is really ripe, and when the organic acids are still too sharp and austere for the dessert. A strawberry with a green or white tip is not yet in fit condition to pick, if one is expecting to reach a really good market.

With the tree-fruits in general, the samples keep longest when they are picked greenest, but they suffer thereby in point of quality. There are no well-marked lines between greenness or immaturity, ripeness or full maturity, and overmaturity and decay. The one stage passes into the other insensibly, and it is a part of the normal chemical history of the fruit that it should begin an incipient breaking down and disorganization of tissue as soon as the ripening process is complete. It will be seen, therefore, that the riper the fruit, the more nearly does it approach this period of disorganization and the sooner the breaking down of the tissues may be expected to begin. When the fruit is picked very green, however, this period of natural disorganization is comparatively remote. On the other hand, fruits picked very green are not yet arrived at their most edible stage, and unless they are kept in the most favorable conditions, they are very likely to shrivel and to become unmarketable.

Apples.-In the case of winter apples, it is best to pick them, if they are to be stored or exported, just as they have arrived at their full size and when they have attained only a part of their full color. Over-ripe or fully ripe fruits must be sent to the market at once, or else they must be kept in artificial cold storage in order to halt the chemical processes, and when they are taken from storage they are very likely to decay quickly. Apples picked slightly green, however, usually continue to keep well 
after being taken from cold storage. This was demonstrated at the World's Fair at Chicago, at which New York apples taken from cold storage remained on the shelves in good condition for several weeks.

Pears, on the other hand, nearly always lose quality by ripening fully upon the tree. The cells of the fruit fill with gritty mineral matter, much to the detriment of texture. It is ordinarily considered that the best time to pick a pear of any variety is just as soon as it reaches its full size and before it has begun to color. In most varieties, this stage is well indicated by the facility with which the fruit-stem parts from the spur. The pear is taken in the hollow of the hand and turned up; if the stem snaps off the spur at its point of articulation, the fruit is considered to be ripe enough to pick.

The pears are then ripened under cover. The best place in which to ripen them is a rather cool but dry room, like a loft or a chamber. Here they are piled on the floor or on racks, and they should not lie, for the best results, more than three or four pears deep. If they are piled too deep, the lower ones are likely to be indented by the weight of those above them. The room should be kept fairly close. If there is too much circulation of air, and if the temperature is high, the pears ripen too quickly, and often shrivel. A Bartlett pear, when properly picked and handled, ordinarily requires a full week in which to ripen to its best quality, and the ripening process may often be continued considerably longer than this by picking the fruit early and keeping it cool. Kieffers, especially if grown in the North, seem to ripen best if they are stored in bulk, like beans, two to three feet deep, or even in barrels, and the ripening process is ordinarily two to three weeks long. If they are given this long time in which to mature, the quality may 
be expected to be very much better than in the general run of samples.

Stone-fruits.-A peach is fit to pick when it is full grown and has begun to develop its characteristic color. Peaches and apricots do not ordinarily color up well after they are picked, although plums usually will do so, especially the Japanese plums, which may be picked very green and yet develop a high color. It is very difficult to describe that period of maturity at which a peach is ready for picking. An experienced picker will take the fruit softly in his hand and press the ball of his thumb very lightly on the side, and if the fruit has a somewhat springy feeling, it is ready to take from the tree. This pressure is never sufficient to leave any mark on the fruit. Pinching a peach will usually spoil it. If the peach is too green, it will feel hard and stone-like. If it is too soft, it will simply indent, and will not have the characteristic elastic feeling.

In the case of cherries and plums, it is very important that the fruits be picked just before they have reached their condition of most edible quality. This is largely because the fruit-rot fungus is likely to destroy the fruits at the time of their ripening, especially on those varieties particularly subject to the disorder. Amongst plums, the Lombard is one of the most seriously attacked; and amongst cherries, nearly all the white-fleshed varieties, like Governor Wood and Napoleon, are greatly subject to injury. If the weather at picking time gives promise of being close and warm or "muggy," then it is exceedingly important that the fruit should be picked early. In sweet cherries, a delay of a few hours will sometimes result in the loss of an entire crop from the fruit-rot fungus. Cherries and plums should always be picked, if possible, when they are perfectly dry. This is especially 
true of the sweet cherries; if they are picked when they are wet, and put into boxes or baskets in this condition, they will be almost certain to decay before reaching the market, unless the weather remains very cool.

This fruit-rot fungus is very damaging on many stonefruits. In sweet cherries, writes G. H. Powell, "the losses from this disease which have come under my observation are invariably the result of letting the fruit hang on the trees till ripe, and then the rot is very active; but cherries should be picked a few days before ripe, before they soften, and then the rot does not seriously affect them. An illustration of this point, which is a most important one, was brought to my notice the present season. The last week of June, in eastern New York, was very hot and close, with showers every day or two. The cherries were then ripening, and the conditions were favorable for the rot to spread. In one orchard, from which several tons of cherries were shipped that week, there was not more than one hundred and fifty pounds destroyed by the rot, while in another orchard a few miles distant at least ten tons of the same varieties were ruined on the trees. In the first orchard the fruit was picked before it had ripened, and all that was fit was taken off as soon as the trees dried off after a shower; in the other orchard it was left till nearly ripe, and onehalf to two-thirds of the crop was lost before the fruit could be picked. So rapid is the work of this fungus at this period, that the owner of the orchard told me that he lost three tons of one variety in one night. It might be added that the orchard first mentioned was a much stronger one, as it was in cultivation, while the last had been in sod for years, and the general debility and neglect of the trees made them good subjects for the attacks of rot or any other disease." 
How to pick.

In picking the soft fruits, like cherries and plums, the operator grasps the stem and not the fruit itself. In this

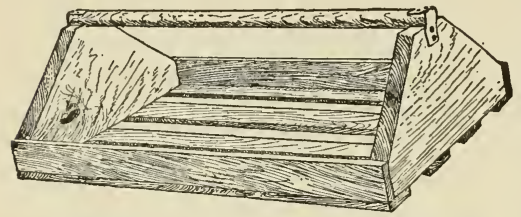

FIG. 133. A good berry-stand for the field. way he does not remove the delicate bloom, and does not injure the fruit when pulling it from the spur. In the case of grapes, it is likewise very important, especially in. those with a heavy bloom, that the picker should not grasp the bunch itself, but should take the cluster by the stem and snip it off with shears (which are made for the purpose). In the case of peaches and apricots, this precaution, of course, need not be taken, because the stem does not naturally adhere to the fruit; but the operator must be very careful, when picking these fruits, not to grasp them too tightly, otherwise he will bruise them and cause them to become discolored. Strawberries should always be picked with the stems on. A berry that has the hull pulled out is not fit for the market. The picker should grasp the stem itself and pinch it off between the thumb and finger. Every evidence of fruits having been touched by the hands detracts from their market value.

On all fruits that grow on a distinct pedicel or stem, this stem should be allowed to remain. Pears with the stems pulled out or broken in two are never first-class fruits, no matter how good and uniform the specimens otherwise may be. This is even true of apples when they

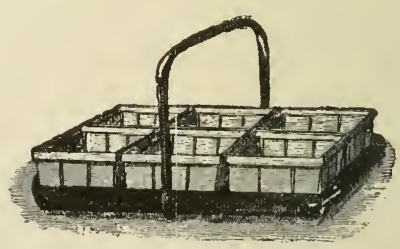

Fig. 134. Berry-tray made of sheetiron, with band-iron handle. 
are put up for the finest dessert trade; but as they are ordinarily handled, very little attention is paid to leaving the stems on. Leaving the stems on is vital to the handling of plums and cherries, not only because the market demands it, but because the fruit will be very likely to rot if the stems are pulled out, and they will not pack so snugly and will not stand the transportation so well. The stems

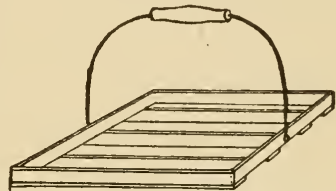

FIG. 135. Tray for berry-boxes. of cherries, plums and currants, and the hulls of strawberries, serve a most useful purpose in holding the fruits in place in the box or basket, and in taking up the slack

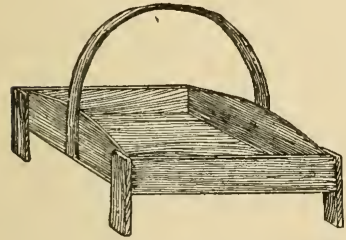

FrG. 136. Berry-stand on legs. from settling or shrinkage.

It is only in rare cases that fruit should be sent to the market in the packages in which the pickers place it; it will need to be sorted from these packages into others, and this sorting should be done in a cool shed or packingroom. In the picking of small-fruits, various kinds of trays or stands are used. In strawberries, it is important that these stands should have legs, so that when the package is set down it will not crush berries on the vines, and neither will it be so likely to tip over. Such stands are handy for grapes, or for any kind of berry fruits as well. Fig. 133 shows a type of berry-stand largely used for the picking of raspberries and blackberries. This stand holds six one-quart boxes, and a tier is easily stacked upon another, one tier or layer of stands breaking joints with those above and

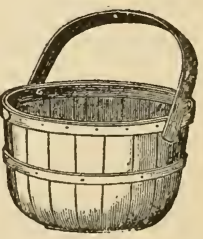

FIG. 137. A halfbushel pickingbasket. 
below. Other types of berry-stands are shown in Figs. 134-136.

In the picking of tender or ripe tree-fruits, it is best to use a basket (Fig. 137) and not a bag, for in spite of all one can do, the fruit is bruised when it is thrown into a bag slung over the shoulder. Winter apples, however, are sometimes picked in bags (Fig. 138). In the picking

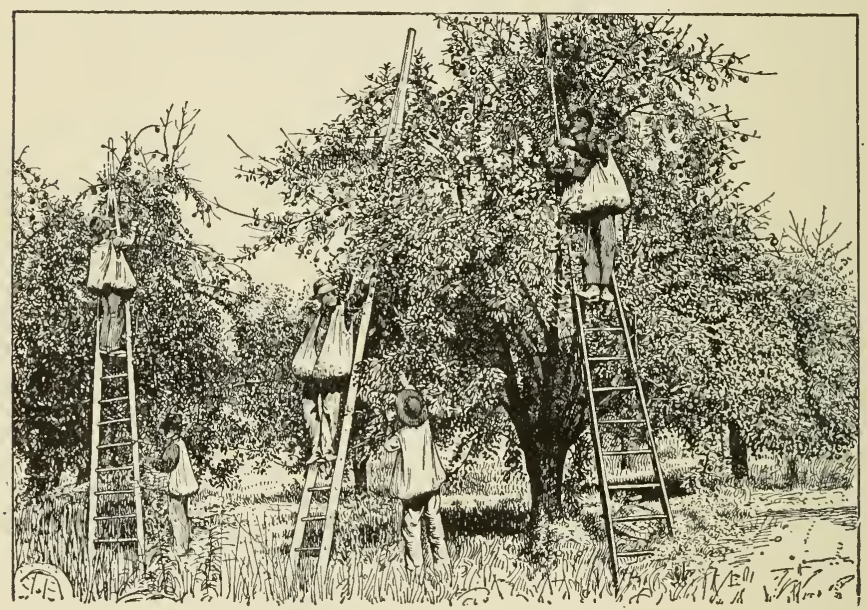

FIG. 138. The apple harvest.

of peaches and other soft fruits, it is customary to pick in something like a Climax basket or, better still, in the old-fashioned, tall, round-top, peck baskets, such as are standards in New Jersey and other places. These baskets may be held at about one's middle by dropping them into a hoop held on the person by a strap running over the shoulder and under one arm (Fig. 139). This allows the picker the free use of both arms, and obviates the necessity of his being obliged to stretch or stoop to 
deposit the fruit after he has picked it. The baskets are filled about level full, all the fruits that are ripe enough for picking being saved indiscriminately. The basket is then set in the shade alongside the tree from which the fruit was taken, and at intervals a wagon or cart collects the baskets and takes them to the packing-room, where the fruit is sorted, graded and packed.

In the picking of apples, the best method is ordinarily to use a half-bushel, roundbottomed, splint (not woven) basket with a swinging handle (as in Fig. 137). If the basket is lined on the inside with thick cloth or burlap, it will answer the purpose all the better. This basket is provided

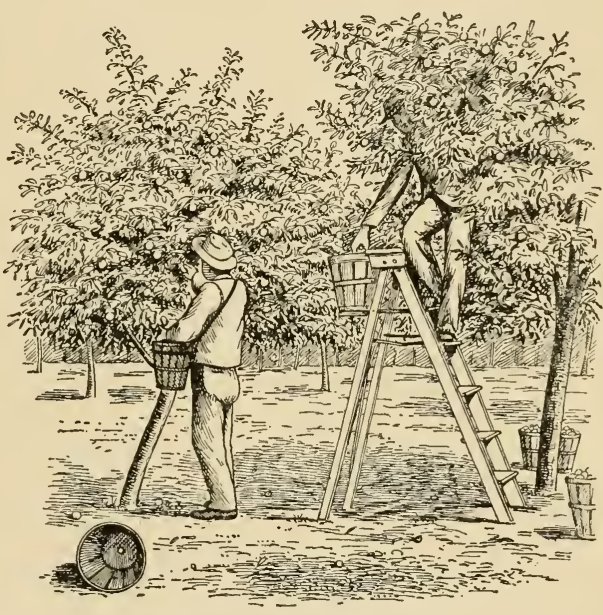

FIG. 139. Picking stone-fruits. with a strong wire hook that can be hung over a limb, allowing the picker to have both hands free. There are special conveniences for apple-picking, which are not proper subjects for discussion in a general fruit-book.

There are various appliances to facilitate the picking of fruit, some of which may be briefly mentioned. The fruit-picker should provide himself with an ample supply of crates or baskets, or whatever other receptacle may be used in the field. The receptacles should be strong and 
durable, so that they may be used year after year; this is especially true of the baskets and crates used for the picking of the heavier fruits, as pears, apples and grapes. It is usually advisable to take the fruits to the packinghouse in the very baskets or boxes in which they are placed from the tree, thereby avoiding unnecessary handling of the fruit. In the case of winter apples, however, it is sometimes admissible carefully to pour the apples from the round-bottomed baskets, into which they are picked, into bushel baskets, or sometimes into crates such as are used for potatoes. In any case it is always advisable, in the best quality of fruit, to have all these baskets or crates lined with burlap or padded.

The best wagons for use in orchards are those of the platform style, with low and very broad-tired wheels, and the platform extending over the wheels. Such wagons are not only capable of carrying a very large load, but do not cut up the ground; they are easily drawn and managed, and they escape the limbs in low orchards. It is desirable that the front wheels move under the platform, in order that the wagon may be turned at sharp angles. The practice of loading apples and other fruits into a wagon box in bulk cannot be too strongly deprecated. It is admissible only when the apples are of low quality, and are fit for sale as second and third grades, or for manufacture into cider, evaporated stock or other products.

\section{Ladders for picking.}

The styles of ladders to be used must depend directly on the height of the trees. In old apple orchards, it is necessary to have long and light ladders, with a sharp or peaked top, which can be run directly up into the top of the tree and find lodgment against the branches. Exten- 
sion ladders are also used, but they are usually more cumbersome and more difficult to manage than the light pointed-top pattern. In most other orchards, however, a step-ladder of the ordinary pattern, but perhaps somewhat taller (running from 10 to even 12 feet high), is all that will be required. This ladder should have a flat top, and also a movable shelf on its back, where baskets may be placed. The facility of picking fruit is very much increased if the trees have been well trained and pruned. Dwarf pears should rarely reach a height of more than 12 to 15 feet; and if pear and apple trees are planted sufficiently far apart, and are kept
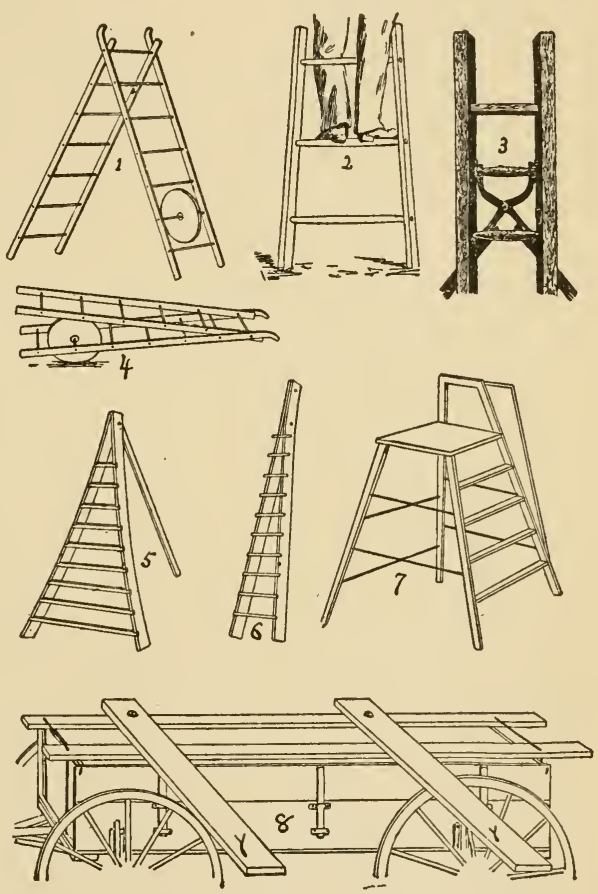

FIG. 140. Various types of ladder arrangements.

open at the base, the pickers can reach most of the fruit by climbing. In the picking of apples and pears, nothing answers the purpose so well as a strong, nimble boy who is not afraid to climb. In many orchards the long and cumbersome ladders may be almost entirely dispensed 
with if this requisite is at hand. In a fruit country, good workmen may usually be secured.

For getting into the tops of

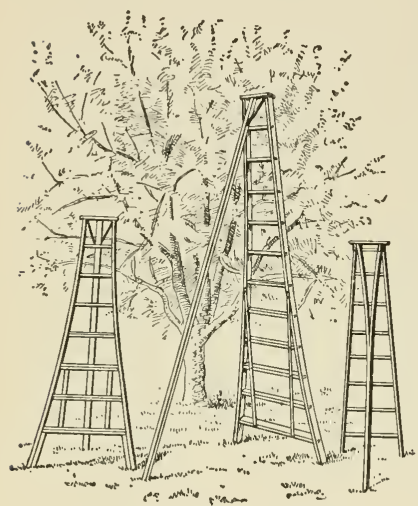

FIG. 141. Two types of tripod picking-ladders. fruit trees, a short and very light ladder with three or four rungs is exceedingly useful. This little ladder will also aid greatly in the gathering of fruit that hangs on the lower limbs just out of the reach of the picker. The ladder is stood upright and the picker mounts it quickly, crossing his legs over the top one or two rungs, and holds himself erect by grasping a limb above his head, as shown in the illustration (Fig. 140, 2). This type of ladder is used by professional top-grafters.

The pictures show various forms of fruit ladders. In Fig. 140, the items are as follows: No. 1 is a light ladder with a wheel, allowing it to be wheeled like a barrow when it is shut, as at $4 ; 2$ is the short ladder, not requiring support, described in the text; 3 , a German device for securing a support to the ladder, allowing the two supporting legs to be shut together; 5 is a pointed ladder with support; 6 , a similar ladder, without support, very useful in tall trees; 7 is a platform ladder; 8 is a wagon rigged for picking, the planks, $y$, y, upon which the picker stands, being swung lengthwise the box when driving from tree to

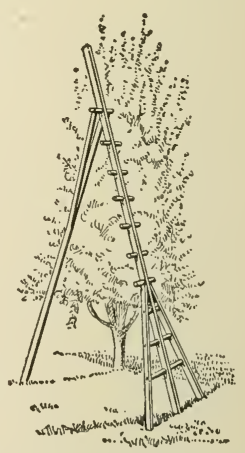

FIG. 142. The Japanese ladder. 
tree. The so-called tripod ladders are shown in Fig. 141, and the Japanese ladder in Fig. 142 (both adapted from Ore. Bull. No. 118). The picking scene in Fig. 138 shows ladders in actual use in tall apple trees.

Fruit-pickers and harvesters.

The various kinds of fruit-picking devices on the market are useful only for gathering the few outlying fruits on the tall and far-reaching limbs. In Fig. 143 are shown some of the fruit-picking implements, as follows: No. 1, picker composed of two pincer-like jaws, with wire guards to receive the fruits, the jaws being closed by means of a cord, which is worked below and 3) by a catch; 4 , hook used for cutting off the fruits (the curved edge being sharp); 5, V-picker with delivery sack; 6, bag-picker, hung on a wire frame (as shown in 7); 8 , a wire finger-picker; 9 , cranberry picker (now probably little used); 10, 6-quart

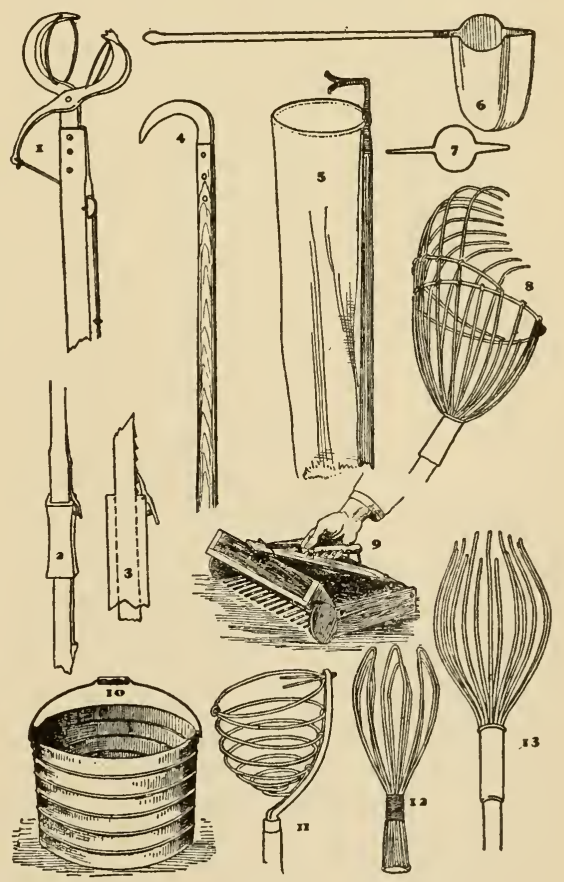

FIG. 143. Different implements for picking fruits. 
cranberry measure; $11,12,13$, forms of wire-pickers. There are many other forms.

It is never practicable to use picking implements for the gathering of the entire crop, except in those very rare cases in which the crop is small and all the fruits are fit for the dessert trade. The labor of picking with these devices is slow and onerous. One of the best types of fruit-pickers is shown at 5 in Fig. 143 which may be made by any handy man. The fruits are hooked off by the $\mathrm{V}$-shaped trigger at the top, and are delivered to the picker through the canvas or burlap bag that extends along the handle. Of course, only one fruit should be allowed to go through the bag at a time. Another very handy device is the finger-picker, illustrated at 13. This may be made by any handy tinsmith, who, however, should be cautioned against making it too heavy and cumbersome. In this instance, the apple is delivered to the picker by taking down the instrument. The disadvantage of this tool is that the fingers are likely to spring with use, and the apple will pull through between them rather than be pulled off. There are also devices in use for catching the

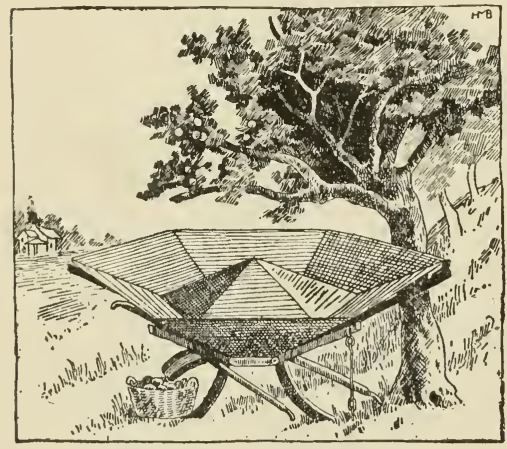

FIG. 144. Cook's apple-picker. fruit when it is shaken from the tree or bush. These are usually on the principle of a soft cloth hopper (see Fig. 144). Such machines are often very useful in the gathering of black currants and gooseberries. For these purposes, inverted umbrellas are sometimes 
used. Cherries were formerly sometimes gathered by being shaken into the machines used for the catching of curculios. It is needless to say that these means of gathering fruit is to be manuuct, or when the price of fruit is extremely small.

To lessen the cost of harvesting and to overcome the difficulty of securing pickers in remote places, a harvester for raspberries has come into use. are advisable only when the fruit factured intosomecommercial prod-

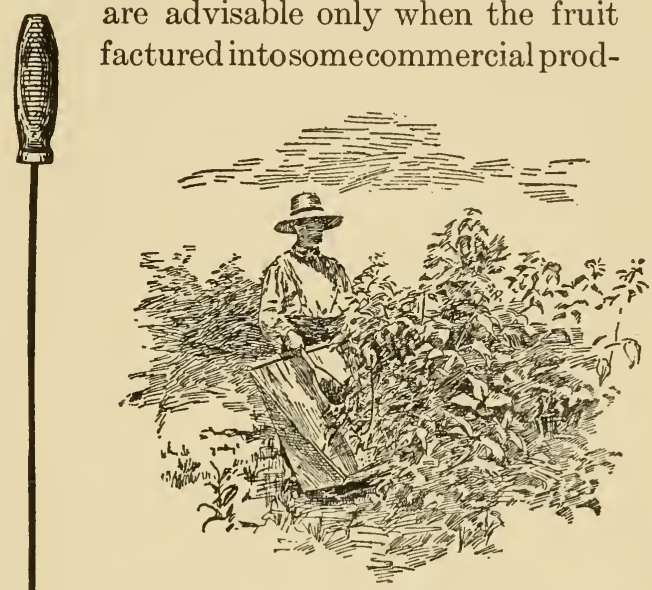

FIG. 145. Harvesting raspberries by batting; and the batter's hook.

This is a canvas

tray, made by stretching the cloth over a light wooden frame about 3 feet wide and 4 to 5 feet long. At the bottom, the frame projects upward at right angle to the body of the frame to a distance of 5 or 6 inches, to catch the berries as they fall upon the canvas. A wooden shoe or runner is placed on the bottom of the apparatus, to allow the operator to slide it along from bush to bush, as shown in Fig. 145. A long wire hook is used to pull the bushes over the tray, or to lift up the fallen canes, while with the other hand the operator deftly cuffs off the berries with a paddle of wood, or of wire covered with canvas, and about the size of a butter-ladle. This harvester 
is used only for the gathering of berries that are to be evaporated. The berries are allowed to become fully ripe, so that they fall easily, and the patch is gone over about three times. Much litter falls with the berries, but this is readily removed by running the dried fruit through a fanning mill. There are few growers who use this harvester exclusively. It is often brought into requisition for the last picking, or in seasons of low prices, and it also has a stimulating effect on a lot of disaffected berry-pickers.

\section{Necessity of hand-picking.}

It would seem to be unnecessary to say that all fruits intended for a good market should be hand-picked, and yet it is a fact that a great quantity of the apples, and even of the pears and plums, that go into our common markets are shaken from the trees. It is impracticable to grade or assort such fruits, because the proportion of jammed or bruised specimens is so great that the samples of first quality are found to be very few. It is an axiom in fruit-marketing that only the best fruit pays for careful packing, and that the poor fruit is rarely worth the trouble of grading. The better the fruit, therefore, and the more carefully it is picked, the more profitable may be the attention given to sorting and packing.

\section{CARING FOR THE FRUIT AFTER PICKING}

After fruit is picked, it is very important that it be kept cool and away from the direct sun. This is particularly true with the soft and berry-like fruits, as grapes, strawberries, cherries and peaches. The fruits not only ripen rapidly after they are picked if the sun strikes them, but they may also become so warm that they will not with- 
stand shipment. It is ordinarily best to pick the perishable fruits early in the morning, if they are dry, and then to pack them up tight and send them directly to the railway station; or, if they have become too warm, or if it is desired to delay the shipment, they should be put in the cellar or a cold storage to reduce them to a low temperature. If the soft fruits, as strawberries and raspberries, are treated in this way, they will ordinarily endure shipment best if they are sent in tight, unventilated crates.

Apples ripen very rapidly in the pile if they are exposed directly to the rays of the sun. It is always well, therefore, if they are piled in the field, to place them on the shady side of the tree, if possible; but, no doubt, the very best results in long-keeping qualities are secured when the apples are taken directly from the trees to a cool room and there kept in storage, where the ripening process is wholly or partially checked. This is especially

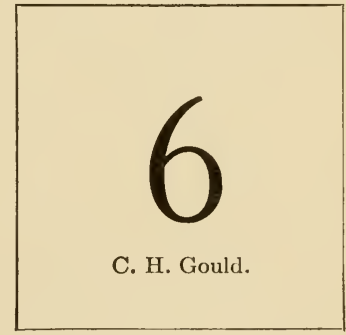

FIG. 146. Picker's ticket. important if they are to be shipped long distances, and particularly if they are to be exported. If the weather is cool and somewhat dull at the picking time, this precaution is not so essential as in autumns that are dry, bright and warm.

Keeping records with the pickers.

There are various ways of keeping accounts with berry-pickers. Perhaps the commonest way in large patches is to use a simple ticket, like Fig. 146, given to the picker in exchange for the berries delivered. There are tickets of various denominations, the figures repre- 
senting quarts, so that any number of quarts can be represented by combinations of tickets. These tickets are so often lost that they may soon come to be a nuisance, although some growers may not object to them for this reason, for all that are lost do not have to be redeemed. Some growers, therefore, have designed tickets that can be tied to the person by a string, bearing the picker's name, and in which the numbers are cancelled by a punch.

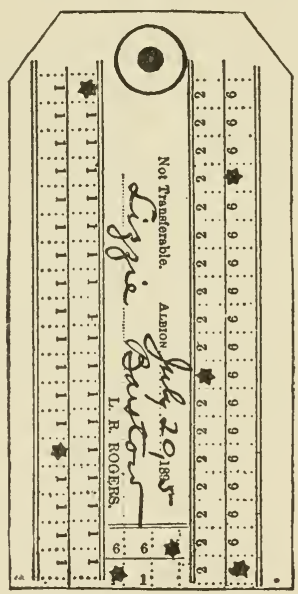

FIG. 147. Picker's tag.

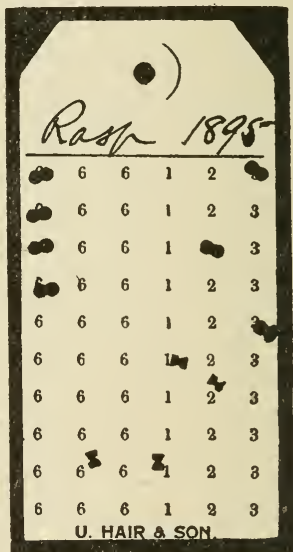

Fig. 148. Picker's tag.

Two good styles are shown, half-size, in Figs. 147 and 148. In the latter are two styles of punch marks, representing different foremen.

Other growers disregard all ticket systems outright, and keep a book account with each picker; and, what is better, they pay by the pound. A small, flat-topped grocers' scale may be taken to the shed in the berry field. Each picker is numbered, and he picks in an eight-pound or ten-pound Climax basket. As he comes to the shed, he 
slips his number into the basket on a bit of card or splint, and he sees the basket weighed and the credit given; or, if the picker has no suspicions, the foreman may gather the baskets from the field.

It is always essential that each picker finish the particular job to which he is assigned. This is specially important in the small-fruits, for the picker must follow a certain row, and not be wandering over the plantation in search of the best picking.

\section{THE GRADING AND PACKING OF FRUIT}

One never grades fruit accurately until he establishes the grades in the mind. One must first visualize certain standards, from which departures may be made.

What is first-class fruit?

The first thing to be considered in the grading and packing of fruit is to determine what first-class fruit is. Even amongst those persons who sell apples for the export trade, there is very little exact practice in the sorting of the apples. It seems to be ordinarily considered that any fruit sound enough to reach its destination is good enough to be called first-class; but such standard is a grievous error. The fruit should not only reach its destination in approximately the same condition in which it leaves the orchard, but it should also be attractive and uniform in quality, and capable of being held for some time when it reaches the wholesaler. Mere soundness or perfectness of form, and freedom from all bruises and blemishes, do not constitute a first-class sample. All the specimens should grade up to a more or less uniform standard of size and shape; and any fruit ever so perfect in 
itself would not be considered to be first class if placed amongst fruits either very much larger or very much smaller. In other words, there is a great difference between a perfect specimen and a first-class parcel.

Perhaps it will answer all requirements to define firstclass fruit as a quantity of sufficient amount to be quoted in the market (as one box, basket or barrel), that is thoroughly well packed and of one variety, and in which the individual specimens are very nearly uniform in size, shape and degree of ripeness, are possessed of full-length stems (in stem-bearing fruits), are free from bruises and injuries and all insect and fungous blemishes, are fully characteristic of the variety, and are in that stage of maturity that the market demands at the time of their exposure for sale.

\section{The grading.}

The more personal and local the market, the more exacting that market is; and therefore the greater the attention to be paid to the details of sorting and grading.

The proper grading of fruit is greatly facilitated by thinning the fruits on the trees, a subject that has received specific treatment in Chapter VII. Recently, useful mechanical graders have been devised, and used even for the softer tree fruits. They are to be considered when different sizes are to be made in the same grade. The recent laws to regulate grades and packages will necessarily demand more attention to the sizes in the pack.

It is evident, therefore, that if fruit is sorted, two grades will result,- - the first-class grade and the remainder. In small-fruits, these two grades-known as the firsts and the seconds-usually comprise the entire crop, and 
the same may be true of tree-fruits that have been well grown and rigorously thinned. In most cases, however, tree-fruits are made into three grades, the third grade being known as culls. Persons who sort their fruit as carefully as our definition requires will do well to designate the first grade by some special name or mark, as "Selected," "First Choice," and the like, to distinguish it from the common type of socalled first-class fruit. In such thorough sorting, four grades are often necessary properly to present the fruit to the various types of consumers. It should be remarked, how-
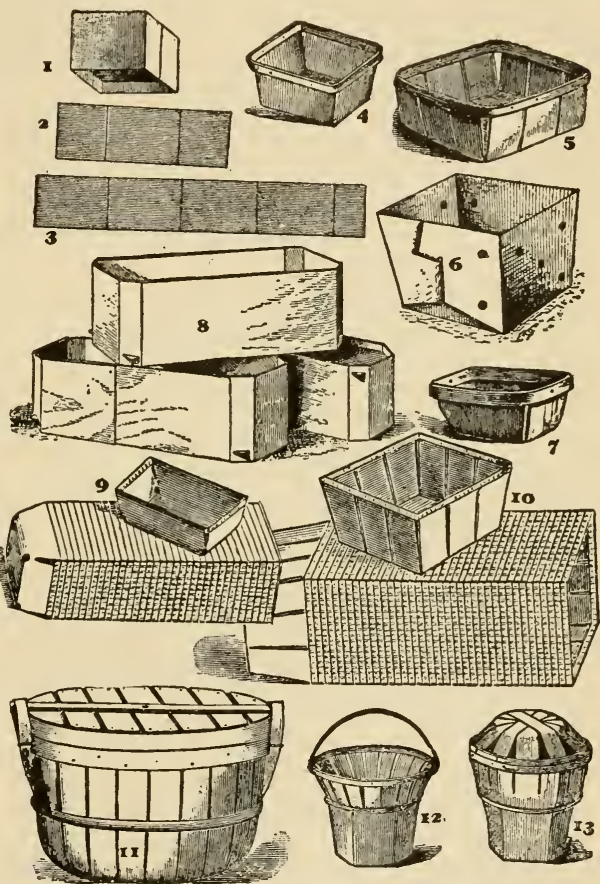

FIG. 149. Various types of fruit packages. ever, that the better the fruit as it hangs on the tree or vine, the fewer will be the grades in the packing-house.

The packing of fruit, therefore, comprises two rather distinct elements, - the sorting or grading (which has now been considered), and the placing of the fruits in the final receptacles, or packing proper, to which we now proceed. 
The packages.

Some of the many forms of packages for fruits are shown in the pictures. These are:

Fig. 149.-No. 1, common quart berry box; 2, the bottom, in flat; 3 , the sides, in flat; 4, 5, 7, till baskets; 6 , paper basket, set up; 8 , oblong quart boxes; 9,10 , metaltopped baskets; 11 , bushel basket with slat cover; 12 , common splint peach basket; 13 , same, with cover.

Fig. 150.-No. 1, veneer peach basket; 2, standard peach basket; 3 , veneer straight-sided basket; 4 , vegetable basket; 5 ,

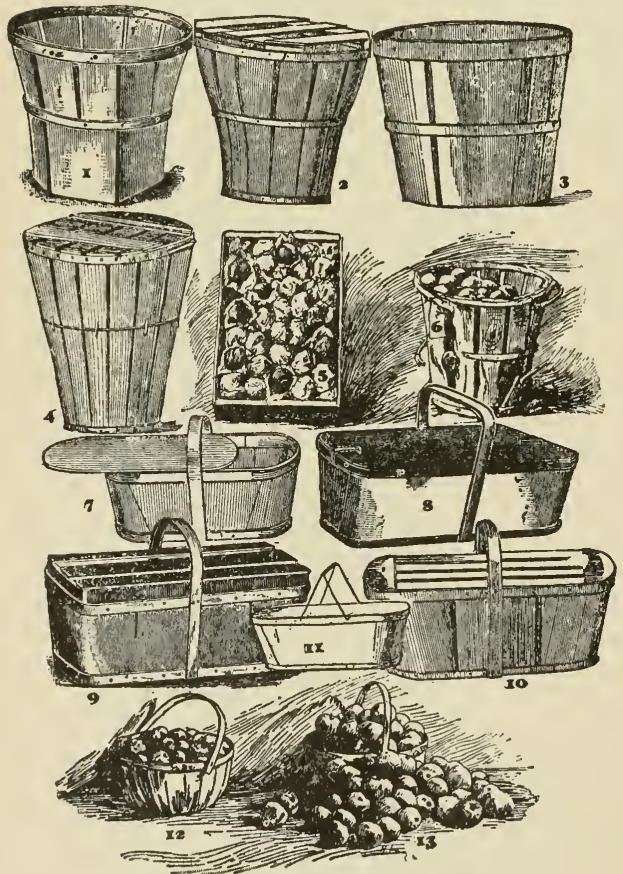

FrG. 150. Various types of baskets. California peaches, wrapped in paper; 6 , a frequent result in the market;7-11, various styles of Climax baskets; 12 , 13, basketsforapplepicking (the illustration also shows same number of apples in each basket or pile, but those in 13 from sprayed trees, those in 12 from untreated trees).

Fig. 151. - No. 1, Diamond market basket; 2, 16-pint basket-tray; 3-9, various styles of crates for berry boxes. 
Fig. 152.-No. 1, crate for Leslie boxes; 2, 4-quart handtray; 3, 24-quart crate; 4, till-basket crate; 5, 6, fruit boxes (holding from $1 / 2$ to 1 bus.); 7 , the bushel handling box; 8 , patent fruit barrel; 9 , Highcliffe patent barrel for export apples (arranged to be sawn in two without disturbing the fruit).

Of the peach-basket type there are many varieties. Fig. 153 shows two of them, the upper one being the "New York" basket and the lower one the "Jersey" basket. Covers or hoods are shown in Fig. 154. The shipper's half-bushel, a very handy package for firm fruits handled loose, is shown in Fig. 155. Other forms of carriers are displayed in Fig.

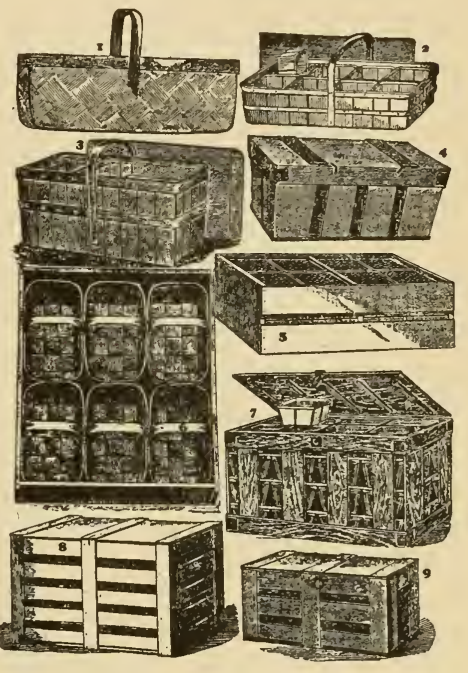

Fig. 151. Baskets and crates. 156. The bushel box (Fig. 157) is standard, and is used for a great variety of purposes. In Fig. 158 is seen the crate used in Hawaii for shipping papayas (Higgins and Holt), each fruit being in a separate carton.

It is well nigh useless to try to make specific remarks about the packages used for fruits, because so much depends on the particular grade of the fruit and the way in which it is shipped and handled; very much also depends on the demands of the given market. It is an excellent plan for the fruit-grower to visit markets in advance of the ripening of his crop, and to determine just what style of package his market will most appreciate. When fruits 
are pooled, or shipped through exchanges or unions, it is imperative that a uniform style of package be used; but when a man handles fruit solely on his own account, and has a superior quality, he may often advertise his product by a unique package, or at least by one that is unlike those in most common use. Such a package

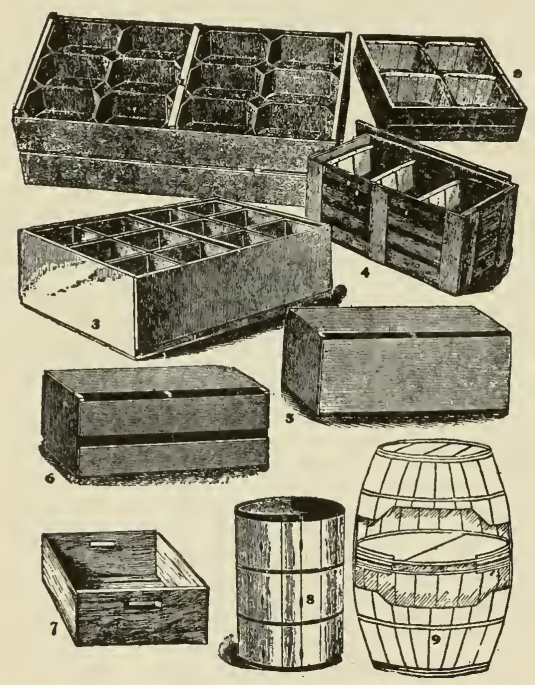

Fig. 152. Crates and barrels. singles him out from his neighbors, and answers as a trademark for his product. The writer has known profitable returns to be secured from fruit shipped in colored baskets. A dye was made of aniline, and the baskets were dipped into the kettle (being handled with a pitchfork), and fruit no better than the ordinary run brought several cents a basket more than that packed in the ordinary white package. This will not often succeed, however, but this example is given to show that a package somewhat out of the ordinary may be desirable for a person to use for special trade.

In all the finest fruits the grower should use nothing but a gift package, one that is given away with the fruit. This insures a clean and dainty parcel, and the purchaser is not bothered with the thought of returning it. In a good market, a package that has been previously used 
is a detriment. In many cases, it is the packing and the package that sells the fruit, as much as the fruit itself.

When fruits are sold by the definite quantity, as by the quart, the peck or the bushel, the packages should be full measure. It sometimes happens that for a time a man secures as much for a short or "snide" package as for

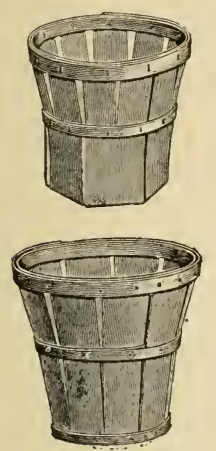

Fig. 153. Peachbasket forms. one of full measure; but such person can scarcely expect to hold a superior trade for a great length of time. The laws are now enforcing full-measure packages.

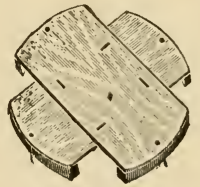

FIG. 154. Peachbasket covers.

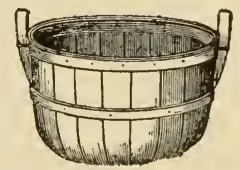

FIG.155. The half-bushel shipping-basket.

One of the standard packages for grapes, peaches and apricots is the Climax basket, made in various styles and sizes. Some of the common forms are shown in Fig. 150, Nos. 7-11. These are made in sizes holding five to ten or twelve pounds of fruit. They are handy, cheap, nest well in the shipment, and are durable. A good basket of any kind should be neatly made, with no splinters or tag-ends hanging from it, which is firm and symmetrical in shape, well nailed, and perfectly clean or white in appearance. Baskets become yellow and discolored if they are left in the sun; therefore, when they are stored, they should be placed in a clean and dark dry loft or room. If packages left over from the last year are somewhat dingy, it is sometimes possible to bleach them by burning a little sulfur in the room. 
The grower, then, will begin some months in advance to look up the packages, for he will thereby not only suit
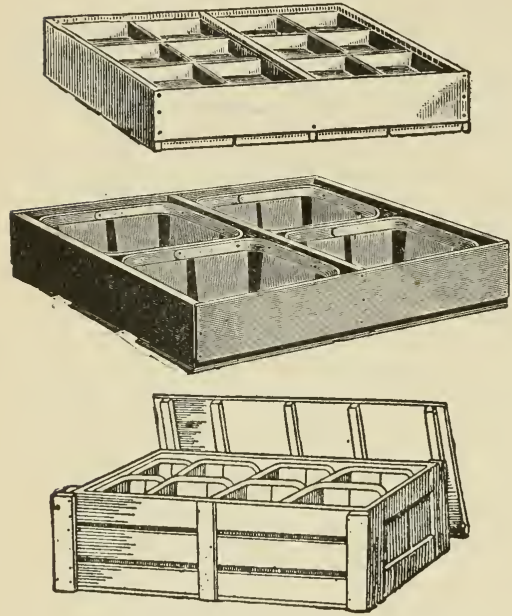

FIG. 156. Carriers. Top, twenty-fourpint crate; middle, four-basket carrier or crate; bottom, sixteen-quart crate.

himself and the market, but he will likely be able to secure his packages at a lower cost; and he will, in any event, be sure of his packages in case there should be a large demand for them at marketing time. It is well to secure the illustrated price-lists of the manufacturers, and to canvass the subjects of styles and prices.

All packages smaller than a half-peck should be shipped in crates. It is customary to use crates with slat sides and many openings, to insure complete ventilation; but, if the fruits are firm and dry when they are picked and are then reduced to a lower temperature, they may be shipped in unventilated crates, usually with better results. The shriveling and shrinkage of the fruits will be less in the tight crates, and decay will ordinarily be less also. These crates may be gift packages, and made of light split stuff.

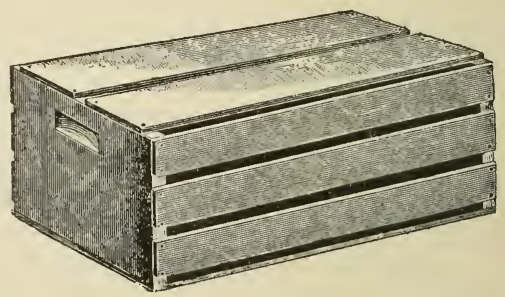

FIG. 157. The bushel box. 
Crates designed to be returned to the grower are usually heavy, are commonly made of sawed stuff, and are provided with hinges and clasps. In shipping long distances by rail, large crates (holding as many as sixty baskets or cups) are usually preferable, as there is less "side shake," because of the greater bulk; and such heavy packages may not be so carelessly handled as are the small ones.

The time is coming when all the better grades and higher qualities of fruits will be put up in special gift packages, and the time cannot be far distant when pasteboard boxes will be

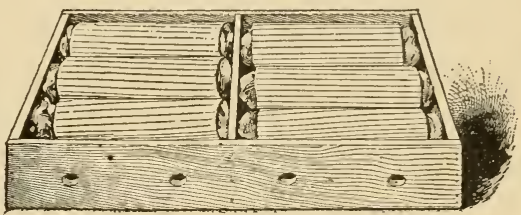
used to some extent. One of the most marked results of the recent advancement and competition in the manufacture of products is the pack-
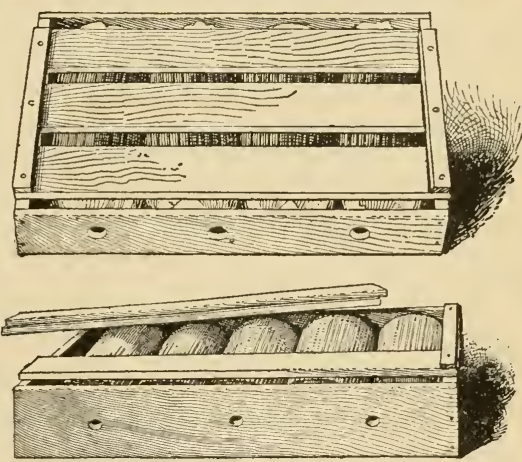

Frg. 158. Papaya crates, Hawaii. ing of single articles in tasty boxes. Boots and shoes, for example, were once shipped loose in large cases, while now, in all the better grades, every pair is boxed by itself. In other words, not only is the product itself a finished article, but it is packed in a dainty and finished way; and the same must come to be true of many of the better kinds of agricultural products.

In the fanciest fruits, as the best dessert pears, and even some of the largest and finest strawberries, it is often 
profitable to ship in cases something like those used for eggs, in which each individual fruit has a compartment or receptacle of its own. If, in addition, the fruit is carefully wrapped in these compartments, the very finest type of packing will result.

\section{How to pack.}

The method of packing must depend very greatly on the market to be reached, on the quality of the fruit, and the package to be used. Ordinarily, women are better fruit-packers than men, especially for the delicate fruits, as peaches, the berries and grapes. Each individual fruit or cluster should be placed in the package separately and by hand. This is emphatically true of all the tender and perishable dessert fruits. The specimens are ordinarily laid in concentric rows, the first row being placed on the outside of the bottom of the basket, and other circles filling in the layer until it is full. Other tiers are then placed in the same way. The top layer is placed with special care, the stems of the fruits being all laid one way, and the same side of the fruit (ordinarily the cheek) showing uppermost. The top of the basket should present a uniform and finished appearance, and should be slightly rounding or oval in shape. There will ordinarily be a difference of 10 to 30 cents a basket between good plums or peaches sent to the market as they are picked from the tree, and those properly packed and finished up. Whether the extra sale price pays will depend, of course, on the extra cost of the careful packing; and this cost will be determined not only by the price of labor but also by the care with which the fruit is grown, the quantity, the training of the packers and the facilities at their disposal. One gains reputation as well as extra sales-price from carefully packed fruits. 
When packing apples and pears in kegs or barrels, it is not always necessary to place every individual; and yet, if the packages are to go abroad, it is ordinarily best to take this pains, laying all the fruits in tiers, for thereby there is tight packing and little shrinkage; and when one handles his fruit so carefully he is constantly throwing out the inferior samples. As apples are ordinarily handled for our domestic trade, however, they are faced only on the two ends. They ought always to be faced on one

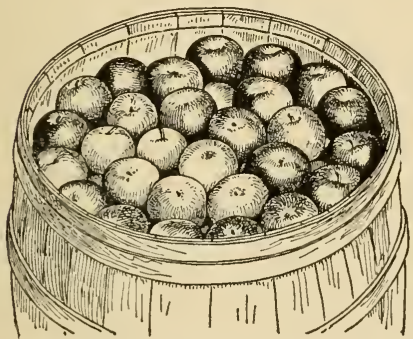

Fig. 159. Well-packed Esopus Spitzenburg apples, removed from storage in March.

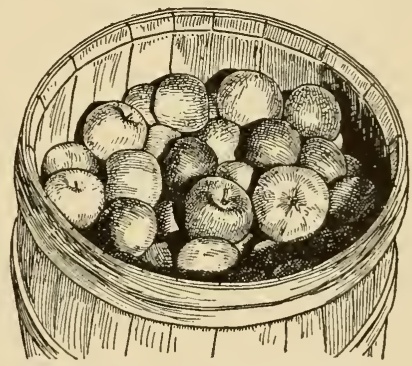

Frg. 160. "Slack"-packed Northern Spy apples removed from storage in March.

end. This facing is done by choosing apples of uniform grade and placing them in concentric rows on the lower head or end of the barrel. About two or three tiers should be faced, the rings of one tier breaking joints with those of another. The stem-end should point toward the head of the barrel. The apples in the middle of the barrel may be turned in from a round-bottomed swing-handle basket, that can be let directly into the barrel (or from a smaller basket that will turn in the barrel), and after every basket is emptied the barrel should be lightly shaken to settle the fruits. It is advisable to face the upper end of the barrel before the head is placed in, but this is not always done. 
The barrel is ordinarily headed up, then ended over, and the opposite or originally faced end is stenciled, and this is the end that the dealer is supposed to open. It frequently happens, however, that the dealer, in order to test the packing, opens the other or unintended end of the barrel; and in selling large lots of apples, two or three barrels are sometimes used as samples, and the entire contents are rolled out on the packing-house or auctionroom floor. A barrel of winter apples properly faced and packed is shown in Fig. 159, just as it was opened in cold storage in March; a barrel of "slacks" is shown in Fig. 160.

The greatest care should be taken in the packing of apples for export, because they are subjected to long and trying transportation, the freight and incidental rates are high, and only the best fruits will pay transportation and other expenses. One reason why the foreign market has sometimes been so poor for American apples is because a great quantity of poorly sorted and poorly packed fruit has been exported. The following suggestions for the exporting of apples are condensed from a report made by George T. Powell, to the New York Commissioner of Agriculture, and will be found to be very useful:

Kind of fruit wanted.-Only good fruit is wanted abroad. The fruit-grower should begin months in advance to secure good quality, by practicing good tillage, efficient fertilizing and thorough spraying. Apples grown on trees which have imperfect (insect-eaten and fungus-infested) foliage generally fail to carry in good condition to Europe. Standard fall and winter varieties are most in demand in the export trade. Duchess and Twenty Ounce generally sell well if picked while hard. Alexander is too soft. Baldwin, Greening, Spy, King, Spitzenburg, Hubbardston (Nonsuch), Newtown (Pippin), Peck's Pleasant and late Russets are popular varieties. Jonathan and other medium-sized apples are especially desired. 
Red apples sell better than solid green ones, as a rule. Soft summer varieties do not ship well.

Picking the fruit.-Apples intended for export should be picked earlier than for the home trade, but not when green and immature. It is largely the beauty of the American apple which sells it; therefore, the color should be well advanced before the apple is picked. Hand-pick the finest very carefully. It is advisable to barrel and ship as soon as picked, rather than to store the fruit for some days in piles in the orchard.

Packing.-Sort carefully. Very fine fruit should be marked "Fancy" or "Selected," with four X's (XXXX), and with the grower's or shipper's name or initials. The second grade should be good, and marked with three X's. Nothing lower than this should be exported. The English law requires that the package be plainly marked "American Produce." Use only standard-size barrels. Put in a double row of facers. Apples somewhat soft in texture, like Greenings, may be pressed down a full inch in barreling, but hard apples should not be squeezed so much. Nail the barrels securely. If the apples become loose in transit, they will be very much injured.

Methods of sale.-Apples are sold in the English markets by sample. Two barrels of a lot are selected, one opened to show the packing, the other turned out so that every apple can be seen. The lot is then sold at auction. The first day of sale they are sold as "sound." These are delivered within twenty-four hours. Any loose barrels, known as "slacks" or "slack-packed," and any from which the jwice is running, called "wets," are closed out at the succeeding sale.

Fruits intended for the dessert may often be put into the consumer's hands in superior condition by wrapping them in soft grocer's paper, of the kind ordinarily called tea-paper, or, when the product is especially choice, and the grower has a large quantity, it may pay him to use a grade of tissue-paper. There are many middlemen who practise this careful packing, and growers may often imitate them with profit. With pears or apples, the inside of the keg or barrel is lined with newspapers or other grades, and each fruit is individually wrapped in soft manila paper. Such 
fruits may be expected to carry thousands of miles without perceptible injury. When opened, their aroma is such that no well-bred consumer can resist the temptation of a

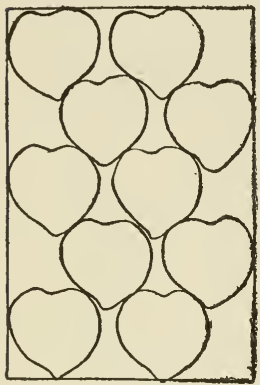

Botiom Ties

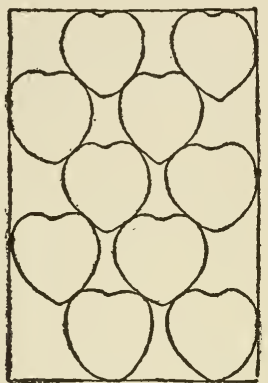

Middle Tiee

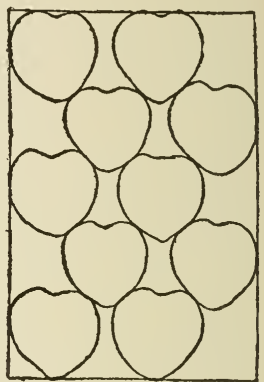

Top Tie.

Fig. 161. The three tiers or layers of the $2 \times 2$ diamond pack.

good price. Ordinary fruits, however, are not worth this care.

It is important that all fruit should be packed very snug, especially that which is to be shipped any distance in barrels or other large packages. Fruit that is "slack" when it reaches the market is nearly always injured, and sells as second- or third-quality product. 'This slacking or shaking in barrels may be prevented by using fruits not over-ripe, by careful attention to grading, so that all the specimens are of uniform maturity, by keeping the product cool after it is packed, and especially by placing the fruits

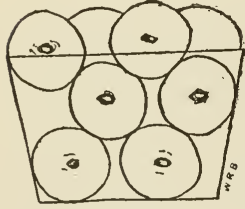

Fig. 162. End view of Fig. 161. in the package by hand. Barrels of apples and pears should ordinarily be filled about an inch above the chine, and the fruit should be pressed in with a screw- or lever-press until the head comes into place. If the fruits are wrapped in paper, or if the package is 
lined with several thicknesses of paper, the spring of the paper itself will take up the slack and will keep the fruit in place; and in such cases it is not necessary to apply heavy pressure in the heading up of the barrel.

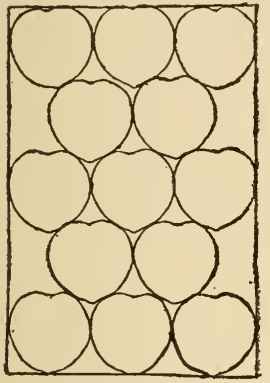

Boltom Tier

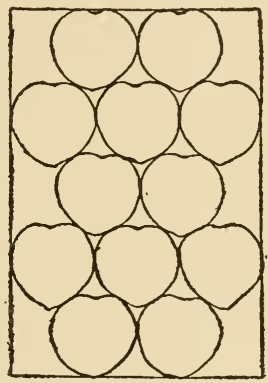

Miadle Ties

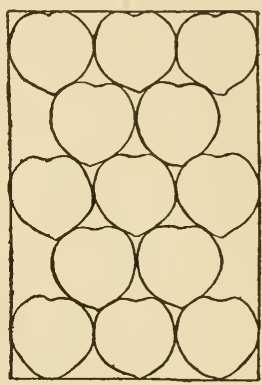

Top Ties

Frg. 163. The three tiers of the $3 \times 2$ diamond pack.

On the best brands of fruit, a trade-mark is often important. Some neat pictorial design, with the name of the grower and a statement to the effect that the fruit is guaranteed to be as represented, attracts the eye of the purchaser and gives him confidence in the article; but to put a trade-mark on fruit of indifferent or even of ordinary quality is little more than a travesty. If a man uses a trade-mark, he must expect, of course, to handle his own produce, or at least to see that it reaches the market under his own name. The fruit-buyers who travel through the country for apples and other produce ordinarily pay little attention to the trade-mark of the grower, but put their own mark on the package. If one really grows a good quality of fruit, it will commonly pay him to give his farm an attractive name,

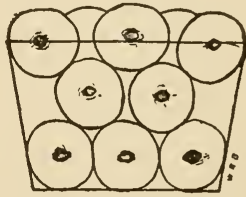

FIG. 164. End view of Fig. 163. 

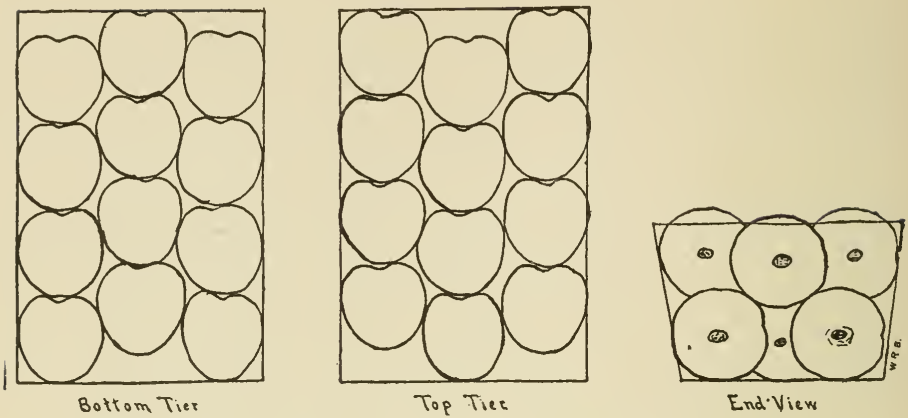

FIG. 165. The two tiers of the $2 \times 1$ diamond pack.

which can go on the labels. Every effort should be made to put up the article as a finished product.

Very much of the success of any fruit in the market depends on how it is grown as well as how it is handled. There may even be a difference in the salableness of samples of fruit that are to all appearances alike. It is now

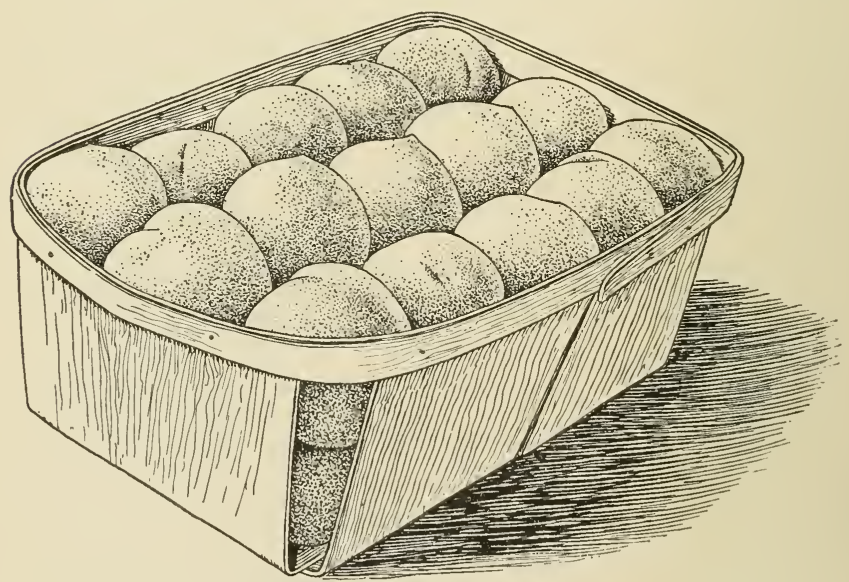

FIG. 166. The square peach pack. 
common opinion, for example, that apples from trees that have been thoroughly sprayed and well tilled are better keepers than those of similar size and appearance

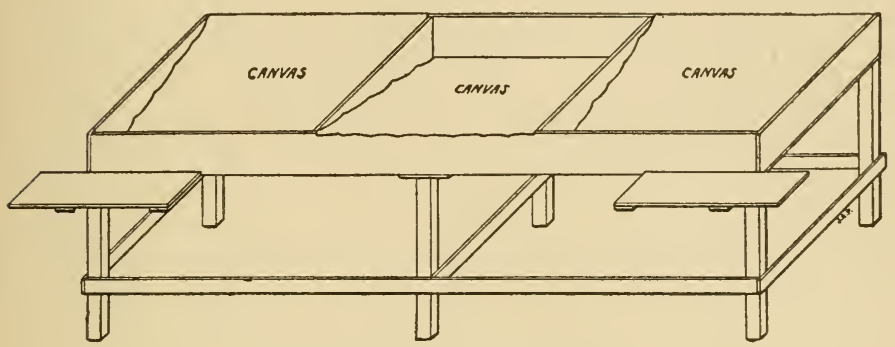

FIG. 167. Packing-table for fruit.

grown on neglected trees. When fruits are to be shipped to any distance, it is important that the tillage and general care of the fruit-plantation should have been the best. Several forms of fancy pack are shown in the illus-

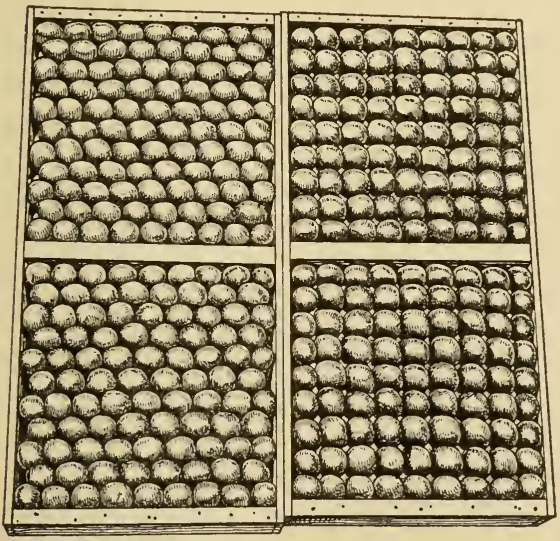

FIG. 168. The straight and diagonal packs of Oregon cherries. trations. For the East, Close and Ballard have given good directions (Md. Bull. No. 159): Fig. 161 is the $2 \times 2$ diamond pack in three tiers packed in the baskets of the Georgia carrier, and Fig. 162 is the end view; Fig. 163 is the $3 \times 2$ diamond pack in three tiers, in baskets of 
the Georgia carrier, and Fig. 164 is the end view of it; Fig. 165 is the $2 \times 1$ two-tier diamond pack in the same

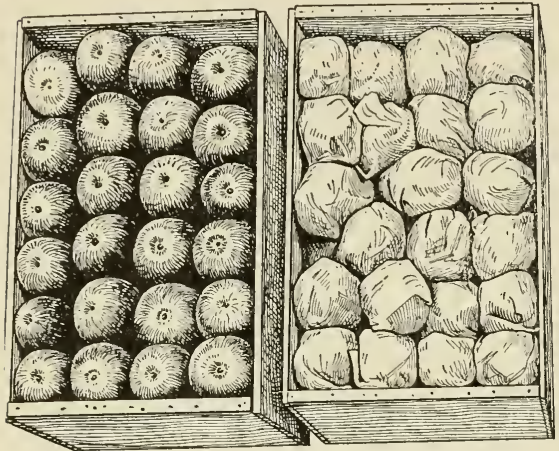

FIG. 169. Apples unwrapped and in tissue, parchment and wax wrappers.

Box-packing of fruits. carrier; Fig. 166 is the square pack in one of the Georgia baskets; Fig. 167 is a packing-table. The straight and diagonal packs of Oregon cherries are shown in Fig. 168 (Lewis and Brown). Wrapped and unwrapped apples box-packed are displayed in Fig. 169.

Western apples and pears are packed in boxes of about one bushel in capacity (Fig. 170), and much interest has recently been aroused in this subject in the East. It seems to be the prevailing opinion in the eastern apple regions that the boxing of apples pays only for special markets and special varieties, and that the barrel is still the most profitable package for the main commercial trade. Varieties grown for a homemarket trade may be packed in boxes with good financial results, particularly when the fruit is unusually good and uniform. The uniformity of the crop, as to size, shape and color, is very important.

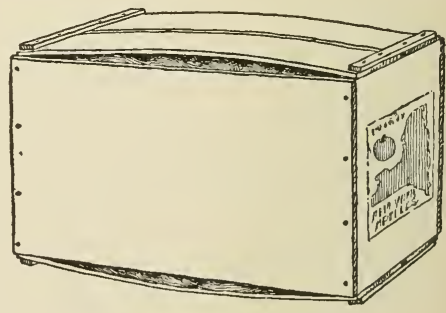

Fig. 170. The apple-box. 
The methods of box-packing have been well described by C. S. Wilson (Cornell Bull. No. 298), from a study of both western and eastern conditions. He writes as follows:

Two sizes of boxes are used in the West, the standard and the special. These differ slightly in width and height $(1 / 2 \mathrm{inch})$ as well as in length, which adapts them to the different sizes of apples. If, therefore, an apple, because of its size, will not pack well in one size of box, it certainly will pack in the other. Most of the western growers have a supply of both sizes on hand.

The dimensions of these boxes are:

(a) Standard, $101 / 2$ by $11 \frac{1}{2}$ by 18 inches, inside measurement.

(b) Special, 10 by 11 by 20 inches, inside measurement.

The ends $3 / 4$ inch; sides, $3 / 8$ inch; top and bottoms, two pieces each, $1 / 4$ inch thick. There should be four cleats for each box, two at the top and two at the bottom. The sides of the box should be nailed with four nails at each end of each side. The cleats should be put neatly on the box and four nails driven through them and through the top or bottom into the ends. Cement-coated or rosined nails are preferable, either six-penny or five-penny. A few other sizes differing from those mentioned above are sold by manufacturers in the East. Odd sizes, however, should be avoided. The boxes are delivered in the shooks and nailed up by the growers themselves.

Lining.-The box is lined on the bottom, sides and top with a white paper called "lining paper." No lining is placed at the ends. Lining paper is made from "white news" in different sizes, according to the box - for the standard, $173 / 4$ by 26 inches, and for the special, $193 / 4$ by 26 inches. This paper can be purchased of any wholesale paper dealer, and should cost approximately $3 \frac{1}{2}$ cents per pound, or about $\$ 1.20$ per thousand sheets.

One piece of lining paper is put into the box in such a way as to cover a little more than one-half of the bottom and all of one side, enough still being left to fold over a little beyond the center when the box is packed. Another piece is put into the box in a similar way on the other side. In order to prevent the tearing of the lining paper along the sides at the bottom, when the top is nailed on and the bottom bulges, a plait or crease is made in the lining paper at this place. The plaits lie across the corners and provide plenty of slack. In the West some growers plait the lining in this manner; others do 
not. Layer papers are also used, commonly one sheet on the bottom and one on the top, inside the lining paper.

Wrapping.-Most growers in the West wrap every apple. To wrap the fruit, the packer stands at the table so that he can pick up an apple with one hand and place it in the box with the other. The wrapping paper is held in a hod which hangs on the side of the box.

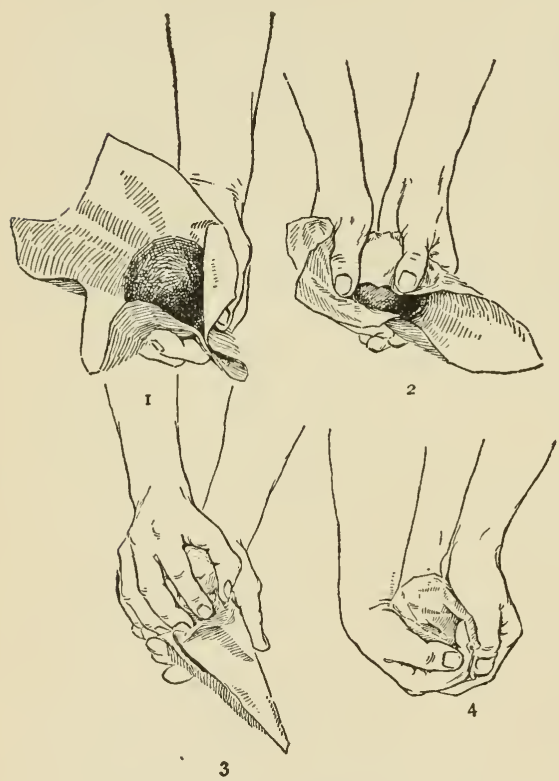

FIG. 171. Successive stages in the wrapping of an apple.

(Shown in Fig. 172). To pick up a sheet of wrapping paper easily, the packer wears a rubber stall on the thumb or middle finger. These rubber stalls can be purchased at almost any drug-store. With the left hand the packer reaches for a sheet of paper; at the same time with the right hand he picks up an apple. The apple is thrown gently into the center of the paper, which is held in the palm of the left hand. With the right hand the packer draws in the corners of the paper, and then, with a slight rolling motion, completes the wrapping, and in so doing leaves the apple in the left hand in the proper position to pack in the box. The illustrations (Fig. 171) show successive steps in the operation. The operation, however, being an individual matter, will differ somewhat with each packer. In every case the object should be to make a neat and attractive wrap, and do it quickly.

Packing-table.-A convenient packing-table can be easily built by any grower. A good type is shown in Fig. 172. The bed of the table is 3 by 4 feet, covered by a double layer of canvas. In order to enable the packer to shake off quickly any dirt or leaves which 
may gather, the top layer is fastened at one end only. Each end of the table is extended about 1 foot on which to rest one end of the box. As a rest for the other end a board projecting about 1 foot at the side is fastened to the bottom of the bed. These supports for the boxes are built at alternate corners of the table. Shelves on which to place wrapping paper, lining paper, or layer paper are often built beneath the table.

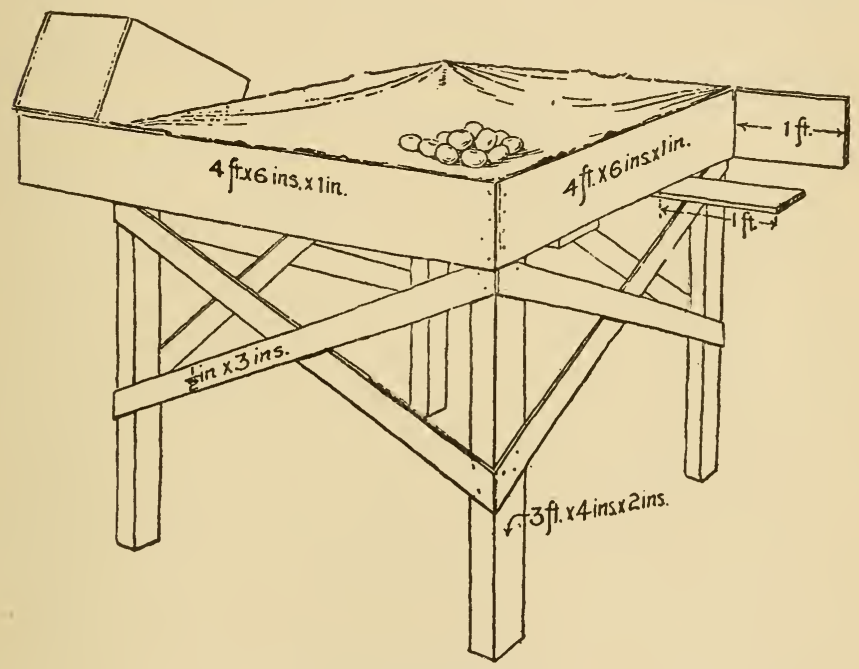

Fig. 172. Packing-table.

$A$ box-press may be devised in various ways, the essential points of construction being: ( $a$ ) to rest the box on the ends so that when the top is nailed down the bottom is free to bulge also; $(b)$ to catch and press down the top pieces from the ends so that a minimum bruising will result. A convenient press is shown in diagram Fig. 173. The box lies across the open space in the center, the pieces being caught and clamped at the end by the arms. This press is built for boxes of different lengths. Many other types of box-presses have been made, and are equally efficient and convenient.

Following is the description of the box-press shown in Fig. 173.

1. Cover boards to table. Length of table, 64 inches; 2. Side 
board to table; 3 . Uprights for attachment of levers (5 and 9); 4. Legs of table $281 / 2$ inches long, $1 \frac{1}{2}$ inches square. (All the arms, legs and levers of the press may be made of $1 \frac{1}{2}$ by $11 / 2$-inch material); 5. Levers, 27 inches long; 6. Upright arms, 32 inches long; 7. Steel springs. Small screen-door springs may be used; 8 . Spring attached to upright arm (6) and support (3); 9. Foot lever, bolted to uprights (3) at back, and working with catch plate and ratchet in front. It is fastened to plate $(13) ; 10$. Brace for legs and lower support for uprights, 3 inches from ground; 11. Horseshoe plate for gripping

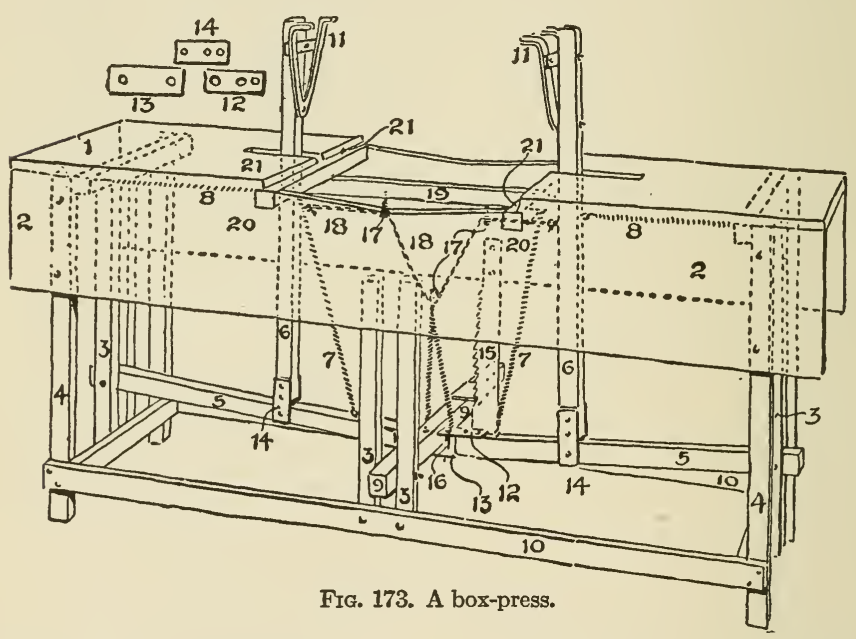

box cleats and cover; 12 . Iron plates bolted to levers (5), with large holes in projecting ends, allowing the bolts (16) to slide freely; 13. Lower plate under lever (9), to which it is bolted loosely, with large holes in each end for free play for bolts $(16) ; 14$. Side plate joining lever (5) and arm (6). Loose joint; 15 . Iron ratchet to engage plate on the front lever $(9) ; 16$. Half-inch bolts, $2 \frac{1}{2}$ inches long, working loosely in the holes in the plates (12 and 13$) ; 17$. Three small pulleys for rope attached to arms $(6) ; 18$. Strong $1 / 4$-inch cord that will not stretch; 19. Spanner running parallel with side; 20. Cross-pieces, providing support for box; 21. Grooves for holding box in place. They are a trifle over 18 inches apart. 
Packing.--Before placing the apples on the packing-table they are usually graded into different sizes. The grading is done by men who are trained for the work. They take the fruit from the boxes as it comes to the packing-house from the orchard and grade it into different sizes. It is then placed on a table, where it is ready for the packer. For growers in the East who are beginners it may be helpful to use a sizer or "grader" at first. This consists of a thin board through which holes of the correct diameter have been made. Beginning with the smallest, the diameter of the holes should be: $23 / 8$ inches for the 5 -tier pack, $25 / 8$ inches for the $4 \frac{1}{2}$-tier pack, $27 / 8$ inches for the 4 -tier pack, $31 / 8$ inches for the $31 / 2$-tier pack, and $33 / 8$ inches for the 3-tier pack. The sizer should be placed in a convenient position so that an apple can be quickly dropped through it if the man, who is grading, is in doubt as to the size of any apple. The eye of the attentive operator is soon trained, however, to distinguish the different sizes.

The packer adapts the pack to the size of the apple and the box. Two kinds of packs are commonly used in the West, the diagonal and the straight. They are the $31 / 2^{-}$and $4 \frac{1}{2}$-tier, the $31 / 2^{1}$-tier being the more common. The apples for this pack are too large for four straight across and too small for three straight across. They are packed, therefore, as shown in the illustration, and the pack is called a " $31 \frac{1}{2}$-tier." To start this, one apple is placed in the corner and another against the end in the middle of the remaining width. The next two apples, alternating with the first two, are set firmly down into the intervening spaces, and so on until the layer is packed. The number of apples in the rows will vary according to the size and shape. The number in the different layers, however, should be the same. The straight packs are the 3-, 4-, and 5-tier, according to the size of the apples. This pack is made by placing the apples in straight rows across the box.

The diagonal pack is preferable to the straight. In the first place, it permits of a wider variation in the size of the apples; with the straight pack the apples must be more uniform in order to fit exactly. In the second place, it permits of more or less pressing without bruising. In the diagonal pack an apple rests in the center of the space between two or four others. In the straight pack every apple rests against the center of every other. Hence, when the top is pulled down, a certain amount of pressing could take place in the diagonal pack without bruising, whereas in the straight, pack only 
a slight pressing would bruise the fruit. For a few sizes of apples one is forced to use the straight pack.

The following table, used at Hood River, Oregon, in the fall of 1910, gives the pack, number of rows, number of apples in the row, box to use, and number of apples in the box. The table is taken from an article written by Professor Claude I. Lewis, and published in "Better Fruit," September, 1910:

\section{Table of Commercial Box Packs}

\begin{tabular}{|c|c|c|c|c|c|}
\hline $\begin{array}{l}\text { Size, ex- } \\
\text { pressed in } \\
\text { number of } \\
\text { apples per } \\
\text { box }\end{array}$ & Tier & Pack & $\begin{array}{c}\text { Number of } \\
\text { apples in } \\
\text { row }\end{array}$ & $\begin{array}{l}\text { Number of } \\
\text { layers in } \\
\text { depth }\end{array}$ & Box used \\
\hline $\begin{array}{r}45 \\
54 \\
63 \\
64 \\
72 \\
80 \\
88 \\
96 \\
104 \\
112 \\
120 \\
128 \\
144 \\
150 \\
163 \\
175 \\
188 \\
200\end{array}$ & $\begin{array}{l}3 \\
3 \\
3 \\
31 / 2 \\
31 / 2 \\
31 / 2 \\
31 / 2 \\
31 / 2 \\
31 / 2 \\
31 / 2 \\
31 / 2 \\
4 \\
4 \\
41 / 2 \\
41 / 2 \\
41 / 2 \\
41 / 2 \\
41 / 2\end{array}$ & $\begin{aligned} & 3 \text { Str. } \\
& 3 \text { Str. } \\
& 3 \text { Str. } \\
& \text { 2-2 Diag. } \\
& \text { 2-2 Diag. } \\
& \text { 2-2 Diag. } \\
& \text { 2-2 Diag. } \\
& \text { 2-2 } \text { Diag. } \\
& \text { 2-2 Diag. } \\
& \text { 2-2 Diag. } \\
& \text { 2-2 Diag. } \\
& 4 \text { Str. } \\
& 4 \text { Str. } \\
& \text { 3-2 Diag. } \\
& \text { 3-2 Diag. } \\
& \text { 3-2 Diag. } \\
& \text { 3-2 Diag. } \\
& \text { 3-2 Diag. }\end{aligned}$ & $\begin{array}{l}5-5 \\
6-6 \\
7-7 \\
4-4 \\
4-5 \\
5-5 \\
5-6 \\
6-6 \\
6-7 \\
7-7 \\
7-8 \\
8-8 \\
9-9 \\
6-6 \\
6-7 \\
7-7 \\
7-8 \\
8-8\end{array}$ & $\begin{array}{l}3 \\
3 \\
3 \\
4 \\
4 \\
4 \\
4 \\
4 \\
4 \\
4 \\
4 \\
4 \\
4 \\
5 \\
5 \\
5 \\
5 \\
5\end{array}$ & $\begin{array}{l}\text { Standard } \\
\text { Special } \\
\text { Special } \\
\text { Standard } \\
\text { Standard } \\
\text { Standard } \\
\text { Standard } \\
\text { Special } \\
\text { Special } \\
\text { Special } \\
\text { Special } \\
\text { Special } \\
\text { Special } \\
\text { Standard } \\
\text { Standard } \\
\text { Standard } \\
\text { Special } \\
\text { Special }\end{array}$ \\
\hline
\end{tabular}

In packing it is not difficult to come out even on top at the ends. The height of the box is planned for this, and one need pay very little attention to it. The packer, however, must plan to secure the proper bulge, which should be about $11 / 2$ inches at the center. He should begin the bulge with the first or second layer, and may proceed in several ways. A natural and common way is to choose for the center of the box apples which are a little larger or thicker than the apples at the ends. Or, in case of flat apples, the packer may pack them on end at the ends of the box and on the side at the center. With practice the proper bulge seems to come naturally, and the packers have very little difficulty with it.

Whether the apples are packed on the end or the side will depend 
on their shape. They may be placed either way, or even both ways, in the same box, in order to secure the bulge described above. Flat apples usually pack more easily on the end than the side, whereas long apples pack better on the side.

When the box has been packed, it is taken from the table to the press and the top nailed on. When the top is nailed, a bulge of $11 / 2$ inches at the center gives $3 / 4$ inch on both top and bottom. The bulging of the top and bottom in this manner acts as a spring to take up any slack or shrinkage during transportation. When the

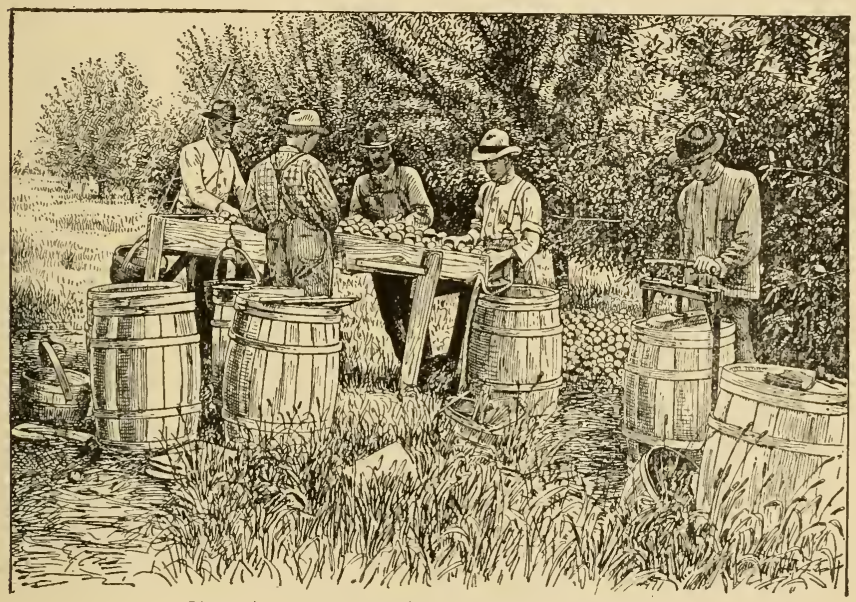

FIG. 174. Field-packing of apples in Missouri.

boxes are piled up they are placed on the side, where there is no bulge. When they are stored in this way no bruising can result from the weight of one box above another.

\section{FARM PACKING-HOUSES AND APPLIANCES}

Many fruits are packed in the field, as exhibited in Fig. 174; particularly is this true of apples. But if one has any quantity of fruit and is to reach the best market, he must consider the making of a packing-house or shed. 
The subject of packing-houses cannot be treated specifically for each grower. Among the best types of packinghouses are those used by the grape men, and there are two distinct types of such houses in use in the grape regions. One type is a combined packing- and storage-house, and is used very largely where Catawbas are grown, and where the grapes are often stored for some time before they are marketed. The other type of house is that used in the Concord regions, and which is a half-way station between the field and the railway station, - - a shelter place for the packing of the grapes, and is not used for the storage of the fruit.

One of the best of the storage type of packing-houses (used for holding the fruit until winter or later) may be described as follows:

It is built on a side hill, and the basement or cellar is used for the storage of grapes, the first floor is used for packing, and the second floor or attic for the storage of baskets, crates and the like. This building measures 25 by 60 feet over all. The foundation walls are 24 inches thick, and the cellar is provided with ample

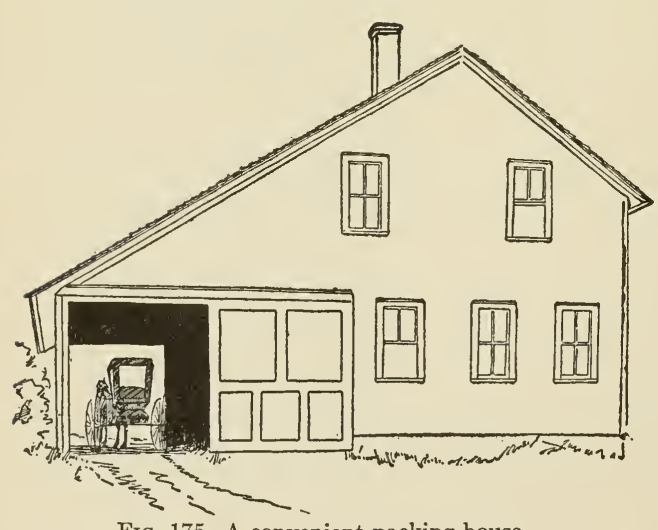

FIg. 175. A convenient packing-house. means of ventilation by outside windows, and also by means of a chimney that runs from near the middle of the cellar up through the roof. The floor is of earth. By means of careful attention to ventilation, this cellar can be kept to $50^{\circ}$ or below in September and October, and is frost-proof in winter. The windows 
are provided with close-fitting screens, to keep out rats and squirrels. This cellar will hold easily fifty tons of grapes in the picking-trays. The first floor is divided into two rooms, the front one being a packingroom 25 feet square, and the back room being a storage and shipping department25 by 35 feet. This packing-room is provided with heat, and is lighted by seven large windows. The floor above the cellar is double, and made of $1 \frac{1}{4}$-inch matched pine, with an abundant air-space between the two layers. This, therefore, protects the cellar from sudden fluctuations of temperature. The building is also shaded, especially from the afternoon sun,

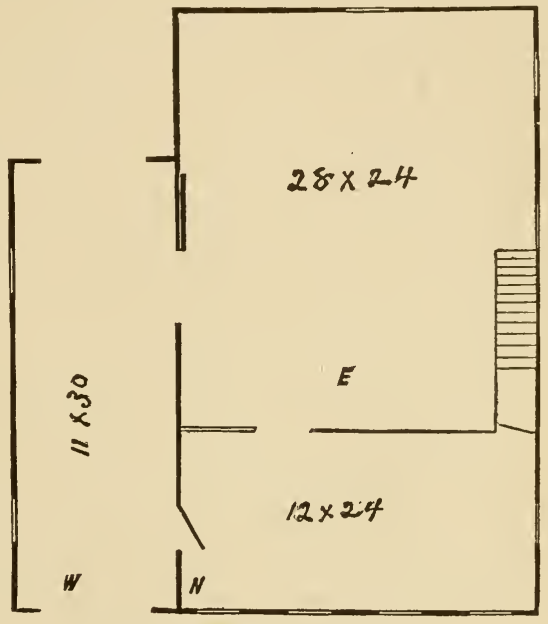

Fig. 176. Ground-plan of Fig. 175. by large trees. It has 18 -foot posts, a tin roof, the two rooms in the first floor ceiled with pine, but the top floor not ceiled.

The other type of packing-house (used only for purposes of packing and of storing packages) is illustrated by Figs. 175 and 176. In this case there is no cellar, for the grapes are not to remain in the house more than a day or two at the longest, and they ordinarily pass directly through it on their way to the railway station. The main floor of the building is 24 by 40 feet, and, aside from this, there is a driveway, $W$, under the same roof, and which measures 11 by 30 feet. This driveway connects with the main floor by two doors. The front room, $N$, which is lighted by four windows in the front and one on the side, and is 12 by 24 feet in size, is the packing- 
room. In the rear of this is a store-room, $E$, for the grapes. The half-story above is used for baskets and crates, and these are delivered into the packing-room by a shute. This building will accommodate ten packers, and will easily handle the grapes from fifty acres.

In the packing of grapes, the greatest care is required to keep the fruit clean and fresh, to prevent the bunches

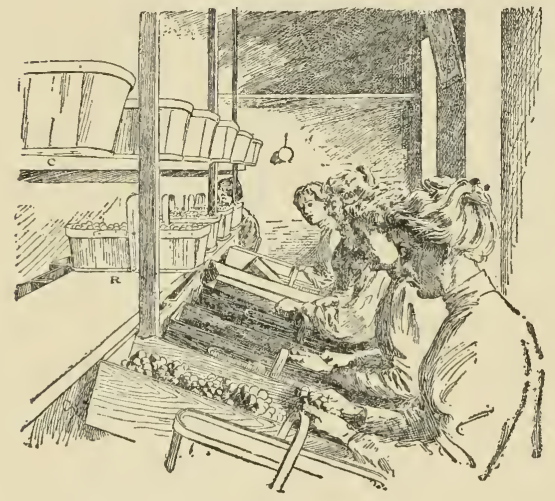

FIG. 177. Sorting and packing grapes. from being broken, and to preserve the bloom. It is essential that the house should be kept thoroughly clean and sweet at all times. It is important that thestorageroom for the baskets and crates be dry and airy, so that the baskets may not become moldy or musty, and also well darkened to prevent the baskets from coloring.

In Fig. 177 is shown a grape packing-room. The picking-trays are set before the packers upon an inclined table, and the packer handles the grapes from this tray into a basket that she places at her left. When the basket is filled, it is placed upon a flat ledge in front of her and is taken off by an attendant, who places the baskets on a truck and rolls them into the back room, from which they are delivered to the wagon. Empty baskets are stored upon the high shelf, and these are replenished by an attendant, as necessary. When the tray is empty, it is 
slid through an opening just in front of the packer and underneath the flat ledge upon which she places her finished baskets. Fig. 178 shows another form of packing-stand. This is a circular revolving table, about which the packers sit. The packer holds the basket in her lap, and takes the grapes from the table, which is

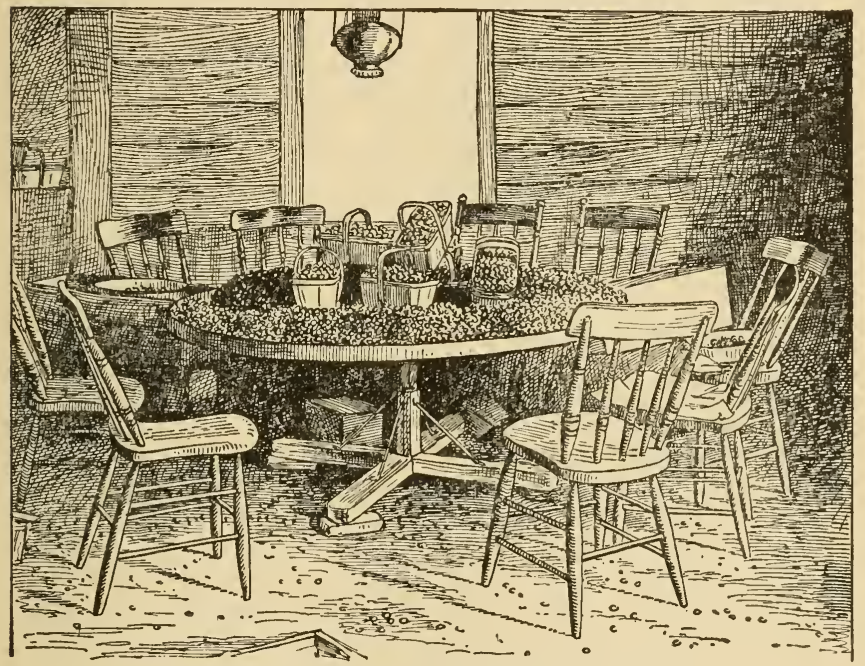

FrG. 178. A revolving packing-table for grapes.

turned as fresh fruit is put upon it. This device allows the packer to choose from a large quantity of fruit.

The packing-house of a large commercial orchard is shown in Fig. 179, and an interior view in Fig. 180. The latter picture is a peach-packing scene.

The suggestions in the last few pages cover most of the points that it is necessary to consider in the construction of a packing-house. The grower will be able to apply them to his own conditions. A simple temporary shed 
erected in the orchard is often made to serve all the purposes of a packing-house. A cloth tent is often used.

The appliances

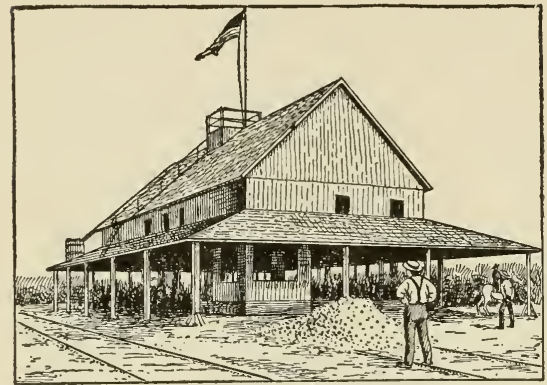

FIG. 179. A peach packing-house for a large business. needed in packinghouses, aside from packages and crates, are trucks, sortingtables, barrel presses, and an abundance of baskets,crates or barrels for the refuse fruit.

Sorting - tables are of various patterns, but those used for apples, cranberries and other firm fruits, consist of a table or tray about twice as long as broad, narrowed at one end, at which it is open to allow the good fruit to roll off into a basket or barrel. The fruits are placed from the picking-baskets on the table, and a number of persons standing on either side remove the litter and the inferior fruit, while they work the good fruit on into the outlet. Compare Figs. 167 and 172 .

Of barrel presses there are several styles. The most expeditious is some kind of lever press (like No. 3 in Fig. 181), but more pressure can be secured with a screw press (7), and such an implement holds itself in place when

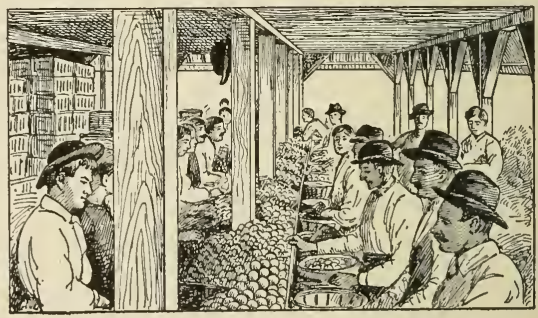

FIG. 180. Interior scene in Fig. 179. 
the head is being adjusted. Fig. 181 presents types of barrel presses in common use. They are: 1, home-made lever press; 2, Climax lever press; 3, improved lever press; 4, stand-up barrel header; 5, packing press (for packing and baling goods); 6 , stirrup press; 7 , iron screw press. Fig. 182 is another form.

STORING FRUITS AT THE FARM

It is impossible to draw the line between a packing-house and a storage-house. In fact, the same structure may be used for both purposes, as is the grapehouse that has been described in the preceding pages (page 408). There is increasing necessity that the fruitgrower provide the means of storing fruits, when prices are low

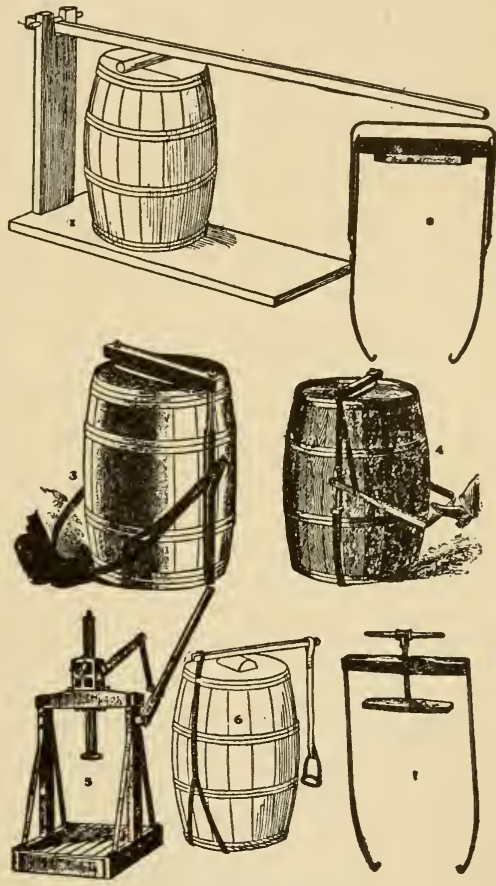

FIG. 181. Barrel-presses. and competition is very sharp.

As a rule, it will not pay the separate fruit-grower to build iced storage or chemical store-houses for his fruit, unless he has a very large acreage. This cold storage of fruit is really a business by itself, and requires much care and skill to carry it through successfully, and a discussion 
of it is foreign to the purpose of this book. If the grower desires to keep his produce until late winter or spring, and has no cellars or natural storage place, it will ordinarily pay him best to put it into some commercial cold-storage house, and to pay a package rate for the storing of it.

For temporary storage, however, these remarks will not apply. Every person who grows fruits, especially perishable kinds, should have some kind of building in which he may place the fruits over night, or for two or

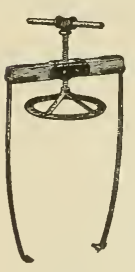

Fig. 182.

A form of barrel-press. three days, when waiting for the market to improve, or for the purpose of cooling them down before shipment. These houses are ordinarily cooled merely by cold air. They are often known as "chill rooms." A room well fitted for the keeping of butter in warm weather may also be used to advantage for fruit. In some cases, arrangements can be made for the use of ice to reduce the temperature for the time being. If one has a considerable quantity of fruit, and has a large cellar that is well adapted to the keeping of apples, he can often store his crop to advantage when the autumn price is low; but the grower must bear in mind that the risks in the storing of fruit are great. The markets may not improve, or the fruit may not keep well. Even when the fruit does keep well, there is frequently a large shrinkage, and the expense of re-packing and handling is a large item. The fruit designed to be kept for the late winter or spring trade should be carefully sorted when it is put in storage, and especial care should be taken that none of it is over-ripe. Fruit in proper condition for storing when it is picked may be ruined for long-keeping quality by allowing it to lie in the sun or in a warm place for a day or two. 
Requisites for domestic storage without ice.

The home storage establishment is commonly either a cellar or a half-cellar, although, by taking particular pains in the construction of air-spaces, a building entirely above ground may be made to serve the purpose. A building wholly on the surface, however, is more likely to give variable temperatures than one partially submerged. An ordinary house cellar, if it has good ventilation and is not too dry or too warm, may answer very well for the storage of fruit; but it is ordinarily best, both for purposes of storage and for health, that the fruit cellar should be a separate structure, if products are to be stored in any quantity. The requisites of a good storage cellar for fruit are chiefly five: Protection from frost; the ability to secure a uniform or unvarying temperature of $40^{\circ}$ or below; facilities for ventilation; air that is moist enough to prevent evaporation; complete safety from rats and other vermin.

The protection from frost is secured either by sinking the building below the surface of the ground, or by making two to four air-spaces in the walls in that part standing above ground. The ventilation should include facilities for removing the warm and impure air from somewhere near the top of the structure. Some kind of shaft or chimney construction, with a valve or shutter that can be opened or closed as necessary, will answer this purpose. In buildings above ground, it will often be necessary to provide some means of taking in the cold air near the bottom of the structure, especially before the cold weather of winter sets in and after the warm weather of spring begins. Cold air being heavier than warm air, it settles on the surface of the ground in still nights, and if the floor of the storage structure is 2 or 3 feet below the top of the ground, 
this cold air may be drained into the building by means of flues laid through the walls, the outer ends standing just above the earth. Six-inch sewer pipes, at intervals about the building, answer this purpose. In a building 30 feet wide and 70 feet long, three of these valves along either side, and one on either end, are probably sufficient for all ordinary requirements.

Sub-ventilation is sometimes recommended, and may often work to good advantage. This is secured by running a long pipe from near the bottom of a cellar storage out to the surface of the ground 6 or more rods away. This pipe has a valve at the outer end, or at least some protecting structure to prevent the leaves and litter from blowing into it, and it is ordinarily best, also, to have a valve at the inner end. Inasmuch as the earth about this subterranean passage is not frozen during the winter, cold air may be drawn in from the outside and be warmed up above the freezing point in its passage through the tube. This type of ventilation has been used with success in cellars designed for the wintering of bees. It should always be remembered that cold air contains less moisture than does warm air. When very cold air is admitted, moisture is rapidly taken up when its temperature rises, and the cellar may be made too dry. It is advisable, therefore, to raise the temperature of such air nearly to its ultimate or required degree before it enters the storage-room.

Very dry cellars cause the fruit to shrivel. Some varieties of apples are very difficult to hold without shriveling, as the Spitzenburg and the russets. Those rooms in which there is a natural sand or gravel bottom ordinarily keep fruit in the best condition. Cement bottoms are very likely to be too dry. Running water is very often desirable 
in a fruit cellar, not only because it furnishes moisture to the air, but also because it is an equalizer of the temperature. One must be cautioned, however, that a cellar not properly ventilated will cause the fruit to mold and decay, if it is wet. In general, it is best to have means for supplying fresh air, and then keep the cellar simply moist, not wet. One should avoid drafts in the storage cellar, for currents of air are very likely to cause the fruit to lose moisture and to shrivel.

Much is said about the keeping of fruit on trays rather than in barrels or crates, but this must be determined by the character of the cellar as to temperature and moisture. In cellars that are too dry, the fruit should be left in the closed packages; but if the air is moist and the temperature very low, the fruit may be placed upon racks or trays to good advantage. But, in any case, it should be remembered that fruit in storage for a month or more should be re-sorted and re-packed before it is put on the market. It has been said (page 414) that the best results in the storing of fruit are had when the product is carefully sorted before it is put into the cellar, for even if the cellar is very nearly perfect for the keeping of the fruit, any over-ripe or decayed specimens will very likely break down, and spread the contamination to the entire sample. The fruit should be cooled down somewhat before it is placed in cold storage, especially if there is much of it, otherwise it raises the temperature of the compartment.

The requisites for keeping grapes during the winter are given as follows by George C. Snow: "Any good building in which the temperature can be held even at about $35^{\circ}$, with ventilation as may be required, this to be determined by noting how the fruit is keeping, will be found available for grapes. No positive rules can be laid down. 
A cooling-room, in which the fruit can be first cooled, is a necessity. If placed directly in cold storage, the temperature will be found to be raised rapidly by placing a quantity of warm fruit in the room. As even a temperature as possible is much the best. Grapes should not be packed in baskets for shipping before being stored. They should be

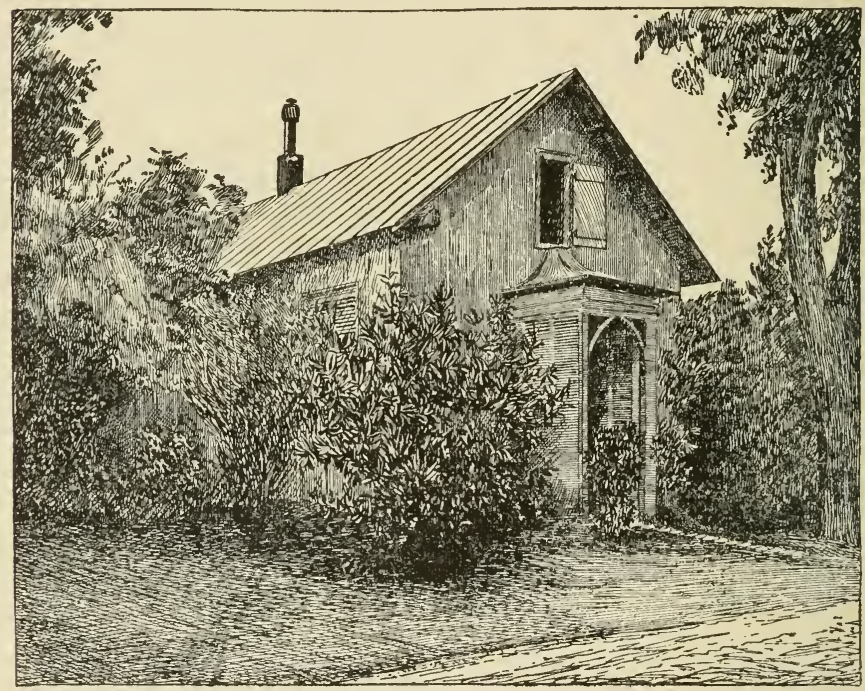

FIG. 183. Charles Downing's fruit-house.

ripe, as grapes do not mature after picking. Niagara or any other variety can be held only for a limited time, some varieties longer than others."

Farm storage-buildings.

There are many forms in which storage-houses may be built for home use. Fig. 183 is a fruit-house of Charles Downing, of pomological fame, used probably for 
temporary storage. It is not intended to discuss the construction of storage buildings, but only to give examples of the way in which two or three growers have met the problem.

The Kinney apple-storage house, in northern Vermont, shown in Fig. 184, is described by the owner as follows: The fruit-house is built on high and dry ground. The cellar was 3 feet deep, and dirt taken from this was used to bank up around the wall. The wall is solid stone and mortar, is 5 feet high, $2 \frac{1}{2}$ feet wide at the bottom, and 2 feet at the top; 2-inch plank for sills on this, bedded in mortar, doubled so as to break joints; 2 by 4 studding above this; outside of studding matched pine, then paper, and then clapboards, painted; in middle of studding, lath and plaster; inside of studding, matched pine, then paper, and then $1 / 2$-inch sheathing, painted. This gives

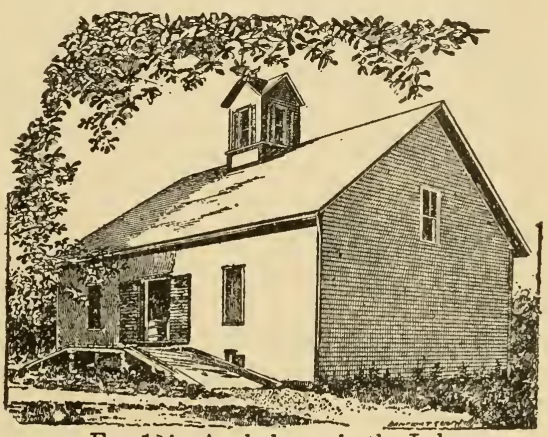

Fig. 184. Apple-house in the Lake Champlain country.

two hollow walls, or dead-air spaces. For ventilating, there is one ventilator from cellar to the observatory on the top of the building, which has four large window frames, with blinds, but no tight windows. The ventilator opens into both storage rooms. We have three 18-inch windows on the east and west sides of the building in the cellar, and three large windows in the west side, next to the storeroom. Both floors are double, with paper between, and the second room is ceiled overhead with matched spruce, and painted. The two windows on the east side show in cut, with the outside doors.

About picking time, we begin to cool off the building by keeping open during westerly winds or cold waves, and closed as much as possible when it is warm. We try not to put in any fruit when the fruit is warm, but have it cool, if possible. In this way the air in the building is cool all the time. 
A "medium-priced packing- and storage-house" in the Hood River country is illustrated in Fig. 185 (from Lewis and Brown, Ore. Bull. No. 118). It is provided with

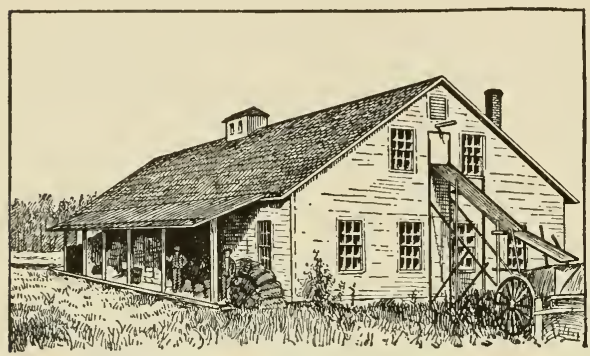

FIG. 185. Combing packing-house and storage-house in the Hood River Valley. ventilator and a chute from the upper floors.

The Alwood storage cellar, in Virginia, is shown in Fig. 186:

The essential features involved in this storage-building are: First, a cellar excavated into a gently sloping hillside, carried into the bank far enough to place the cellar-room entirely below the surface of the earth, and yet give opportunity to enter the cellar easily by an inclined way from the lower side of the slope; secondly, a flue leading out from near the center of the floor of the cellar-room, along the bank of the hillside for a considerable distance, with sufficient fall to make it act both as a drain-pipe and a fresh-air flue; thirdly, ventilating flues placed at each end of the cellar-room or elsewhere, as desired, and rising to the height necessary to give a sufficient draft to carry off rapidly the air from the cellar-room whenever ventilation is desired.

If the air in the cellar becomes warmer than the air in the underground flue, it will rise through the ventilating flues, and the colder air will flow in from the supply flue, as desired. The temperature of the cellar-room can thus be approximately controlled to at least the neighborhood of $55^{\circ}$ to $60^{\circ} \mathrm{F}$. The two ventilators $a$ a rise through the store-room, and are 6 inches in diameter by 15 feet long, thus insuring good draft. The air-flue $b$ enters under the foundation and discharges fresh air into the cellar-room near the center. This flue is 6 inches in diameter, and theoretically should be extended far enough along the hillside to admit of tempering the air to the temperature of the surrounding earth while passing through it. The cellar built here has an air-flue only 150 feet long, and we have never 
been able to cool the air down below $60^{\circ} \mathrm{F}$. when the temperature of the outside air is above $70^{\circ} \mathrm{F}$.

The dotted line $h h$ shows the contour of the hillside, and the line $i$ shows the entry-way into the cellar. The entry-way should preferably be on the north side of the structure, and should be closed in by a vestibule, so as to protect the cellarway from storm, and to prevent influence of outside temperature upon the atmosphere in the cellar.

The roof structure of vestibule is shown at $d$, and one of the side walls of the entry-way at $e$. The floor of the cellar $f f$ pitches slightly to the mouth of the air-flue $b$, which serves as a drain-pipe when one is needed. The cellar floor is made of broken stone and cement, and successfully checks the upward rise of ground water. The bins $c c$ and $c^{\prime}$ on one side of the cellar-room are shown, with dimensions. They are constructed of 2 by 4 scantling and 1-inch oak boards. At

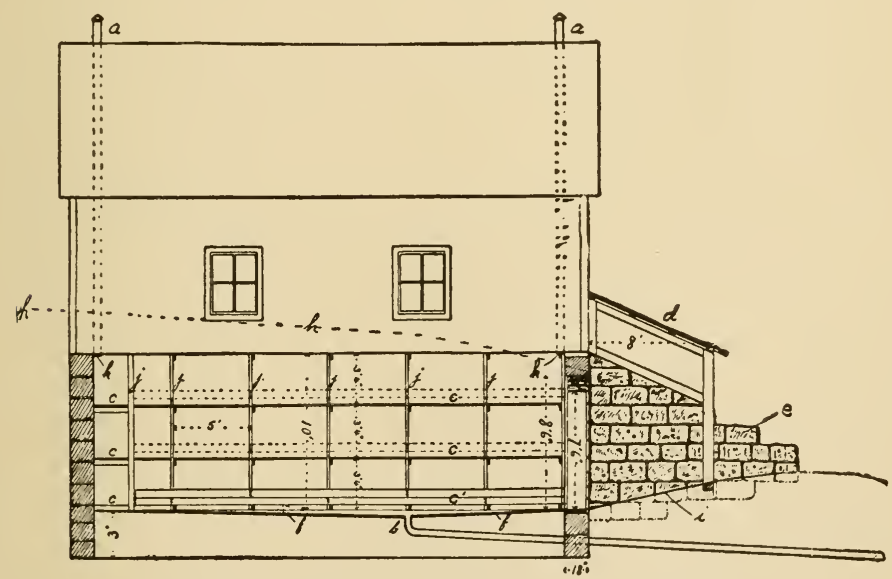

FIG. 186. Longitudinal section of Virginia storage-house.

$c^{\prime}$ the facing on lower bin is shown in position. When we desire to fill the bins, additional facing boards are used. The letters $k k$ at lower ends of ventilating flues indicate position of sliding dampers, by means of which the flow of air from the cellar is effectually controlled. With the short flue used in the cellar here, we find that 
when the mercury remains below $20^{\circ} \mathrm{F}$. for any length of time, the cellar will be reduced below freezing, unless the ventilators are closed.

We have now completed the fruit-book, having surveyed the field. It is a field of great variety, demanding many qualities on the part of the successful grower. This grower should first apprehend the principles and the underlying reasons, and to teach this is the prime purpose of the book, while still everywhere discussing the practice. If the grower knows why, he will teach himself how. The author hopes that the grower will meet with much success, and that his enjoyment in the work will be abiding and real. 


\section{INDEX}

Accidents, 288.

Accounts of fruit-pickers, 381.

Achras Sapota, 5.

Acid phosphate, for apples, 136, 143.

Acleris minuta, 353.

Acme harrow, 85.

Acrobasis nebulella, 359.

Agrilus bilineatus, 352 .

Alfalfa, as cover-crop, 122, 123, 124.

Almond, species of, 5 . temperatures injurious to, 314 .

Alsophila pometaria, 346 .

Alternate system, 211.

Alwood storage cellar, 420 .

Amatungulu, 7.

Amelanchier, species of, 7 .

Ammonium sulfate, for apples, 143.

Ampelophaga myron, 355.

Anacardium occidentale, 5 .

Ananas sativus, 8.

Anarsia lineatella, 357.

Ancylis comptana, 360 .

Annona, species of, 4 .

Anthonomus quadrigibbus, 344 .

Anthracnose, 350, 361.

Aphids, 343.

Aphis, 351, 353, 356, 357. species, $343,356,360$.

Apple, adaptability to soils, 13 .

diseases of, 343 .

early plantings, 67 .

-growing, status of, 22 .

insects, 343.

Mammee, 6.

orchard experiments, 134.

roots, 97.

species of, 3 .

Apples, distance for, 177.

exporting, 394.

fertilizers in, 131, 132.

fertilizers for, 143,144 .

fertilizing of, 134 .

picking, 366, 373.

score-card for, 161.

sterile and fertile, 158, 159.

stock for, 170.

temperatures injurious to, 314 .
Apples, test of fertilizer necds, 145 . thinning of, 243.

trimming, 187.

Apricot, diseases and insects of, 350 . species of, 3 .

Apricots, distance for, 177. exposure for, 54 .

- fertilizers for, 147 . picking, 368 .

temperatures injurious to, 314 .

Arbutus Unedo, 6.

Archips argyrospila, 345.

Archips cerasivorana, 351.

Army-worm, false, 352 .

Arsenate of lead, 337.

Arsenic, as insecticide, 336.

Arsenical poisoning, 361 .

Arsenicals for spraying, 331 .

Artocarpus, species of, 4.

Asimina triloba, 4 .

Aspect of a fruit-plantation, 53.

Aspidiotus perniciosus, 349 .

Atmospheric drainage, 49.

Avocado, 6.

Bacillus amylovorus, 357.

Bacterial diseases, 323.

Bacterium tumefaciens, 350.

Bactris Gasipaes, 6.

Bad spots, treatment for, 296.

Bagging fruits, 282.

Balaninus species, 352.

Baldwin apple, table of points, 161 .

Ballard, mentioned, 399.

Banana, 8.

Banking up trees, 283.

Barbadoes gooseberry, 8 .

Barden, on frost, 50.

Bark-beetle borer, 295.

Bark-bound trees, 274.

Bark disease, 352.

Barked trees, treatment for, 298.

Barley, as cover-crop, 119, 123. seed to the acre, 124.

Barnyard manure, 129.

Barrel-presses, 412.

Barrenness of orchards, 286. 
Basic slag-meal, for apples, 137, 143.

Baskets for fruits, 386.

Batchelor, on thinning apples, 246.

Beach, on sterility of grapes, 158, 159. on thinning apples, 244.

Bean, as cover-crop, 122, 123.

Bean, velvet, weight of seeds, 126.

Bearing wood, 232.

Beattie, on spraying, 330,334 .

Beechnut, 5.

Beetles, attacks by, 322 .

Beggarweed, as cover-crop, 122, 123.

Bembecia marginata, 351.

Bennett, quoted, 93.

Berry bushes, fertilizers for, 149 .

Berry-stands, 371.

Bertholletia excelsa, 6.

"Better Fruit," quoted, 406.

Birds, protection from, 289.

Blackberry, diseases of, 350 . insects, 350. species of, 7.

Blackberries, distance for, 177 . fertilizers for, 149 . injury from frosts, 309 . laying down, 257. on low lands, 53. picking, 365 . thinning of, 249.

Black-knot, 18, 359.

Black leaf, as insecticide, 341 .

Black-rot, 354.

Black-spot, 356.

Blake, quoted, 176, 197.

Blast, 352 .

Blight, 356, 357, 361 .

Bliss, on pruning, 190, 234.

Blister-mite, 358.

Blodgett, on spraying, 330 .

Blossoms, effect of rain on, 41. effect of wind on, 42 .

Blueberry, species of, 7 .

Bone-meal, for apples, 137, 143.

Booth, on lay-out of orchards, 207. on subsoil, 115.

Bordeaux mixture for spraying, 331, 342 .

Borers, 73, 294.

Botryosphæria ribis, 353.

Box-packing fruits, 400.

Box-press, 403.

Bread-fruit, 4.

Breadstuffs, raising of, 9.

Brackett, G. B., quoted, 262.

Bramble fruits, diseases and insects of, 350

Brazil-nut, 6.

Brown, storage, 420 ; packing, 400.
Brown, Edgar, seedman's weights, 125.

Brown-rot, 351, 356.

Brown-tail moth, 346.

Bryobia pratensis, 357.

Buckwheat, as cover-crop, 118.

seed to the acre, 124, 125.

Bud-moth, 346, 359.

Buffalo berry, 7 .

Bush-fruits, definition of, 7.

Butternut, 5.

Cabbage, as cover-crop, 122, 123.

Cabbage palmetto as windbreak, 63

Calocampa nupera, 352.

Canarium ovatum, 6.

Cane-blight, 353.

Cane-fruits, thinning of, 249.

Canker, 352.

Cankers, frost, 304 . treatment for, 296.

Canker-worm, 57, 346, 347.

Caraunda, 7.

Card, on thinning cane-fruits, 249

Carica Papaya, 6.

Carissa, species of, 7 .

Carob, 5.

Carpocapsa pomonella, 347 .

Carya, species of, 5 .

Case-bearers, 347, 359.

Cashew, 5.

Casimiroa edulis, 4.

Castanea, species of, 5 .

Catch-crops, 100.

Caterpillars, attacks by, 322.

Cavanaugh, soil analysis, 115 .

Cedar-apple fungus, 57 .

Ceratonia Siliqua, 5.

Cerinam, 8.

Chænomeles, species of, 3 .

Chandler, on frost injury, 315. on injury to fruit-buds, 101. on stocks, 171.

on winter-killing, 303.

Chemical fertilizers, 131.

Cherimoya, 4.

Cherries, distance for, 177 . fertilizers for, 147.

picking, 368 . sterility of, 160 .

Cherry, diseases of, 351 . insects, 351 .

Mahaleb, as stock, 14 . species of, 3 . stocks for, 171.

Surinam, 4.

Chestnut, diseases and insects, 352 . species of, 5 . 
Chile-hazel, 6.

Chinquapin, 5.

Chrysophyllum Cainito, 5.

Church, on orchard-heating, 272.

Citron, 4.

Citrus, species of, 4.

Cladosporium carpophilum, 356.

Climate, influence of, 10, 11 .

Climax basket, 389 .

Clinton, L. A., quoted, 84 .

Close, cover-crops, 125; packages, 399.

Clover, аз cover-crop, 117, 120, 122, $123,124$.

seed to the acre, 124, 125.

weight of seeds, 126.

Clover Mite, 357.

Cobnut, 5.

Coccoloba uvifera, 6.

Coconut, 6.

Cocos nucifera, 6.

Codlin-moth, 347. distribution of, 17.

Coleophora species, 347.

Collar-rots, treatment for, 298.

Conotrachelus species, 349, 357, 359, 360.

Contour planting, 192.

Cook, A. J., mentioned, 319.

Corbett, on home fruit-garden, 220.

Corn, as cover-crop, 118, 123. in orchards, 104.

Corylus, species of, 5 .

Coryneum beyerinkii, 356.

Cost-accounting, 27.

Cover-crops, 113.

Covering for protection, 257.

Cowberry, 8.

Cowpea, as cover-crop, 119, 123.

seed to the acre, $124,125$.

weight of seeds, 126 .

Cox, on frost, 252.

Crab-apple, species of, 3.

Crambus hortuellus, 352.

Cranberry, 8.

diseases and insects, 352 .

distance for, 177.

fertilizers for, 150 .

flooding, 260.

Craponius inæqualis, 354.

Cricket, tree, 351.

Cronartium ribicola, 353.

Cropping the plantation, 102.

Crosby, on insecticides, 336. on insects, 343 .

Crown-gall, 350.

Cultivators and moisture-saving, 88.

Curculio, 344, 349, 354, 357, 359, 360.
Currant, diseases and insects, 353 .

distance for, 177 .

fertilizers for, 149 .

species of, 7 .

treatment for borers, 295.

Currents of air vs. frost, 260

Custard-apple, 4.

Cydonia oblonga, 3.

Cymatophora ribearia, 353.

Cyphomandra betacea, 8.

Dakruma convolutella, 354 .

Date, 6.

Dehorning, 236.

Determinate growth, 100.

Dewberry, diseases and insects, 350 . species of, 7.

Diaspis pentagona, 357.

Diospyros, species of, 5 .

Diplosis pyrivira, 358 .

Discovery, 8.

Diseases, 323, 343.

Distance for planting, 176.

Double-planting, 178.

Drainage, atmospheric, 49.

Dried blood, for apples, 143.

Dry freezing, 12.

Dust-sprayers, 330.

Dwarfs vs. standards, 167.

Elæagnus multiflora, 7.

Emphytus maculatus, 361.

Empoasca mali, 344.

Endothia parasitica, 352.

Enriching of fruit-lands, 109.

Equilateral triangle system, 192.

Eriobotrya japonica, 3.

Eriocampoides limacina, 352.

Eriophyes pyri, 358.

Erwin, on pruning, 190, 234.

Eudemis vacciniana, 353.

Eugenia, species of, 4 .

Euphoria Longana, 5.

Euphroctis chrysorrhæa, 346.

Europe, fruit-growing in, 32.

Eustace, on frost, 50 .

Euthrips pyri, 358.

Exoascus deformans, 356.

Exploration, 8.

Explosives for frost and hail, 261.

Exposure of a fruit-plantation, 53.

Fagus grandifolia, 5 .

Fall web-worm, 347.

Fallowing, 104.

Family fruit-plantation, 217.

Feijoa Sellowiana, 4 
Fergusson, on orchard-heating, 272.

Fernald, quoted, 19.

Fertility and productiveness, 287.

Fertilizers, 131.

application of, 140, 152 .

Ficus, species of, 4 .

Fidia viticida, 355 .

Fig, 4.

Fig, Indian, 8.

Figs, distance for, 177.

Filbert, 5.

Fillers, 178.

Fire-worm, 353.

Fires for frost, 265.

Fisher, on orchard lay-out, 215.

Flea-beetle, 355 .

Fletcher, on self-sterility, 158.

Floats, 90.

Flooding for frost, 260.

Forests and fruit-growing, 57.

Formulas for spraying, 333.

Fragaria, species of, 8.

Freezes, definition of, 44.

Frost, cankers, 304.

definition of, 44 .

injuries from, 307 .

and location, 45.

prediction of, 252.

protection from, 251.

Fruit, definition of, 1, 2.

Fruit-flies, 351.

Fruit-pickers, 377.

Fruit-rot fungus, 369.

Fruit scale, 359.

Fruit-worm, 353, 354.

Fruit-zones, 11, 12.

Fulgorid, 352.

Fungi, attacks by, 323 .

Fungicides, 336.

Garcia, on frost injury, 315 .

Gardener, on sterility of cherries, 160.

Gevuina Avellana, 6.

Ginkgo biloba, 5.

Girdled trees, remedies for, 290.

Girdling trees, 277.

Glæosporium venetum, 350 .

Glycosmis aurantiaca, 4.

Gooseberry, diseases and insects, 354 .

fertilizers for, 149.

species of, 7 .

Gooseberry, Barbadoes, 8.

Gooseberry, Otaheite, 6.

Goumi, 7.

Gourley, on fertilizing apples, 136. on sod in orchards, 70 .

Grading fruit, 384 .
Grafting-wax, 281.

Grains, raising of, 9 .

Granadilla, 6.

Grapeberry-worm, 355.

Grapefruit, 4.

temperatures injurious to, 314 .

Grapes, diseases of, 354 .

distance for, 177.

fertilizers for, 147 .

injury from frost, 312 .

insects, 354 .

laying down, 257.

packing of, 410 .

soil-adaptation, 13.

species of, 6.

sterile and fertile, 158, 159.

storing of, 417 .

temperatures injurious to, 314 .

Graptodera chalybea, 355.

Gravenstein apple, table of points, 162

Green fruit-worms, 347.

Green, S. B., on sun-scald, 293.

Greene, on orchard-heating, 272.

Guava, 4.

Guava, pineapple, 4 .

Guignardia bidwellii, 354.

Guignardia vaccinii, 352.

Gymnoconia interstitialis, 351.

Gymnosporangium globosum, 360 .

Gypsy-moth, 348.

Hail-gun, 262.

Hail injuries, 292.

Hairy root, treatment for, 299.

Hale, J. H., mentioned, 201.

Halsted, quoted, 307.

Hammon, on temperatures for fruits 314.

Hand-picking, 380.

Hann, on frosts, 51 .

Hansen, on sun-scald, 293.

Hardpan, 82.

'Harrowing to save moisture, 85.

Harrows, 85, 94.

Hartlib, Samuel, quoted, 80 .

Harvesting, 364.

Hawes, Benj. F., quoted, 311.

Hazelnut, 5.

Headden, on arsenic, 362.

Heading-in, 283.

Heating for frosts, 265.

Hedrick, on apple roots, 98 . on effects of rain, 41,318 . on effects of wind, 42 .

on fertilizers for grapes, 148.

on fertilizing apples, 134 .

on low temperature, 317. 
Hedrick, on sod in orchards, 69 . on temperature, 41. on winter-killing, 302 .

Hellebore as insecticide, 338.

Hemerocampa leucostigma, 350.

Herrick, quoted, 93, 248.

Heterocordylus malinus, 349.

Hexagonal system, 192.

Hickory, diseases and insects, 356 .

Hickory, shellbark, 5 .

Hide-bound trees, 274.

Higgins, mentioned, 387.

Himalaya berry, 7 .

Holt, mentioned, 387 .

Home fruit-garden, 217.

Home grounds, plan for, 219.

Hovenia dulcis, 6.

Howard, on frost-injury, 314 . on pruning, 189.

Humidity, influence of, 12.

Hunting, 8.

Hutt, quoted, 216.

Hyphantria cunea, 347.

Indeterminate growth, 100.

Indian fig, 8.

Injuries, 288.

Insecticides, 336.

Insects, 343. attacks by, 322 .

Irrigating for frost, 260.

Irrigation of fruit-lands, 106.

Isohyetals, 12.

Isotherms, 12.

Jack-fruit, 4.

Jambolan, 4.

Jamrosade, 4.

Jarvis, on fillers, 179.

on pruning, 190, 234.

on renovating, 284.

on squaring a field, 214 .

on trimming apples, 188.

Jehle, on cankers, 296, 305.

Jew plum, 5.

Juglans, species of, 5 .

Jujube, 6.

Juneberry, 7.

Kaki, 5.

Kerosene emulsion for spraying, 331,

King, quoted, 43, 85.

Kinney storage house, 419 .

$[339$.

Kumquat, 4.

Labels, 222.

Ladders for picking, 374 .
Laws for pests, 18.

Laying out the plantation, 191.

Leaf-blight, 354, 360, 361 .

Leaf-curl, 356.

Leaf-hopper, 344, 355.

Leaf-miner, 350.

Leaf-roller, 345,360 .

Leaf-spot, $350,356,360$.

Lecanium corni, 359.

Leguminous erops, 119.

Lemon, 4.

Lemons, temperatures injurious to, 314 .

Lepidosaphes ulmi, 348 .

Lestout, M., on frosts, 264.

Lewis, on crossing apples, 159.

on packing, 400,406 .

on storage, 420 .

"Lewiston Orchards Life," quoted, 104.

Lime, 4.

berry, 4 .

Spanish, 6.

Lime for apples and pears, 138, 145.

Lime-sulfur for spraying, 331, 339.

Line, laying-out with, 201.

Lining fruit-boxes, 401.

Lining-in method, 212.

Litchi chinensis, 5.

Live-stock, protection from, 289.

Location and productiveness, 287. for fruit-growing, 38 .

Lodeman, on soil injury, 361.

Lodeman's label, 226.

Lombardy poplars as windbreak, 62 .

Longyen, 5.

Loquat, 3.

Lucuma mammosa, 5.

Lumbering, 8. 9.

Lygidea mendax, 349.

Macomber, J. T., quoted, 258.

Macrodactylus subspinosus, 356.

Mahaleb cherry, as stock, 14.

Making the rows straight, 194.

Malacosoma species, 349.

Mammea americana, 6.

Mammee apple, 6.

Mandarin, 4.

Mandarines, temperatures injurious to, 314.

Mangifera indica, 5 .

Mango, 5.

Manure, 129.

Maples as windbreak, 62.

Maps for orchards, 221.

Market and location, 40.

Marketing, 364.

Marmalade tree, 5 . 
Marsonia juglandis, $356,361$.

Martin, on orchard systems, 192.

Mathewson, on insecticides, 336 . on insects, 343 .

Maynard, on thinning plums, 248.

Measuring-worm, 353.

Medlar, 3.

Melander, on spraying, 330,334 .

Melicocca bijuga, 6 .

Melilotus, as cover-crop, 120.

Merriam, C. H., reference, 10.

Mespilus germanica, 3 .

Metellus rubi, 350.

Mice, protection from, 290.

Midge, 358.

Mildew, 354.

powdery, 352.

Millet, as cover-crop, 119, 123.

seed to the acre, 124.

weight of seeds, 126.

Mineola vaccinii, 353.

Mining, 8. 9.

Mite, 357.

Moisture determinant, 12.

harrowing to save, 85 .

plowing to save, 84 . of soil, 81 .

Monophadnus rubi, 351.

Monstera deliciosa, 8.

Moore, J. C., quoted, 197.

Moore, on orchard lay-out, 211.

Morus, species of, 4.

Mulberry, species of, 4.

Mulching as frost-protection, 255, 260.

Mulching trees, 183.

Muriate of potash, for apples, 143.

Musa, species of, 8.

Mycosphærella fragariæ, 360 .

Myrica Nagi, 6.

Myzus species, $351,353,357$.

Natal plum, 7 .

Nectarine, 3.

Nectarines, distance for, 177.

Nematode root-knot, 17.

Nicofume, as insecticide, 341 .

Nitrate, for apples, 143.

Nitrogen, amount of, 131; for apples, 143.

Nozzles for spraying, 326, 334 .

Nursery lands, 112.

Nursery stock, growing in orchards, 103.

Oats, as cover-crop, 119, 123.

seed to the acre, 124, 125.

Ecanthus nigricornis, 351.

O'Gara, on frost-protection, 251.
O'Gara, on orchard-heating, 266.

Oil-heating for frost, 267.

Olea europæa, 6.

Olive, 6.

temperatures injurious to, 314 .

Opuntia, species of, 8.

Orange, soil-adaptation, 13.

species of, 4.

temperatures injurious to, 314 .

Orchard crops, 104.

definition of, 3 .

-heating, 265.

lay-out, 206.

renovating, 283 .

systems, 192.

Organizing the business, 24.

Otaheite gooseberry, 6.

Outlook for fruit-growing, 20.

Over-production of fruit, 23.

Oyster-shell scale, 348.

Package label, 223.

Packages for fruits, 386 .

Packing fruit, 383.

-houses, 407.

-table, 402.

Paddock, chemical analysis of covercrops, 122.

Paddock's vineyard label, 226.

Pæcilocapsus lineatus, 354.

Paleacrita vernata, 347.

Palm, peach, 6.

Palmer worm, 348.

Palmetto, cabbage, as windbreak, 63.

Papaw, 6. northern, 4.

Parasite determinant, 16.

Parasites and productiveness, 287.

Passiflora edulis, 6.

Payne, on windbreaks, 63.

Peach, 3.

palm, 6 .

tree borers, 295.

trees, laying down, 258.

yellows, 18.

Peaches, diseases of, 356 .

distance for, 177.

exposures for, 54 .

fertilizers for, 146 .

insects, 356.

picking, 368 .

soil-adaptation, 13.

stock for, 170.

temperatures injurious to, 314,315 .

trimming, 185.

Pear buds, on mountain-ash, 14.

prickly, 8. 
Pear roots, 97. species of, 3.

Pears, diseases of, 357 . distance for, 177 .

fertilizers for, 144 .

insects, 357.

picking, 367.

sterile and fertile, 157.

stock for, 170.

temperatures injurious to, 314 . trimming, 186.

Peas, as cover-crop, 123.

seed to the acre, 124, 125.

temperatures injurious to, 314 .

weight of seeds, 126.

Pecan, 5.

diseases and insects, 359 .

distance for, 177 .

Pedigree plants, 168.

Pereskia aculeata, 8.

Persea gratissima, 6 .

Persimmon, 5.

Phonix dactylifera, 6.

Phosphoric acid, amount of, 131. for apples, 143.

Phyllanthus disticha, 6.

Phylloscelis atra, 352 .

Phylloxera species, 386.

Physiological diseases, 323.

Pickett, on results of tillage, 71 .

Picking fruits, 365.

Pili nut, 6.

Pineapple, 8. screening, 259. soil-adaptation, 13.

Pine-hole borer, 295.

Pistacio vera, 6.

Place for fruit-growing, 39.

Planker, 90.

Plantain, 8.

Plantation and productiveness, 287.

Plant-bug, four-striped, 354.

-lice, 343.

-lice, attacks by, 323 .

Planting-board, 195. plan, 181.

Plants, securing of, 164. setting of, 174 .

Plasmopara viticola, 354.

Plat of orchards, 221.

Plowing to save moisture, 84 .

Plow, laying out with, 198.

Plowrightia morbosa, 359.

Plum buds, on peach, 14 . domestica, soil-adaptation, 13 . Jew, 5 .

Natal, 7.
Plum, species of, 3 .

Plums, diseases of, 359 .

distance for, 177 .

fertilizers for, 147 .

insects, 359.

picking, 368 .

sterile and fertile, 158.

stock for, 171 .

temperatures injurious to, 314 .

thinning of, 248.

trimming, 187.

Podosphæra oxycanth $x, 352$.

Poisoning, arsenical, 361 .

Polychrosis viteana, 355.

Pome, 2.

Pomegranate, 6.

Pomelo, 4.

Pomology, definition of, 1.

Poncirus trifoliata, 4.

Pond-apple, 4.

Porthetria dispar, 348.

Potash, amount of, 131. for apples, 139, 143.

Powell, G. H., quoted, 281, 369.

Powell, George T., cover-crops, 115. on exporting apples, 394.

Power sprayer, 334 .

Prediction of frost, 252.

Prickly pear, 8.

Propagation and productiveness, 287.

Protection from frost, 251.

Proteopteryx deludana, 359.

Prunes, temperatures injurious to, 314 .

Pruning, 184, 230. and productiveness, 287.

Prunus, species of, 3,5 .

Pseudomonas juglandis, 361.

Psidium Guajava, 4.

Psylla pyricola, 358.

Pteronus ribesii, 354.

Puddling, 184.

Pumps for spraying, 326.

Punica Granatum, 6.

Pyrus, species of, 3.

Quince, diseases and insects, 360 .

distance for, 177 .

fertilizers for, 147.

on low lands, 53.

species of, 3 .

sterility of, 158 .

Quincunx system, 192.

Rabbits, protection from, 290.

Rain at blooming-time, 41 .

effect on setting of fruit, 317 .

Rape, as cover-crop, 118, 122, 123, 124. 
Rape, seed to the acre, 124, 125. weight of seeds, 126.

Raspberries, diseases of, 350 . distance for, 177.

fertilizers for, 149 . insects, 350 .

laying down, 257.

picking, 379.

species of, 7 .

sterile and fertile, 457.

thinning of, 249.

treatment for borers, 295.

Records of orchards, 221.

for picking, 381.

Rectangular system, 192.

Red bugs, 349 .

Reddick, on diseases, 343.

on fungicides, 336 .

on winter-killing, 302 .

Red-rust, 57.

Red-spider, 357.

Renovating orchards, 283.

Rest-periods in relation to frost, 101.

Rhagoletis species, $345,351$.

Rhode Island Greening apple, table of points, 162.

Ribes, species of, 7 .

Rigney, on frost-injury, 315.

Ringing trees, 277.

Roberts, on fertilizers, 131.

Rodents, protection from, 289.

Rollers and moisture-saving, 89.

Root-borer, 351, 360 .

gall, 350 .

treatment for, 298.

knot, 17, 299.

louse, 360 .

worm, 355 .

Roots, broken, 228.

Rose-apple, 4.

Rose-chafer, 57, 356.

Rotation of plantations, 126.

Rows, making straight, 194.

Rubus, species of, 7 .

Rusts, 351, 353, 360 .

Rye, as cover-crop, 118, 123, 124. seed to the acre, $124,125$.

San Jose scale, 349 .

Sapodilla, 5 .

Sapote, white, 4.

Saw-fly, 351, 354, 355, 361.

Scab, 356, 358.

Scald, 352.

Scale insects, attacks by, 323 .

Schizoneura lanigera, 350 .

Sclerotinia fructigena, 351, 356.
Scraping trees, 276.

Sea-grape, 6.

Sears, clover as cover-crop, 120. on scoring apples, 161.

Selandria vitis, 355 .

Self-sterile fruits, 156.

Septoria rubi, 350.

Setting-board, 196. of fruit, effect of rain on, 317 . the plants, 174 .

Shaddock, 4 .

Shellbark hickory, 5 .

Shepherdia argentea, 7.

Siphocoryne avenæ, 343.

Site for fruit-growing, 39, 52 .

Skinner irrigation system, 107.

Slug, $352,355$.

Small-fruits, care of, 229 . definition of, 7 . setting in an orchard, 216.

Smoke for frost, 263.

Smudges for frost, 263.

Snow, G. C., on storing grapes, 417.

Soaps, as insecticides, 338.

Sod-mulch in orchards, 69. orchards, 69.

Soil determinant, 13. moisture of, 81 . -poisoning, 361 . structure of, 77.

Sorting-tables, 412.

Sour-sop, 4.

Soybean, as cover-crop, 122, 123. seed to the acre, $124,125$. weight of seeds, 126 .

Spanish lime, 6.

Span-worm, 353.

Speculation, 8 .

Sphærotheca mors-uvæ, 354.

Sphinx, 355.

Spondias dulcis, 5 .

Spraying, 319.

for frost, 260 .

Spray pumps, 326.

Square system, 192.

Squaring a field, 214.

Stable manure, 129.

Staking out orchards, 202. young trees, 273.

Standards vs. dwarfs, 167.

Star-apple, 5.

Stewart, on fertilizing apples, 138, 143.

Stiger, Albert, mentioned, 261.

St. John's Bread, 5.

Stocks, 169.

Stone-fruits, picking, 368 .

Storage, 413. 
Storing fruits, 413.

Strawberries, diseases and insects, 360 . distance for, 177.

fertilizers for, 150 .

unjury from frosts, 309 .

on low lands, 52.

picking, 366 .

sterile and fertile, 157.

temperatures injurious to, 314 .

Strawberry, species of, 8.

tree, 6.

Stripping trees, 175.

Stuart, on pruning, 234. on setting-board, 196.

Subsoil, as soil determinant, 15 .

Sugar-apple, 4.

Sulfate, low-grade, for apples, 143. of potash, for apples, 137.

Summer-fallow, 104.

Sun-scald, protection from, 292.

Surinam cherry, 4.

Sweet-sop, 4.

Tamarind, 5.

Tamarindus indica, 5 .

Tangerine, 4.

temperatures injurious to, 314 .

Tare, as cover-crop, 120.

Tarr, quoted, 46.

Temperature, dangers of, 44 . determinant, 11.

injurious to fruits, 314.

Tent-caterpillars, 57, 349 .

Terminalia Catappa, 6.

Tetrancyhus bimaculatus, 357.

Thinning the fruit, 241, 249.

Thornber, on fillers, 180 . on use of corn in orchards, 104.

Thrips, 358.

Tight-jacket trees, 275.

Tillage, 64, 91. and productiveness, 287.

benefits of, 76 .

philosophy of, 75 .

Tilling for frost, 260.

Tmetocera ocellana, 346 .

Tobacco, as insecticide, 341 .

Tools in relation to moisture-saving, 84 .

Top-grafting trees, 279.

Top-working stocks, 171.

Tortrix, 351.

Tree-cricket, 351 .

Tree tortrix, 351.

Triangular system, 192.

"Tribune Farmer," quoted, 13.

Trimming, 184.

Triphasia trifoliata, 4 .
Turnips, as cover-crop, 118, 123, 124. seed to the acre, $124,12^{\mathrm{F}}$

Tussock-moth, 350 .

Twig-moth, 357.

Typhlocyba comes, 355 .

Typophrus canellus, 360.

Vaccinium, species of, 7,8 .

Valsa leucostoma, 305.

Van Deman, H. E., on planting, 198.

Vapor vs. frost, 260.

Varieties and productiveness, 287.

choice of, 153.

scoring of, 161.

Vegetables for home fruit-garden, 220.

Venturia inequalis, 344.

Veratrum album, 338.

Vetch, as cover-crop, 120, 122, 124.

seed to the acre, 124, 125.

weight of seeds, 126 .

Vicia species, as cover-crop, 120.

Vigna sinensis, as cover-crop, 119.

Vincent, on erossing apples, 159.

Vitis, species of, 6 .

Wagons for picking, 374 .

Waite, quoted, 157.

Walnut, diseases and insects, 361 .

English,temperatures injurious to, 314 species of, 5 .

Warner, on cost-accounting, 27.

Water in air, 260.

Watering young trees, 274.

Wax, grafting, 281.

Wealthy apple, table of points, 162 .

Weather and location, 41, 49.

Weeds, as cover-crops, 123.

Weevils, 352.

Wellhouse orchards, 201.

Wellington, on orchard-heating, 271.

Wheat, as cover-crop, $119,123,124$. constituents of, 133. seed to the acre, 124.

Wheeler, on fertilizers, $144,146,148$, $149,150,151,152$,

Whetzel, 344 .

White, Elizabeth C., quoted, 260.

Whitewashing as protection, 259.

trees, 277.

Whitten, on whitewashing, 259.

Wickson, on windbreaks, 63.

Wilder, H. J•, on soil-adaptations, 13 .

Wilson, C. S., on irrigation in the East, 106.

on packing, 401 .

quantity of seed for cover-crops, 124. 
Wilson, W. M., on frosts, 51, 252.

Wilt, 353.

Windbreaks, 55.

Wind, effects of, 41.

Wineberry, 7.

Winter-killing of fruit-buds, 306 . of wood, 299.

Winter preparations, 282.

Wire-compass, method, 213.

Wood-ashes, effects on apples, 136.

Woodberry, on orchard-heating, 271.

Woolly aphis, 350 .
Worms, attacks by, 322 .

Wounds, dressing of, 233. treatment for, 296.

Wrapping fruit, 402.

Xylina species, 347 .

Yeomans, staking plan, 202.

Ypsolophus pometellus, 348.

Zizyphus Jujuba, 6.

Zones, 11, 12. 


\section{The following pages}

contain advertisements of books by the same author or on kindred subjects 



\section{RURAL SCIENCE SERIES Edited by L. H. BAILEY \\ Each volume illustrated. Cloth, $12 \mathrm{mo}$.}

A series of practical books for farmers and gardeners, sold as a set or separately. Each one is the work of a competent specialist, and is suitable for eonsultation alike by the amateur or professional tiller of the soil, the seientist or the student. Illustrations of marked beauty are freely used, and the books are clearly printed and well bound.

ON SELECTION OF LAND, ETC.

Isaae P. Roberts' The Farmstead .

T. F. Hunt's How to Choose a Farm

E. S. Cheyney and J. P. Wentling's The Farm Woodlot

Glenn W. Herriek's Insects Injurious to the Household

$\$ 150$ net

175 net

150 net

175 net

ON TILLAGE, ETC.

F. H. King's The Soil

Isaae P. Roberts' The Fertility of the Land

F. H. King's Irrigation and Drainage

Edward B. Voorhees' Fertilizers

Edward B. Voorhees' Forage Crops

J. A. Widtsoe's Dry Farming

L. H. Bailey's Principles of Agrieulture

S. M: Tracy's Forage Crops for the South

ON PLANT DISEASES, ETC.

E. C. Lodeman's The Spraying of Plants

150 net

150 net

150 net

125 net

150 net

150 net

12.5 net

150 net

ON GARDEN-MAKING

L. H. Bailey's Garden-Making

L. H. Bailey's Vegetable-Gardening

L. H. Bailey's Forcing Book

L. H. Bailey's Plant Breeding : (New edition preparing)

ON FRUIT-GROWING, ETC.

L. H. Bailey's Nursery Book

L. H. Bailey's Fruit-Growing (New Edition).

L. H. Bailey's The Pruning Book

F. W. Card's Bush Fruits

W. Paddock \& O. B. Whipple's Fruit-Growing in Arid Regions

125 net

150 net

$150 \mathrm{net}$

125 net

\section{ON THE CARE OF LIVE-STOCK}

Nelson S. Mayo's The Diseases of Animals

W. H. Jordan's The Feeding of Animals

I. P. Roberts' The Horse

M. W. Harper's Breaking and Training of Horses

George C. Watson's Farm Poultry. New edition

John A. Craig's Sheep Farming

ON DAIRY WORK, FARM CHEMISTRY, ETC.

Henry H. Wing's Milk and Its Produets. New edition . . . . 150 net

J. G. Lipman's Bacteria and Country Life

150 net

150 net

150 net

1.50 net

150 net

150 net

150 net

125 net

175 net

150 net

150 net

150 net

ON ECONOMICS AND ORGANIZATION

William A. McKeever's Farm Boys and Girls

I. P. Roberts' The Farmer's Business Handbook

George T. Fairchild's Rural Wealth and Welfare

H. N. Ogden's Rural Hygiene

J. Green's Law for the American Farmer :

150 net

125 net

125 net

150 net

150 net

G. H. Powell's Coöperation in Agriculture

150 net 


\section{RURAL TEXT-BOOK SERIES}

Edited by L. H. BAILEY

Each volume illustrated. Cloth, $12 \mathrm{mo}$.

While the RURAL SCIENCE SERIES is designed primarily for popular reading and for general use, this related new series is designed for classroom work and for special use in consultation and reference. The RURAL TEXT-BOOK SERIES is planned to cover eventually the entire range of public school and college texts.

Duggar, B. M.

Physiology of Plant Production

Duggar, John Frederick

Southern Field Crops

GaY, C. Warren

Principles and Practice of Judging Live-Stock . . 150 nct HARPER, M. W.

Animal Husbandry for Schools

Нгтснсоск, A. S.

Grasses

Livingston, George

Field Crop Production

Lyon, T. L. and Fippin, E. O.

Principles of Soil Management

Mann, A. R.

Beginnings in Agriculture.

140 net

150 net

Montgonery, G. F.

Corn Crops

140 net

175 net

75 net

Piper, Charles V.

Forage Plants and Their Culture . . . . . 175 net

WARREN, G. F.

Elements of Agriculture . . . . . . . . 110 net

WARREN, G. F.

Farm Management . . . . . . . . . 175 net

WheEler, H. J.

Manures and Fertilizers . . . . . . 160 nct

Widtsoe, John A.

Principles of Irrigation Practice

175 net

\section{THE MACMILLAN COMPANY}

PUBLISHERS

64-66 Fifth Avenue

NEW YORK 


\section{THE RURAL MANUALS}

Edited by L. H. BAILEY

\section{MANUAL OF FRUIT INSECTS \\ By MARK VERNON SLINGERLAND and CYRUS R. CROSBY}

Of the New York State College of Agriculture, at Cornell University Illustrated, 12 mo, 503 pages, $\$ 2.00$ net; postage extra.

\section{A MANUAL OF WEEDS}

By ADA E. GEORGIA

Assistant in the Farm Course, New York State College of Agriculture, Cornell University

With 385 Illustrations by F. SCHUYLER MATHEWS

Illustrated, cloth, $12 \mathrm{mo}, 593$ pages, index, $\$ 2.00$ net: postage extra.

\section{MANUAL OF FARM ANIMALS}

A Practical Guide to the Choosing, Breeding and Keep of Horses, Cattle, Sheep and Swine By MERRITT W. HARPER

Assistant Professor of Animal Husbandry in the New York State College of Agriculture, at Cornell University

Illustrated, $12 m o, 545$ pages, index, $\$ 2.00$ net; postage extra.

"A book deserving of elose study as well as being handy for reference, and should be in the possession of every farmer interested in stock."Rural World.

\section{MANUAL OF GARDENING}

A Practical Guide to the Making of Home Grounds and the. Growing of Flowers, Fruits and Vegetables for Home Use By L. H. BAILEY

Illustrated, cloth, $12 \mathrm{mo}, 544$ pages, $\$ 2.00$ net; postage extra.

This new work is a combination and revision of the main parts of two other books by the same author, "Garden-Making" and "Practical Garden Book," together with much new material and the result of the experience of ten added years.

\section{THE FARM AND GARDEN RULE BOOK}

\section{By L. H. BAILEY}

Revised and enlarged edition-Illustrated, cloth, $12 \mathrm{mo}, \$ 2.00$ net. It is essentially a small cyclopedia of ready rules and references packed full from cover to cover of condensed, meaty information and precepts on almost every leading subject connected with country life.

\section{THE MACMILLAN COMPANY}




\section{The Rural Outlook Set By L. H. BAILEY}

Four Volumes. Each, cloth, 12mo. Uniform binding, attractively boxed. $\$ 5.00$ net per set; carriage extra. Each volume also sola separately.

In this set are included three of Professor Bailey's most popular books as well as a hitherto unpublished one,- "The Country-Life Movement." The long and persistent demand for a uniform edition of these little classics is answered with the publication of this attractive series.

\section{The Country Life Movement}

Cloth, 12mo, 220 pages, \$1.25 net; postage extra

This hitherto unpublished volume deals with the present movement for the redirection of rural civilization, discussing the real country-life problem as distinguished from the city problem, known as the back-to-theland movement.

\section{The Outlook to Nature (New and Revised Edition)}

Cloth, 12mo, 195 pages, \$1.25 net; postage extra

In this alive and bracing book, full of suggestions and encouragement, Professor Bailey argues the importance of contact with nature, a sympathetic attitude toward which "means greater efficiency, hopefulness, and repose."

\section{The State and the Farmer (New Edition)}

Cloth, 12mo, $\$ 1.25$ net; postage extra

It is the relation of the farmer to the government that Professor Bailey here discusses in its varying aspects. He deals specifically with the change in agricultural methods, in the shifting of the geographical centers of farming in the United States, and in the growth of agricultural institutions.

\section{The Nature Study Idea (New Edition)}

Cloth, $12 \mathrm{mo}, \$ 1.25$ net; postage extra

"It would be well," the critic of The Tribune Farmer once wrote, "if 'The Nature Study Idea' were in the hands of every person who favors nature study in the public schools, of every one who is opposed to it, and most important, of every one who teaches it or thinks he does." It has been Professor Bailey's purpose to interpret the new school movement to put the young into relation and sympathy with nature, - a purpose which he has admirably accomplished.

\section{THE MACMILLAN COMPANY}

PUBLISHERS 64-66 Fifth Avenue

NEW YORK 


\title{
The Standard \\ Cyclopedia of Horticulture
}

\author{
Edited by L. H. BAILEY
}

With the assistance of over 500 collaborators

New edition, entirely rewritten and enlarged with many features, with 24 plates in color, 96 full-page half-tones and over 4,000 text illustrations.

To be complete in six volumes.

Each volume: Cloth, \$6.00; Leather, \$10.00. Sold only in sets by subscription.

Two opinions of Volume I of the new Cyclopedia:

"No one who knows anything at all about the literature of gardening needs to be told that the Cyclopedia is unique. It is the Bible and Britannica of the garden-folk, amateur and professional alike. And the remarkable thing is that, while it is fundamentaly a work of reference, it also contains limitless quantities of good reading of the sort dear to the heart of the garden enthusiast."-The Nation.

"It is no exaggeration to state that Bailey's new work is the best cyclopedia obtainable for all who are connected, either remotely or intimately, as amateurs or professionals, with horticultural pursuits. It is the best for the student of botany who is investigating the subject in a purely scientific way; best for the commercial grower who likes to be well informed on matters in general and his own trade in particular, and best for the other sort of commercial grower, who does not bother himself particularly about hunting for any information except such as will give him immediate help in producing a better crop."-The Florist's Review.

\section{THE MACMILLAN COMPANY}




\section{CYCLOPEDIA OF AMERICAN AGRICULTURE}

Edited by L. H. BAILEY

With 100 full-page plates and more than 2,000 illustrations in the text; four volumes; the set, $\$ 20.00$ net; half morocco, $\$ 32.00$ net.

Vol. I-Farms

Vol. III-Animals

Vol. II-Crops

Vol. IV-The Farm and the Community

This is unquestionably the most important agricultural cyclopedic work published in this country. The leading experts in the United States and Canada, both investigators and practical farmers, contribute to its chapters, which are arranged not alphabetically, but topically, each subject being treated in its various aspects by men especially familiar with it. It contains advice for the city man who is seeking a home in the country, as well as for the professional farmer. The book is strictly new and up-to-date in its methods and advice, thoroughly readable, and a standard work of reference. It is profusely illustrated, about one-third of the total space being assigned to illustrations-all original.

"Indispensable to public and reference libraries . . . readily comprehensible to any person of average education."-The Nation.

"The completest existing thesaurus of up-to-date facts and opinions on modern agricultural methods. It is safe to say that many years must pass before it can be surpassed in comprehensiveness, accuracy, practical value, and mechanical excellence. It ought to be in every library in the country."-Record-Herald, Chicago.

\section{THE MACMILLAN COMPANY}







\section{LIBRARY OF CONGRESS}

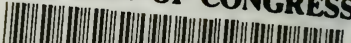
| I. ||II|. 00009170704 